PLUTONIUM UTILIZATION PROGRAM ANNUAL REPORT

FISCAL YEAR 1967

\title{
JANUARY 1968
}

\section{AEC RESEARCH \& DEVELOPMENT REPORT}

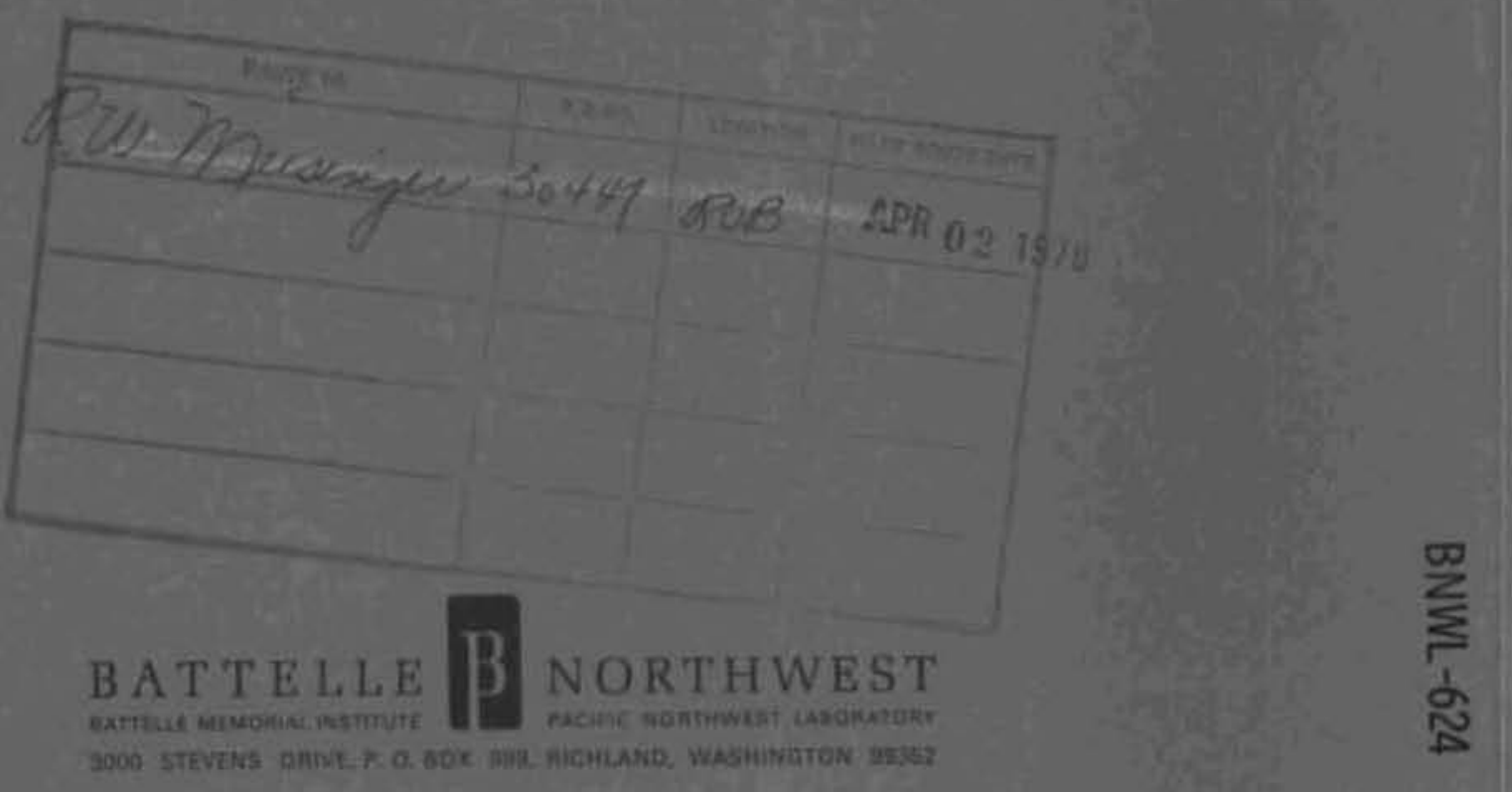




\section{LEGAL NOTICE}

This repont was prepand es an acceunt of Government sponsored work. Neithet the United Stotes. nor the Commissian, nor any penon asting an behalf of the Comtuistion

A. Makes any eatranty or representation, expcessed of lmplied with renpectso the aicair ocy, com. pleteness, of utefulness of the intarmestion contained in this raport, ar that the use of gayliniarmation, apparatus, insthod, of process discloied in this report moy not intringe privataly owned rights; or

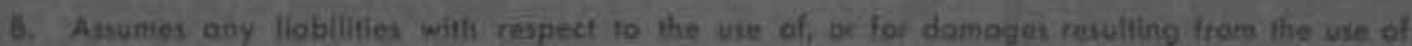
ahy hiformation, apparotus, method, or process disclesed in this repont.

As used in the obovs. "gerson acting on betialf of the Commistane includes any enplayse or contractor of the Camentssion, of emploves of sush contractor, to the extent that luch empleyee or cen-

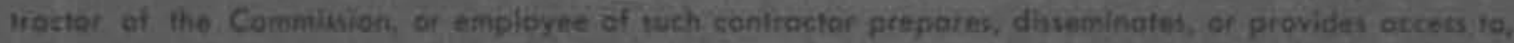
any lifiormolion pursucat is his employment of confrast with the Commision, or his enploymant with such controstor:

\section{PACIFIC NORTHWEST LABORATORY \\ RLCHLAND, WASHINGTON \\ operated by \\ BATHELIE MENORIAL INSTIYUTE}

for the

UNITED STATES ATOMIE ENERGY COMMISSION UNDER CONTRACT AT(45.1)-1830 

BNWL- 624

PLUTONIUM UTILIZATION PROGRAM ANNUAL REPORT

\title{
FISCAL YEAR 1967
}

\author{
Compiled By \\ Members of the Staff of the \\ Pacific Northwest Laboratory \\ Coordinated By \\ F. G. Dawson, Program Leader
}

December, 1967

FER 68 


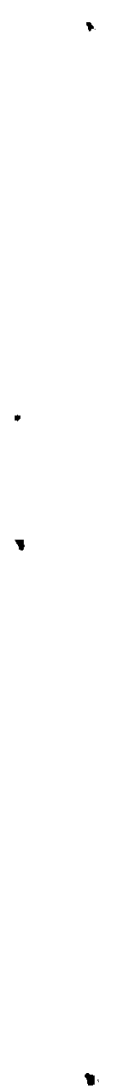




\section{ACKNOWLEDGEMENT}

Success of the program is credited to the many managers, scientists, engineers, and supporting personnel who contributed much of their time to the program. It is difficult to properly acknowledge all of these contributors. However, many of these can be recognized by reference to the authorship of the contributions to this report and the references made within these reports. Direct acknowledgement is made to the managers of organizations making significantcontributions to the program and to their staff by listing these organizations below.

F. W. Albaugh - Director, Pacific Northwest Laboratory

W. D. Richmond - Engineering Services Department

J. R. Fishbaugher - PRTR Section

K. L. Young - Reactor Operations

R. A. Kennedy - Engineering Support

R. H. Purcel1 - Process Technology

D. R. de Halas - Chemistry Department

R. L. Dillon - Corrosion \& Coolant Chemistry

B. Griggs - Water Reactor Corrosion \& Chemistry

L. D. Perrigo - Corrosion Engineering

A. R. Keene - Environmental Health Department

R. L. Junkins - Nuclear Safety

R. O. Budd - Nuclear Materials Management

R. H. Scott - Industrial Safety

C. A. Bennett - Mathematics Department

E. A. Eschbach - Advanced Concepts \& Analysis

D. E. Deonigi - Fuel Cycle Analysis

E. A. Evans - Materials Department

D. C. Lehfeldt - Radiometallurgy Laboratory

W. L. Hampson - Plutonium Fuel Engineering

H. A. Taylor - Fuel Process Development

S. Goldsmith - Fuel Design \& Evaluation

F. G. Dawson - Reactor Physics Department

C. W. Lindenmeier - Theoretical Physics

D. D. Lanning - Applied Reactor Physics

H. L. Henry - Experimental Reactors

G. J. Busselman - Engineering Physics

L. C. Schmid - Nuclear Experiments \& Analys is

R. I Smith - Light Moderator Reactor Physics

R. C. Liikala - Analytical Physics 
J. M. Batch - Engineering Development

F. R. Zaloudek - Thermal Hydraulic Analysis

L. T. Pedersen - Mechanical Engineering

D. E. Rasmussen - Equipment Development

P. C. Walkup - Systems Design \& Development

R. G. Wheeler - Engineering Materials \& Mechanics

J. C. Fox - Engineering Analysis

J. R. Worden - Nuclear Engineering 


\section{TABLE OF CONTENTS}

1.0 INTRODUCTION and PROGRAM HIGHLIGHTS

2.0 FUELS DEVELOPMENT

PRTR Batch Core Testing - M. D. Freshley ............ 2.1 FERTF (Fuel Element Rupture Test Facility) Testing -

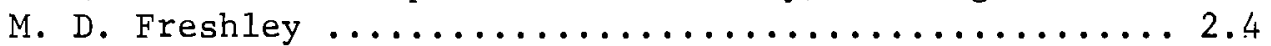
High Exposure Plutonium Studies - R. C. Smith .......... 2.11

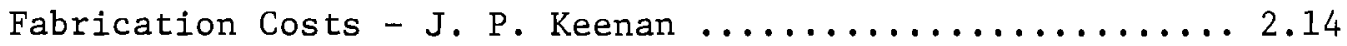
Special Batch Core Testing - T. B. Burley .............. 2.15

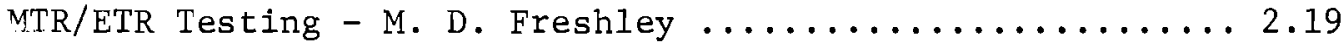

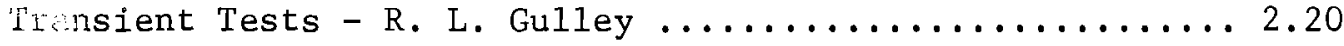
PRTR Fringe Position Tests - M. D. Freshley ............ 2.31 Commercial Fuels Study - R. L. Gulley and M. D. Freshley .. 2.31

\subsection{REACTUR PHYSICS}

\section{Subcritical and Critical Experiments}

Subcritical Measurements With $\mathrm{UO}_{2}-2 \mathrm{wt} \% \mathrm{PuO}_{2}$ Fuel -

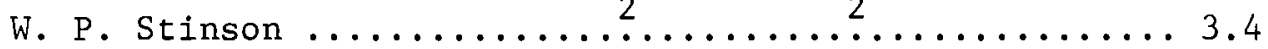

Experiments with Hafnium Oxide Rods in $\mathrm{UO}_{2}-\mathrm{PuO}_{2}-\mathrm{H}_{2} \mathrm{O}$ Lattices - V. 0 . Uotinen ..................... 3.5

Clean Critical Loading of Al-2 wt\% Pu Fuel in an $\mathrm{H}_{2} \mathrm{O}$ Moderated Core - V. 0. Uotinen .................... 3

Critical Experiments in $\mathrm{H}_{2} \mathrm{O}$-Moderated Assemblies Containing $\mathrm{UO}_{2}-2$ wt\% $\mathrm{PuO}_{2}{ }^{2}$ Fuel Rods - V. O. Uotinen and

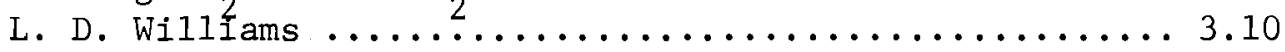

A "Poison-Free" Loading of $\mathrm{UO}_{2}$ and $\mathrm{Al}-\mathrm{Pu}$ in the PRCF with $\mathrm{D}_{2} \mathrm{O}$ Moderator $-\mathrm{V}$. O. Uotinen .................... 3.18

Reactivity Worth of a Central Safety Rod With and Without an Internal Scatterer - V. O. Uotinen and A. L. Pitner. . 3.19

PCTR Experiments - H. A. Hill ...................... 22

\section{PRTR Batch Core Experiment}

P-6 PRTR Batch Core Experiment - R. I. Smith .......... 3. 31 Critical Tests - R. I. Smith and J. W. Kutcher .........3.33

Power Tests - J. W. Kutcher and R. I. Smith .......... 3.34

\section{EBWR Experiment}

Power Operation History - R. C. Liikala ............. 3.43 Irradiated Fuel Sampling and Post Irradiation Experiments -

R. C. Liikala and U. P. Jenquin ................... 34

Irradiated Fuel Shipments - J. B. Edgar, R. C. Liikala, A. R. Maki, and L. D. Williams ................. 3.45

Non-Destructive Analysis - E. S. Murphy and D. E.

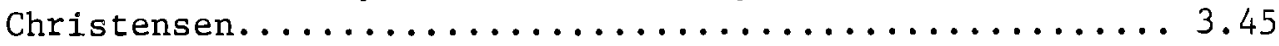




\section{Analysis of Irradiated Fuels}

Underwater Gamma Scanning Facility - D. E. Christensen

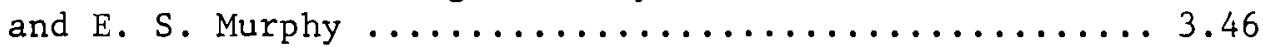

Burnup Analysis of Aluminum-Plutonium Fuel Irradiated in the PRTR - D. E. Christensen and R. P. Matsen ....... 3.53

\section{Saxton Experiment}

Analysis of WREC Experiments - G. L. Simmons ......... 3.59

Analytical Survey Studies

$\mathrm{H}_{2} \mathrm{O}$ Moderated Lattices of $\mathrm{UO}_{2}-4 \mathrm{wt} \% \mathrm{PuO}_{2}$ Fuel -

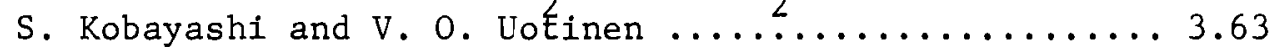
$\mathrm{UO}_{2}-\mathrm{PuO}_{2}-\mathrm{H}_{2} \mathrm{O}$ Systems-Reactivity Coefficients -

Photoneutron Calculations for $\mathrm{D}_{2}$ O Systems - U. P. Jenquin

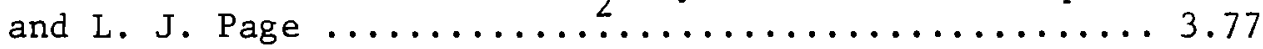

\section{Cross Section Measurements}

Doubly Differential Cross Sections and the Scattering Law for $\mathrm{H}_{2} \mathrm{O}$ and $\mathrm{D}_{2} \mathrm{O}$ at $299^{\circ} \mathrm{K}$ and for $\mathrm{H}_{2} \mathrm{O}$ at $268^{\circ} \mathrm{K}-$

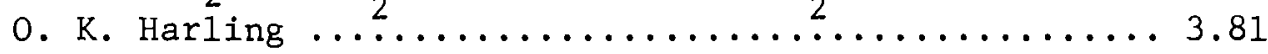

Neutron Scattering Law for Light water at $95^{\circ} \mathrm{C}-$

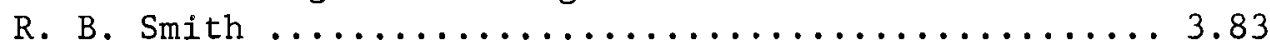

Completion of Fast-Neutron Total-Cross-Section Measurements - D. G. Foster, Jr. and D. W. Glasgow ....... 3.87

The Dineutron and n-d Total Cross Section - D. W. Glasgow

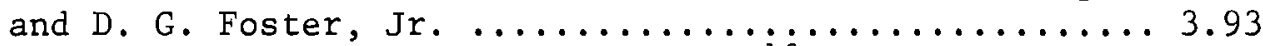

The Existence of the $2.86 \mathrm{MeV}$ State in $1{ }^{0} \mathrm{~B}-\mathrm{D}$. W. Glasgow

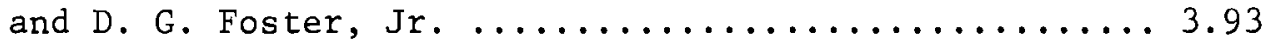

\section{Methods Development}

Calculation of Thermal Neutron Scattering Cross Sections -

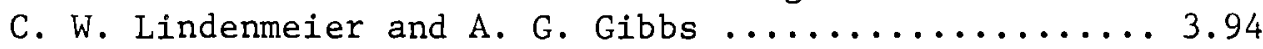

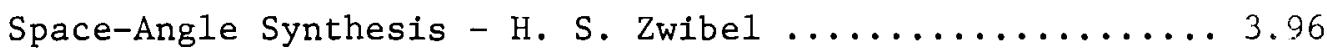

Effective Cross Sections for Resonances in HRG -

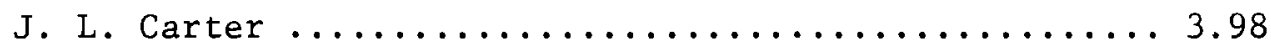

ZODIAC - D. D. Matsumoto and R. H. Holeman ........... 3.99

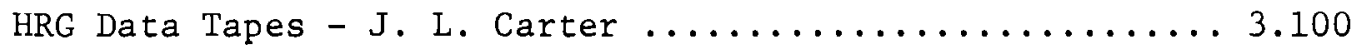

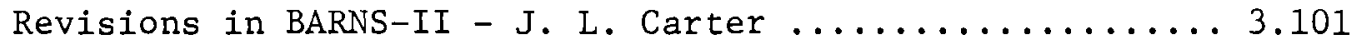

RBU Monte Carlo Code - D. H. Thomsen and A. G. Gibbs ..... 3.101

Program GAMMAX - L. J. Page and H. S. Zwibel .......... 3.111

Program Beta - A. Reactor Kinetics Code - L. J. Page ..... 3.111

Program DANCOF - W. L. Purcell and G. L. Simmons ........ 3.112

Program NOISE - G. D. Seybold and L. C. Schmid .......... 3.113

Cross Section Evaluation Working Group - B. R. Leonard

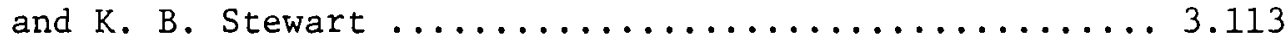

ENDF/B Neutron Cross Section Library System -

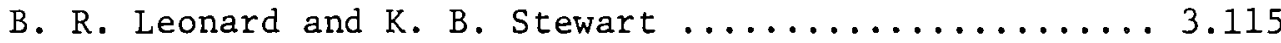

BNW Master Cross Section Library - K. B. Stewart ........ 3.115 


\section{Methods Evaluation}

Comparison of Calculated and Measured Multiplications, $\mathrm{k}$, for Some Uranium and/or Plutonium Fueled $\mathrm{H}_{2} \mathrm{O}$ LaEtices - R. C. Liikala and W. L. Purcell .......... 3.118 Analytical Correlations of $\mathrm{UO}_{2}-2 \mathrm{wt} \% \mathrm{PuO}_{2}-\mathrm{H}_{2} \mathrm{O}$ Moderated Critical Experiments - V. O. Uotinen and ${ }^{2}$. Kobayashi.. 3.132 Correlation of Effective Cross Sections - R. C. Liikala

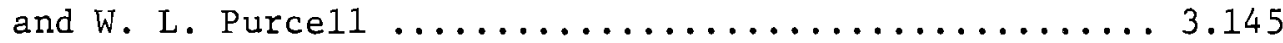

Correlations of Effective Cross Section Ratios and Isotopic Concentrations - L. J. Page and L. C. Schmid.. 3.152

\subsection{PLUTONIUM UTILIZATION STUDIES}

Optimized Lattices for Plutonium Utilization -

J. H. Nail .......................... 4.1

Power Peaking With Plutonium Recycle - R. T. Thompson ...4 4.8

\subsection{PLUTONIUM RECYCLE TEST REACTOR (PRTR)}

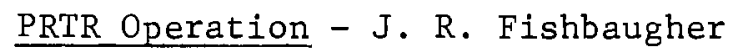

Recovery From the CY 1965 FERTF Incident ............. 5.1 Nuclear Critical Tests ....................... 5.1

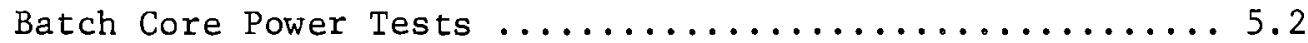

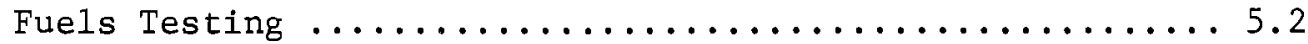

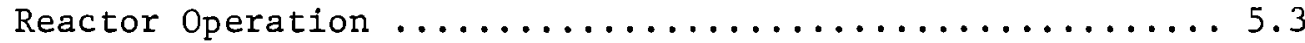

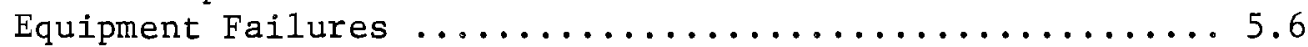

PRTR Modifications - J. R. Fishbaugher

Project CBB-001 - Increased Power Leve1 ........... 5.6

Project BCP-007 - Waste Handling ................... 5.6

Reflector Change to Light Water ............... 5.7

Primary System Filters .................. 5.7

New Instrument Power Supply .................... 5.7

Safety Circuit Modifications $\ldots \ldots \ldots \ldots \ldots \ldots \ldots \ldots \ldots .7$

\section{PRTR Analysis}

Boiling Burnout Limits for 8-Rod Element in FERTF -

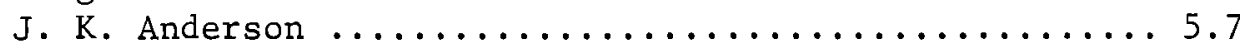

Therma1-Hydraulic Limits for PRTR Thorium Loading -

J. K. Anderson ....................... 5.10

Physics Analysis for PRTR Thorium Loading - U. P. Jenquin. 5.11

\subsection{MATERIALS}

Effects of Flux on the Alloys in the PRTR

Corrosion and Hydriding of Tubular Zircaloy-2 and Zircaloy-4 Specimens - A. B. Johnson, Jr., B. Griggs,

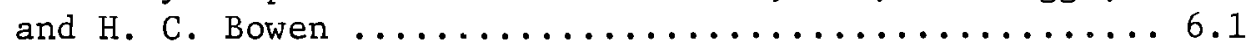

Corrosion and Hydriding of PRTR Zircaloy-2 Process

Tubes - A. B. Johnson, Jr. and B. Griggs .........6.10 


\section{Chemistry Studies}

Ceramic Fuel Dissolution Studies - L. D. Perrigo ........ 6.13

Corrosion and Boron Deposition in $\mathrm{H}_{3}-\mathrm{BO}_{3}$ Solutions -

G. R. Boom and T. F. Demmitt ................... 6.15

$\underline{\text { PRTR Pressure Tube Technology and Surveillance }}$

Specification for Flaw Detection Limits - P. J. Panaskie

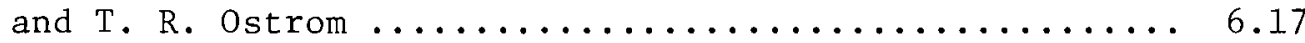

Process Tube Examination - M. C. Fraser and T. R. Ostrom .. 6.17

Crack Propagation Tests - T. R. Ostrom .............. 6.18

\subsection{PUBLICATIONS}

8.0 DISTRIBUTION 


\section{PLUTONIUM UTILIZATION PROGRAM ANNUAL REPORT}

\section{FISCAL YEAR 1967}

The Plutonium Utilization Program was initiated in 1956 with the objectives of developing technology for safe and economical recycle of plutonium fuel in power reactor systems, and demonstrating plutonium recycle in a practical manner. The program is conducted by the Pacific Northwest Laboratory, Battelle Memorial Institute under sponsorship of the AEC Division of Reactor Development and Technology. This report summarizes Plutonium Utilization Program results for fiscal year 1967.

During the past year, it has become increasingly more evident that plutonium recycle in thermal reactors will be required in order to attain the most economic fuel cycle. This has come about because of the surge in orders from the utilities for water reactors and the uncertainty in the timing of fast reactor introduction. Based on present reactor startup projections, it appears that excess plutonium will be available for plutonium recycle by 1973. Although technical feasibility of plutonium recycle is now established, many questions remain to be answered to ensure optimum utilization of the plutonium. This will require an integrated effort of the AEC's and industry's programs. Specific steps are being taken by Pacific Northwest Laboratory to transfer to industry the technology developed in the AEC program and to cooperate with industry in developing programs of mutual interest.

The present phase of the program is focused on obtaining the data required to assure timely application of plutonium to water reactors. The over-all program is comprised of research and development in fuels development, reactor physics, fuel cycle analysis, reactor engineering and materials with the major emphasis on the first two areas.

Fuels development effort is emphasizing the irradiation behavior of $\mathrm{PuO}_{2}-\mathrm{UO}_{2}$ under high linear power ratings and exposure, transient and defect behavior, evaluation and comparison of $\mathrm{PuO}_{2}-\mathrm{UO}_{2}$ fuels fabricated using several methods, and investigation of problems and techniques 
involved in fuel fabrication. Experimental physics efforts have in the past emphasized measurements on uniform lattices of several fuel compositions. Emphasis has shifted to measurement of core nuclear characteristics as a function of exposure and to specific problems associated with loading plutonium in water reactors. The primary objective of the physics efforts is to evaluate and improve where necessary design and analysis methods to a stage where reliable engineering calculations can be made for predicting the nuclear characteristics of plutonium fueled thermal reactors.

Highlights of the program are presented followed by detailed discussion of accomplishments in FY 1967. 


\section{PROGRAM HIGHLIGHTS}

\section{FUELS DEVELOPMENT}

\section{Batch Core Testing}

The Batch Core Experiment is providing irradiation behavior data on a statistically significant number of $\mathrm{UO}_{2}-\mathrm{PuO}_{2}$ fuel elements operating at maximum linear rod powers of nearly $20 \mathrm{~kW} / \mathrm{ft}$ with maximum fuel temperatures near melting. Goal exposure is 13,000 MWd/tonne. During FY 1967 fuel elements reached an average burnup as high as $1200 \mathrm{MWd} /$ tonne. Nondestructive and destructive examinations of selected fuel rods indicate that performance is satisfactory. Results of the program to date indicate that for the low plutonium concentrations of interest in thermal reactor fuels, the performance characteristics such as physical fuel behavior, fission gas release, sintering, and fission product migration are not significantly different for $\mathrm{UO}_{2}$ and vibrationally compacted $\mathrm{UO}_{2}-\mathrm{PuO}_{2}$ fuels.

Fuel irradiations were performed to determine the maximum allowable reactor power level as limited by a maximum permissible fuel temperature. Thirteen fuel rods were metallographically examined to ascertain fuel structures formed during these irradiations. Under PRTR operating conditions the onset of melting in vibrationally compacted $\mathrm{UO}_{2}-2 \mathrm{wt} \% \mathrm{PuO}_{2}$ fuel rods apparently occurs at $20.5 \pm 0.5 \mathrm{~kW} / \mathrm{ft}$. This power to produce melting is equivalent to an $\int_{0}^{\mathrm{T}}{ }_{0} \mathrm{KdT}$ of about $68 \mathrm{w} / \mathrm{cm}$. Fuel melting occurred in two of the vibrationally compacted rods examined. Destructive examination of the end regions of these two rods show that the depleted $\mathrm{UO}_{2}$ pellets used at the end of the fuel column effectively prevented excessive fuel temperatures in the end cap region. No pellet fuel interaction and only minor pellet cracking was observed. FERTF (Fuel Element Rupture Test Facility) Testing

During FY 1967, a 19-rod cluster of commercially designed and fabricated fuel rods containing hot pressed pellets of $\mathrm{UO}_{2}-1.94 \mathrm{wt} \% \mathrm{PuO}_{2}$ was tested in the FERTF. The objective of this test was to gain 
irradiation experience with fuel assemblies containing hot pressed pellets before charging such fuel into the batch core.

A special 8-rod FERTF Test Element to be used for defect tests was designed, fabricated, and tested. The FERTF test element consists of a protective sleeve assembly surrounding the fuel rod rack that supports an 8 -rod ring of Mark $I-R_{2}$ fuel rods. The sleeve assembly provides protection for the surrounding Zircaloy pressure tubes. The flexibility to meaintain the desired power match between fuel rods in the FERTF and fuel rods in Ring 1 of the batch core is achieve by changing the macroscopic absorption cross-section of the assembly. This can be accomplished by changing the types of sleeve and insert materials used in the assembly. The physics and power generation characteristics of the FERTF Test Element were computed and also determined experimentally by zero power tests in PRTR. The thermal hydraulic characteristics of the FERTF Test Element were also determined experimentally. Boiling burnout limits were determined analytically.

A testing program was formulated for irradiating fuel rods containing vibrationally compacted $\mathrm{UO}_{2}-\mathrm{PuO}_{2}$ fuel, $\mathrm{UO}_{2}-\mathrm{PuO}_{2}$ pellet fuel, and vibrationally compacted enriched $\mathrm{UO}_{2}$ fuel. The first test series will be run at rod powers up to $20 \mathrm{~kW} / \mathrm{ft}$ and will require approximately nine irradiation periods (reactor operating cycles).

High Exposure Plutonium Studies

As a first step in determining dose rates and shielding requirements for high exposure plutonium, detailed isotopic analyses of uranium, plutonium, and transplutonium nuclides were completed on Shippingport and Yankee high exposure fuel samples. Evaluation of the Shippingport aniyses are reported in BNWL-478.

Dosimetry measurements were made on Shippingport, Yankee, Hanford and other high exposure plutonium samples. Practically all samples were in the form of oxides or metal. Gamma dose rates were fairly well defined and special studies were made of the $2+$ Am buildup contribution. Some neutron dosimetry was completed. $\mathrm{X}$-ray and gamma energy spectra measurements were made on Shippingport and Yankee plutonium product samples from fuel 
irradiated to exposures of approximately 30,000 and 40,000 MWd/tonne, respectively.

Fabrication Costs

An analytical model was used to investigate the influence of plant throughput on thermal reactor fuel element costs. A detailed estimate was made of costs at $1 / 4$ and $1 / 2$ ton/day output levels, for fuel elements enriched with uranium and with high exposure plutonium. These costs are compared with previously estimated costs for producing the same fuels at an output of 1 ton/day. Costs have also been extrapolated to cover 5 and 10 ton/day throughput levels.

\section{Special Batch Core Testing}

Four $\mathrm{UO}_{2}-2 \mathrm{wt} \% \mathrm{PuO}_{2}$ fuel rods instrumented to measure fuel rod gas pressure and plenum gas temperature are presently operating in the PRTR. Two of these rods have operated at $20 \mathrm{~kW} / \mathrm{ft}$ and have obtained exposures of $1280 \mathrm{MWd} /$ tonne. The other two have operated at $10 \mathrm{~kW} / \mathrm{ft}$ and have reached exposures of $590 \mathrm{MWd} /$ tonne. Plenum gas pressure measured in the higher power rods is $56 \mathrm{psi}$ and in the lower power rods, $17 \mathrm{psi}$.

The exposures on these rods were obtained during relatively short periods (100 hours, maximum) of steady-state operation. Because extended periods of steady-state operation have not been obtained, the gas release characteristics have not been established. It appears, however, that gas pressure increases in a stepwise manner during reactor startups and then levels off or decreases slightly during steady-state operation. Though it is difficult to ascertain fission gas release values at the low exposures reached by the fuel rods, the trend of increasing internal gas pressures with exposures is apparent. MTR/ETR Testing

A 7-rod cluster fuel element containing a defected vibrationally compacted $\mathrm{UO}_{2}$ fuel rod was successfully irradiated in the ETR pressurized water loop at a maximum linear rod power of $28-29 \mathrm{~kW} / \mathrm{ft}$. This rod power resulted in an estimated $60-65 \%$ of the radius molten at the plane of the defect. After irradiation under these conditions for nine effective full power days, the test was terminated. Examination of the defected 
rod in the ETR basin did not reveal any physical changes as a result of the irradiation. Hot cell examination is in progress.

\section{Transient Tests}

Two transient irradiation experiments were conducted in TREAT to investigate the meltdown behavior, in water, of nonirradiated Zircaloyclad vibrationally compacted $\mathrm{UO}_{2}$ fuel rods with and without simulated fission gas pressure. Although all of the fuel rods received the same total amount of transient energy, approximately one-third less power was required to cause failure of the pressurized fuel rods than the low-pressure fuel rods. Pressure rise rates resulting from the meltdown of vibrationally compacted $\mathrm{UO}_{2}$ fuel rods were higher than those resulting from the meltdown of pellet-containing fuel rods tested by ANL. The more energetic pressure pulses with vibrationally compacted fuel are attributed to the smaller $\mathrm{UO}_{2}$ fragments resulting from the transients.

Examination of a high speed motion picture obtained from the transient irradiation of a vibrationally compacted $\mathrm{UO}_{2}$ fuel rod suggests that unexpected differences may exist in the behavior of pellet-contained fuel rods (previously tested and filmed by ANL) and vibrationally compacted fuel rods undergoing similar transient irradiations.

A series of experiments was formulated to establish the failure thresholds of fuel rods undergoing power transients. Approval in principle to conduct such tests was obtained from the Laboratory Director's Office of ANL.

\section{PRTR Fringe Position Test}

Irradiation of selected $\mathrm{UO}_{2}$ and $\mathrm{UO}_{2}-\mathrm{PuO}_{2}$ fuel elements (pre-Batch Core Experiment vintage) containing $0.5,1.0$, and $2.0 \mathrm{wt} \% \mathrm{PuO}_{2}$ is continuing in fringe positions of the PRTR during the Batch Core Experinent. These elements are being irradiated to determine performance at high exposures $>10,000 \mathrm{MWd} /$ tonne). Periodic underwater examination of these elements indicates that their performance continues to be satisfactory. Commercial Fuels Study

Plutonium fuel rods designed and fabricated by a commercial fuel fabricator are currently undergoing irradiations in the PRTR. A total of seventy-seven fuel rods containing hot pressed $\mathrm{UO}_{2}-\mathrm{PuO}_{2}$ pellets were 
purchased. A 19-rod cluster of these rods was irradiated in the FERTF and performed satisfactorily. Two 19-rod clusters of hot pressed pellet rods are scheduled to be charged in the batch core.

Three fuel rods containing cold pressed and sintered $\mathrm{UO}_{2}-\mathrm{PuO}_{2}$ pellets are also being purchased from a commercial fuel fabricator. The performance of these fuel rods will be compared to that of vibrationally compacted fuel rods as well as the hot pressed pellet rods.

\section{REACTOR PHYSICS}

Sub-Critical and Critical Experiments

Experiments were conducted in the Critical Approach Facility and the Plutonium Recycle Critical Facility to investigate the detailed physics properties of plutonium-fueled reactor systems. Measurements have been made using $\mathrm{UO}_{2}-2 \mathrm{wt} \% \mathrm{PuO}_{2}$ rods in $\mathrm{H}_{2} \mathrm{O}$ moderator. Experiments were conducted at lattice spacings covering the range of moderator to $\mathrm{PuO}_{2}-\mathrm{UO}_{2}$ volume ratios of 0.61 to 9.7 and the plutonium contained either 8,16 or 24 percent $\mathrm{Pu}^{240}$. The results included critical masses, bucklings, flux and power distributions, reactivity coefficients, kinetic parameters, and control rod worths. The experimental results provide data for evaluation of calculational methods and approximations. These measurements, when combined with results obtained in other years, make data available which is a rigorous check of calculational methods for a range of plutonium concentrations and of volume ratios of moderator-to-fuel of importance to pressurized and boiling water reactors.

The PCTR is being used for evaluating the effect on reactivity of finite $\mathrm{PuO}_{2}$ particles in $\mathrm{UO}_{2}$ and for obtaining additional data on water lattices not obtainable from other facilities which is required for further evaluation of analysis methods. The initial results of the $\mathrm{PuO}_{2}$ particle size experiments indicate that the reactivity decreases as the size is increased from $100 \mu$ to $350 \mu$ for the fuel composition used (2.0 $\left.\mathrm{wt} \% \mathrm{PuO}_{2}, 8.05 \mathrm{wt} \% \mathrm{Pu}^{240}\right)$. The design of the first experiment in the water tank is complete and will contain $\mathrm{PuO}_{2}-\mathrm{UO}_{2}$ fuel on a 1.0 inch lattice pitch. The water tank experiments will supplement lattice 
experiments performed in the CAF and PRCF. The PCTR technique will evaluate neutron leakage which is a major effect in the CAF and PRCF experiments. PRTR Batch Core Experiments

A large scale burnup experiment has been initiated in the $\mathrm{D}_{2} \mathrm{O}^{-}$ moderated Plutonium Recycle Test Reactor using 19-rod clusters of $\mathrm{UO}_{2}$-wt\% $\mathrm{PuO}_{2}$ rods. This experiment is providing data relating the reactivity characteristics of the core and the isotopic composition of the fuel in the core as a function of exposure of the fuel. The basic fuel loading will remain essentially unperturbed to the end of the core reactivity lifetime thus providing a unique set of the data for use in checking methods of calculating reactivity lifetimes of reactor cores. Another important aspect of the experiment is the simultaneous irradiation of a statistically significant number of plutonium-bearing, packed particle fuel elements under conditions similar to those in an operating power reactor.

The first phase of the experiment has been completed and consisted of an extensive set of tests at zero power during the initial loading of the core. A series of power tests designed primarily to verify predicted operational characteristics of the reactor were conducted when the loading was completed. The boron concentration in the $\mathrm{D}_{2} 0$ moderator needed to compensate for the initial excess reactivity in the core agreed with predicted concentration requirement to within a few percent and in general all parameters measured during the test were in reasonable agreement with values which had been predicted earlier. The power tests which have been completed have also generally confirmed the predicted operational behavior of the reactor and the power has been increased to its operat ng level of approximately $50 \mathrm{MW}$. Further tests will measure growth and decay of fission product poisoning in the power coefficient of reactivity. EBWR Experiment

An irradiation experiment was conducted in the Experimental Boiling Water Reactor at Argonne National Laboratory. This experiment is part of the joint ANL-PNL program to demonstrate the utilization of plutonium in a boiling $\mathrm{H}_{2} \mathrm{O}$ power reactor and to obtain useful physics information on the 
behavior of a plutonium fuel in such a reactor system. Information obtained in this experiment for the plutonium zone will be compared to results of calculations to identify areas of uncertainty in the computations.

At three stages of burnup a series of rods were removed from the plutonium zone for nondestructive and destructive analysis. The series of rods contained $\mathrm{Al}-\mathrm{Pu}$, natural $\mathrm{UO}_{2}$, and $\mathrm{UO}_{2}-\mathrm{PuO}_{2}$ fuels. In addition, the fuels which contained plutonium differed in their $\mathrm{Pu}^{240}$ concentration. Some of the rods are selected from positions in the core so that the spatial distribution of burnup can be obtained from the nondestructive and destructive analysis.

Analysis of Irradiated Fuels

Fuel rods removed from selected location in the EBWR and from past and present experiments in the PRTR are both nondestructively and destructively analyzed to obtained fission and fuel concentration and isotopic composition. From these data effective cross section ratios are derived for use in evaluating burnup analysis methods. New techniques for this purpose using multi-parameter, non-linear regression methods have been developed and applied to data from four sets of irradiated A1-Pu samples. The PNL Gamma Scanner has been improved and continues to be used for the nondestructive analysis.

Saxton Experiment

Information on the physics characteristics of pressurized water power reactor systems which were obtained during the Saxton plutonium program is compared to results obtained with zero, one, and two-dimensional diffusion theory methods. The purpose of the comparison is to evaluate nuclear design methods by pointing out discrepancies, identifying the reasons the discrepancies, and illustrating schemes for normalizing the methods to bring about agreement between calculation and experiment. The conclusion that is reached is that a one-dimensional cylindrical model of the reactor seems adequate from the standpoint of reactivity calculations for single zone lattices. 


\section{Analytical Survey Studies}

Analytical survey studies have been performed to provide information on the physics characteristics for various reactor systems of interest. Results of these studies are directed toward providing the scope for possible experiments and providing information on certain physics characteristics of reactor systems in the absence of experimental information.

It is shown that the $\mathrm{UO}_{2}-4 \mathrm{wt} \% \mathrm{PuO}_{2}-\mathrm{H}_{2} \mathrm{O}$ cores which were studied would be undermoderated and that the characteristic parameters such as $n$, $f$, and $p$ play an important role in the physics behavior of these cores. As a result an experimental program is planned.

A survey study was conducted to determine the approximate magnitude of various reactivity coefficients for $\mathrm{UO}_{2}-\mathrm{PuO}_{2}$ fueled light water reactors. The composition of the plutonium is assumed typical of first cycle plutonium fuel from light water reactors.

Calculations were also performed to determine the reactor charac teristics of thorium loadings in $\mathrm{D}_{2} \mathrm{O}$ moderator. The feasibility of the thorium loading in the PRTR was determined either as a batch core or as a driver region for a $\mathrm{UO}_{2}-\mathrm{PuO}_{2}$ core. The physics characteristics of metallic fuel and of ceramic fuels were investigated along with the variation in rod size in thorium enrichment.

\section{Cross Section Measurements}

Cross section measurements were phased out of the program at the end of FY 1966. Data reduction was completed in FY 1967 and several reports prepared. Slow neutron inelastic scattering cross sections have been reported for $\mathrm{H}_{2} \mathrm{O}$ and $\mathrm{D}_{2} \mathrm{O}$. The double differential cross section and corresponding Egelstaff scattering law have been obtained from measurements for room temperature $\mathrm{H}_{2} \mathrm{O}$ and $\mathrm{D}_{2} \mathrm{O}$ and for $\mathrm{H}_{2} \mathrm{O}$ of five degrees below its freezing point using the Battelle Rotating Crystal time-of-flight Spectrometer. In addition, results of measurements for $\mathrm{H}_{2} \mathrm{O}$ at $95^{\circ} \mathrm{C}$ using the Battelle Triple-Axis Spectrometer have been reported.

The results provide significant information in two areas. One is the area of nuclear reactor design in which a knowledge of the slow-neutron 
differential scattering cross section is required for accurate calculations of neutron-thermalization effects of moderator and coolant. The second area is the physics of liquids, for which the same scattering cross section provides detailed information on the motions of the hydrogen atoms. The results for $\mathrm{H}_{2} \mathrm{O}$ include the first known observation of well resolved high energy vibrations using the neutron scattering technique. Methods Development

An extensive evaluation of the RBU Monte Carlo Code has been completed. The purpose of the evaluation is to check the formulation and coding of the code and to provide a base of problems to help in the selection of future applications. The test problems specifically test the various routines (fission, resonance, thermalization, geometry, etc.). Results of this evaluation indicate that the RBU Monte Carlo code is free of gross program errors and can be used reliably for reactor physics calculations.

Knowledge of the Legendre moments of moderator scattering cross sections is of particular importance in the prediction of the thermal neutron spectrum of plutonium fueled reactors. Based on the EgelstaffSchofield formalism, two methods for calculating scattering moments for moderators have been developed and programmed on the computer. Starting with identical width functions, the programs generate results that are in agreement. Each has advantages in certain applications. A model for water is being evaluated using available experimental data.

Several computer codes have been adapted, modified, or improved for use in the physics programs. The RBU Monte Carlo code has been thoroughly tested and appears to be working satisfactorily. The ZODTAC-2 burnup code was modified and enlarged to increase its burnup capabili... .s. The HRG (Hanford Revised GAM) code spectrum model used in resonance integral calculations was improved. Several special purpose codes have been developed.

At the request of $\mathrm{RD} \& \mathrm{~T}$, assistance was provided to Brookhaven National Laboratory in preparing nuclear data for the ENDF/B. Data were furnished for the ten isotopes which Battelle accepted responsibility to evaluate as a member of the Cross Section Evaluation Working Group. Adaption of 
the ENDF/B system to the local UNIVAC 1108 is in progress. Methods Evaluation

Theoretical studies have been directed toward developing a mathematical physics model which accurately predicts the observed physics behavior of power reactor systems. A measure of the validity of the mathematical model is obtained by comparing measured and calculated integral parameters such as reactor multiplication and effective cross sections. Frequently the results of comparison are in such good agreement that the effects of uncertainties in the model must be considered in determining the model's figure of merit. Comparisons have been performed for numerous plutonium and/or uranium fueled $\mathrm{H}_{2} \mathrm{O}$ lattices.

The calculated multiplications are all low compared to experimental values for the $\mathrm{UO}_{2}$-fueled $\mathrm{H}_{2} \mathrm{O}$ critical experiments; high for aluminumplutonium fueled experiments; and are in good agreement for $\mathrm{UO}_{2}-\mathrm{PuO}_{2}$ fueled experiments. For the latter experiments there does not appear to be any trend in the results with $\mathrm{Pu}^{240}$ concentrations; however, for high (6.6 wt\%) $\mathrm{PuO}_{2}$ concentration in $\mathrm{UO}_{2}$, the multiplications are overpredicted by about 1-2 percent. Sources of the discrepancies have also been evaluated and it is concluded that the theoretical methods utilized in this study cause uncertainties as large as those caused by the cross section data.

Comparisons of flux and power densities, reactivity coefficients, kinetic parameters, and effective cross section ratios, have also been made. The results of the comparisons show that in many cases the calculational techniques need to be refined. As an example, calculated localto-average power peaking factors in rods adjacent to water holes are greater than the measured values by approximately 6 percent and average void coefficients are 20-30 percent higher than the measured values. A conclusion from the comparison of calculated ratios of effective cross sections to values deduced from burnup experiments is that the comparison is best when the thermal cross sections for $\mathrm{Pu}^{239}$ and $\mathrm{Pu}^{241}$ are normalized to the $2200 \mathrm{~m} / \mathrm{sec}$ values of the Leonard evaluation, but the 
calculated values using Westcott normalization differ from the experimental values by only about one standard deviation.

\section{PLUTONIUM UTILIZATION STUDIES}

There is an economic incentive for reoptimizing the lattices of reactors originally designed for uranium fuel to utilize plutonium fuel. The magnitude of the saving is dependent on both the method of changing the lattice and the plutonium composition. The three methods examined were reduced fuel density, reduced rod size, and increased lattice pitch. of these, the reduced rod size and increased pitch showed more savings (up to $0.3 \mathrm{mills} / \mathrm{kWh}$ ) with the rod size reduction possibly being technologically the more desirable.

Power sharing between freshly charged fuel bundles containing plutonium and those containing only slightly enriched uranium also depends upon fuel density, rod size and lattice pitch. Reduced fuel density and increased lattice spacing both increase the power peak in plutonium bearing fuel above the $20 \%$ increase found in the reference lattice. Reducing the rod diameter reduces the power peak in the plutonium bearing fuel. Placing the plutonium in a few rods in each assembly reduces the power peak in the assembly, but the plutonium bearing rods produce more than their share of the power in the assembly. Reducing the enrichment of the plutonium bearing rods tends to equalize the power produced in each rod of the assembly.

\section{PRTR OPERATIONS}

Recovery from the FY 1966 Fuel Element Rupture Test Facility (FERTF) incident was completed during the early part of FY 1967. All nuclear critical experiments were completed for the Batch Core Experiment and the FERTF program. The PRTR began the batch core power tests on January 24, 1967, and all power tests, except the measurement of the transient fission product poisoning, were completed by the end of FY 1967.

Modifications to the PRTR were initiated to update the reactor safety circuits. Modifications were made to permit the change of the primary coolant $\mathrm{pH}$ from 10 to 7 ; to replace the $\mathrm{D}_{2} \mathrm{O}$ in the reflector with $\mathrm{H}_{2} \mathrm{O}$; to permit control of the reactor with a chemical shim (boron); to measure 
fission product pressure in fuel rods during irradiation; to permit better control of the aqueous and ventilation waste; and to permit power generation of the PRTR to be increased to $85 \mathrm{MW}$.

Thirty $\rightarrow$ four irradiated fuel elements were chemically processed at the Redox Plant of Isochem, Inc., to produce $9 \mathrm{~kg}$ of plutonium containing $14.6 \%$ of the $\mathrm{Pu}^{240}$ isotope.

\section{MATERIALS}

Effects of Flux on the Corrosion and Hydriding of Zirconium Alloys in the $\underline{\text { PRTR }}$

Sixty tubular Zircaloy-2 and Zircaloy-4 specimens were exposed in-flux on a Zircaloy-2 rod at a position normally occupied by a fuel rod. The specimens were exposed in as-etched and prefilmed (pretransition and posttransition) surface conditions. Corrosion rates were accelerated at the higher flux positions for all surface conditions of both alloys. However, accelerated corrosion was slight on as-etched specimens. Prefilming adversely affected the in-flux corrosion rates. Hydrogen pickups also were higher for the prefilmed specimens.

Two Zircaloy-2 process tubes were examined for oxidation and hydriding at several points along each tube. Accelerated corrosion occurred on both tubes. The corrosion followed the flux profile along the tube axes. Influx weight gains up to $180 \mathrm{mg} / \mathrm{dm}^{2}$ were observed. However, deuterium pickups were 3 to $20 \mathrm{ppm}$, corresponding to absorption of less than 4 to $27 \%$ of the corrosion product deuterium. Hydrogen concentrations were higher toward the cooler ends of the tubes, likely due to thermal diffusion. Ceramic Fuel Dissolution Studies

Application of the oxalic acid, peroxide, gluconic acid decontamination mixture to the 9-29-65 PRTR rupture debris was highly effective. The dependence of the $\mathrm{UO}_{2}$ dissolution rate on temperature was found to correspond to an activation energy of about $12 \mathrm{kcal}$, similar to dissolution in $4 \mathrm{~N} \mathrm{HNO}_{3}$. The rate of dissolution in OPG increased with mixing (unlike dissolution in nitric acid). 
For effective dissolution of high fired $\mathrm{PuO}_{2}$, more strenuous reagents are required. Phosphoric acid, $99 \%$, even in the presence of $\mathrm{Fe}\left(\mathrm{NO}_{3}\right)_{3} \cdot 9 \mathrm{H}_{2} \mathrm{O}$ as an inhibitor to reduce attack on stainless steel was still much more effective than $85 \%$ phosphoric acid. Generally, the high acid decontamination procedures are compatible with Inconel 600, AISI 446 and AISI 304 alone or in combination. The corrosion rates on carbon steel are excessive.

Attempts to reduce ceramic fuel material in sodium $-\mathrm{NH}_{3}$ solutions were dropped after it was shown that $\mathrm{Fe}_{3} \mathrm{O}_{4}$ catalyzed the formation of sodium amide, without affecting significant reduction of the magnetite. Corrosion and Boron Deposition in $\mathrm{H}_{3}-\mathrm{BO}_{3}$ Solutions

Materials and components representative of the PRTR moderator system have been exposed to boric acid solutions in pilot plant installations and in the PRTR moderator system. These tests have demonstrated the potential for localized Al corrosion in the shroud tube bellows assembly. If specified operating criteria are observed, no other corrosion problems are anticipated.

Boron deposition on moderator system surfaces is expected from laboratory studies to be $<3 \mu \mathrm{g} \mathrm{B} / \mathrm{cm}^{2}$, well within PRTR reactivity control capabilities. Measurements in-reactor indicate boron deposition of $<0.1 \mu \mathrm{B} / \mathrm{cm}^{2}$. PRTR Pressure Tube Technology and Surveillance

Tube number 5696 was examined for the cause of a flaw in the tapered section and destructively examined to determine irradiation effects on PRTR tubing. The flaw was found to be caused by a falling alignment mandrel. Tests on the remainder of the tube showed an increase in both $300^{\circ} \mathrm{C}$ and room temperature burst strength, and no loss of crack propjeation strength with increasing exposure to $3 \times 10^{21}$ nvt.

Tests were completed for hoop stress at failure vs. temperature curves out to $300^{\circ} \mathrm{C}$ for constant slot lengths of $3 / 4,1-1 / 2$, and 3 inches. The crack arrest temperature was between room temperature and $150^{\circ} \mathrm{C}$ for all slot lengths. Room temperature crack propagation tests were run on specimens with 1-1/2 inch flaws and varying amounts of hydrogen; they showed no decrease in hoop stress with increasing hydrogen. 
Tests were completed for hoop stress at failure vs. temperature curves for tubes with $275 \mathrm{ppm}$ hydrogen and slot lengths of $3 / 4$ and $1-1 / 2$ inches. These curves showed no decrease in stress with increasing temperature for hydrided tubes when compared to similar curves for "as-received" tubing. There was an increase in the crack arrest temperature for the $3 / 4$ inch slot to over $300^{\circ} \mathrm{C}$ and an increase to between $150^{\circ} \mathrm{C}$ and $300^{\circ} \mathrm{C}$ for the $1-1 / 2$ inch slot. 
The prime objective of the Fuels Development portion of the Plutonium Utilization Program is to prove the feasibility of recycling plutonium fuels in thermal reactors. The broad scope of this objective calls for a diversity of studies on (1) the development of fabrication techniques, particularly as affected by the inclusion of power reactor plutonium in the fuel material, (2) fuel fabrication cost studies, and (3) investigation of the irradiation performance characteristics of plutonium-bearing fuel elements.

The PUP Fuel Development studies to date strongly indicate that at existing power reactor operating conditions, performance characteristics of $\mathrm{UO}_{2}-\mathrm{PuO}_{2}$ fuels are not significantly different from $\mathrm{UO}_{2}$ fuels. A major area of concern which still exists relative to $\mathrm{UO}_{2}-\mathrm{PuO}_{2}$, and also $\mathrm{UO}_{2}$ fuels, is failure behavior and behavior under out-of-limit transient conditions. Accordingly, during the past year, BNW's efforts on fuel development has been refocused to better obtain the information needed in these areas. Another emerging need is that of determining dose rates obtained from utilizing high exposure plutonium (the type of plutonium that will be available from many commercial power reactors) in recycle fuels. In response to this need, efforts on these studies have been accelerated during the past year. Other shifts in program emphasis will undoubtedly be required to insure a viable PUP Fuels Development effort. Efforts will be refocused as necessitated by a developing fuels technology.

PRTR Batch Core Testing - M. D. Freshley

Fuel Performance

The Batch Core Experiment is providing statistically significant irradiation behavior data on $\mathrm{UO}_{2}-\mathrm{PuO}_{2}$ fuel elements operated at power generations greater than those currently employed in commercial power reactors, i.e., maximum linea: rod power generations of nearly $20 \mathrm{~kW} / \mathrm{ft}$ with maximum fuel temperatures near melting to goal burnups over 13,000 MWd/tonne. A summary of the preser core loading status is presented in Table $I$.

Vibrationally compacted $\mathrm{UO}_{2}-2 \mathrm{wt} \% \mathrm{PuO}_{2}$ elements in the batch core reached an average burnup as high as $1200 \mathrm{MWd} /$ tonne. Nondestructive and destructive examinations of selected fuel rods indicate that performance is satisfactory. No fuel failures have occurred thus far in the program. A transverse cross section of a vibrationally compacted $\mathrm{UO}_{2}-2 \mathrm{wt} \% \mathrm{PuO}_{2}$ fuel rod irradiated in PRTR at approximately the maximum power expected during the Batch Core Experiment is shown in Figure 1. 
$\underline{\text { Table I }}$

PRTR Core Loading Status

Element Type ${ }^{(1)}$

Batch Core Experiment:

Vipac $\mathrm{PI}{ }^{(2)} \mathrm{UO}_{2}-2$ wt\% $\mathrm{PuO}_{2}$ (Batch Core Experiment

Elements)

Hot Pressed Pellet

$\mathrm{UO}_{2}-1.94 \mathrm{wt} \% \mathrm{PuO}_{2}$

Fringe Position Tests:

Vipac PI UO $\mathrm{UH}_{2}-2$ wt\% $\mathrm{PuO}_{2}$
(Spare Batch Core Experiment Elements)

Swaged $\mathrm{PI} \mathrm{UO}_{2}-2$ wt\% $\mathrm{PuO}_{2}$

Swaged $\mathrm{PI} \mathrm{UO} 2^{-1} \mathrm{wt} \% \mathrm{PuO}_{2}$

Vipac PI $\mathrm{UO}_{2}-1$ wt\% $\mathrm{PuO}_{2}$

Vipac PI $\mathrm{UO}_{2}-1.5$ wt\% $\mathrm{PuO}_{2}$

Vipac $\mathrm{MM}^{(3)} \mathrm{UO}_{2}-0.5 \mathrm{wt} \% \mathrm{PuO}_{2}$

Swaged $\mathrm{MM} \mathrm{UO} \mathrm{UO}_{2}-0.5 \mathrm{wt} \% \mathrm{PuO}_{2}$

Swaged $\mathrm{UO}_{2}$
No. of

Elements
Max. Rod

Power Gen.

$(\mathrm{kW} / \mathrm{ft})$
Burnup

(MWd/tonne)
66

1

$\sim 21.5$ $\sim 1200$

$>500$
4

1

1

2

1

1

2

1 $\sim 20$

$\sim 20$

$\sim 17$

$\sim 15$

$\sim 6$

$\sim 16$

$\sim 13$

$\sim 12$
$>4800$

$>2500$

$>7000$

$>6000$

$>3000$

$>11,000$

$>9000$

$>9000$

(1) PRTR elements are 19-rod cluster bundles of 0.565 O.D. Zircaloy-clad rods with active fuel lengths of 58.5 and 88.5 inches.

${ }^{(2)} \mathrm{PI}=$ High energy rate pneumatically impacted fuel.

(3) ${ }_{\mathrm{MM}}=$ Mechanically mixed fuel. 


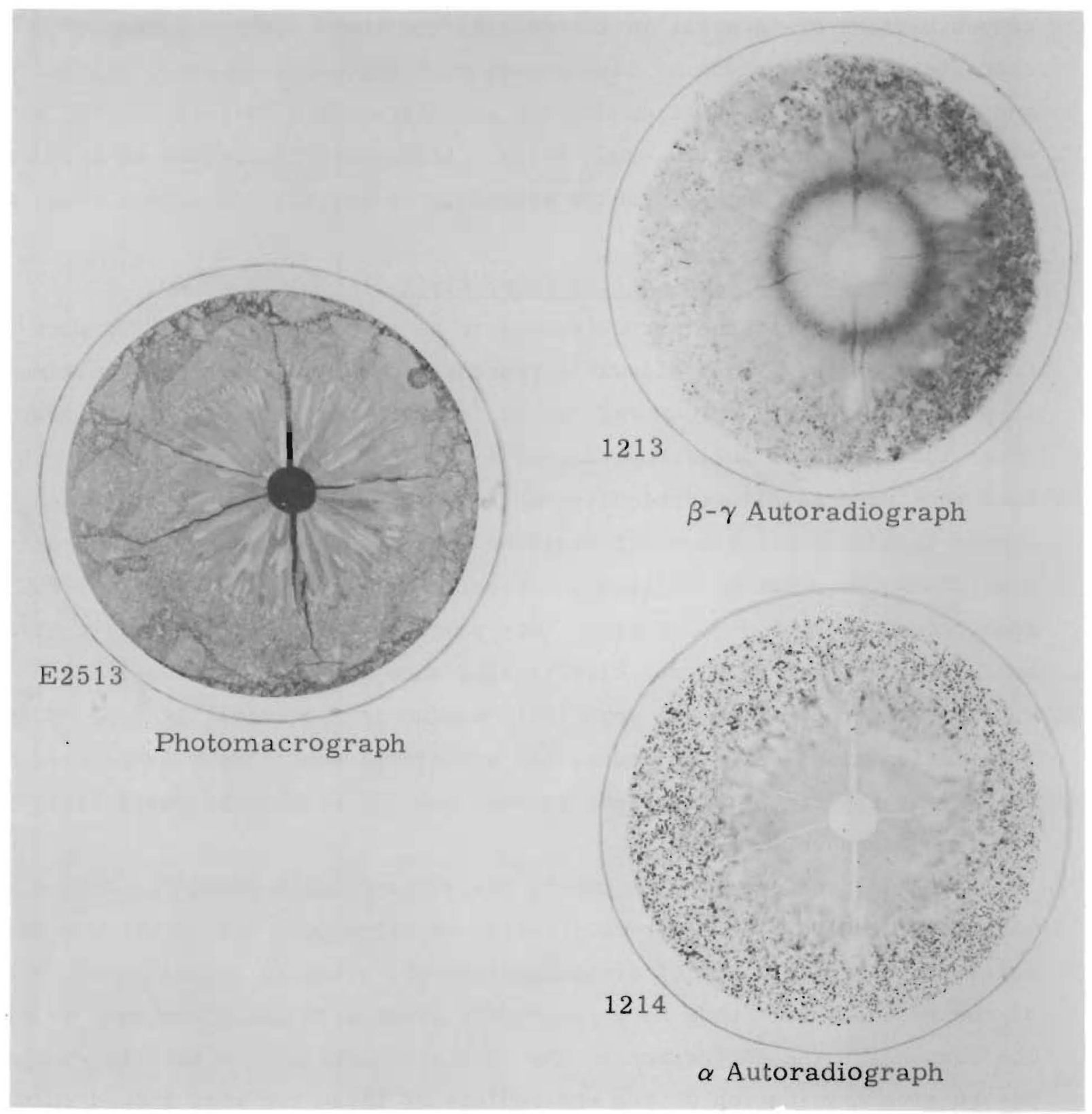

Figure I

Transverse Section of a Vibrationally Compacted $\mathrm{UO}_{2}-2$ wt.\% $\mathrm{PuO}_{2}$ Fuel Rod Irradiated Under the Maximum High Power Density Conditions in PRTR, i.e. $20 \mathrm{~kW} / \mathrm{ft}$ with Maximum Fuel Temperatures near Melting 
Results of the program to date indicate that for the low plutonium concentrations of interest in thermal reactor fuels such performance characteristics as physical fuel behavior, fission gas release, sintering, and fission product migration are not significantly different for $\mathrm{UO}_{2}$ and vibrationally compacted $\mathrm{UO}_{2}-\mathrm{PuO}_{2}$ fuels. Alpha autoradiographs of irradiated rods indicate that some plutonium migration or segregation occurs under molten fuel conditions.

Irradiations to Establish Reactor Power Limit

Among the first fuel irradiations to be performed in the PRTR were tests to determine the maximum allowable reactor power level based on a maximum fuel temperature limit. Maximum PRTR power level is determined by the linear rod power that produces fuel temperatures $\left(2790^{\circ} \mathrm{C}\right)$ just below melting. Thirteen fuel rods were metallographically examined to ascertain fuel structures formed during irradiation. These irradiations indicate that under PRTR operating conditions the onset of melting in vibrationally compacted $\mathrm{UO}_{2}-2 \mathrm{wt} \% \mathrm{PuO}_{2}$ fuel rods occurs at $20.5 \pm 0.5 \mathrm{~kW} / \mathrm{ft}$. This power to produce melting is equivalent to an $\int_{0}^{\mathrm{T}_{\mathrm{O}}} \mathrm{KdT}$ of about $68 \mathrm{w} / \mathrm{cm}$. Results also show that (1) the temperature at which columnar grain growth apparently begins is approximately $2000{ }^{\circ} \mathrm{C}$ for irradiation times up to 80 hours, (2) structural equilibrium is reached more rapidly at the higher power generations, and (3) structural characteristics are time dependent.

Fuel melting occurred in two of the vibrationally compacted rods examined as part of the reactor power calibration experiments. One of the two rods melted to approximately $10 \%$ of the radius; the other to approximately $33 \%$ of the radius. Both rods were presumably irradiated under the same conditions. The reason for the difference in the indicated melt radius is being investigated. Destructive examination of the end regions of these two rods showed that the depleted $\mathrm{UO}_{2}$ pellets effectively prevent excessive fuel temperatures in the end cap regions. No pellet-powder fuel interaction and only minor pellet cracking was observed. Prior to batch core operation, excessive fuel temperatures due to flux peaking in the end cap regions limited reactor power.

FERTF (Fuel Element Rupture Test Facility) Testing - M. D. Freshley

Because no commercial power reactor can be operated economically without accommodating defective fuel rods, the study of fuel rod defect behavior is an important part of the Fuels Development Sub-Program. It is especially important to determine limits of operability with defected rods so that commercial 
reactor operators are able to maintain optimum operating efficiency and power density. Toward this end, the Fuel Element Rupture Test Facility (FERTF) was installed in the PRTR and a test program on defective fuel rods was formulated. This program is designed to study the effect of specific power, burnup, and fuel form on defect behavior of fuel rods. The determination of defect behavior is also an important consideration in the comparative performance evaluation of pellet and packed-powder fuel.

The FERTF will also be used to test fuels which may require some additional irradiation testing prior to charging into the batch core proper, or which may represent a potential high risk if tested in the batch core.

During FY 1967, a series of power and calibration runs were performed to bring the PRTR power level up to about $65 \mathrm{MW}$ (the equivalent of a maximum linear rod power of about $20 \mathrm{~kW} / \mathrm{ft}$ ). During this time, a 19-rod cluster of commercially designed and fabricated fuel rods was tested in the FERTF at a linear rod power of $21.5 \mathrm{~kW} / \mathrm{ft}$. These rods contained hot pressed pellets made of $\mathrm{UO}_{2}-1.94 \mathrm{wt} \% \mathrm{PuO}_{2}$. The objective of this test was to gain irradiation experience with hot pressed pellet rods before charging the rod cluster into the batch core.

Periodic examination of the pellet-containing element in the reactor basin indicates that the irradiation performance of this type of fuel is satisfactory. Postirradiation examination of one of the pellet fuel rods in radiometallurgy is currently in progress. Preliminary examination results indicate that some fuel melting had occurred (Figure II).

Vibrationally compacted $\mathrm{UO}_{2}-\mathrm{PuO}_{2}$ fuel rods, pellet-containing $\mathrm{UO}_{2}-\mathrm{PuO}_{2}$ fuel rods, and vibrationally compacted enriched $\mathrm{UO}_{2}$ fuel rods will be irradiated in the FERTF Test Element at powers up to $20 \mathrm{~kW} / \mathrm{ft}$. This test series will require approximately nine irradiation periods. (Subsequent test series are planned for rod powers of 23 and $28 \mathrm{~kW} / \mathrm{ft}$.) Testing during the $20 \mathrm{~kW} / \mathrm{ft}$ series will include irradiation of both nondefected and deliberately defected fuel rods at linear rod powers sufficient to produce the onset of fuel melting in the vibrationally compacted fuel rods and temperatures below melting in the pellet-containing rods. A schedule for the disposition of 


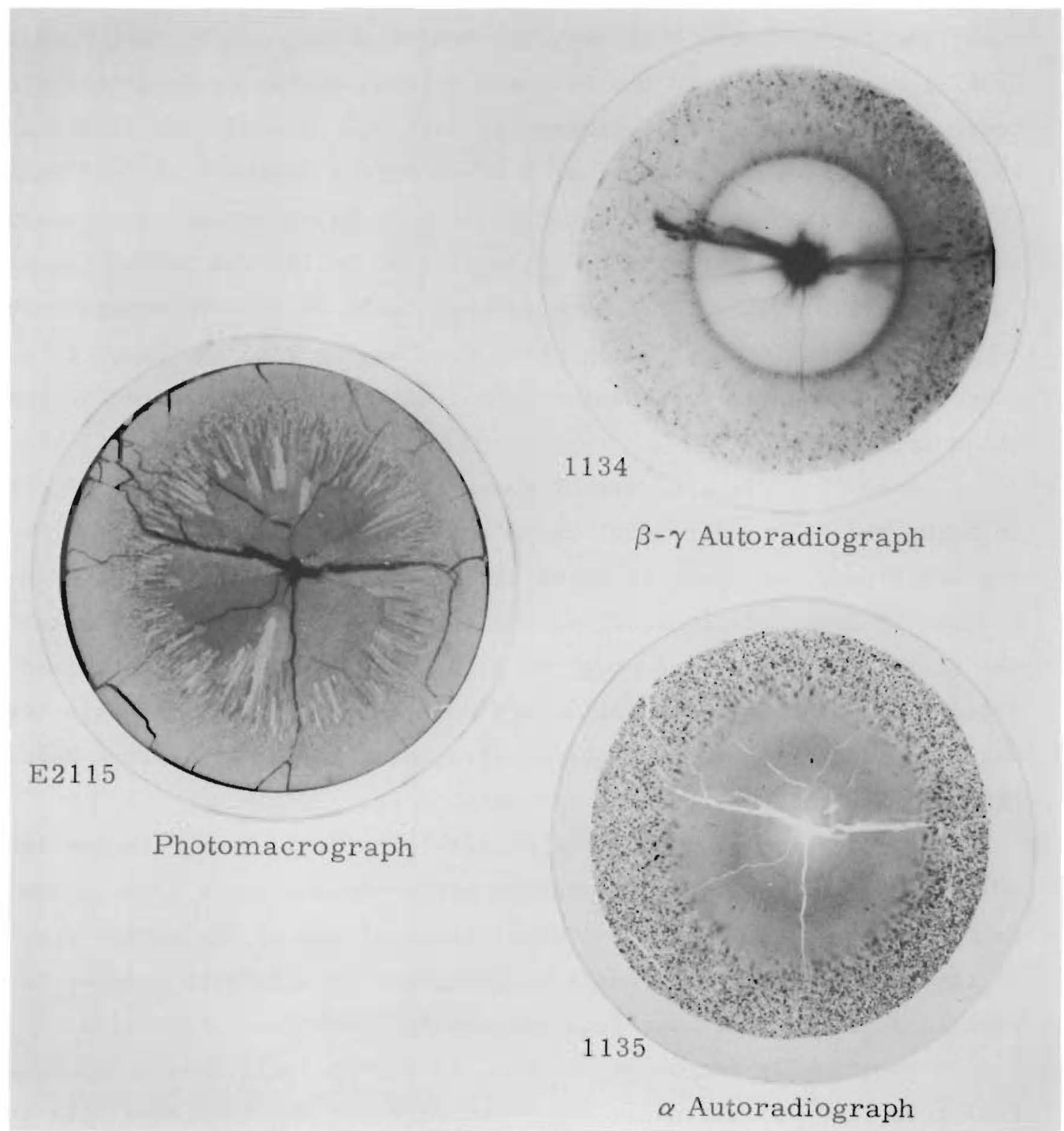

Figure II

Transverse Section Through a Hot Pressed $\mathrm{UO}_{2}-1.94$ wt.\% $\mathrm{PuO}_{2}$ Fuel Rod Irradiated in PRTR at a Linear Power Generation of $21.2 \pm 1.0 \mathrm{~kW} / \mathrm{ft}$ 
individual rods used in the FERTF Test Element is presented in Table II. The sequence and number of irradiations outlined in Table II may change during the course of the test series depending upon experimental results, operating experience, and reactor schedules. A summary of the fuel rods tested as part of the $20 \mathrm{~kW} / \mathrm{ft}$ test series is presented in Table III. Some nondefected fuel rods irradiated in the FERTF Test Element may subsequently be irradiated in reactor core positions. Also some fuel rods from the HPD fuel elements in the Batch Core may be irradiated in the FERTF Test Element.

The FERTF Test Element consists of a protective sleeve assembly surrounding the fuel rod rack that supports an eight-rod ring of Mark $I-R_{2}$ fuel rods. The sleeve assembly provides protection for the surrounding Zircaloy pressure tube. The fuel rod rack assembly can be removed from the sleeve assembly as an integral unit to facilitate rod manipulations. The fuel rods are suspended from the top of the rack assembly and are free to expand or contract independently. Four circumferential strip bands secure the rods to the rack assembly. The flexibility required to obtain the desired power match between fuel rods in the FERTF and fuel rods in Ring 1 is achieved by changing the macroscopic absorption cross-section of the assembly. This can be accomplished by changing the types of sleeve and insert materials used in the assembly.

The physics and power generating characteristics of the FERTF Test Element were computed and also determined experimentally by zero power tests in PRTR. These tests included measurements of relative power generation, reactivity worth of the FERTF Test Element compared to a water filled tube, and coolant void worth of the element. The most reliable relative power generation data obtained from zero power irradiations with the present FERTF Test Element design are summarized in Table IV. Based upon the results of the experimentally determined values, estimates were made of the $\theta$ ive power generation for various combinations of FERTF Test Element components. These calculated values are also listed in Table IV. The thermal hydraulic characteristics of the FERTF Test Element were determined experimentally and the boiling burnout limits were determined analytically. The boiling burnout analysis indicates that at tube powers below $680 \mathrm{~kW}$ with the insert removed and below $710 \mathrm{~kW}$ with the insert installed, boiling limits are more restrictive than burnout limits are at a mass velocity as low as $1 \times 10^{6} \mathrm{lb} / \mathrm{hr}-\mathrm{ft}^{2}$. 


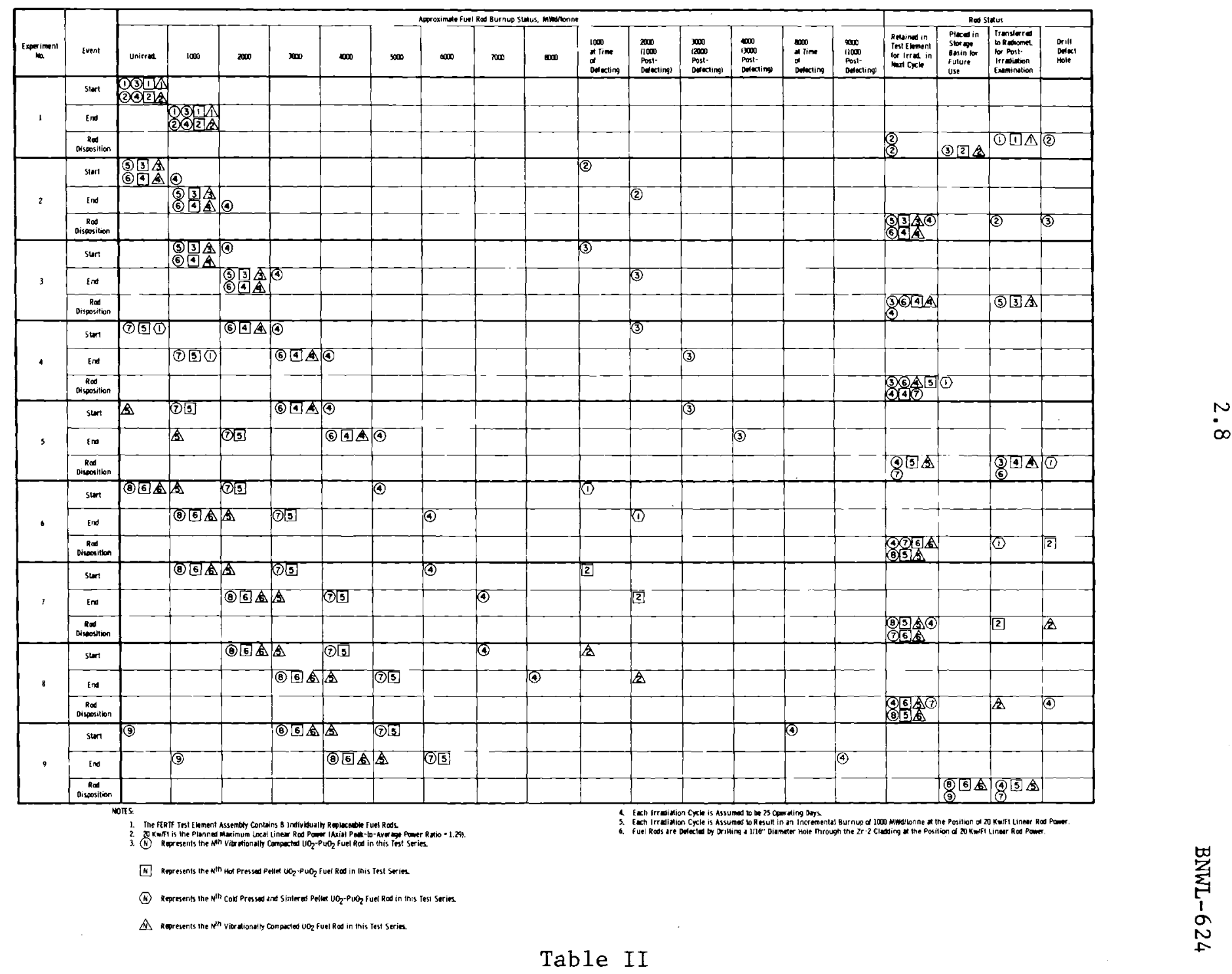

Disposition of Individual Fuel Rods for $20 \mathrm{~kW} / \mathrm{ft}$ Test Series 


\begin{tabular}{|c|c|c|c|c|c|c|c|c|c|}
\hline \multirow[b]{2}{*}{$\begin{array}{l}\text { Fuel } \\
\text { Rod Type }\end{array}$} & \multicolumn{8}{|c|}{ Number of Rods of Approximate Burnup, MWd/tonne } & \multirow[b]{2}{*}{$\begin{array}{l}\text { Total } \\
\text { Rods }\end{array}$} \\
\hline & 1000 & 2000 & 4000 & 5000 & 6000 & \begin{tabular}{|l|}
2000 \\
$(1000$ \\
Post- \\
Defecting $)$
\end{tabular} & $\begin{array}{l}4000 \\
(3000 \\
\text { Post- } \\
\text { Defecting) }\end{array}$ & $\begin{array}{l}9000 \\
(1000 \\
\text { Post- } \\
\text { Defecting })\end{array}$ & \\
\hline $\begin{array}{l}\text { Vibrationaliy } \\
\text { Compacted } \\
\mathrm{UO}_{2}-\mathrm{PuO}_{2}\end{array}$ & 1 & 1 & 1 & & 1 & 1 & 1 & 1 & 7 \\
\hline $\begin{array}{l}\text { Hot-Pressed } \\
\text { Pellet } \\
\mathrm{UO}_{2}-\mathrm{PuO}_{2}\end{array}$ & 1 & 1 & 1 & & 1 & 1 & & & 5 \\
\hline $\begin{array}{c}\text { Cold-Pressed } \\
\text { and } \\
\text { Sintered } \\
\text { Pellet } \\
\mathrm{UO}_{2}-\mathrm{PuO}_{2}\end{array}$ & & & & & & 1 & & & 1 \\
\hline $\begin{array}{c}\text { Vibrationally } \\
\text { Compacted } \\
\mathrm{UO}_{2}\end{array}$ & 1 & I & $\mathrm{I}$ & 1 & & 1 & & & 5 \\
\hline
\end{tabular}

Summary of Destructively Examined Fuel Rods from $20 \mathrm{~kW} / \mathrm{ft}$ Test Series 
$\underline{\text { Table IV }}$

Relative Power Generation in the FERTF Test Element Using Vibrationa11y Compacted $\mathrm{UO}_{2}-2 \quad \mathrm{wt} \% \mathrm{PuO}_{2}$ Rods

\begin{tabular}{|c|c|c|c|c|}
\hline \multirow{3}{*}{$\begin{array}{l}\text { S1eeve } \\
\text { Mat'1 }\end{array}$} & \multirow{3}{*}{$\begin{array}{c}\text { Stainless } \\
\text { Stee } 1 \\
\text { Insert } \\
\end{array}$} & \multirow{3}{*}{$\begin{array}{c}\text { Absorber } \\
\text { P1ug } \\
\text { Mat'1 } \\
\end{array}$} & \multicolumn{2}{|c|}{ FERTF } \\
\hline & & & Power $R$ & Ring 1 \\
\hline & & & Calculated & Measured \\
\hline $\mathrm{SST}^{*}$ & No & SST & 1.02 & $0.95 \pm 0.03$ \\
\hline $\mathrm{SST}^{*}$ & No & Hast-X & 1.01 & $0.95 \pm 0.03$ \\
\hline SST* & Yes & SST & 0.91 & $0.89 \pm 0.04$ \\
\hline $\mathrm{SST}^{*}$ & Yes & Hast $-\mathrm{X}$ & 0.90 & $0.90 \pm 0.06$ \\
\hline $\mathrm{SST} * \star$ & No & $\mathrm{A} 1$ & 1.10 & \\
\hline $\mathrm{SST}_{* *}$ & Yes & A1 & 0.98 & \\
\hline $\mathrm{SST}^{* *}$ & No & $\mathrm{Zr}$ & 1.10 & \\
\hline SST** & Yes & $\mathrm{Zr}$ & 0.99 & \\
\hline $\mathrm{Zr} * *$ & No & $\mathrm{Zr}$ & 1.21 & \\
\hline $\mathrm{Zr} * *$ & Yes & $\mathrm{Zr}$ & 1.08 & \\
\hline $2 r * *$ & No & SST & 1.12 & \\
\hline
\end{tabular}

*Experimentally determined values.

**Estimated values based upon the experimentally determined data. 
An 8-rod prototype FERTF Test assembly is being tested in an ex-reactor hydraulic test loop (EDEL-1) to determine the wear and fretting characteristics of the assembly under PRTR coolant conditions. After 84 days of testing at a coolant temperature of $475^{\circ} \mathrm{F}$, coolant pressure of 1050 psig, and coolant $\mathrm{pH}$ of 7.5 the test assembly shows no wear between components within the assembly and only a minimum amount of fretting or wear between the sleeve and pressure tube. Testing was conducted at coolant flow rates between 70 and $122 \mathrm{gpm}$.

A considerable amount of special underwater handing equipment has been developed for use with the FERTF Test Element. Equipment is included which will permit interim and postirradiation measurements and inspection of fuels. Equipment is also available which will permit rapid removal, manipulation, and replacement of fuel rods so as to minimize reactor down time associated with FERTF testing.

\section{High Exposure Plutonium Studies - R. C. Smith}

The radiation hazards associated with high exposure plutonium must be established to determine the amount of shielding which may be required when fabricating fuels containing such plutonium.

Detailed heavy element nuclide analyses were completed on Shippingport and Yankee fuel samples. Shippingport fuel samples ranged in exposure from approximately 10,000 to $30,000 \mathrm{MWd} /$ tonne; some Yankee fuel samples had reached exposures of approximately 40,000 MWd/to-ne. Plutonium product solutions were also obtained from Dresden and Hanford high exposure fuels.

Data on heavy nuclide formation appear to fall into consistent patterns which show a relatively large variation in the formation of the higher nuclides with neutron spectra variations. This is particularly noticeable in the Shippingport fuel and is evaluated in BNW-478. (1) The amount of ${ }^{236} \mathrm{Pu}$ formed was consistently small and apparently will not contribute significantly to handling hazards.

Analyses have generally confirmed predicted trends for heavy nuclide formation. The fuel samples analyzed indicate that for natural and ${ }^{235} \mathrm{U}$ enriched fuels from light water reactors, the ${ }^{2 \div 0} \mathrm{Pu}$ tends to peak out at concentrations between 25 and 35 per cent of the total $\mathrm{Pu}$ isotopic composition.

(1) Smith, R. C. and Van Tuyl, H. H., "High Exposure Plutonium Studies Analys is of Shippingport Fuel," BNWL-478, Battelle-Northwest, July, 1967. 


\section{X-ray and Gamma Ray Measurements}

$\mathrm{X}$-ray and gamma energy spectra measurements made on Shippingport and Yankee plutonium revealed no significant quantities of photo-peaks above $400 \mathrm{keV}$. Substantial quantities of very low energy photo-peaks were resolved. A breakthrough in the resolution of low energy spectral determinations was made with the use of a Si(Li) detector to supplement the normally used $\mathrm{Ge}(\mathrm{Li})$ detectors. Greatly improved resolution was obtained particularly for x-rays in the range below $20 \mathrm{keV}$. Only preliminary readout of the energy spectra was made as a Lawrence Radiation Laboratory computer program is being adapted for photo-peak evaluation. The new computer program will save many manhours and provide greater accuracy in spectral energy data evaluation. The computer program is also being adapted to incorporate the experimentally determined efficiency of the spectrometer system and allow practical yield data readout in addition to the energy information now obtained.

Gamm and $x$-ray yields and surface dose rates from high exposure plutonium were found to significantly increase with time after chemical separation. The energy spectra determinations showed the increase was primarily caused by the $59.6 \mathrm{keV}$ photons from ${ }^{241} \mathrm{Am}$ which grew in via $241 \mathrm{Pu}$ beta decay $(\mathrm{T} 1 / 2=13 \mathrm{y})$. For the most of the high exposure plutonium measured containing 23 per cent ${ }^{241} \mathrm{Pu}$, the gamma dose rate would double within one year after chemical separation due to the ${ }^{241}$ Am buildin.

Representative surface dose rates are given in Table V. Measurements are being repeated monthly to follow the ${ }^{241} \mathrm{Am}$ growth and to correlate actual surface dose rate measurements and theoretical calculations as a function of plutonium isotopic content, chemical and physical form, and time since chemical separation.

$\underline{X-r a y}$ and Gamma Ray Shielding Requirements and Personnel Exposure

Very preliminary shielding measurements indicate the gamma and $x$-ray radiation from pure high exposure plutonium is very easily shielded. This is to be expected from the predominance of low energy photo-peaks revealed in the gamma spectral measurements. 


\section{$\underline{\text { Table V }}$}

Measured Surface* Dose Rates on High Exposure Plutonium

\begin{tabular}{|c|c|c|c|c|c|c|}
\hline $\mathrm{Pu}$ Source & $\begin{array}{c}\text { Wt } \\
\text { Grams }\end{array}$ & $\begin{array}{c}\text { Days } \\
\text { Since } \\
\text { Separation } \\
\end{array}$ & $\begin{array}{l}240^{\circ} \mathrm{Pu} \\
\text { Atom \% }\end{array}$ & $\begin{array}{l}2{ }^{1} \mathrm{Pu} \\
\text { Atom \% }\end{array}$ & $\begin{array}{l}\text { Container } \\
\text { Material } \\
\text { Thickness, } \\
\quad \text { Inches } \\
\end{array}$ & $\begin{array}{c}\text { Surface } \\
\text { Dose Rate } \\
\text { Rad/hr } \\
\end{array}$ \\
\hline Shippingport $\mathrm{PuO}_{2}$ & 73 & 85 & 23.18 & 7.63 & $0.033 \mathrm{P} *$ & 3.65 \\
\hline Shippingport $\mathrm{PuO}_{2}$ & 61 & 86 & 23.60 & 7.66 & $0.033 \mathrm{P}$ & 3.37 \\
\hline Dresden $\mathrm{PuO}_{2}$ & 63 & 164 & 21.56 & 6.88 & $0.033 \mathrm{P}$ & 2.73 \\
\hline $20 \mathrm{wt} \% \mathrm{Pu}-\mathrm{A} 1$ & & Unknown & 19.22 & 3.00 & $0.020 \mathrm{~A} 1$ & 1.47 \\
\hline $20 \mathrm{wt} \% \mathrm{Pu}-\mathrm{A} 1$ & & Unknown & 19.22 & 2.75 & $0.020 \mathrm{P}$ & 2.46 \\
\hline
\end{tabular}

*Dose rate as measured through polyethylene plastic (P) bag or aluminum (A1) cladding material not extrapolated to the plutonium compound surface. 
Actual personnel exposure records were kept during the fabrication of 280 fuel rods containing recycled plutonium from Dresden fuel process by Nuclear Fuels Services. The isotopic content of the plutonium was approximately $0.3{ }^{238} \mathrm{Pu}$, $75.3^{239} \mathrm{Pu}, 18.15^{240} \mathrm{Pu}, 5.1{ }^{241} \mathrm{Pu}$, and $1.15^{242} \mathrm{Pu}$ (atom \%). The surface dose rate for plutonium of this isotopic content would be over $2.5 \mathrm{Rad} / \mathrm{hr}$. The actual hood readings through neoprene gloves were about $500 \mathrm{mrad} / \mathrm{hr}$ at approximately one foot above the $\mathrm{PuO}_{2}$. The plutonium was processed in the normal fuel fabrication facilities with special housekeeping precautions. After blending the $\mathrm{PuO}_{2}$ with $\mathrm{UO}_{2}\left(4 \% \mathrm{PuO}_{2}-\mathrm{UO}_{2}\right)$ and pneumatic impaction, the fuel dose rates were nominal and essentially normal fuel handling procedures were used. The final surface dose rate from a $1 / 2$ inch diameter fuel rod with .035 inch thick Zircaloy-2 cladding was $2 \mathrm{mrad} / \mathrm{hr}$.

\section{Neutron Measurements}

Initial neutron yields were made with a "Long Counter." A 70 gram sample of Shippingport $\mathrm{PuO}_{2}$ gave a neutron yield of $3.86 \times 10^{4} \mathrm{n} / \mathrm{sec}$. A $200 \mathrm{gram}$ sample gave approximately $1.05 \times 10^{5} \mathrm{n} / \mathrm{sec}$. Measurements of a 942 gram Shippingport plutonium metal disk approximately 3 inches by $1 / 2$ inches thick gave values for neutron yields of $4.23 \times 10^{5} \mathrm{n} / \mathrm{sec}$ from the flat side and $2.71 \times 10^{5} \mathrm{n} / \mathrm{sec}$ from the edge.

Fabrication Costs - J. P. Keenan

A model has been developed at Battelle-Northwest Laboratories by J. B. Burnham, L: G. Merker, and D. E. Deonigi for calculating fuel element cost ${ }^{(2)}$. The model is based on a 1 ton/day plant to produce a 1000 MWe PWR fuel ${ }^{(3)}$. This model was used to calculate costs in a plant producing a single type of fuel by six different fuel fabrication schemes. In these cost studies throughput was varied, but plant capacity was not changed. More recent studies have investigate the influence of plant throughput on the cost of the same fuel element, produced under the same conditions as before except that plant capacity is varied. Throughput relationships were developed for vibratory compacted fuels enriched with either ${ }^{235} \mathrm{U}$ or high exposure plutonium.

(2) Burnham, J. B., Merker, L. G., and Deonigi, D. E., "Comparative Cost of Oxide Fuel Elements, Volumes 1, 2, and 3," Battelle-Northwest. BNWL-273. July, 1966.

(3) "1000 MWE Closed-Cycle Water Reactor Study," Westinghouse Atomic Power Department. WCAP-2385. March, 1963. 
Results are summarized in Table VI and Figure III.

Calculated costs can be quite sensitive to the assumptions used in the cost model. For example, a cost differential of one dollar/kg for a one ton/day throughput represents an annual cost of approximately $\$ 250,000$.

Raw material conversion costs are a very significant portion (50\%) of the total cost (Table VI). These costs become more significant as throughput increases. Enough fuel fabrication plants are assumed to be in operation that the size of any one plant will not affect raw material costs.

Elements of profit to cover research and development and risk were not considered in computing fuel costs. A higher risk factor would probably be associated with plutonium enrichment and the difference between uranium enrichment and plutonium enrichment shown by these studies therefore is not as great as it should be.

Special Batch Core Testing - T. B. Burley

The Batch Core Experiment includes a study to determine internal pressure buildup as a function of burnup in vibrationally compacted-mixed oxide fuel rods operating at different powers. Toward this end, four instrumented $\mathrm{UO}_{2}-2 \mathrm{wt} \% \mathrm{PuO}_{2}$ fuel rods (two in each of two fuel assemblies) are presently operating in PRTR. The instrumented fuel rods contain thermocouples to measure plenum gas temperature. Gas pressure in each rod is measured by a transducer containing a null-pressure balance diaphragm. (4) Gases within the fuel rod (fission gases and sorbed gases) produce pressure on one side of the diaphragm keeping an electrical contact closed. Pressure is applied to the secondary side of the diaphragm through a pressure regulating valve until the electrical contact just opens, thereby indicating balanced or internal pressure. (Figure IV)

(4) Reynolds, M. D., "The Measurement of Free Fission Gas Pressure in Operating Reactor Fuel Elements," GEAP-4135, January 23, 1963. 


\section{Table VI}

\section{Breakdown of Costs}

Throughput Tons/Day

\section{Direct Material}

Labor

Building and Equipment

Indirect Manufacturing Expense

Use Charge

Nuclear Losses

Ordinary Losses

Fixed Manufacturing Cost

General and Administration Cost

Working Capital

Cost/Fuel Element

Cost $/ \mathrm{kg}$

\begin{tabular}{|c|c|c|c|c|}
\hline $1 / 4$ & $1 / 2$ & 1 & $5^{(3)}$ & 10 \\
\hline 14,435 & 14,435 & 14,415 & 14,415 & \\
\hline 3,529 & 3,090 & 2,780 & & \\
\hline 5,187 & 2,848 & 1,671 & 1,700 & \\
\hline 5,095 & 4,035 & 3,625 & 2,700 & \\
\hline 822 & 822 & 822 & 280 & \\
\hline 1,170 & 1,170 & 1,170 & 1,170 & \\
\hline 152 & 152 & 152 & 152 & \\
\hline 2,854 & 1,451 & 772 & 260 & \\
\hline 1,399 & 700 & 351 & 120 & \\
\hline 422 & 371 & 346 & 115 & \\
\hline 35,065 & 29,074 & 26,114 & 20,912 & \\
\hline 71.00 & $58.90^{(6}$ & 52.90 & 43.00 & 40.00 \\
\hline
\end{tabular}

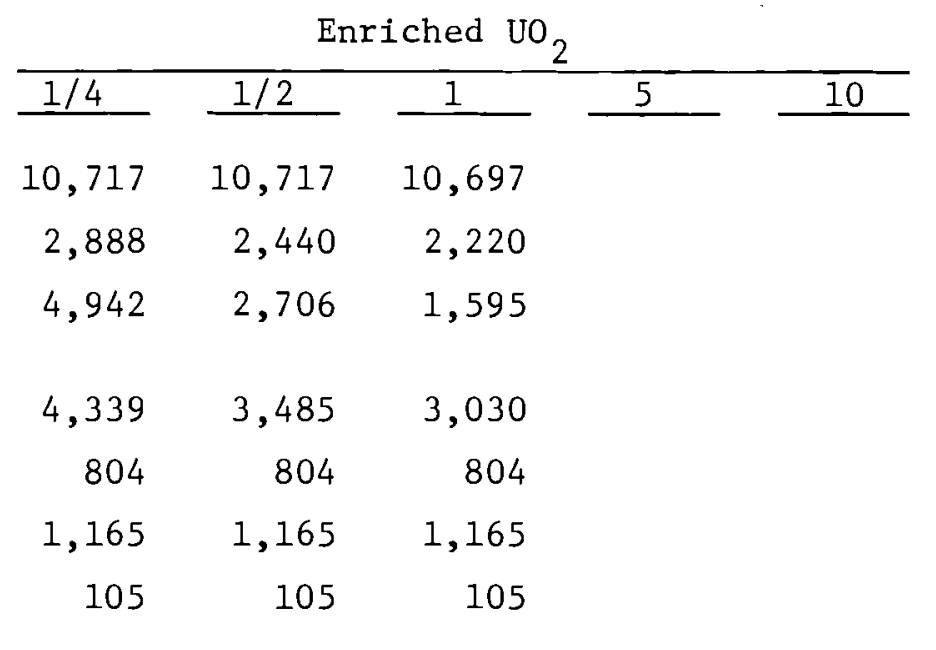

$1,399-700-351$

$\begin{array}{rrrrr}\frac{335}{29,410} & \frac{288}{23,790} \frac{265}{20,959} & & \\ 59.53 & 48.16^{(6)} & 42.43 & 33.00 & 31.00\end{array}$

(5) All extrapolated data.

(6) In Volume III of BNWL-273, costs were calculated for operating a 1 ton/day plant on one shift or at one-half design capacity. The cost per kilogram was 1.00 higher than this. 


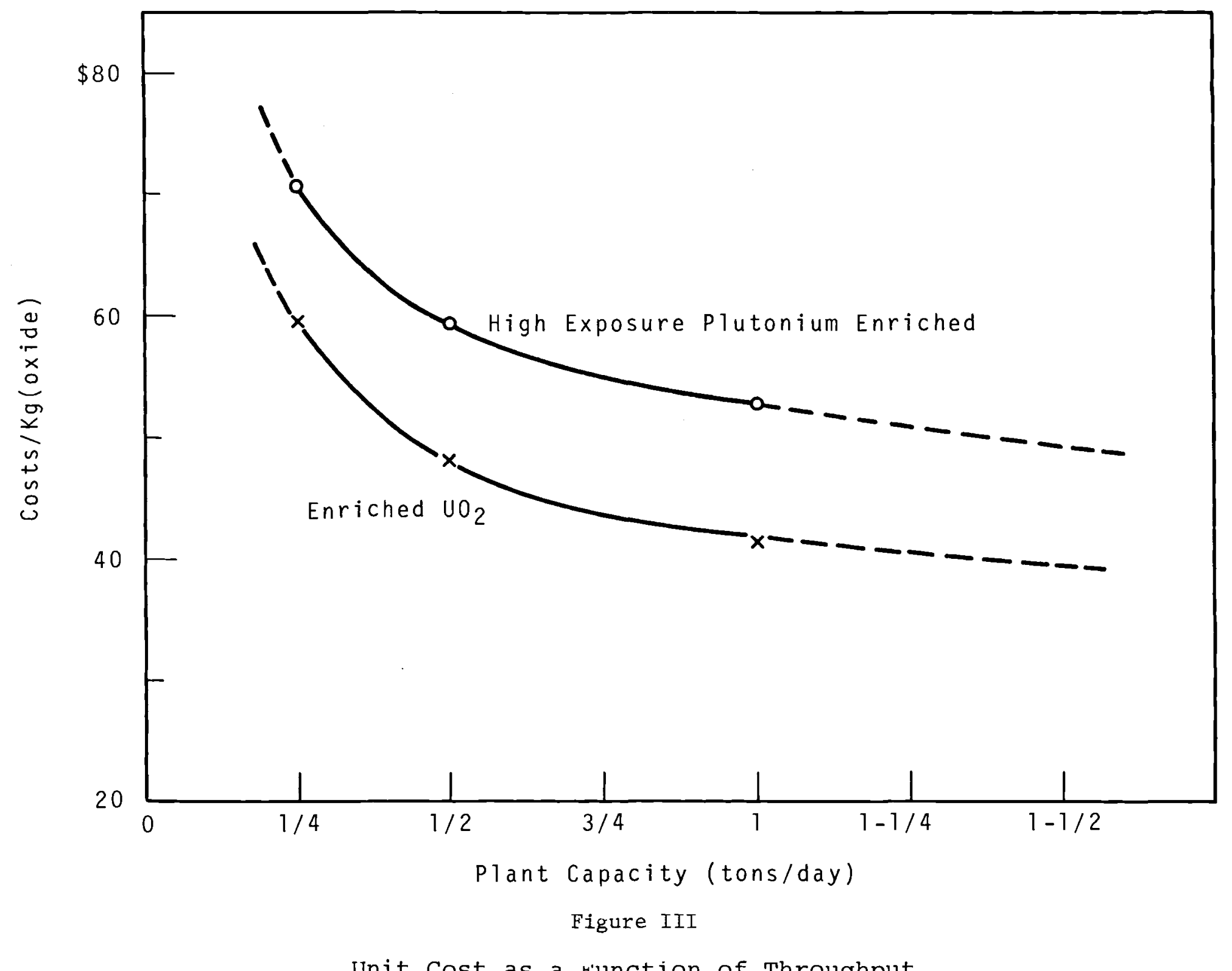

Unit Cost as a runction of Throughput 


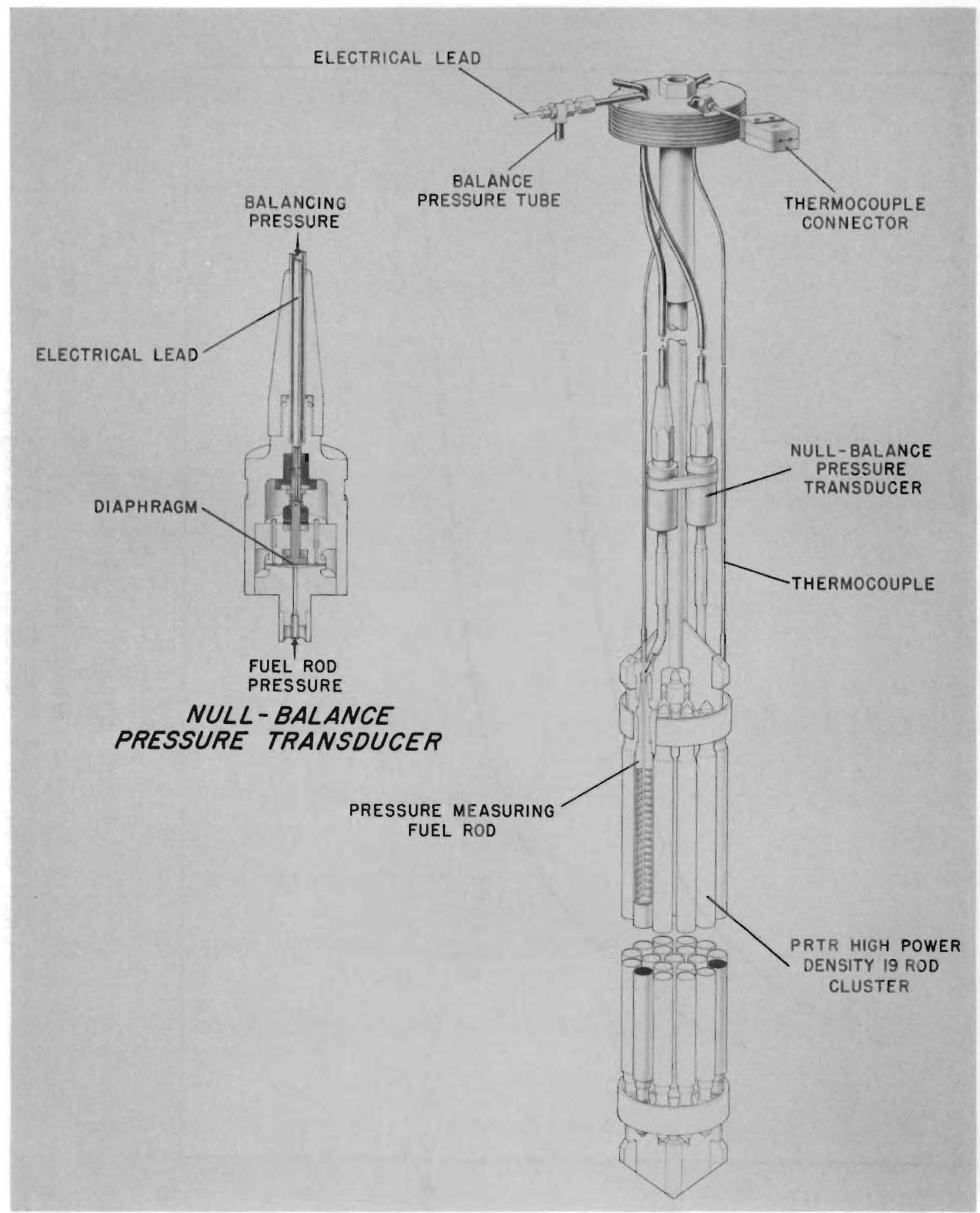

Figure IV

PRTR In-Reactor Fuel Rod Pressure Measuring Element 
Test conditions for the two sets of instrumented fuel rods are given below:

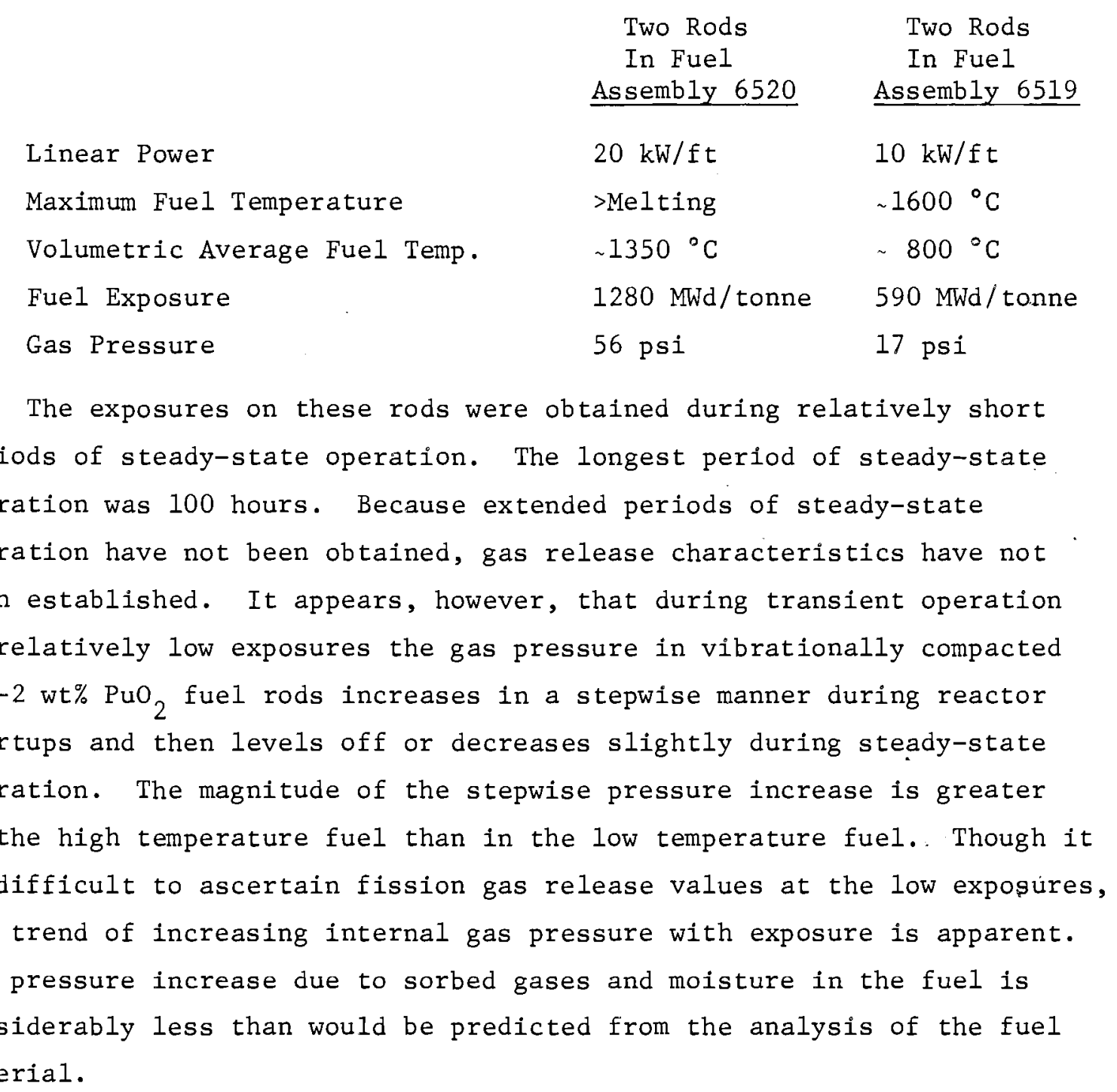

A vibrationally compacted $\mathrm{ThO}_{2}-5 \mathrm{wt} \% \mathrm{PuO}_{2}$ element with two rods instrumented in the manner described above has been fabricated and will soon be charged into one of the batch core fringe positions.

MTR/ETR Testing - M. D. Freshley

A 7-rod cluster fuel element containing a defected vibrationally compacted $\mathrm{UO}_{2}$ fuel rod was successfully irradiated in the ETR P-7 pressurized water loop at a maximum linear rod power of 28 to $29 \mathrm{~kW} / \mathrm{ft}$. This rod power resulted in an estimated 60 to 65 per cent of the radius molten at the plane of the defect. The defect consisted of a 1/16 inch diameter hole 
drilled through the Zircaloy cladding of one rod. After irradiation under these conditions for nine effective full power days, the element was discharged from the reactor for postirradiation examination. This test will provide a basis for performing defect tests at the same power in the FERTF using $\mathrm{UO}_{2}-\mathrm{PuO}_{2}$ fuel.

During its residence time in the reactor, the defected element was subjected to three programmed power increases, two of which were from zero power. The element was also subjected to one scram recovery which included a very rapid ( 3 minutes) power increase from 1 to 50 per cent of full power. Although the activity release to the loop piping was quite high during the scram recovery, modest amounts of activity were released during the programmed power increases. Increases in reactor power and coolant temperature caused activity bursts which decreased to low equilibrium values during steady-state operation.

Examination of the defected rod in the ETR basin did not reveal any physical changes as a result of 1rradiation. A detailed postirradiation examination will be conducted to compare the performance of the defected rod with the performance of adjacent nondefected rods. The defected rod will also be examined for evidence of dimensional changes, water-logging, fuel washout, fuel relocation, fission product and/or plutonium migration, and stoichiometry changes,

Transient Tests - R. L. Gulley

The transient behavior of $\mathrm{UO}_{2}-\mathrm{PuO}_{2}$ fuels must be determined to fully establish their performance characteristics. To accomplish this objective, a transient testing program utilizing the Transient Reactor Test Facility (TREAT) was started. To provide a basis for comparison, $\mathrm{UO}_{2}$ fuels are also being tested as part of this program. The first series of transient experiments were performed in cooperation with staff members of the Chemical Engineering Division and the TREAT Facility of Argonne National Laboratory. Pressure Autoclave Tests

Two transient irradiation experiments were conducted in instrumented autoclaves to investigate the meltdown behavior, in water, of non-irradiated Zircaloy-clad vibrationally compacted fuel rods with and without simulated fission gas pressure. Each experiment involved four fuel rods which 
contained pneumatically impacted $\mathrm{UO}_{2}$ (15 atom $\%{ }^{235} \mathrm{U}$ ) with an $0: \mathrm{U}$ ratio of 2.02. Particular emphasis was placed on determining (1) the extent of cladding metal-water reaction and fuel-water reaction, (2) the peak pressure produced in the autoclave, (3) the rate of pressure rise, and (4) the particle size distribution of the fragmented fuel and cladding. The four fuel rods in the first experiment contained helium at a room temperature pressure of 1500 psia to simulate fuel irradiated to high burnup. The reactor transient characteristics and experiment results are summarized in Table VII. (7)

Observations from the simulated burnup transient experiments and from comparison with the transient behavior of pellet containing fuel rods (previously tested by ANL) are:

1. Although both sets of fuel rods received the same total amount

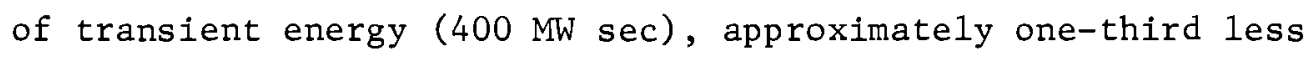
power was required to cause failure of the pressurized fuel rods than the low-pressure fuel rods.

2. The extent of $\mathrm{Zr}-\mathrm{H}_{2} \mathrm{O}$ chemical reaction, about $40 \%$, is approximately the same as was previously observed with $\mathrm{UO}_{2}$ pellet-containing fuel rods. The extent of metal-water reaction was slightly greater for the low-pressure fuel rods than for the high-pressure fuel rods (45 versus 38\%) probably because the cladding on the low-pressure capsules was hotter at the time of failure, thus resulting in more reaction.

3. X-ray diffraction analysis of the meltdown residue showed the presence of compositions between $\mathrm{UO}_{2.0}$ through $\mathrm{UO}_{2.20^{\circ}}$ If it is assumed that all the residue is $\mathrm{UO}_{2.20}$, approximately $10 \%$ of the total $\mathrm{H}_{2}$ generated would have come from $\mathrm{UO}_{2}$ oxidation.

(7) Limatainen, R. C. (ANL), Freshley, M. D. (BNW), Testa, F. J. (ANL), "Transient Irradiations of Vibrationally Compacted 10 , Fuel In TREAT," Trans. Am. Nuc. Soc., Vol. 9, No. 2, pp. 395-396, Oct. 30-Nov. 3, 1966. 
Table VII

Summary of Transient Experiments With Zircaloy-2-Clad, Vibrationally Compacted $\mathrm{UO}_{2}$ (15 Atom \% ${ }^{235} \mathrm{U}$ ) Fuel in a

Pressure Autoclave

Internal Fuel

Capsule Pressure

He, psia

Experiment No.

$218-S^{(a)} \quad \underline{219-S^{(a)}}$

\section{Reactor Characteristics}

Integrated Power, MW sec

Peak Power, MW

1280

1275

Period, msec

74

75

Fission Energy

Input, cal/g UO 2

Experiment Results

$\mathrm{Zr}_{-} \mathrm{H}_{2} \mathrm{O}$ Reaction ${ }^{(b)}$, per cent

45

38

Fuel Appearance After Transient

$\begin{array}{cc}\text { Complete } & \text { Complete } \\ \text { Fragmentation, Fragmentation, } \\ \text { particles and particles and } \\ \text { fines }\end{array}$

Particle Size After Transient
$d_{\text {sv }}$ mils

Peak Autoclave Pressure, psig

$\begin{array}{rr}36 & 30 \\ 800 & 700 \\ 4000 & 3000\end{array}$

Total (Chemical \& Nuclear) Energy

Released, cal/g $\mathrm{H}_{2} \mathrm{O}$

416

385

Percent Chemical Energy Release (d)

51

46

(a) Four fuel rods were irradiated simultaneously in each test. Each fuel rod was $24.1 \mathrm{~cm}(9.5 \mathrm{in})$ long by $1.44 \mathrm{~cm}(0.566 \mathrm{in})$ oD and contained 110 $\mathrm{g} \mathrm{UO}_{2}\left(15 \mathrm{at} \%{ }^{235} \mathrm{U}\right)$ vibrationally compacted to about $80 \% \mathrm{TD}$.

(b) Calculated on the assumption that all the evolved hydrogen (measured by mass spectrographic analysis) resulted from the reaction $\mathrm{Zr}+2 \mathrm{H}_{2} \mathrm{O} \rightarrow$ $\mathrm{ZrO}_{2}+2 \mathrm{H}_{2}$

(c) $\begin{aligned} \mathrm{d}_{\mathrm{sv}}=\frac{1}{\sum \frac{\mathrm{Wi}}{\mathrm{di}}} \text { where } \mathrm{d}_{\mathrm{sv}} & =\text { mean particle size } \\ \mathrm{Wi} & =\text { weight of particle in a given group }\end{aligned}$

$\mathrm{d} i=$ average diameter of particles in a given group

(d) Percent Chemical energy release $=\frac{\text { chemical energy }}{\text { total (chemical }}$

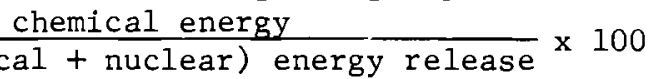


4. Both the peak pressures in the autoclave and the maximum rate of pressure rise were higher for vibrationally compacted fuel than for pellet-containing fuel. These more energetic pressure pulses with vibrationally compacted fuel are attributed to the smaller $\mathrm{UO}_{2}$ fragments resulting from the transient. $\mathrm{UO}_{2}$ fragments from vibrationally compacted fuel were about one-third as large as from pelleted fuel. The larger surface area of vibrationally compacted fuel residue promotes more rapid dissipation of heat into the coolant water. The peak autoclave pressure was slightly lower ( 700 versus 800 psig) for the simulated high-burnup fuel rods than for the simulated low-burnup materia. It is postulated that this resulted because the pressurized fuel rods failed sooner in the transient and the fuel contained less fission heat at that time.

Transparent Autoclave Tests

Three experiments involving vibrationally compacted $\mathrm{UO}_{2}(9.54$ atom\% ${ }^{235} \mathrm{U}$ ) fuel rods, submerged in water, were conducted in transparent autoclaves to obtain high speed motion pictures of single fuel rods undergoing transient irradiations in TREAT. A Zircaloy-clad $\mathrm{UO}_{2}$ fuel rod (Experiment No. $229 \mathrm{~T}$ ), vibrationally compacted to about $84 \% \mathrm{TD}$, separated into four individual sections (Figure $V$ ) when subjected to a transient energy input of $357 \mathrm{cal} / \mathrm{g} \mathrm{UO}_{2}$. A blow-out type failure of the cladding occurred first near a depleted $\mathrm{UO}_{2}$ insulator pellet. The failure occurred on the surface nearest the center of the reactor and before heating of the surface nearest the camera was visibly detectable. It appears that very hot or molten fuel came in contact with water in this region. Immediately after the failure, three distinct high temperature bands, each about one-eighth inch long, formed around the rod. The high temperature bands occurred at each end and at the center of the fuel column. As nuclear heating proceeded, the cladding between the two bands nearest the original failure did not visibly overheat, whereas, the cladding between 


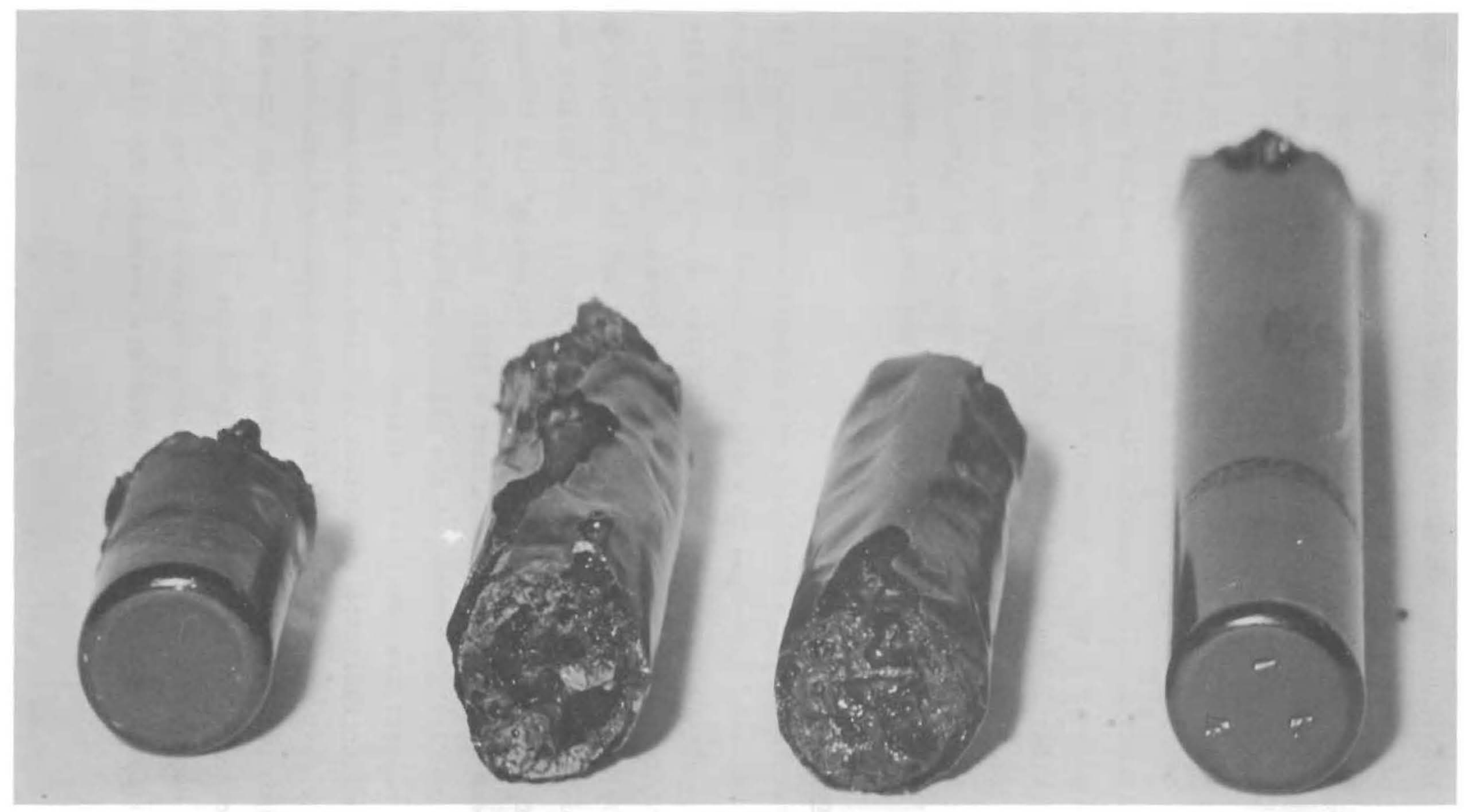

$\stackrel{+}{n}$

Figure V

Vibrationally Compacted $\mathrm{UO}_{2}$ (9.54 atom\% ${ }^{235} \mathrm{U}$ ) Fuel Rod After Transient Irradiation in TREAT at a Fission Energy Input of $357 \mathrm{cal} / \mathrm{g} \mathrm{UO}$ (Experiment No. 229T) 
the bands furthest from the original failure heated uniformly and finally failed, releasing molten fuel. Postirradiation examination of two other vibrationally compacted $\mathrm{UO}_{2}(9.54$ atom\% $235 \mathrm{U})$ fuel rods subjected to energy inputs of approximately 241 and $255 \mathrm{cal} / \mathrm{g} \mathrm{UO}_{2}$ showed evidence of similar high temperature bands (Figures VI and VII). A postirradiation radiograph of these two rods (Figure VIII) suggests that initial clad penetration was aided by the release of entrained gases in the fuel at elevated temperatures. Offgas analysis of fuel obtained from history samples indicate that the entrained gas release as a function of temperature is approximately $1.3 \times 10^{-4} \mathrm{cc} / \mathrm{g}$ fuel $/{ }^{\circ} \mathrm{C}$ in the range of 900 to $1650^{\circ} \mathrm{C}$. A summary of the reactor characteristics and experiment results obtained from the transient irradiation of the three $\mathrm{UO}_{2}$ (9.54 atom\% ${ }^{235} \mathrm{U}$ ) fuel rods is presented in Table VIII.

Two additional experiments involving single vibrationally compacted $\mathrm{UO}_{2}(5.01$ atom\% $235 \mathrm{U})$ fuel rods, submerged in water, were conducted in transparent autoclaves to obtain high speed motion pictures. A summary of the reactor characteristics and experiment results obtained from these two tests is presented in Table VIII. The cladding near the center of both fuel rods appeared to fail first followed by fragmentation of the rods into small particles and fines. Neither rod displayed the well defined high temperature bands that occurred during Test $229 \mathrm{~T}$ with a vibrationally compacted $\mathrm{UO}_{2}(9.54$ atom\% $235 \mathrm{U})$ fuel rod. Further irradiations utilizng the transparent autoclave are planned to better define the transient behavior of vibrationally compacted oxide fuel rods.

\section{Planned Transient Testing Program}

A series of experiments was formulated to establish the failure thresholds of fuel rods undergoing power transients. Approval in principal to conduct such tests was obtained from the Laboratory Director's Office of Argonne National Laboratory. Proposed tests to be performed in instrumented pressure vessels are summarized in Table IX. Specific objectives of these experiments are to:

- provide information about the failure mechanisms and performance limitations of $\mathrm{UO}_{2}$ and $\mathrm{UO}_{2}-\mathrm{PuO}_{2}$ thermal reactor oxide fuels, 


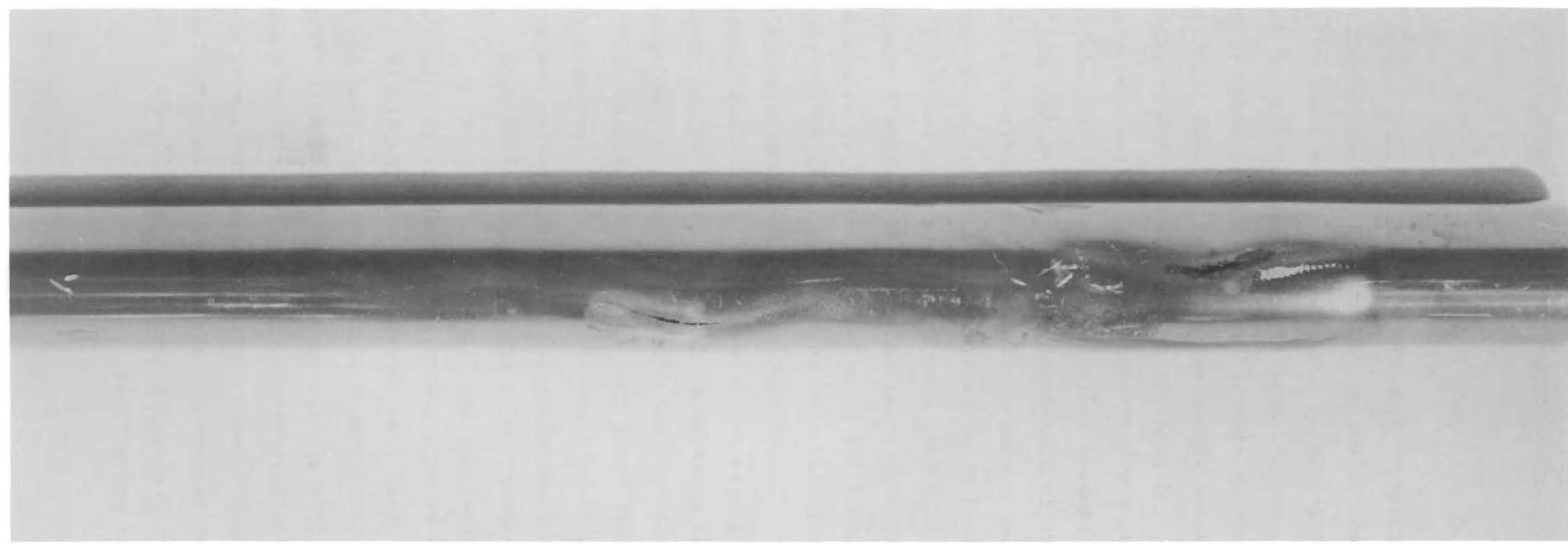

Figure VI

Vibrationally Compacted $\mathrm{UO}_{2}\left(9.54\right.$ atom\% $\left.{ }^{235} \mathrm{U}\right)$

Fuel Rod After Transient Irradiation in TREAT

at a Fission Energy Input of $241 \mathrm{cal} / \mathrm{g} \mathrm{UO}$

(Experiment No. 227T-2) 


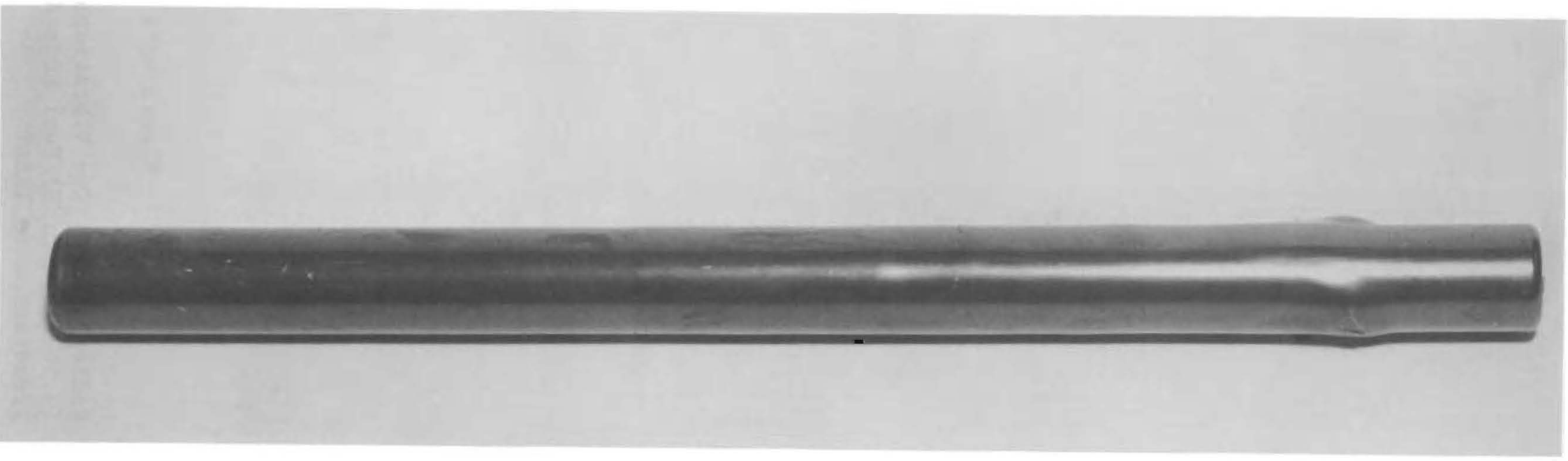

Vibrationally Compacted UO (9.54 atom\% ${ }^{235} \mathrm{U}$ ) Fuel Rod After Transient Irradiation in TREAT at a Fission Energy Input of $255 \mathrm{cal} / \mathrm{g} \mathrm{UO}$
(Experiment No. 228T) 


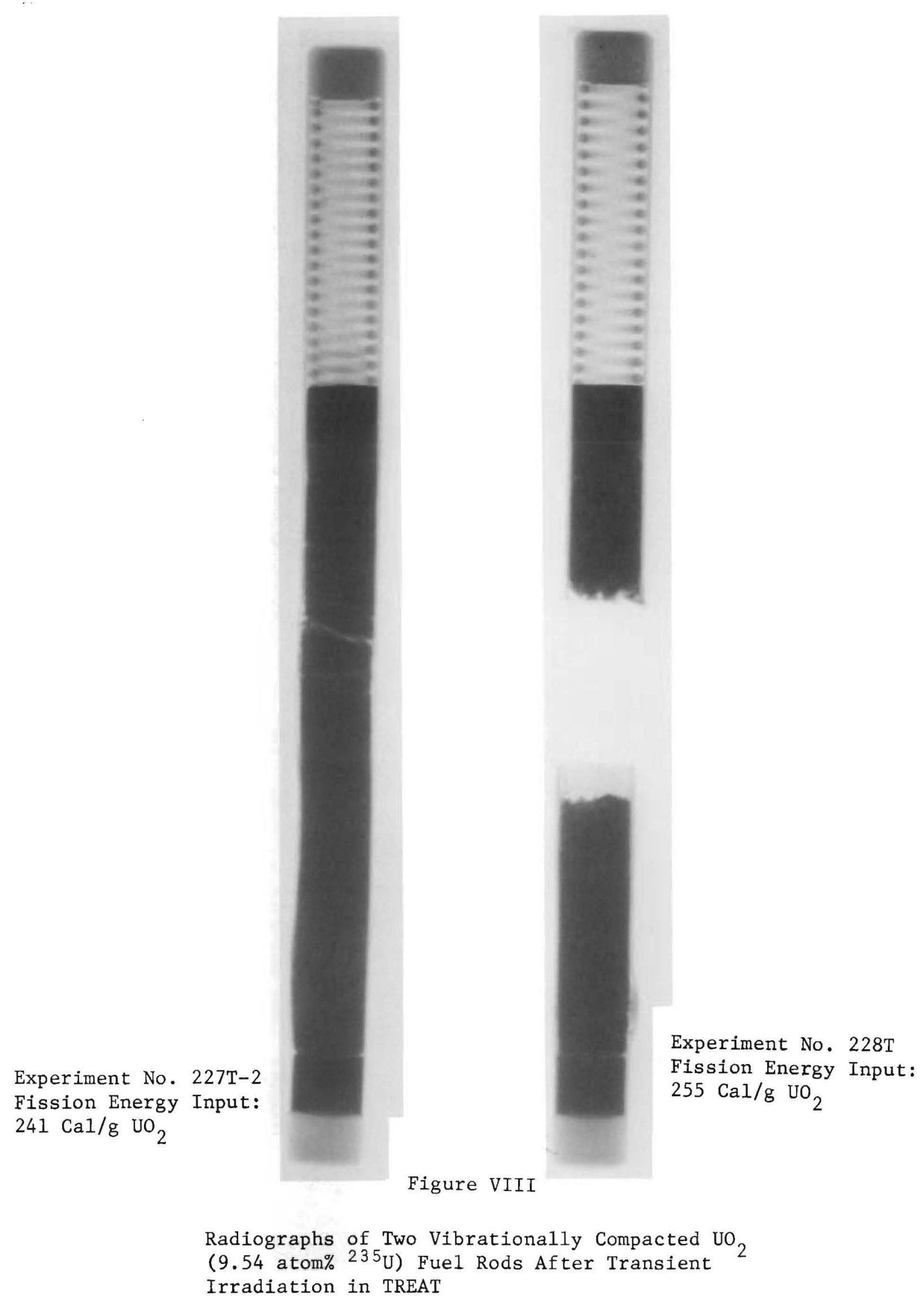


Table VIII

Summary of Transient Experiments With Zircaloy-2-Clad Vibrationally Compacted $\mathrm{UO}_{2}$ Fuel in Transparent Autoclaves

\section{Fuel Rod Characteristics}

Internal Fuel Capsule Pressure He, psia

Fuel Enrichment

Nom. O. D., inch

Clad Thickness, inch

Plenum Length, inch

Enriched $\mathrm{UO}_{2}$ Length, inch

Calculated Enriched $\mathrm{UO}_{2} \%$ T.D.

Enriched $\mathrm{UO}_{2}$ Weight, gram

Reactor Characteristics

Integrated Power, MW sec

Peak Power, MW

Period, msec

Fission Energy Input, cal/g UO

Fuel Appearance After Transient

\begin{tabular}{|c|c|c|c|c|}
\hline $227 \mathrm{~T}-2$ & $228 \mathrm{~T}$ & $229 \mathrm{~T}$ & $233 \mathrm{~T}$ & $234 \mathrm{~T}$ \\
\hline 15 & 15 & 15 & 15 & 15 \\
\hline 9.54 at\% ${ }^{23} 5_{\mathrm{U}}$ & 9.54 at\% ${ }^{235} \mathrm{U}$ & 9.54 at\% ${ }^{235} \mathrm{U}$ & 5.01 at\% ${ }^{235} \mathrm{U}$ & 5.01 at\% $235 \mathrm{U}$ \\
\hline 0.564 & 0.564 & 0.564 & 0.564 & 0.564 \\
\hline 0.030 & 0.030 & 0.030 & 0.030 & -0.030 \\
\hline 2 & 2 & 2 & 0.72 & 0.72 \\
\hline 4.2 & 4.2 & 4.2 & 5.43 & 5.43 \\
\hline 83.4 & 84.0 & 83.9 & 86.1 & 86.5 \\
\hline 126.9 & 127.0 & 127.0 & 167.6 & 168.3 \\
\hline 225 & 238 & 334 & 507 & 634 \\
\hline 281 & 481 & 1015 & 2472 & 3541 \\
\hline 139 & 108 & 74 & 48 & 43 \\
\hline 241 & 255 & 357 & 335 & 418 \\
\hline $\begin{array}{l}\text { Cladding } \\
\text { split in } \\
\text { two spots }\end{array}$ & $\begin{array}{l}\text { Cladding } \\
\text { split in } \\
\text { one spot } \\
\text { and bulged } \\
\text { in another } \\
\text { spot }\end{array}$ & $\begin{array}{l}\text { Rod separated } \\
\text { into four } \\
\text { individual } \\
\text { sections }\end{array}$ & $\begin{array}{l}\text { Complete } \\
\text { fragmentation, } \\
\text { particles and } \\
\text { fines }\end{array}$ & $\begin{array}{l}\text { Complete } \\
\text { fragmentation, } \\
\text { particles and } \\
\text { fines }\end{array}$ \\
\hline
\end{tabular}


$\underline{\text { Table IX }}$

PNL Transient Irradiation Program on Thermal Reactor Oxide Fuel in the TREAT Facility

Fuel Type and Form

$\mathrm{UO}_{2}$ Powder

$\mathrm{UO}_{2}$ Pellet

$\mathrm{UO}_{2}-\mathrm{PuO}_{2}$ Powder

$\mathrm{UO}_{2}-\mathrm{PuO}_{2}$ Pellet

$\mathrm{UO}_{2}$ Powder

$\mathrm{UO}_{2}$ Pellet

$\mathrm{UO}_{2}-\mathrm{PuO}_{2}$ Powder

$\mathrm{UO}_{2}-\mathrm{PuO}_{2}$ Pellet

$\mathrm{UO}_{2}$ Powder

$\mathrm{UO}_{2}$ Pellet

$\mathrm{UO}_{2}-\mathrm{PuO}_{2}$ Powder

$\mathrm{UO}_{2}-\mathrm{PuO}_{2}$ Pellet

$\mathrm{UO}_{2}$ Powder

$\mathrm{UO}_{2}$ Pellet

$\mathrm{UO}_{2}-\mathrm{PuO}_{2}$ Powder

$\mathrm{UO}_{2}-\mathrm{PuO}_{2}$ Pellet
Preirradiation Exposure (MWd/T)

0

0

0

0

1,000

1,000

1,000

1,000

10,000

10,000

10,000

10,000

25,000

25,000

25,000

25,000
Approximate Number of

Experiments

4

4

3

4

1

1

2

1

2

2

2

2

2

2

2

2 
- compare the transient behavior of pellet (hot pressed and cold pressed and sintered) and vibrationally compacted oxide fuels; and

- determine the effect of different preirradiation conditions (i.e., unsintered fuel, sintered fuel, molten fuel, and burnup) on the transient behavior of oxide fuels.

Fuel rods tested under this program will contain fuel enriched with 5 atom\% ${ }^{23}{ }^{5} \mathrm{U}$ (or equivalent $\mathrm{Pu}$ content). All experiments will be conducted with the rods submerged in water. It is anticipated that about 50 experiments will be conducted under this program over the next three to four years.

PRTR Fringe Position Tests - M. D. Freshley

Irradiation of selected $\mathrm{UO}_{2}$ and $\mathrm{UO}_{2}-\mathrm{PuO}_{2}$ fuel elements (pre-Batch Core Experiment vintage*) containing 0.5, 1.0 , and $2.0 \mathrm{wt}^{*} \mathrm{PuO}_{2}$ is continuing in fringe positions of the PRTR during the Batch Core Experiment. These elements are being irradiated to determine their performance at high burnups ( $>10,000 \mathrm{MWd} /$ tonne). A listing of these elements and their current status is given in Table $I$.

The fringe elements contain both pneumatically impacted and mechanically mixed (incrementally loaded) $\mathrm{UO}_{2}-\mathrm{PuO}_{2}$ fuel material. The highest burnup (over 10,000 MWd/tonne) is being attained on one of the first mechanically mixed elements charged into the PRTR. Periodic underwater examination of these elements indicates that their performance continues to be satisfactory. Irradiation of these elements will continue throughout the duration of the Batch Core Experiment.

Commercial Fuels Study - R. L. Gulley and M. D. Freshley

An important part of the PUP Fuel Development studies is to procure and test plutonium fuel rods designed and fabricated by commercial fuel

*The High Power Density (HPD) fuel elements used in the Batch Core Experiment are shorter (76 inches) than the pre-Batch Core Experiment fuel (106 inches). The HPD fuel also contains a gas plenum and all fuel is enriched with 2 wt\% $\mathrm{PuO}_{2}$. 
vendors. Seventy-seven rods containing hot pressed $\mathrm{UO}_{2}-\mathrm{PuO}_{2}$ pellets were procured. A 19-rod cluster of these rods was tested in the FERTF prior to the insertion of two such clusters in the batch core. As described in the section on FERTF Testing, the 19-rod cluster performed satisfactorily. Individual rods, defected and nondefected, will be tested in the FERTF using the special 8-rod cluster test assembly. Performance of these rods in the FERTF will be compared to performance of vibrationally compacted fuel rods.

Three fuel rods containing cold pressed and sintered $\mathrm{UO}_{2}-\mathrm{PuO}_{2}$ fuel pellets are being purchased from a commercial fuel fabricator. Performance of these fuel rods will be compared to that of vibrationally compacted fuel rods as well as that of fuel rods containing hot pressed pellets. 


\section{REACTOR PHYSICS}

The main objective of the physics program is to evaluate and improve where necessary calculational methods and approximations to a stage where reliable engineering calculations can be made for predicting the nuclear characteristics of plutonium fueled thermal reactors. Existing methods are modified and adapted when adequate. New methods are developed when required. In order to evaluate these methods, extensive experimental data are required. These data come from experiments conducted at Pacific Northwest Laboratory as well as laboratories at other sites. Data are obtained from both critical experiments and irradiation experiments. During the past year emphasis has changed from measurements of zero exposure characteristics in uniform lattices to characteristics of reactor cores as a function of exposure and to specific problems associated with loading plutonium fuels in water reactors.

Uniform lattice studies over a range of moderator-to-fuel ratio and ${ }^{240} \mathrm{Pu}$ concentrations were completed for $\mathrm{UO}_{2}-\mathrm{PuO}_{2}$ fuel rods. These results allow computational techniques to be evaluated over a range of moderator-to-fuel ratios and fuel characteristics of interest to pressurized water reactors and boiling water reactors. In addition, the importance of the approximations utilized in the calculational methods depends on the moderator-to-fuel ratio. Therefore, a range of moderator to fuel ratios broader than necessary for pressurized or boiling water designs allow conclusions to be made about the adequacies of the approximations. The reactivity associated with temperature and voiding is of particular interest in plutonium power reactor designs. The temperature and void coefficients of reactivity are very sensitive to the plutonium concentration. Because of this plans have 
have been made to conduct experiments using $4 \mathrm{wt} \% \mathrm{PuO}_{2}$ in $\mathrm{UO}_{2}$. This concentration is of specific interest for the use of plutonium in power reactors moderated with $\mathrm{H}_{2} \mathrm{O}$.

There is cost incentive from a fuel fabrication standpoint to allow the $\mathrm{PuO}_{2}$ particle size in the $\mathrm{UO}_{2}$ matrix to be as large as possible compatible with the physics and heat transfer characteristics for the fuel. An experiment was initiated in the Physical Constants Testing Reactor to study the effect of particle size on the value of $\mathrm{k}_{\infty}$ for the lattice. The first experiments were conducted in a graphite lattice. The fabrication of an $\mathrm{H}_{2} \mathrm{O}$ tank for use in the Physical Constants Testing Reactor will allow these measurements to be extended to $\mathrm{H}_{2} \mathrm{O}$. In addition, the unique capability of the Physical Constants Testing Reactor will now be available to study the lattice characteristics of $\mathrm{H}_{2} \mathrm{O}$ moderated systems.

The accurate prediction of fuel burnup and reactor core lifetime is important to the production of low cost power with nuclear power systems. Reasonably accurate predictions of initial loading, depletion rate and final fuel exposure can result in savings of fuel cycle and plant depreciation costs. Important to studies which determine reactor Ifetime is the correlation of experimental burnup data with results from burnup calculations. For these reasons, fuel burnup studies utilizing clusters of specific fuel composition have continued in the Plutonium Recycle Test Reactor. In addition, experiments have been initiated which will measure the burnup behavior of batch loadings of plutonium fuels in the Plutonium Recycle Test Reactor and in the Experimental Boiling Water Reactor. Because of other program priorities, the Experimental Boiling Water Reactor experiment was shortened. However, the information obtained from fuel rods removed from nondestructive and destructive analysis during the irradiation and the terminal critical experiment which was performed on the plutonium enriched zone will be an important supplement to the Saxton burnup experiment and the more 
detailed information obtained from the Batch Core Experiment in the Plutonium Recycle Test Reactor.

Where necessary methods are developed, modified, or improved for use in the evaluation. One important development has been a unique statistical analysis technique which has been applied to the analysis of burnup data obtained from plutonium-aluminum clusters irradiated in the Plutonium Recycle Test Reactor to obtain ratios of effective cross sections. The application of this technique to burnup data allows separate evaluations to be made of the cross section data and the calculational model and it is believed to be a more stringent test of the methods than either the isotopic concentrations or reactivity.

Experimental data obtained to date have been very helpful in extensive evaluations made to determine how accurately the observed physics behavior of power reactors can be predicted. Major emphasis in the evaluation has been on clean uniform lattices with future work expected to be on clean non-uniform lattices and on irradiation behavior. The objective is to be able to predict criticality reactivity coefficients, power distributions and fuel exposure relationships with sufficient accuracy to permit reliable reactor design calculations and accurate fuel cycle predictions to be made. Comparisons between experiment and calculations are made for systems which contain plutonium only, uranium only, and the more interesting mixture of uranium and plutonium. Such a systematic approach allows conclusions to be drawn about the reliability of the calculational methods.

\section{Subcritical and Critical Experiments}

Experiments were conducted in the Critical Approach Facility (CAF), (1) Plutonium Recycle Critical Facility (PRCF), (2) and Physical Constants

(1) Henry, H. L., Swanberg, Jr., F., "Critical Approach Facility Final Safeguards Analysis," BNWL-CC-1319.

(2) Bennett, R. A. and Schmid, L, C., "Approach to Critical and Calibration Experiments in the Plutonium Recycle Critical Facility," HW-80206, July 1964. 
Testing Reactor (PCTR), (3) investigating the detailed physics properties of plutonium fueled reactor systems. The experimental results provide data for use in evaluating the adequacy of calculational methods. Results of experiments which were conducted during this reporting period are described here.

\section{Subcritical Experiments}

Subcritical Measurements With UO $2-2 \mathrm{wt} \%$ PuO 2 Fuel - W. P. Stinson

Measurements have been made in the Critical Approach Facility (CAF) of the critical masses and bucklings for a wide range of lattice spacings of one-half inch diameter rods of $\mathrm{UO}_{2}-2$ wt\% $\mathrm{PuO}_{2}$ in $\mathrm{H}_{2} \mathrm{O}$ moderator.

The fuel rods were 0.030 inches thick Zircaloy tubes with a 0.508 inch I.D. filled with vibratory compacted $2 \mathrm{wt} \% \mathrm{PuO}_{2}-\mathrm{UO}_{2}$ to a length of 36.0 inches. Each rod contained an average of $1128 \mathrm{~g}$ of $\mathrm{PuO}_{2}-\mathrm{UO}_{2}$. The $\mathrm{U}$ in $\mathrm{UO}_{2}$ was natural, and the isotopic compositions of the plutonium were, by weight, $91.62 \% \mathrm{Pu}^{239}, 7.65 \% \mathrm{Pu}^{240}, 0.70 \mathrm{Pu}^{241}, 0.03 \% \mathrm{Pu}^{242}$, and $81.11 \% \mathrm{Pu}^{239}, 16.54 \mathrm{Pu}^{240}, 2.15 \% \mathrm{Pu}^{241}, 0.20 \% \mathrm{Pu}^{242}$, and $71.76 \% \mathrm{Pu}^{239}$, $23.50 \% \mathrm{Pu}^{240}, 4.08 \% \mathrm{Pu}^{2}+1,0.66 \% \mathrm{Pu}^{242}$. The rods were loaded in hexagonal lattices at spacings covering the range of moderator-to- $\mathrm{PuO}_{2}$ volume ratios of 0.61 to 9.7. All lattices were completely reflected with $\mathrm{H}_{2} \mathrm{O}$.

The number of rods for a critical loading was determined by the extrapolation of neutron multiplication data obtained with as much as $96 \%$ of the critical mass. Count rates were also obtained along the

(3) Donahue, D. J., Lanning, D. D., Bennett, R. A., Heineman, R. E., "Determination of $\mathrm{k}_{x}$ From Critical Experiments with The PCTR," Nucl. Sci. and Eng., 4.297 (1958). 


\section{5}

BNWL- -624

central axis of each loading when $50 \%$ of the aritical mass was loaded. From these data the material buckling was computed and equated to the geometracal buskling of the critical loading. A value of the reflector savings was calculated from the equality, for each lattice with the assumption that the savings are equal in the vertical and horizontal directions.

A preliminary summary of these data has been presented earlier. (4) The tabulation in Table I represents the results of the final analysis of these expeximents.

\section{Critica1 Experiments}

Experiments With Hafnium Oxide Rods in $\mathrm{UO}_{2}-\mathrm{PuO}_{2}-\mathrm{H}_{2} \mathrm{O}$ Lattices $-\mathrm{V}$. O. Uotinen Reactivity worths of $\mathrm{HfO}_{2}$-bearing rods have been measured (5) in the Plutonium Recycle Critical Facility (PRCF) in a loading of half-inch diameter, $\mathrm{JO}_{2}-2 \mathrm{wt} \% \mathrm{PuO}_{2}$ fuel rods moderated with $\mathrm{H}_{2} \mathrm{O}$. The fuel rods are clad with Zircaloy-2 (0.030 Inches thick) and were loaded in a hexagonal lattice with 0.85 inch pitch. This corresponds to a moderatorto-oxide volume ratio of 1.83 . Each fuel rod contains an average of $1128 \mathrm{~g}$ $\mathrm{UO}_{2}-\mathrm{PuO}_{2} \cdot$ The plutonium isotopic composition is, by weight, $91.62 \% \mathrm{Pu} 239$, $7.65 \% \mathrm{Pu}^{240}, 0.70 \% \mathrm{Pu}^{24}$, and $0.03 \% \mathrm{PL}^{242}$. The lattice was surrounded with a thickness of $\mathrm{H}_{2} \mathrm{O}$ greater than that corresponding to an infinite reflector. These fuel rods have been as sd for other critical ${ }^{(6)}$ and subcritical experiments. (4)

Rods with $\mathrm{HfO}_{2}$ concentrations of $5.11 \mathrm{~g} / \mathrm{cm}^{3}, 3.42 \mathrm{~g} / \mathrm{cm}^{3}, 1.74 \mathrm{~g} / \mathrm{cm}^{3}$, and $0.52 \mathrm{~g} / \mathrm{cm}^{3}$, and an aluminum $x o d$, were used. The matrix materia? in the

(4) Likala, R. C, and Stinson, W. P., "Experimental and Analytical Results for $\mathrm{PuO}_{2}-\mathrm{UO}_{2}-\mathrm{H}_{2} \mathrm{O}$ Lattines," Trans. Am. Nucl. Son. 9 :127! June 1966.

(5) Uotinen, V. O., "Measirements of the Reantivity Worth of Hafnium Oxide Rods in a $\mathrm{PuO}_{2}-\mathrm{UO}_{2}-\mathrm{H}_{2} \mathrm{O}$ Lattice," Trans. Am. Nucl. Soc. 9 (520)

(6) Uotinen, V. O. and Williams, 1. D., "Experiments and Calculations for $\mathrm{H}_{2}$-Moderated Assembliss Containing $1 \mathrm{O}_{2}-2$ wt: $\mathrm{PuO}_{2}$ Fuel Rods," Trans. Am. Nucl. Soc., 10 1520! Iane 1967. 
Table I

Results of Subcritical Measurements With $\mathrm{UO}_{2}-2 \mathrm{wt} \% \quad \mathrm{PuO}_{2}$ Rods in $\mathrm{H}_{2} \mathrm{O}$

\begin{tabular}{|c|c|c|c|c|c|c|c|c|}
\hline \multirow[b]{3}{*}{$\begin{array}{l}\text { Temperature } \\
\left({ }^{\circ} \mathrm{C}\right) \\
\end{array}$} & \multirow{3}{*}{$\begin{array}{l}\text { Lattice } \\
\text { Spacing } \\
\text { (in.) } \\
\end{array}$} & \multirow{3}{*}{$\begin{array}{l}\mathrm{H} / \mathrm{Pu} \\
\text { Atom } \\
\text { Ratio }\end{array}$} & \multirow{3}{*}{$\begin{array}{l}\mathrm{H}_{2} \mathrm{O} / \text { Rod } \\
\text { Volume } \\
\text { Ratio } \\
\end{array}$} & \multirow{2}{*}{\multicolumn{2}{|c|}{ Critical }} & \multicolumn{3}{|c|}{ Exponential } \\
\hline & & & & & & \multirow[b]{2}{*}{ No. Rods } & \multirow{2}{*}{$\begin{array}{l}\text { Vertical } \\
\text { Relaxation } \\
\text { Length }(\mathrm{cm}) \\
\end{array}$} & \multirow{2}{*}{$\begin{array}{l}\text { Reflector Savings } \\
\text { and Extrapolation } \\
\text { Length } \lambda(\mathrm{cm}) \\
\end{array}$} \\
\hline & & & & No. Rods & $\begin{array}{c}\text { Buckling } \\
\left(10^{-6} \mathrm{~cm}^{-2}\right) \\
\end{array}$ & & & \\
\hline \multicolumn{9}{|c|}{$8 \% \mathrm{Pu}^{240} \mathrm{Rods}$} \\
\hline 23.9 & 0.80 & 238 & 1.187 & $319.0 \pm 0.3$ & $8801 \pm 28$ & 163 & $-15.46 \pm 0.09$ & $7.93 \pm 0.04$ \\
\hline 20.2 & 0.93 & 391 & 1.956 & $193.0 \pm 0.1$ & $10288 \pm 27$ & 97 & $-14.88 \pm 0.07$ & $7.55 \pm 0.03$ \\
\hline 26.2 & 1.386 & 1113 & 5.564 & $180.9 \pm 0.4$ & $6995+35$ & 91 & $-17.75 \pm 0.11$ & $6.00 \div 0.06$ \\
\hline 19.4 & 1.6107 & 1550 & 7.750 & $472 \pm 3$ & $3271 \pm 38$ & 241 & $-33.15 \pm 0.50$ & $3.85 \pm 0.21$ \\
\hline \multicolumn{9}{|c|}{$16 \% \mathrm{Pu}^{240}$ Rods } \\
\hline 20.0 & 0.93 & 391 & 1.956 & $241.2 \div 0.3$ & $8837 \pm 27$ & 121 & $-16.03 \pm 0.07$ & $7.67 \pm 0.04$ \\
\hline \multicolumn{9}{|c|}{$24 \% \mathrm{Pu}^{240}$ Rods } \\
\hline 24.4 & 0.80 & 238 & 1.187 & $524.2 \pm 1.3$ & $6239 \pm 27$ & 253 & $-18.88 \pm 0.08$ & $8.32 \pm 0.05$ \\
\hline 24.7 & 0.93 & 391 & 1.956 & $287.5 \pm 0.4$ & $7887 \pm 25$ & 139 & $-16.33 \pm 0.07$ & $7.67 \pm 0.04$ \\
\hline 23.5 & 1.05 & 554 & 2.768 & $234.2 \pm 0.3$ & $7714 \pm 29$ & 121 & $-17.72 \pm 0.11$ & $7.63 \div 0.05$ \\
\hline 22.0 & 1.143 & 693 & 3.464 & $232.1 \pm 0.2$ & $7220 \pm 18$ & 109 & $-16.23 \pm 0.06$ & $7.00 \pm 0.04$ \\
\hline 25.3 & 1.32 & 991 & 4.956 & $296.7 \pm 0.4$ & $5358 \pm 15$ & 151 & $-20.76 \pm 0.07$ & $5.81 \pm 0.04$ \\
\hline 23.6 & 1.386 & 1113 & 5.564 & $366.7 \pm 0.4$ & $4405 \pm 11$ & 181 & $-23.07 \pm 0.08$ & $5.47 \pm 0.4$ \\
\hline
\end{tabular}


$\mathrm{HfO}_{2}$ rods is aluminum. Each of these rods is 0.368 inches in diameter, 36.0 inches long, and surrounded by a Zircaloy-2 sleeve, 0.372 inches I.D. and 0.426 inches $0 . D$.

The worth of one of the $\mathrm{HfO}_{2}$ rods $\left(0.52 \mathrm{~g} / \mathrm{cm}^{3}\right)$ was measured at three positions in the core. The worth of each of the rods was measured in the central lattice position. In each case the worth was determined for the exchange of a fuel rod for a poison rod and for the exchange of a column of water for a poison rod.

The results of the PRCF experiment are summarized in Figure I along with the results of earlier subcritical experiments. (7) The subcritical experiments were performed in the Critical Approach Facility (CAF) at moderator-to-oxide volume ratios of 3.47 and 6.21 . These results indicate that the worth of a poison rod increases with decreasing lattice pitch over the range of lattice pitches considered. As the lattice pitch decreases from 1.32 inches to 1.05 inches to 0.85 inches, the relative worth of a $\mathrm{HfO}_{2}$ rod replacing $\mathrm{H}_{2} \mathrm{O}$ increases approximately from 1.0 to 1.5 to 2.0 .

The present experiment provides a test of the accuracy of the subcritical method, (7) which depends on how well a diffusion-theory calculation (8) can predict the worth of fuel rods at the measured critical radius. In the present core, the calculated and measured worth of a peripheral fuel rod are 0.203 and 0.200 dollars, respectively. This agreement between calculated and measured fuel rod worth, and the consistency of subcritical and supercritical measurements, indicate that the accuracy of the subcritical method is satisfactory.

Clean Critical Loading of Al-2 wt\% Pu Fuel in an $\mathrm{H}_{2} \mathrm{O}$ Moderated Core $\mathrm{V}, 0$. Uotinen

An experiment was performed in the Plutonium Recycle Critical $a$ ility (PRCF) to determine the "clean" critical mass of an $\mathrm{H}_{2} \mathrm{O}$-moderated lattice of Al-2 wt\% Pu rods whose plutonium contained $16.46 \mathrm{wt} \% 2-0 \mathrm{Pu}$. The critical

(7) Uotinen, V. O. and Likala, R. C., "Reactivity Worth of Neutron Absorbing Rods in Pu-Fueled, Ho Moderated Systems," Trans. Am. Nucl. Soc., Vol. 9, No. 1, p. 180, June 9966 .

(8) Lilley, J. R., "Computer Code HFN-Multigroup, Multiregion Diffusion Theory in one Space Dimension," HW-71545 1961!. 

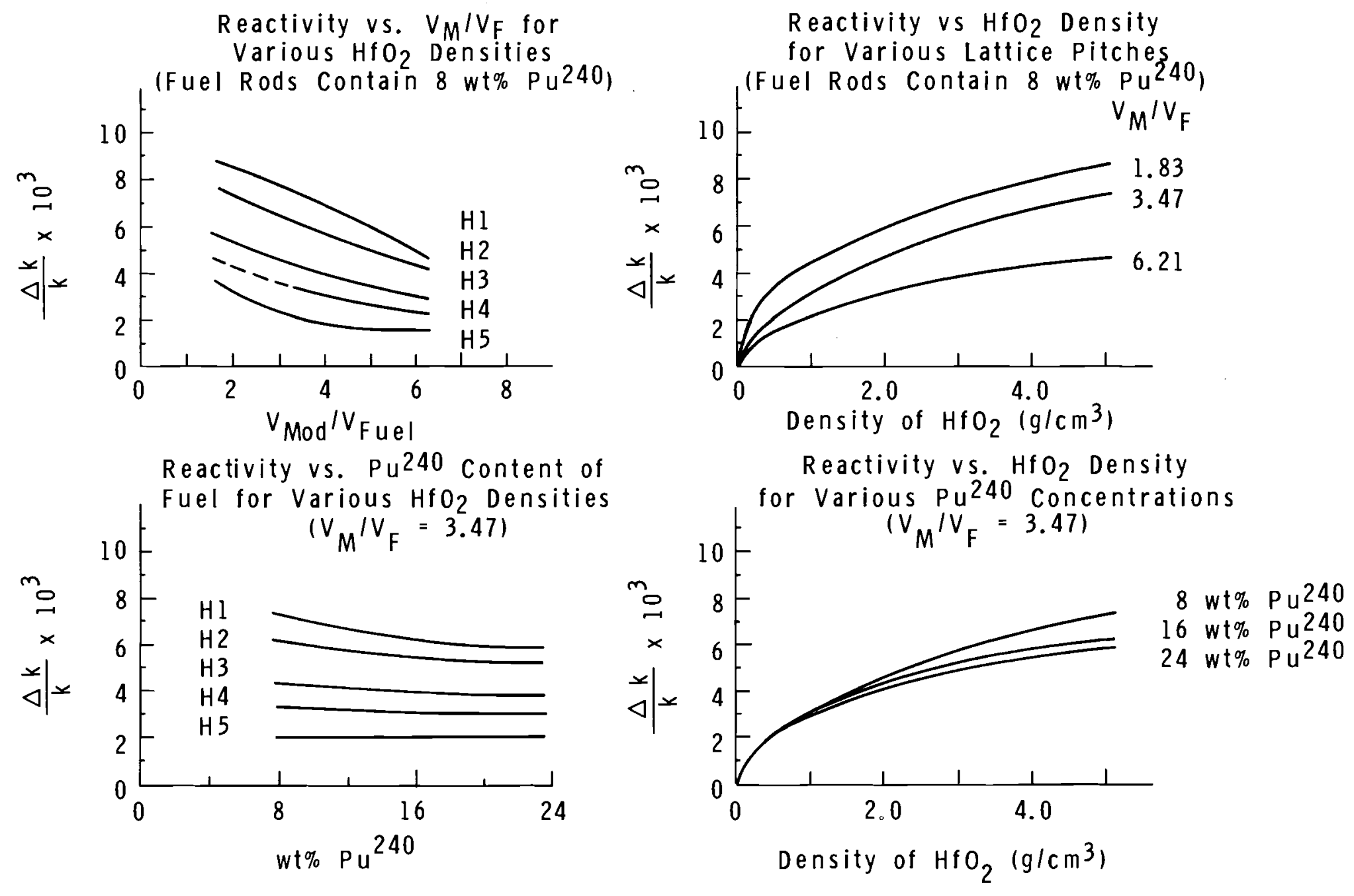

Figure I

Summary of Reactivity Measurements of Hafnium Oxide Rods 
mass had previously been measured ${ }^{(9)}$ in the Critical Approach Facility (CAF) using a subcritical method. The fuel rods were 0.500 inches in diameter, 36 inches long, and enclosed in Zircaloy-2 tubes 0.566 inches in O.D. and 0.030 inches thick. Each fuel rod contained an average of $6.38 \mathrm{~g}$ plutonium. The rods were arranged in an equilateral triangular lattice with a lattice pitch of 0.85 inches. The core was surrounded by an effectively infinite $\mathrm{H}_{2} \mathrm{O}$ reflector.

The PRCF was critical when the core contained 740.2 fuel rods. However, this does not correspond to the critical number of fuel rods for a "clean" core, because the PRCF contained two lucite lattice plates, three lucite sheet followers, - 30 lucite sleeves surrounding certain fuel rods, and control rod fuel followers which contained fuel different from that in the surrounding lattice.

Measurements were made to determine the reactivity worth of these foreign materials. When the control rod followers are replaced with the proper fuel, the critical number of rods increases by $60 \pm 6$. Removing the lattice plates, sleeves, and sheet followers from the core decreased the critical number of rods by a total of 3.2 . Thus, the clean critical mass if $797 \pm 6$ fuel rods.

An earlier subcritical measurement ${ }^{(9)}$ in the CAF gave a value of $785.6 \pm 0.4$ fuel rods for the critical mass. The CAF value has to be corrected for the presence of 785 lucite sleeves, two lucite lattice plates, and one aluminum lattice plate. Using the PRCF measurements, we can estimate that removing the lucite plates and sleeves from the CAF would increase the critical mass by $\sim 1$ and $\sim 15 \pm 8$ fuel rods, respectively. The worth of aluminum was not measured, so we have no estimate of the worth of the aluminum lattice plate. However, it was positioned $a^{+}$a point of minimum worth (just below the top of the fuel) and its removal is expected to decrease the critical mass by only a few fuel rods. If we neglect the worth of the aluminum plate, the clean critical mass from the $\mathrm{CAF}$ experiment is $802 \pm 8$ fuel rods.

(9) Stinson, W. P., Marks, J. A., and Schmid, L, C., "Subcritical Measurements with 2 wt: Pu-Al Rods in Light water," Physics Research Quarterly Report, July, August, September, 1963, H(w-79054, October 15, 1963. 
From this comparison we can conclude that critical mass measurements in the PRCF and CAF give consistent results within experimental uncertainties. The same conclusion was reached in an earlier comparison (10) of results for a $\mathrm{UO}_{2}-1.5 \mathrm{wt} \% \mathrm{PuO}_{2}$ core.

Critical Experiments in $\mathrm{H}_{2}$ O-Moderated Assemblies Containing $\mathrm{UO}_{2}-2 \mathrm{wt} \% \mathrm{PuO}_{2}$ Fuel Rods - V. O. Uotinen and L. D. Williams

Critical experiments have been performed in the Plutonium Recycle Critical Facility ( $\mathrm{PRCF}$ ) in six configurations of $\mathrm{UO}_{2}-2 \mathrm{wt} \% \mathrm{PuO}_{2}$ fuel rods in $\mathrm{H}_{2} \mathrm{O}$ moderator. Each rod contains $1128 \mathrm{~g}$ of $\mathrm{UO}_{2}-\mathrm{PuO}_{2}$ and is 36 inches long, 0.508 inches in diameter, and clad with 0.030 inches of Zircaloy-2. The rods are of three types which have respectively the following weight percent of ${ }^{239} \mathrm{Pu} /{ }^{240} \mathrm{Pu} /{ }^{241} \mathrm{Pu} / 242 \mathrm{Pu}$ :

1. $91.62 / 7.65 / 0.70 / 0.03$

2. $81.11 / 16.54 / 2.15 / 0.20$

3. $71.76 / 23.50 / 4.08 / 0.66$

The rods were assembled in a hexagonal array with a lattice spacing of 0.85 inches and a water-to-oxide volume ratio of 1.83 .

Single-zone cores were studied using fuel types 1 and 3 . Two-zone cores were studied using various combinations of the three fuel types. An effectively infinite $\mathrm{H}_{2} \mathrm{O}$ relfector surrounded the core.

Measured parameters included critical mass; spatial flux and power distributions; power peaking and power sharing; bucklings, reflector savings; worth of fuel rods; moderator void worth; moderator level reactivity coefficient; moderator temperature reactivity coefficient; and the ratio of effective delayed-neutron fraction to mean neutron lifetime, $B / \ell$. A brief summary of the results has been recently presented. (6) A more detailed description of the experimental techniques utilized and results obtained in this study are given elsewhere.

(10) Schmid, L. C., et al., "Sumary of Results of EBWR Critical Experiments," Physics Research Quarterly Report, October, November, December, 1964, HW-84608, January 15, 1965.

(11) Uotinen, V. O. and Williams, L. D., "Experiments and Calculations for $H_{2} O$ Moderated Assemblies Containing $40_{2}^{-2}$ wt: PUO 2 Fuel Rods," BNWL-SA-1107, May 23, 1967. 
Critical Mass, Bucklings and Reflector Savings

The critical mass with full moderator height and with all control elements completely withdrawn, was determined for each of the loadings. Measurements were then made to determine the reactivity worth of lucite templates, sleeves, and safety sheet followers, and of the control rod fuel follower rods. These results were used to correct the measured critical mass for these perturbations. The resulting corrected critical number of fuel rods represents a "clean" loading.

Radial and axial bucklings and reflector savings were deduced from two types of measurements: (1) spatial distribution of thermal activation of copper pins, and (2) spatial distribution of gamma-ray activity from fuel rods.

The appropriate functions (cosine and $J_{0}$ Bessel function) were fitted to the axial and radial distributions to obtain the bucklings. The reflector savings were then obtained from the difference between the effective height and the fuel height, and the difference between the effective radius and the critical radius. The critical mass, bucklings, and reflector savings are given in Table II.

Spatial Activation and Power Density Distributions

Spatial distributions of copper pin activity were measured in the axial and radial directions in the two single-zone cores, and in the radial direction in all two-zone cores. Spatial distributions of relative power density were obtained by measuring the gamma-ray activities of fuel rods after short irradiations $(\sim \mathrm{hr}$.$) at low power levels (\sim 100 \mathrm{w})$. Axial and radial distributions were measured in five of the six cores. The radial distributions in the two-zones cores provide a measurement of power sharing between different types of fuels.

Typical distributions of spatial activation and power density in the radial direction are presented in the methods evaluation section of this report where comparisons to calculated results are given. Fuel Rod Worth, Moderator Voiding, and Kinetics

The worth of a fuel rod replacing water was measured as a function of radius in the two single-zone cores. The results are plotted in Figure II. 


\section{$\underline{\text { Table II }}$}

Summary of Critical Loadings For $\mathrm{UO}_{2}-2 \mathrm{wt} \% \mathrm{PuO}_{2}$ Lattices (a)

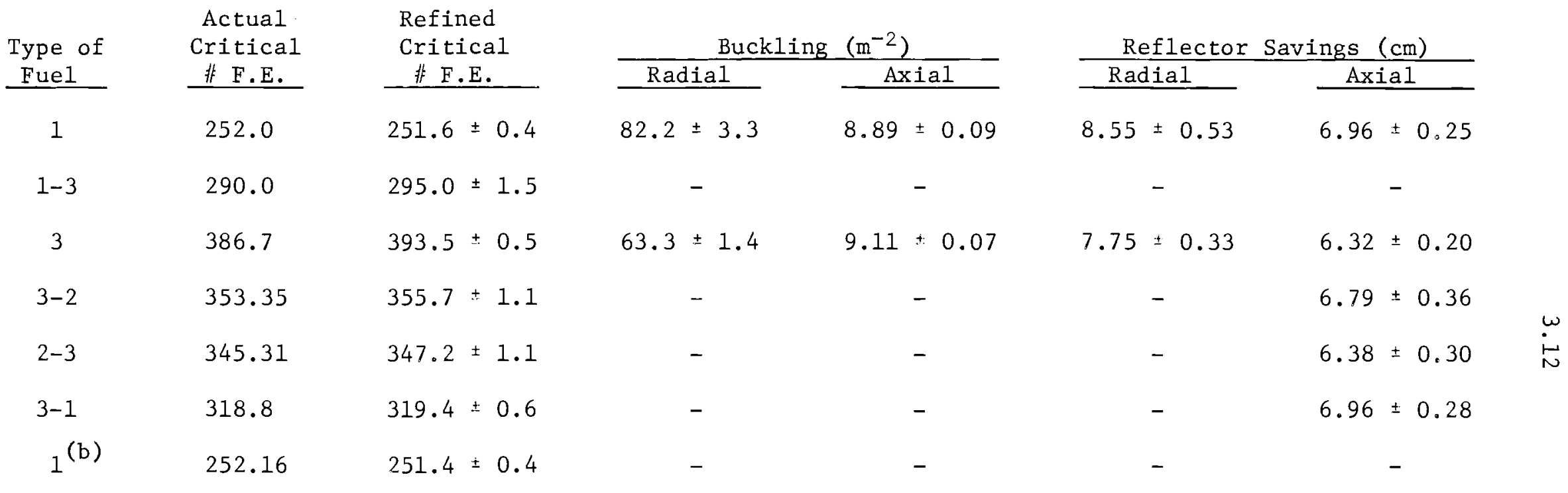

(a) All quantities are in terms of number of fuel elements.

(b) The $7.65 \% 240 \mathrm{Pu}$ loading was repeated. 


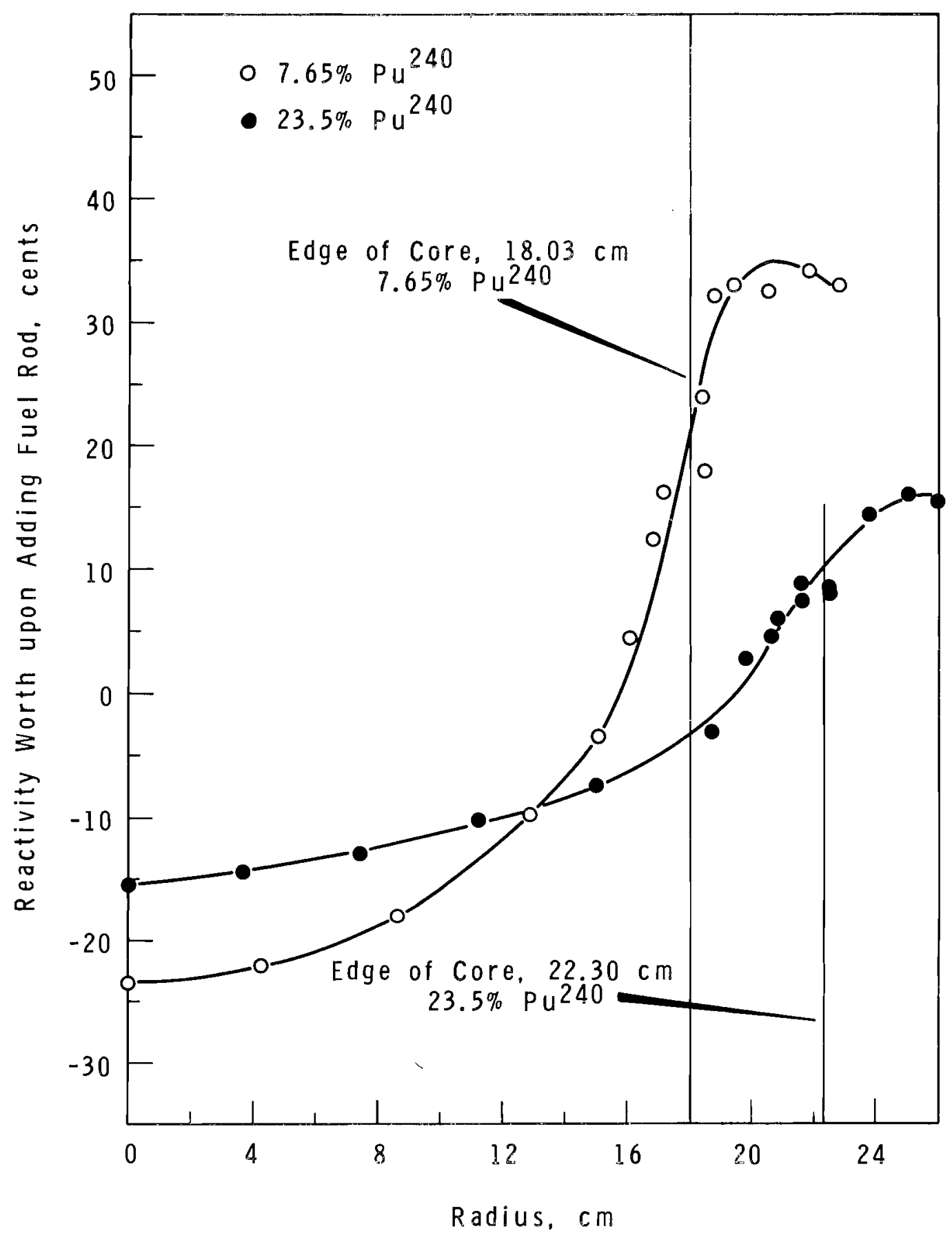

Figure II

Measured Fuel Rod Worth Relative to Water 
Worths of cylindrical (tube) voids and annular (film) voids were measured as a function of radius in the two single-zone cores. The tube void was formed by a lucite tube with an I.D. of 0,625 inches. The annular film void replaced $14 \%$ of the moderator in a cell around a fuel rod; this void was formed by a lucite tube (0.625 inches I.D.) which surrounded the fuel rod. The annular region between fuel rod and lucite thimble was filled with either water or air; and the difference in reactivity between these two cases was taken to be the worth of the void. The results are plotted in Figure III.

By summing the worths of individual film voids one can obtain an estimate of the worth of simultaneously voiding the entire moderator by $14 \%$. Such a value is an estimate because it does not take into account interactions among cells, and because the exact shape of the curve is not known.

The ratio of effective delayed-neutron fraction to mean neutron lifetime $(B / \ell)$ was obtained in the two single-zone cases from measurements of reactor noise.

A summary of the measurements of fuel rod worth, moderator voiding, and kinetics parameters are given in Table III.

Moderator Level Reactivity Coefficient

Moderator level reactivity coefficients were measured in five of the six cores. In some cases measurements were made in the top reflector only; in other cases measurements were also made below the top of the fuel. The results for the two single-zone cores are plotted in Figure IV. Temperature Coefficient

The temperature coefficient of reactivity was measured in the two single-zone cores over the temperature range between $\sim 20$ C and 50 " $\mathrm{C}$ The moderator was heated (or cooled) in a storage tank and was pumf $=1 \quad 1$ and out of the reactor vessel between measurement,

The effect of thermal expansion of the lucite lattice plates is estimated to be a very large correction. Preliminary results are presented in the Methods Evaluation section of this report. The interpretation of this experiment is continuing. 


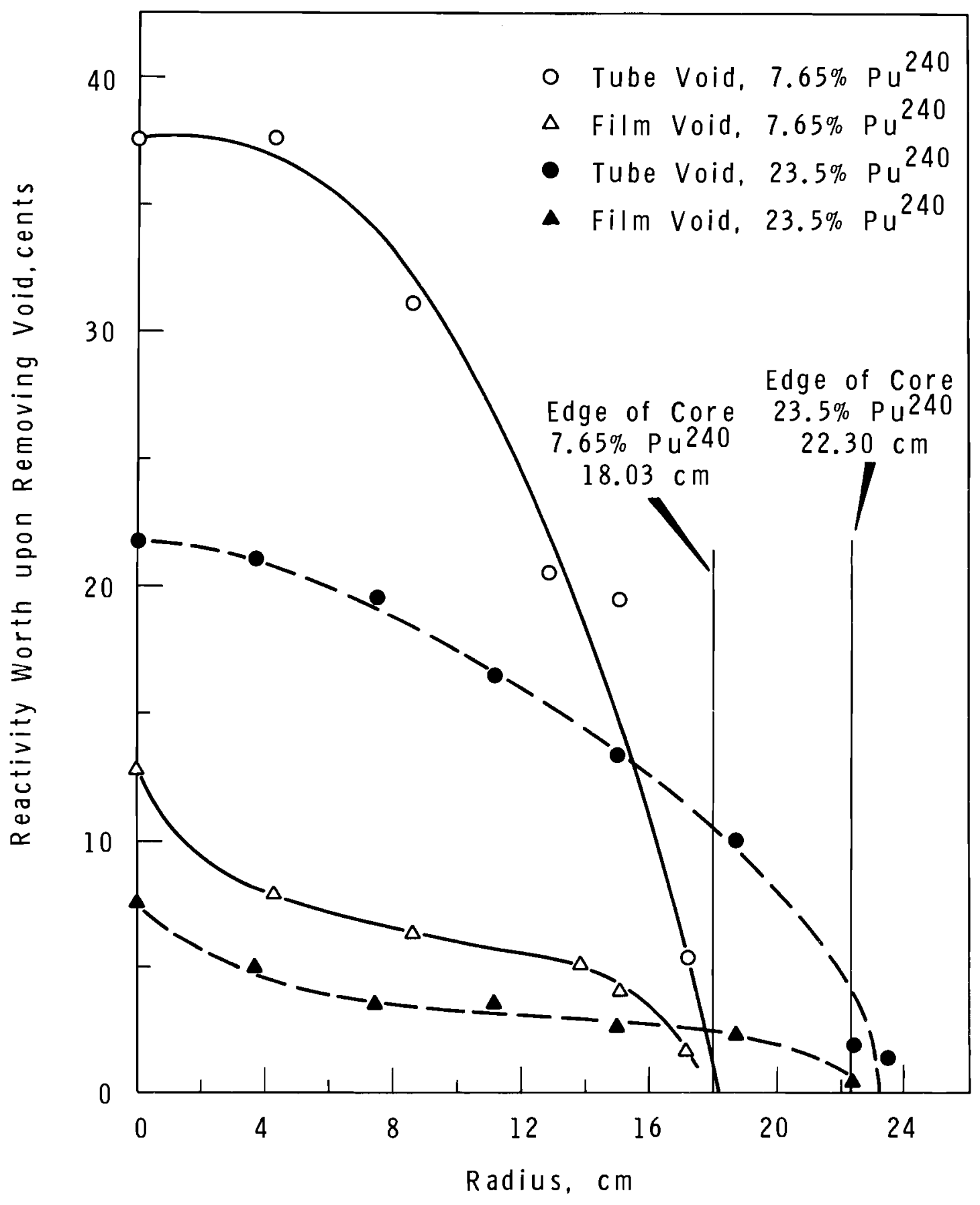

Figure III

Measured Void Worth Relative to Water 
Table IiI

Fuel Rod Worth, Moderator Vold Worth and Kinetics Parameters

\begin{tabular}{|c|c|c|}
\hline \multirow[b]{2}{*}{ Fuel Type } & \multicolumn{2}{|c|}{ Fue1 Rod Worth ${ }^{(a)}$ (cents) } \\
\hline & Central Fue1 Rod & Peripheral Fuel Rod \\
\hline 1 & $-23.2 \cdot 0.2$ & $21.0^{(\mathrm{b})}$ \\
\hline 3 & $-15.3 \cdot 0.2$ & $10.2^{(b)}$ \\
\hline
\end{tabular}

$\begin{array}{cc}\frac{\text { Worth of } 14 \% \text { Volds }}{\text { Integrated }} \\ \frac{\text { In Central Ce11 (cents) }}{\text { Over Core (\$) }} \\ -12.8 \cdot 0.2 & -12.2^{(\mathrm{c})} \\ -7.5 \cdot 0.2 & -9.9^{(-)}\end{array}$

$\begin{array}{cc}\begin{array}{c}\text { Average } \\ \text { Vold Cuefficient } \\ \text { C/\% Void }\end{array} & \text { B/x, S:-: } \\ -87 & 127 \cdot 11 \\ -71 & 114,15\end{array}$

(a) For a fuel rod replacing $\mathrm{H}_{2} \mathrm{O}$.

(b) Estimated uncertainty is $5 \%$. Read off curves in Flguce II at effective radius of core.

(c) Values do not include interaction effects between cells, estimaced uncertainty is

$10 \%$. 


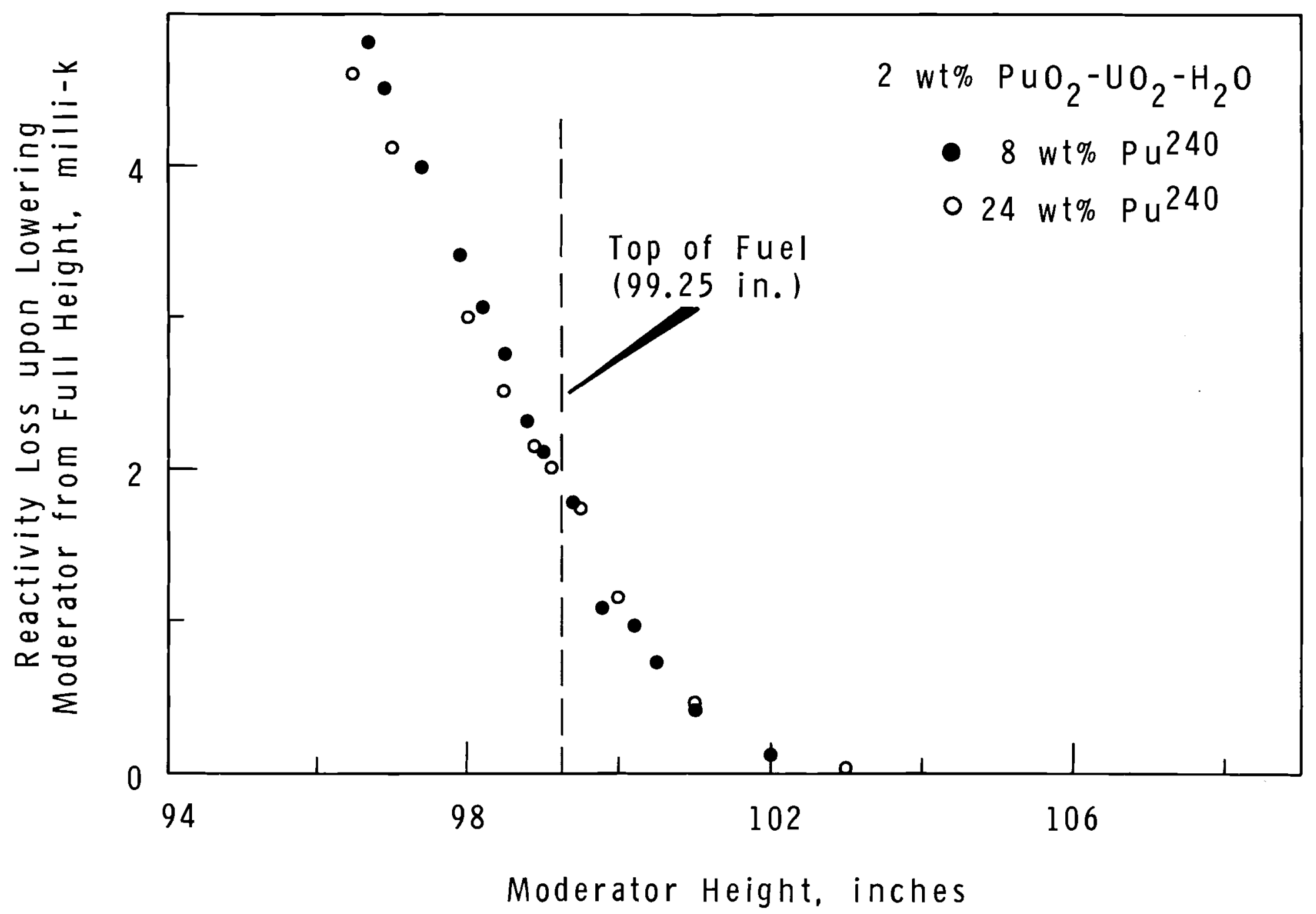

Figure IV

Measured Effects of Moderator Hejght Changes 


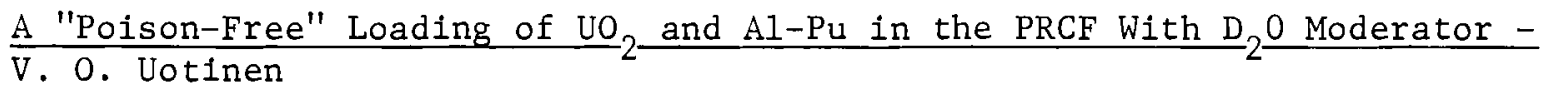

The control rods that are used in the $\mathrm{D}_{2} \mathrm{O}$-moderated Plutonium Recycle Critical Facility (PRCF) are of the "shutter" type so that, in their normal "withdrawn" position, there is still a large amount of cadmium in the reactor. (1) Thus, under normal operating conditions the three control rods create three large flux sinks in the reactor. It is difficult to accurately represent discrete control rods in a one-dimensional diffusion theory calculation. To assist in the evaluation of calculational methods, a control-rod-free critical configuration was assembled $(12)$ in the $\mathrm{D}_{2} \mathrm{O}^{-}$ moderated PRCF.

The PRCF contained fuel in a two-zone loading, an inner zone of natural uranium oxide ${ }^{(13)}$ and an outer zone of A1-1.8 wt\% Pu. (14) The fuel elements were 19-rod clusters and were arranged in a hexagonal lattice with an 8-inch pitch. Details of this experiment along with results of other reactivity measurements and reaction rates of gold and lutetium foils are given in Reference 12 .

The "poison-free" critical configuration contained $24 \mathrm{UO}_{2}$ fuel elements and $16 \mathrm{Al}-\mathrm{Pu}$ fuel elements. With this loading, the reactor was critical at a moderator height of 98.15 inches.

A calculation with the diffusion theory code HFN ${ }^{(8)}$ using cell-averaged cross sections generated with the codes THERMOS, (15) TEMPEST, (16) and HRG, (17) predicts the effective multiplication factor to within $0.7 \%$ of the measured value for the control-rod-free loading of $\mathrm{UO}_{2}$ and $\mathrm{Al}-\mathrm{Pu}$ clusters.

(12) Uotinen, V. O. "A Poison-Free" Loading of $10_{2}$ and Pu-Al in the PRCF With $D_{2}$ O Moderator," BNWL-372, May 1967.

(13) Millhollen, M. K., "Specifications for Swaged U0, 19-Rod Cluster, PRTR Fuel Element Mark I," Ha'-64359, General Electric ${ }^{2}$ Co., Richland, Wasin., 1960. .

(14) Freshley, M. D., "Plutonium Spike Fuel Elements for the PRTR Part I The Mark I-G," HW-69200, Pt. 1, 1961, and Sharp, R. E., "The Mark I-H," HW-69200, Pt. 2, General Electric Co., Richland, Wash., 1961.

(15) Honeck, H. C., "THERMOS: A Thermalization Transport Theory Code for Reactor Lattice Calculations," BNL-5826.

(16) Shudde, R. H. and Dyer, J., NAA Program Description, "Tempest, A Neutron Thermalization Code," North American Aviation Corporation, 1960.

(17) Carter, J. L., Ir., "Computer Code Abstracts, Computer Code-HRG," Reactor Physics Department Technical Activities Quarterly Report July, August, September, 1966, October 15, 1966. 
Reactivity Worth of a Central Safety Rod With and Without an Internal Scatterer - V. O. Uotinen and A. L. Pitner

An experiment was performed in the $\mathrm{D}_{2}$--moderated Plutonium Recycle Critical Facility (PRCF) to determine the increase in negative reactivity worth of a hollow cadmium safety rod when a scattering material (Lucite) was placed inside the safety rod. The experiment was conducted to investigate the feasibility of increasing the worth of the PRCF safety system for special purposes and to evaluate calculational methods of determining the worth of safety rods with internal scattering.

The PRCF was loaded with a two-zone configuration of Al-1.8 wt\% Pu (14) and natural $\mathrm{UO}_{2}{ }^{\text {(13) }}$ The core loading consisted of an inner zone of natural $\mathrm{UO}_{2}$ fuel elements surrounded by a zone of Al-Pu fuel elements with a safety rod located in a central fuel channel. Each fuel element was a cluster of 19 fuel rods. The fuel clusters were arranged in a hexagonal lattice with an 8 inch pitch. The moderator height was 105.25 inches during the reactivity measurements; and the thickness of the $\mathrm{D}_{2} 0$ reflectors at the top and botan of the core were 8.34 and 9.04 inches, respectively.

The safety rod, consisting of a 2.695 inch O.D., 2.303 inch I.D, and 85 inch long aluminum cylinder coated with a 0.025 inch layer of cadmium, placed in an aluminum thimble in the center of the PRCF. The aluminum thino had an outer diameter of 3.47 inches and a wall thickness of 0.18 inches

The worth of this safety rod was determined from subcritical multiplication data which were obtained from three $\mathrm{BF}_{3}$ chambers positioned in the radial reflector. The count rate was measured with and without the safety rod in the thimble, and the worth was calculated using the equation

$$
\Delta \mathrm{k}_{\text {eff }}=A\left(\frac{\mathrm{N}_{1}}{\mathrm{~N}_{2}}-1\right)\left(1-\mathrm{k}_{\mathrm{eff}}\right)
$$

In Equation (1) $\Delta \mathrm{k}_{\text {eff }}$ is the worth of the safety rod, and $\mathrm{N}_{2}$ and $\mathrm{N}_{1}$, respectively, are the count rates with and without the safety rod in the thimble. The $k_{\text {eff }}$ is the effective multiplication factor of the reastor in the absence of the safety rod, and $A$ is an empirically determined constant The constant A was determined for each chamber by measuring multiplication before and after inserting into the reactor (at a radius of 16 inches) a safety rod of known worth, and using Equation (1). 
Measurements were made to determine the decrease in reactivity caused by the addition of lucite to the interior of the safety rod. A lucite sleeve 2.240 in. O.D., 1.550 in. I.D., and 84 in. long was placed in the safety rod. Subsequently a lucite rod $1.510 \mathrm{in.}$ in diameter and $75 \mathrm{in.}$ long was placed inside the lucite sleeve. The lucite rod rested on a guide and was flush with the lucite sleeve at the top (Figure V), A measurement was also made of the reactivity worth of a stainless steel rod to simulate the lead screw of a regular PRCF safety rod. This simulated lead screw of diameter 0.875 in. penetrated $7.7 \mathrm{in}$. below the top of the cadmium section of the safety rod.

The negative worth of the safety rod in the center of the reactor, as determined from subcritical multiplication measurements, was $(40.7 \pm 0.6) \mathrm{mk}$ or $(8.78 \pm 0.13) \$$.

Addition of the lucite sleeve to the safety rod increased the negative worth of the safety rod $(2.36 \cdot 0.02) \mathrm{mk}$, or $(51.0+0.4) \mathrm{c}$. Placing the lucite rod inside the sleeve increased the negative worth by an additional $(1.40=0.01) \mathrm{mk}$, or $(29.2 \div 0.2) \mathrm{c}$. The total effect of replacing the internal void of the safety rod with lucite is a $9.2 \%$ enhancement of its negative worth.

The simulated lead screw was worth $(-0.040: 0.004) \mathrm{mk},(-0.9 \pm 0.1)$ c. The net contribution of the lucite sleeve to the worth of a PRCF safety rod (with lead screw present) was $(2.34=0.02) \mathrm{mk}$, (50.5 5.4$) \mathrm{c}$, or an increase of $5.7 \%$.

The worth of the safety rod, with and without lucite, was calculated using the system of computer codes $\mathrm{HRG}^{(17)}$ for determining fast cross sections, THERMOS ${ }^{(15)}$ for thermal cross sections, TEMPEST ${ }^{(16)}$ for thermal diffusion coefficient, and $\mathrm{HFN}^{(8)}$ for a one-dimensional, 4-group, diffusiontheory calculation of the neutron leakage from the reactor.

Homogenized cross sections, generated with HRG, THERMOS, and TEMrEST, were used in the diffusion-theory code HFN to calculate the effective multiplication factor. The calculated change in $k_{\text {eff }}$ when $\mathrm{D}_{2} 0$ replaces the safety rod cell which contains lucite is $48,2 \mathrm{mk}$, and the change in $\mathrm{k}_{\text {eff }}$ when $\mathrm{D}_{2} 0$ replaces the safety rod cell without lucite is $41.9 \mathrm{mk}$. The safety rod cell considered in the calculations includes the thimble into which the cadmium-coated safety rod is inserted. To compare the calculated results with measured results we must subtract from the calculated results the $\Delta k$ eff 


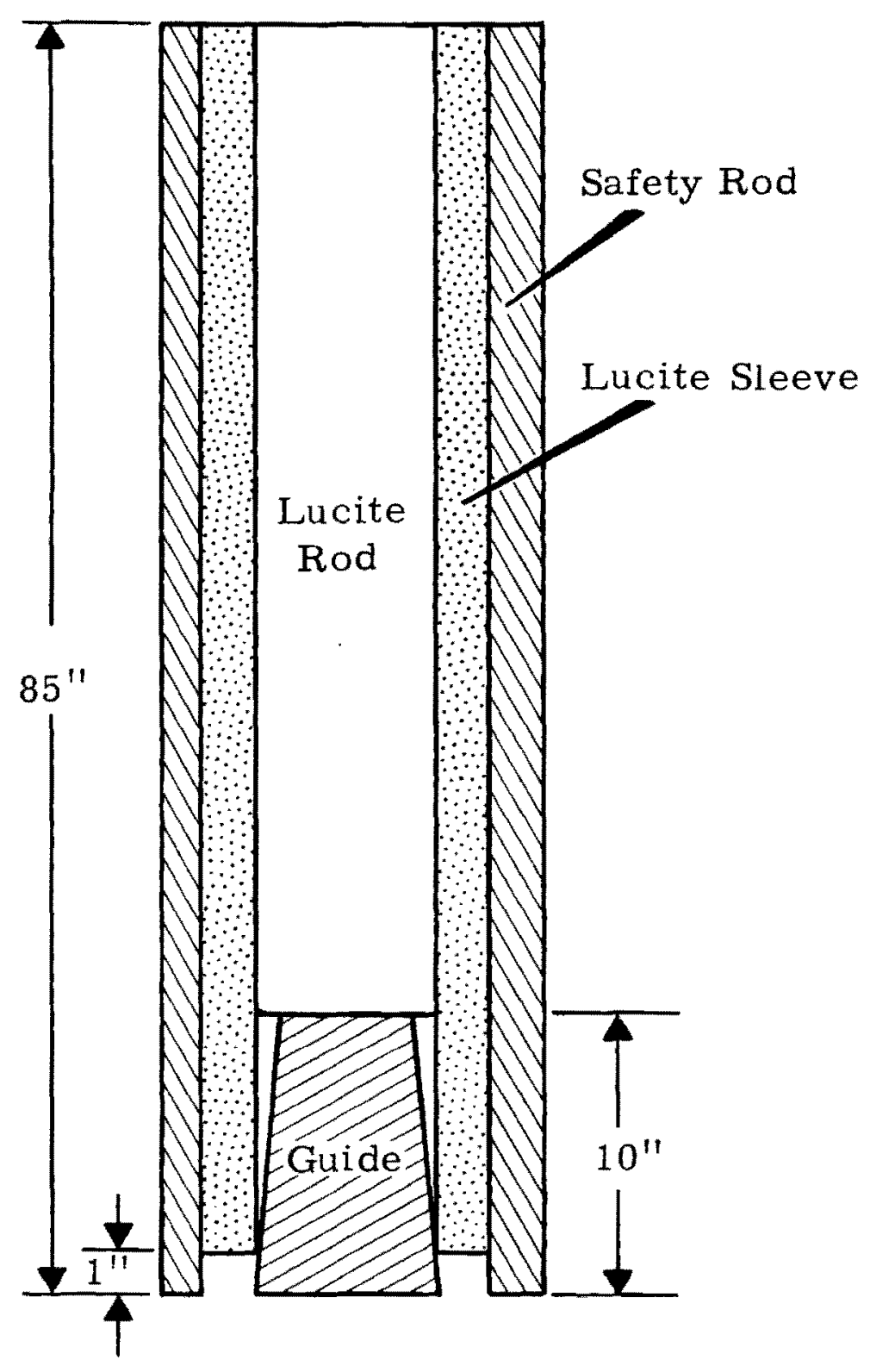

Figure V

The Arrangement of the Lucite Inside the Safety Rod 
produced when the thimble is replaced by $\mathrm{D}_{2} 0$; namely, $1.5 \mathrm{mk}$. When this is done, the calculated worth of the safety rod with no lucite is $40.4 \mathrm{mk}$ and the calculated worth of the safety rod containing lucite is $46.7 \mathrm{mk}$. The calculated effect of filling the interior of the safety rod with lucite is an increase of $15.6 \%$ in the negative worth of the safety rod. The calculated worth of the safety rod agrees well with the measured worth, but the increase in worth produced by adding lucite is overestimated by the calculation.

The rather small effect that the internal scatterer had on the worth of a safety rod indicates that for the PRCF loading which was studied this is not a practical method of increasing the worth of the safety system. However, the effect of adding lucite would be greater in a loading in which the ratio of epicadmium neutrons to subcadmium neutrons is greater than in this core.

Effective multiplication factors, calculated for the present core using the series of computer codes HRG, THERMOS, TEMPEST, and HFN, are $\sim 1.2 \%$ higher than experimental values. The worth of a central safety rod, as calculated with these codes, agrees well with the measured worth; however, the decrease in reactivity produced by adding lucite to the interior of the safety rod is over-estimated.

PCTR Experiments - N. A. Hill

Introduction and Results

The experiments described in this section are being conducted in the Physical Constants Testing Reactor (PCTR) as a part of the study of plutonium utilization in thermal reactors. The experiments contain $\mathrm{PuO}_{2}-\mathrm{UO}_{2}$ fuel in several configurations; 19-rod clusters in square graphite cells and single rods in square graphite cells, and single rods in water moderated cells. One fuel composition was used in the 19-rod geometry for two pitches; 6.5 inches and 8.375 inches. Two fuel compositions were used in the single rod geometry for two pitches; 2.0 inches and 4.0 inches. A third fuel composition containing varying sizes of $\mathrm{PuO}_{2}$ particles was used in the single rod geometry for the 4.0 inch pitch lattice. A water tank has been designed and built for conducting light water moderator experiments in the PCTR. 
The results of the experiments include values of the infinite medium neutron multiplication factor $\left(k_{\infty}\right)$. An adjoint weighted excess neutron production cross section $\left(<\sum_{p}>\right)^{(18)}$ was obtained for four lattices. Relative plutonium and uranium fission rates in the fuel were measured with plutonium and uranium foils.

The initial results of the $\mathrm{PuO}_{2}$ particle sizes versus reactivity indicate that the reactivity decreases as the size is increased from $100 \mu$ to $350 \mu$ for the fuel composition used $\left(2.0 \mathrm{wt} \% \mathrm{PuO}_{2} ; 8.05 \mathrm{wt} \% \mathrm{Pu}^{240}\right)$.

The experimental values of $k_{\infty}$ are summarized in Table IV. The values of $\left\langle\sum_{\rho}>\right.$ are given in Table $V$.

Description of Experiments

The PCTR has a 41.25 inch by 41.25 inch by 37.5 inch cavity into which test lattices are placed. The test lattices for these experiments were $3 \times 3$ cell arrays for the 19-rod cluster experiments and $8 \times 8$ cell arrays for the single rod experiments.

Figures VI and VII show the reactor loading for the 6.5 inch and the 4.0 inch lattices, respectively.

The experiments containing 19-fuel rod clusters ${ }^{(19)}$ (e.g., Figure VI had eight cells surrounding the central test cell in the radial direction and a short buffer cell on each end in the axial direction).

The correct amount of copper is determined from the null reactivity technique when the central cell has the neutron energy distribution of a cell in an infinite array of like cells. This criterion was satisfied in these experiments by changing the reactor loading around the test lattice until the gold cadmium ratio of the test cell matched the cadmium ratios of the surrounding buffer cells.

Figures VI and VII show the placement of the flux matching fue wetween the test lattice and the PCTR driver fuel for the purpose of matching the gold cadmium ratios.

(18) Hill, N. A., Lippincott, E. P., Neuman, D. F., Lanning, D. D., Heineman, R. E., "Comparisons of PCTR Measurements Using Unpoisoned and Poisoned Techniques on $\mathrm{PuO}_{2}-\mathrm{UO}_{2}$ Graphite Systems," BNWL-472 (1967).

(19) Thornbury, T. B., Hill, N. A., "Determination of $\mathrm{k}_{\infty}$ for a $\mathrm{PuO}_{2}-\mathrm{UO}_{2}$ Graphite Lattice," Trans. An. Nucl. Soc., Vol. 8, No. 1, June 1965. 


\section{Table IV}

Experimental Values of $k_{\infty}$

\begin{tabular}{|c|c|c|c|c|c|}
\hline \multicolumn{2}{|c|}{ Fuel } & \multicolumn{2}{|c|}{ 19-Rod Clusters } & & \\
\hline $\mathrm{PuO}_{2}$ & $\mathrm{Pu}^{240}$ & & & & \multicolumn{2}{c|}{ Single Rod } \\
\hline $\begin{array}{c}\mathrm{PuO}_{2}-\mathrm{UO}_{2} \\
(\mathrm{wt} \%)\end{array}$ & $\begin{array}{c}\mathrm{Pu} \\
(\mathrm{wt} \%)\end{array}$ & $\begin{array}{c}6.5 \text { inch } \\
\text { Pitch }\end{array}$ & $\begin{array}{c}8.375 \text { inch } \\
\text { Pitch }\end{array}$ & $\begin{array}{c}2.0 \text { inch } \\
\text { Pitch } \\
\text { Pitch }\end{array}$ \\
\hline 9 & 7.24 & 0.95 & 1.21 & 1.104 & 1.339 \\
\hline 2.6 & 29.34 & - & - & - & 1.376 \\
\hline
\end{tabular}


Table V

Lattice Pitch $\quad \frac{\mathrm{PuO}_{2}}{\mathrm{PuO}_{2}-\mathrm{UO}_{2}} \quad \frac{\mathrm{Pu}^{240}}{\mathrm{Pu}} \quad \frac{\mathrm{U}^{235}}{\mathrm{U}} \quad<\sum_{\rho}{ }_{0}$

\begin{tabular}{crrrr}
\hline Inches & wt\% & at\% & \multicolumn{1}{c}{$\mathrm{cm}^{-1}$} \\
\hline 2.0 & .9 & 7.24 & .234 & $3.1 \pm 0.1 \times 10^{-4}$ \\
2.0 & 2.6 & 29.34 & .182 & $-2.8 \pm 0.2 \times 10^{-4}$ \\
4.0 & .9 & 7.24 & .234 & $1.21 \pm 0.02 \times 10^{-3}$ \\
4.0 & 2.6 & 29.34 & .182 & $2.47 \pm .005 \times 10^{-3}$ \\
\hline
\end{tabular}

Reference (18) describes the normalization and usefulness of $\left\langle\sum_{p}\right\rangle_{0}$. 


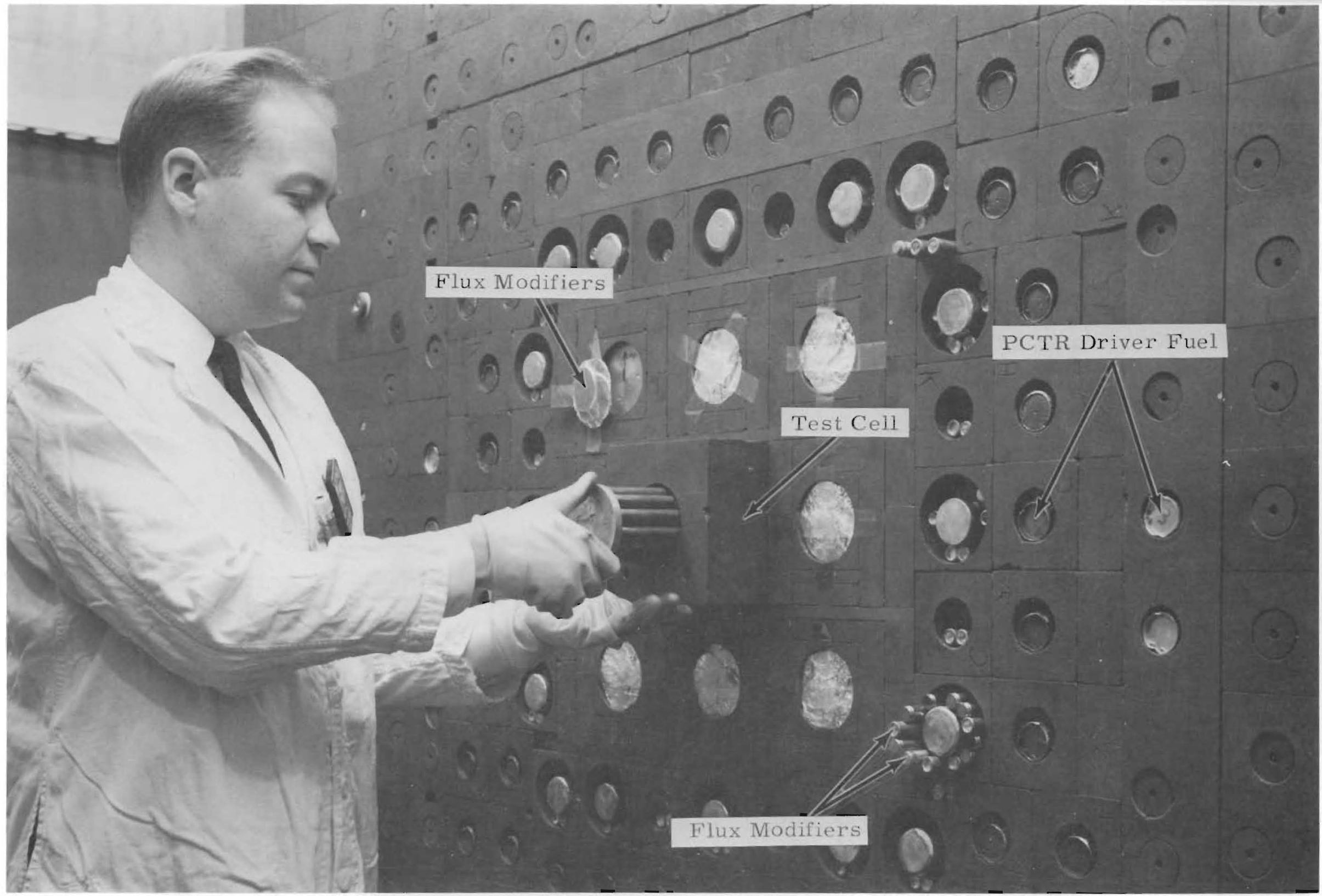

$\stackrel{\omega}{\dot{\alpha}}$

Figure VI

PCTR with 6.5" Pitch Lattice in Test Core with $\mathrm{PuO}_{2}-\mathrm{UO}_{2}$ Fuel Bundles 


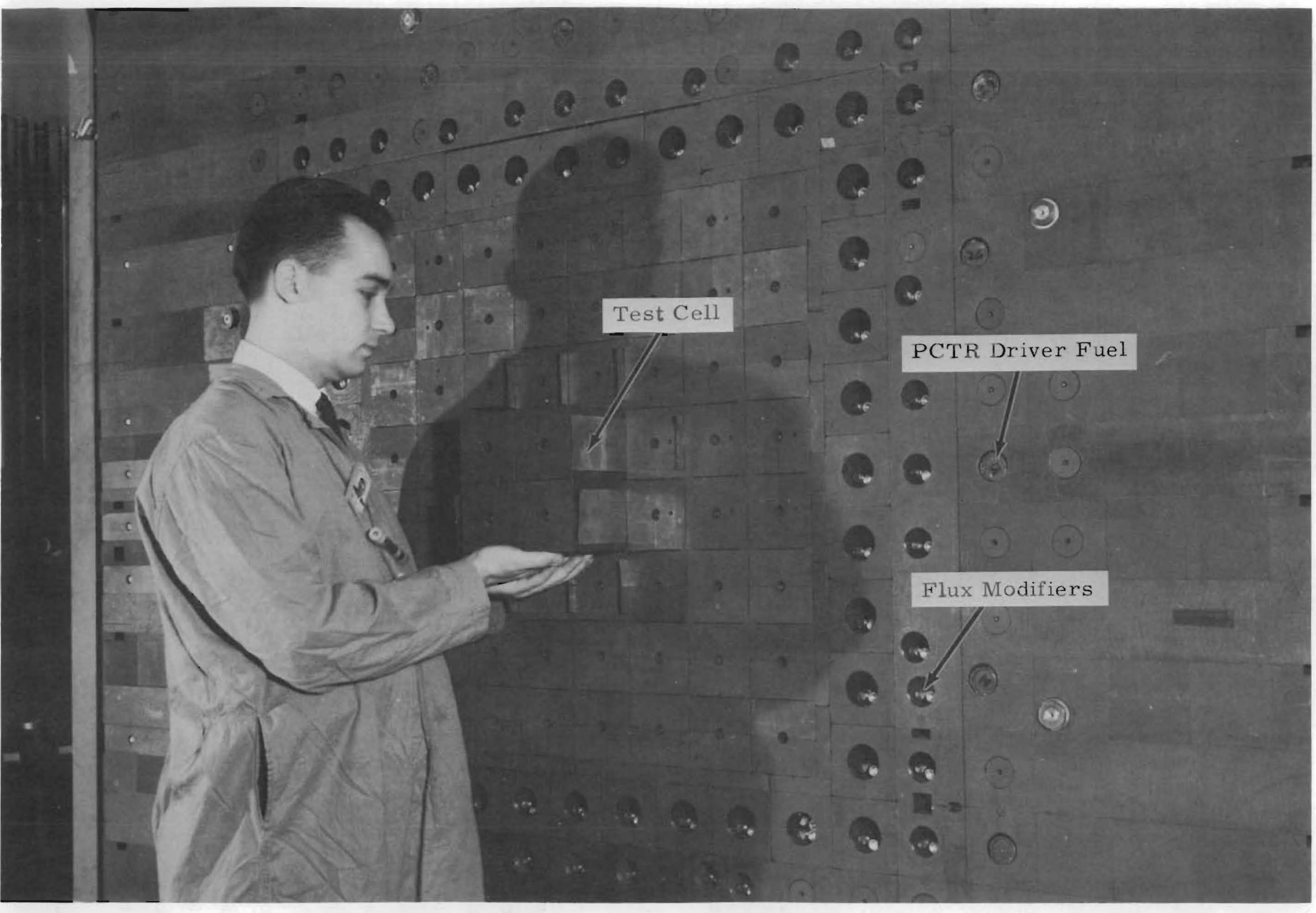

Figure VII

PCTR with 4.0" Pitch Lattice in Test Core with $\mathrm{PuO}_{2}-\mathrm{UO}_{2}$ Fuel Rods 
The test cells for the null reactivity measurements are shown in Figure VII. The slots provided in the lattice for copper poison are shown in Figure VII with a few sample strips of copper inserted.

A reactivity series was done for most of the reactor loadings for which gold cadmium ratios were measured. A reactivity series consisted of measuring the reactivity worth of three quantities:

1. The central test cell $\left(\Delta \rho_{c e l l}\right)$, including any copper $\left(M_{c u}\right)$ loaded in the slots on the boundaries.

2. A small increment of copper on the boundary ( $\Delta \rho_{c u}$ bound, and

3. A small amount of copper in the cavity $\left(\Delta \rho_{c u} \text { void }\right)^{c u}$, which is vacated by the central supercell when it is out of the reactor.

The three quantities, $\Delta \rho_{c e l l}, \Delta \rho_{c u}$ bound, and $\Delta \rho_{c u}$ void, were combined to calculate the amount of copper $\left(\Delta_{c u}\right)$ which must be added to or subtracted from the copper already loaded $\left(\mathrm{M}_{\mathrm{Cu}}\right)$ on the test cell so that the null reactivity condition could be satisfied.

Each reactivity series gave an estimate for the mass of copper, Mo, required to absorb the excess neutrons of the test cell for the respective gold cadmium ratio measurements.

The relative reaction rates of the test cell components were also determined in the match conditions. Figures VIII and IX show two of the central test cells which were prepared for detector traverses. The fission rates in the plutonium were measured by inserting dilute Pu-Al foils between specially designed separable fuel elements. The effective subcadmium (<.64 ev) absorption rates in the $1 / \mathrm{v}$ absorbers were monitored with copper foils whose activities were corrected for epi-cadmium activity by measured cadmium ratios. The subcadmium absorption rates in all cell components were normalized to the total production rates in the cells for both the poisoned and unpoisoned cases. A small correction is included for the epi-cadmium absorption in the copper which is multiplied by an estimated resonance escape probability and normalized to the total productions for the poisoned cases. The effective subcadmium capture to fission cross section ratio for $\mathrm{Pu}^{239}$ was calculated by the THERMOS ${ }^{(20)}$ computer code using

(20) Honeck, H. C., "THERMOS, A Thermalization Transport Theory Code for Reactor Lattice Calculations," BNL-5826, September 1961. 


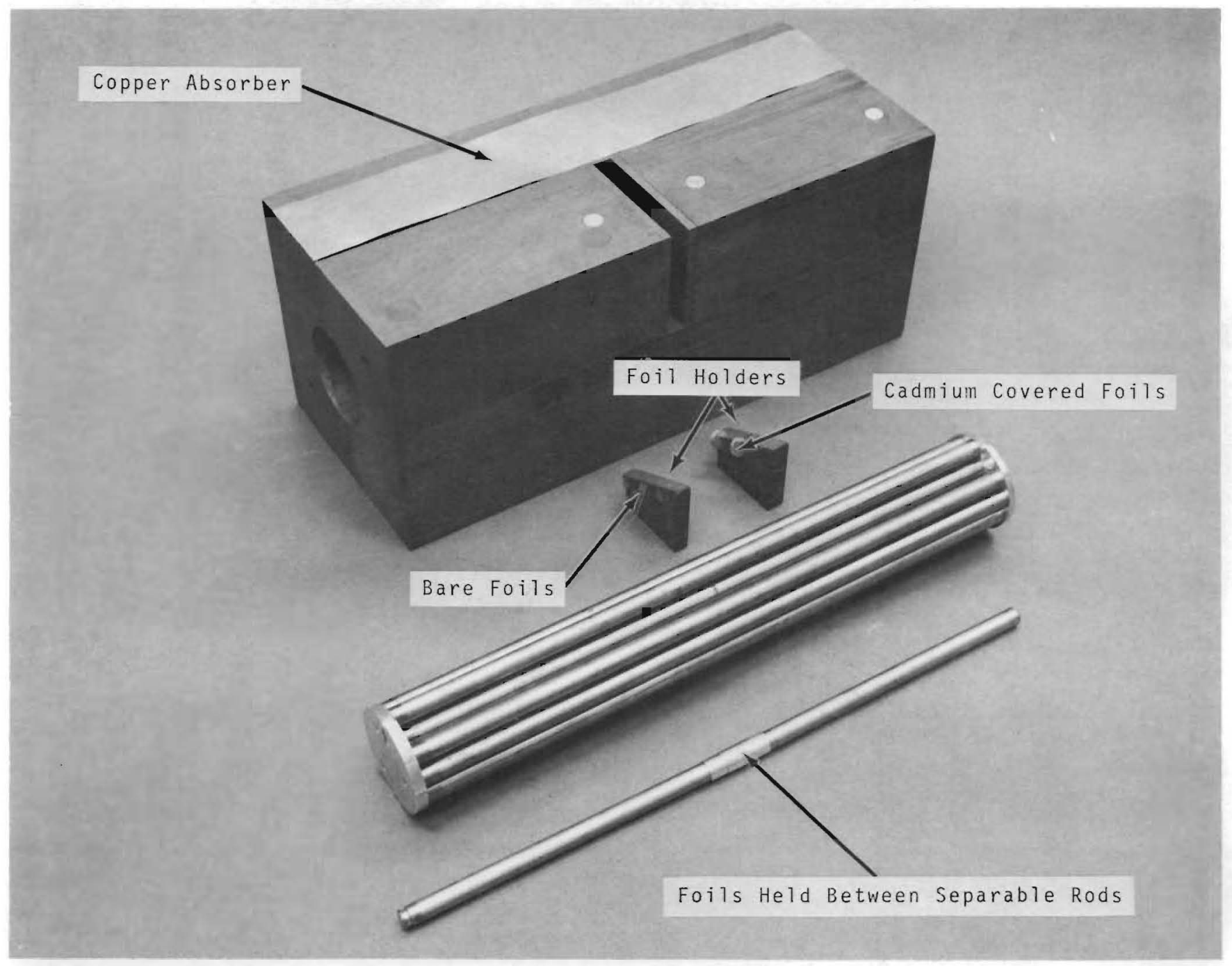

FIGURE VIII

Central Test Cell Used for Foil Traverses - Nineteen Rod Cluster Experiments 


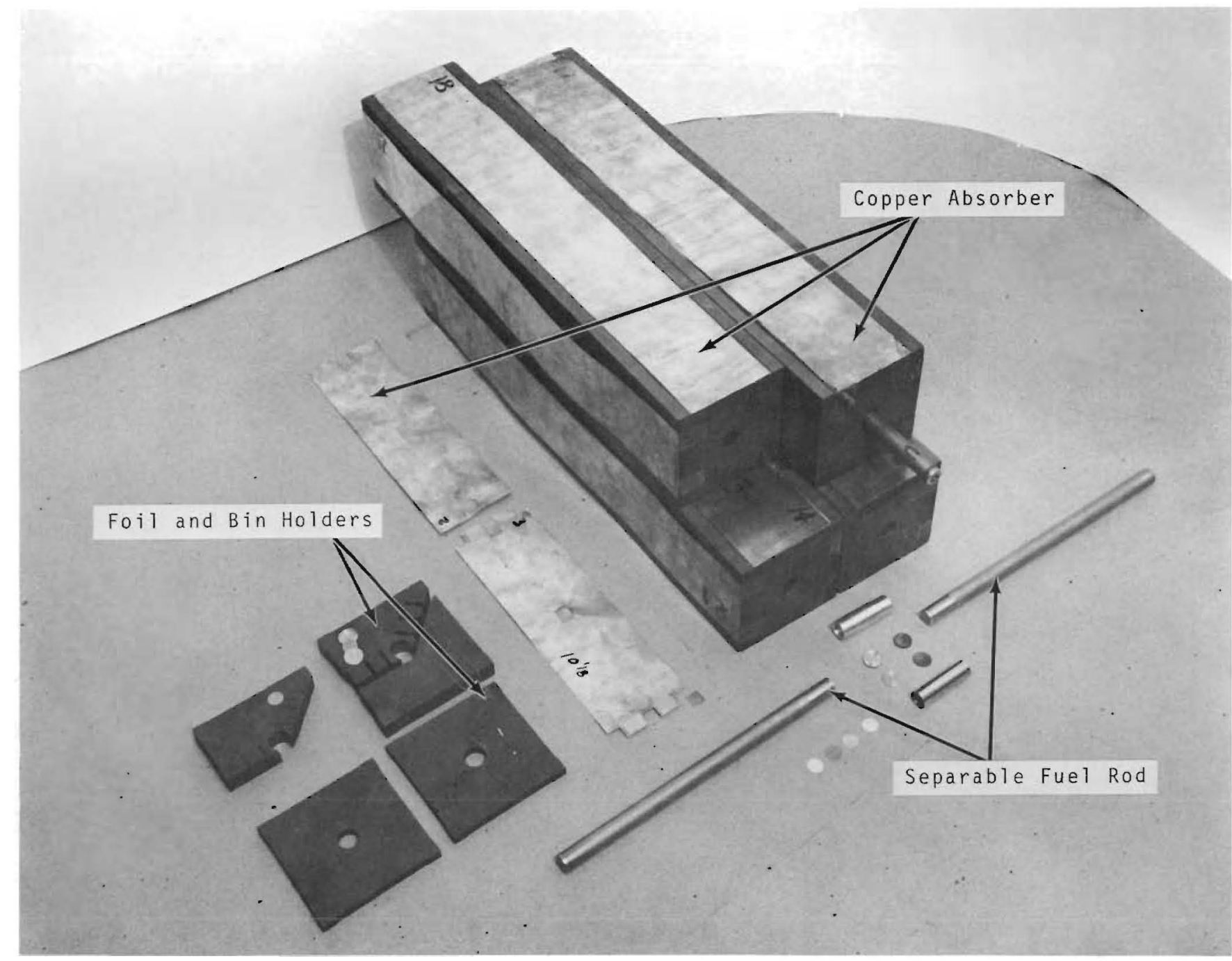


experimentally determined copper concentrations in the poisoned cases. The Determination of $k_{\infty}$ From These Experiments

The method of analysis to obtain $k_{\infty}$ has been described in previous documents. (3)(18) The presence of plutonium in the system required a careful review of the definition of $k_{\infty}$. The values of $k_{\infty}$ are derived from the activation ratios normalized to the thermal column activations where the cross sections are known. These values of $\mathrm{k}_{\infty}$, when multiplied by the appropriate leakage terms from a two-group analysis, yield values of $k_{\text {eff }}$ defined as the total neutron production divided by the sum of the total neutron loss due to absorption and leakage. This expression for evaluating $\mathrm{k}_{\infty}$ from the experimental data is given in reference (18), where the relation between the calculated $k_{\infty}$ and the defined $k_{\text {eff }}$ is also presented.

Light Water Moderator Experiments

Figure $X$ shows the water tank in the core of the PCTR. The design of the first experiment in the water tank is complete. Reactivity changes due to increasing the $\mathrm{PuO}_{2}$ particle size will be determined in $\mathrm{H}_{2} \mathrm{O}$ for the same fuel used to determine the effect in graphite. The pitch of the first lattice in $\mathrm{H}_{2} \mathrm{O}$ will be 1.0 inch.

\section{$\underline{\text { PRTR Batch Core Experiment }}$}

\section{P-6 PRTR Batch Core Experiment - R. I. Smith}

A large-scale burnup experiment (the Batch Core Experiment) ${ }^{(21)}$ has been initiated in the Plutonium Recycle Test Reactor (PRTR). (22) This experiment is providing data relating the reactivity characteristics of the core and the isotopic composition of the fuel in the core as a function of the exposure of the fuel. The basic fuel loading will remain essentially unperturbed to the end of the core reactivity lifetime, thus providing a unique set of data for use in checking methods of calculating reactivity lifetimes of reactor cores. Another important aspect of the experiment is

(21) Worden, J. R., Purcell, w. L., Schmid, L. C., "Physics Experiment, High Power Density Core of the PRTR," BNWL-221, Battelle-Northwest (1966). Fresheey, M. D., Sharp, R. E., Skavdahe, R. E., "Plutonium Utilization Program: PRTR Irradiation Plans," BNWL-314, Battelle-Northwest (1966).

(22) Wittenbrock, N. G., et al, "Plutonium Recycle Test Reactor, Final Safeguards Analysis," H(w-61236, Hanford Works (1959). 


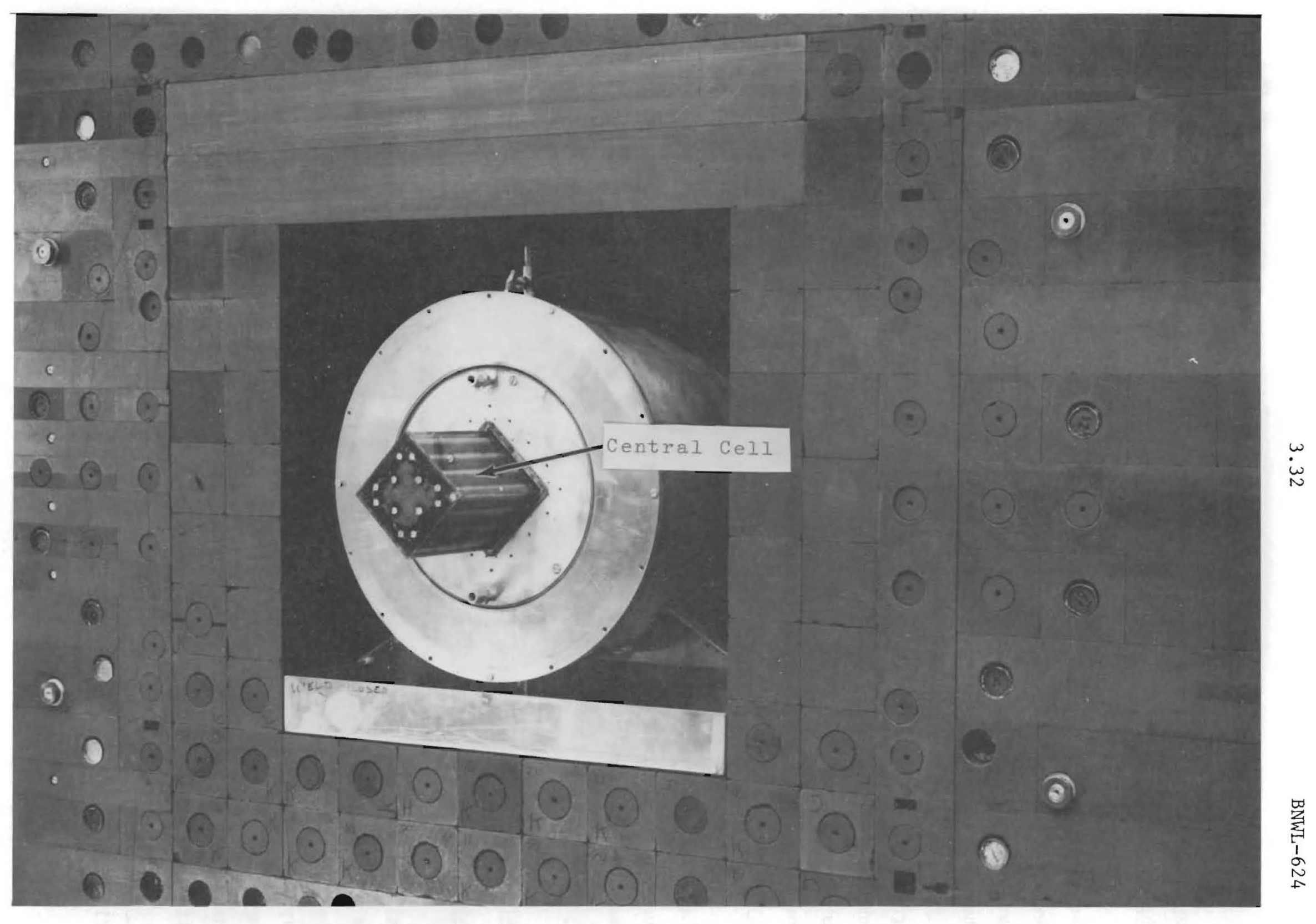

Figure $\mathrm{X}$

- PCTR With Light Water Tank Centered in the Test Core 
the simultaneous irradiation of a statistically-significant number of plutonium-bearing, packed-particle fuel elements at power densities similar to those in an operating power reactor.

The fuel elements for the Batch Core Experiment are 19-rod clusters of vibrationally-compacted $\mathrm{UO}_{2}-2 \mathrm{wt} \% \mathrm{PuO}_{2}$ rods. ${ }^{(23)}$ The fuel in each rod is 0.505 inches in diameter and 58-1/2 inches in length, and is contained in tubes of Zircaloy-2 which have wall thicknesses of 0.030 inches. This same fuel has been studied previously ${ }^{(24)}$ in the Plutonium Recycle Critical Facility (PRCF).

The basic core for the physics experiment occupies the central fifty-five channels in the eighty-five channel core of the PRTR. This core provides the large excess reactivity ( 260 milli-k) necessary to obtain a planned full power lifetime of about one year (at $100 \%$ operating efficiency). The excess reactivity is controlled by dissolving boron, enriched to $92 \% 10 \mathrm{~B}$, in the $\mathrm{D}_{2} \mathrm{O}$ moderator. The $\mathrm{D}_{2} \mathrm{O}$ coolant is not borated. Twelve additional $\mathrm{UO}_{2}-2 \mathrm{wt} \%$ $\mathrm{PuO}_{2}$ elements are charged to form a buffer zone between the physics core and the irradiated elements from earlier PRTR operations which will make up the balance of the core for the power phase of the experiment.

The first phase of the experiment has been completed (25) and consisted of an extensive set of tests at zero power during the initial loading of the 55 element core, to establish the physics characteristics of the unirradiated core.

Critical Tests - R. I. Smith and J.W. Kutcher

Fuel loading began on July 16, 1966 and initial criticality was achieved with nine fuel elements on July 19. Loading and testing continued on an around-the-clock basis until the basic 55 element core had been

(23) Keenan, J. P., Sharp, R. E., "PRTR quality Control System," BNWL-349, Battelle-Northwest (1967).

(24) Kutcher, J. W., et al, "Critical Experiments with PuO $-\mathrm{UO}_{2}$ Fuel and D, O Moderator," Trans. Am. Nucl. Soc., 9, 2448 (1966).

(25) Smith, R. I., Kutcher, J, W., Lauby, J. H., "Critical Experiments with The $40_{2}-2$ wt: PuO Batch Core in the PRTR," Trans. Am. Nucl. SOC., 10, $1,185^{2}: 1967$. 
charged and all major tests had been completed on August 25, 1966. Additional measurements were performed at various times in the interval prior to receipt of authorization to begin Power Tests in December, 1966.

The measurements performed during the Critical Test period included: the critical number of elements for boron concentrations in the moderator ranging from zero to about 21 wppm ${ }^{0} \mathrm{~B}$ in $\mathrm{D}_{2} \mathrm{O}$ and thermal neutron flux distributions axially in the core (Table VI), moderator level coefficients of reactivity over a 25 inch range of critical moderator heights at several boron concentrations (Figure XI) reactivity effects due to loss of coolant from the fuel channels (Table VII), the integrated boron worth and the differential boron worth as a function of boron concentration in the moderator (Figure XII).

Additional measurements were made to determine (by gamma scanning) the relative power match between fuel rods in the center channel and rods in elements in the first ring of channels in PRTR. The reactivity effects due to changes in coolant, and to changes in configuration of the special fuel element designed for use in the Fuel Element Rupture Test Facility (FERTF) have also been measured. The results of these measurements are summarized in Table VIII.

No surprises were encountered during the critical test program. The boron concentration in the $\mathrm{D}_{2} 0$ moderator needed to compensate for the initial excess reactivity of the core agreed with the predicted concentration requirements to within a few percent. In general, all parameters measured during the tests were in reasonable agreement with the values which had been predicted earlier. $(21)$

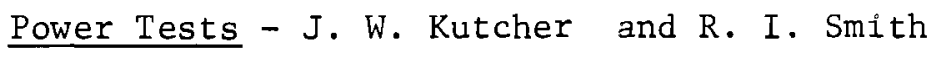

A series of power tests was conducted when the reactor loading was completed and power was increased to its operating level of approximately $50 \mathrm{MW}$. These tests were primarily designed to verify predicted operational characteristics of the PRTR with the Batch Core Loading, but included those physics tests which required power operation.

For normal power operation of the PRTR, the central channel of the reactor was connected to the Fuel Element Rupture Test Facility (FERTF) and was cooled with $\mathrm{H}_{2} 0$. During the power tests the FERTF contained a 19-rod 


\section{Table VI}

No. of Fuel

Elements

9

12

16

23

31

55

55
Boron-10

Concentration (wppm)

0

$$
2.6 \pm 0.03
$$

$5.6 \pm 0.03$

$10.2 \pm 0.03$

$14.1 \pm 0.03$

$14.1 \pm 0.03$

$20.9 \pm 0.03$
Critical

Moderator Level

(Inches)

$98.5 \pm 0.02$

$99.75 \pm 0.02$

$94.55=0.02$

$95.15=0.02$

$96.7=0.02$

$72.2=0.02$

$98.0 \div 0.02$
Axial

Peak-to-Average

Flux Ratio

$1.28 \pm 0.02$

$1.29 \pm 0.02$

$1.34=0.02$

$1.34 \pm 0.02$

$1.32 \pm 0.02$

$1.86 \div 0.02$

$1.34 \pm 0.02$

$\underline{\text { Table VII }}$

Core Coolant Worth Measurements

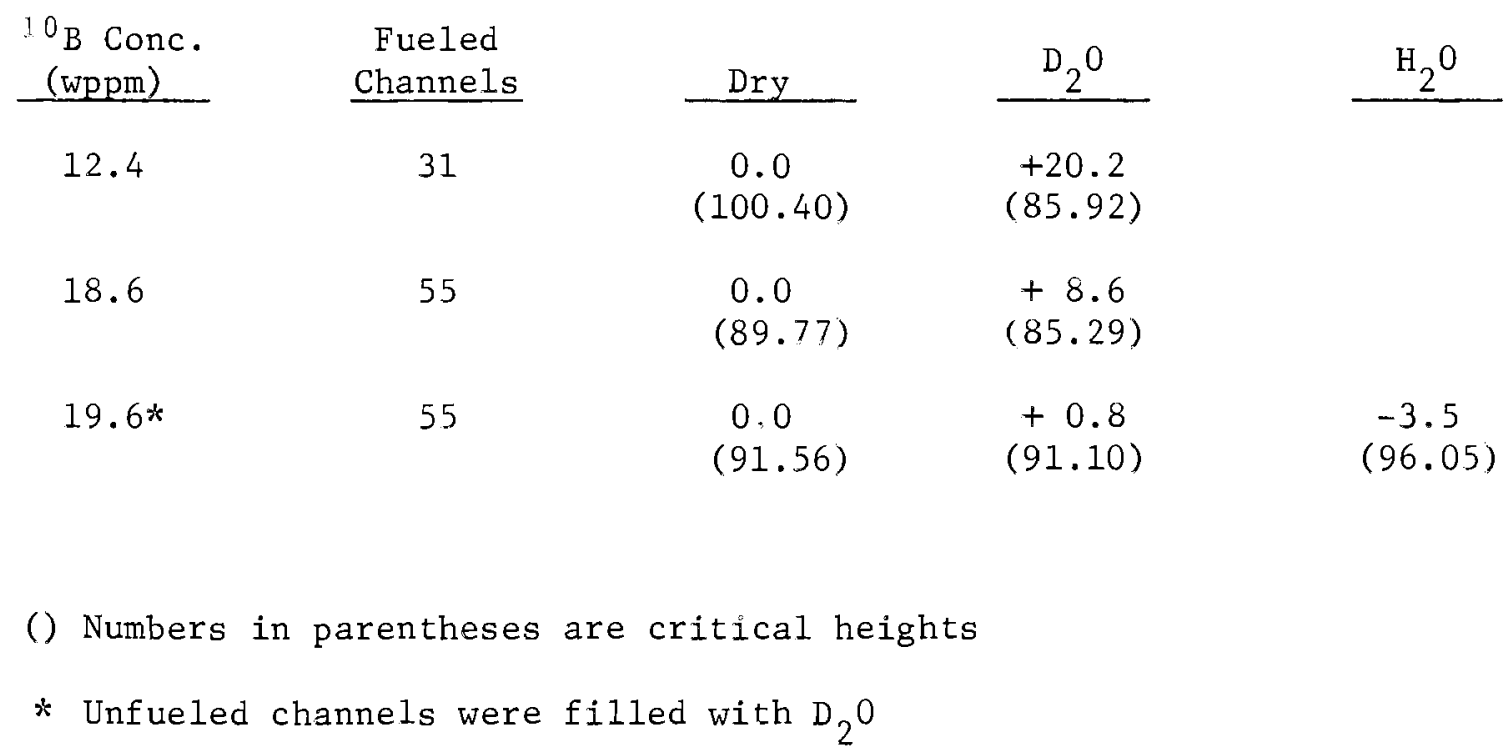


Moderator Level Coefficient of Reactivity (milli-k/inch)

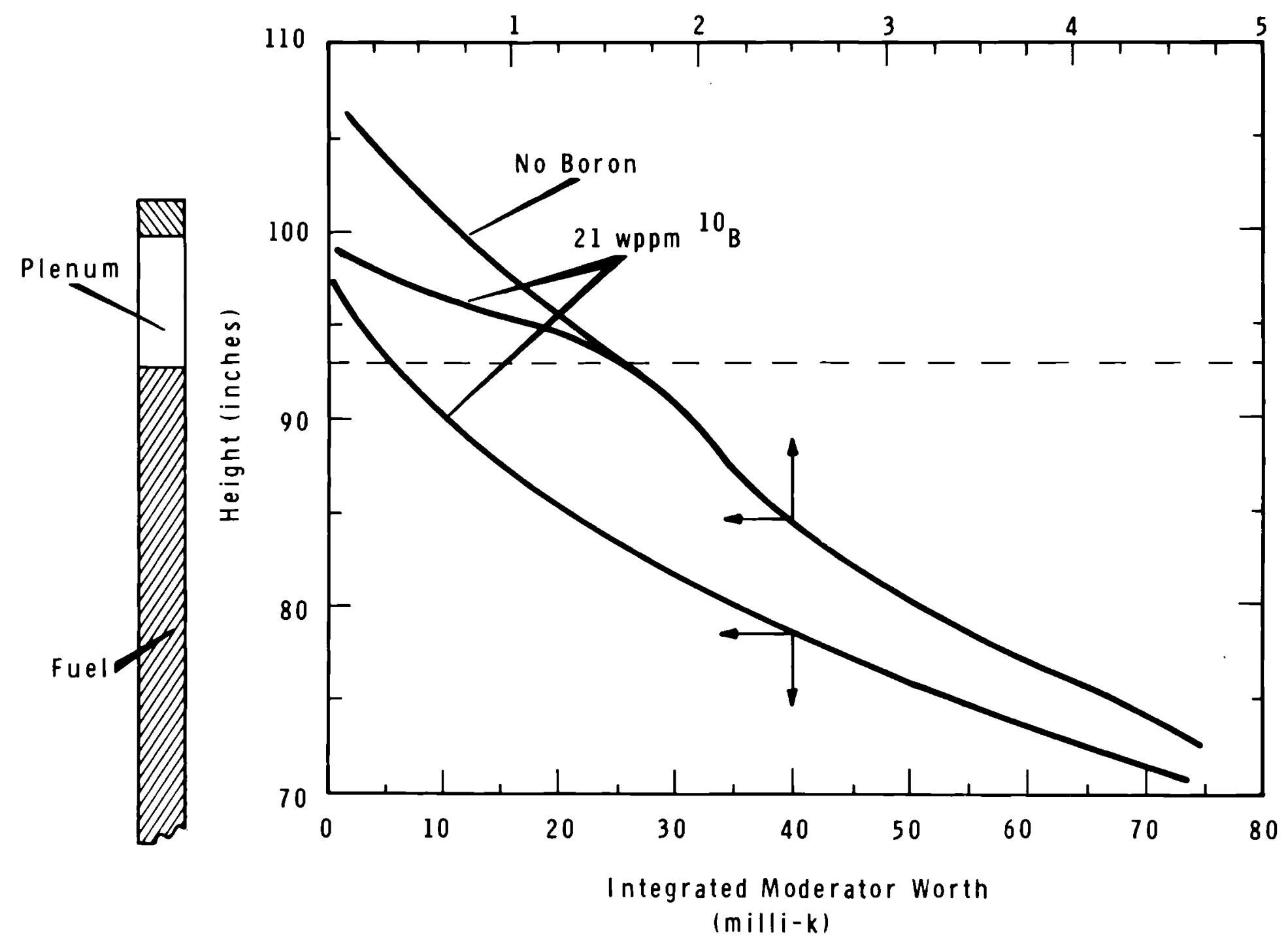

Figure XI 


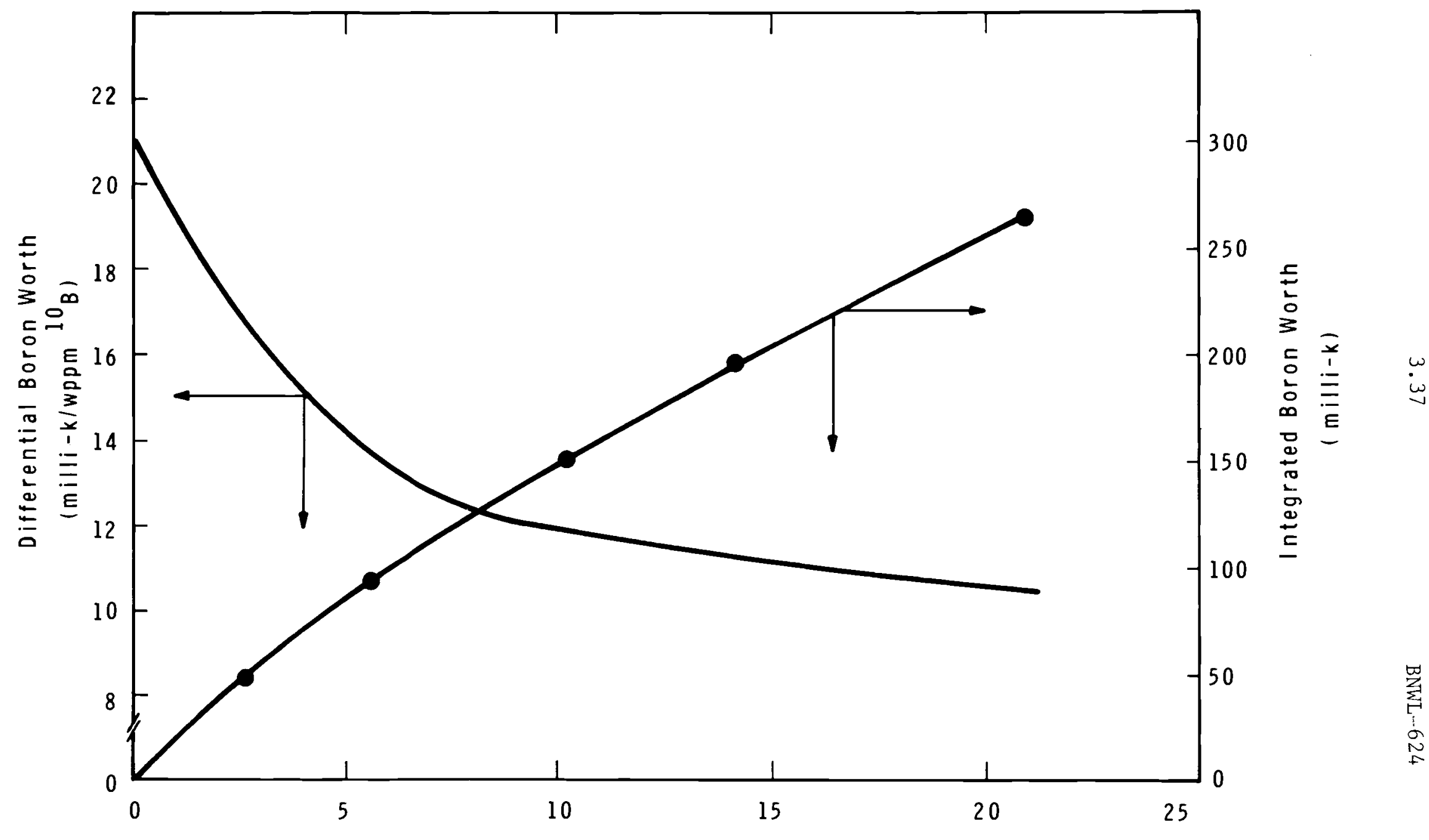

Boron Concentration in $D_{2} 0$ Moderator (wppm ${ }^{10} \mathrm{~B}$ ) 


\section{Table VIII}

\begin{tabular}{|c|c|c|c|c|c|c|c|c|}
\hline Fuel Type & Coolant & $\begin{array}{l}\text { No. of Rods } \\
\text { in FERTF } \\
\text { Element } \\
\end{array}$ & $\begin{array}{l}\text { Stainless Steel } \\
\text { Basket Thickness } \\
\text { (inches) }\end{array}$ & $\begin{array}{l}\text { Center } \\
\text { of FERTF } \\
\text { Element } \\
\end{array}$ & $\frac{\text { Power Ratio, }}{\text { Measured }}$ & $\frac{\text { FERTF/list Ring F.E. }}{\text { Calculated }}$ & $\begin{array}{c}\text { Void } \\
\text { Worth } \\
\text { (m1111-k) } \\
\end{array}$ & $\begin{array}{c}\text { FERTF } \\
\text { Element } \\
\text { Worth } \\
\text { (milli-k) } \\
\end{array}$ \\
\hline $\mathrm{UO}_{2}$ & $\mathrm{H}_{2} \mathrm{O}$ & 6 & 0.125 & $\mathrm{H}_{2} \mathrm{O}$ & $0.62 \pm 0.05$ & 0.55 & $+4.8 \pm 0.2$ & - \\
\hline $\mathrm{UO}_{2}-3 \mathrm{wt} \% \mathrm{PuO}_{2}$ & $"$ & 6 & 0.125 & $\mathrm{H}_{2} \mathrm{O}$ & $1.76 \pm 0.03$ & 1.70 & - & - \\
\hline $\mathrm{UO}_{2}-2$ wt\% $\mathrm{PuO}_{2}$ & " & 6 & 0.125 & $\mathrm{H}_{2} \mathrm{O}$ & $1.53 \pm 0.01$ & 1.48 & $+2.1 \pm 0.2$ & - \\
\hline $\mathrm{UO}_{2}-2 \mathrm{wt} \% \mathrm{PuO}_{2}$ & " & 8 & 0.125 & Has $t-\mathrm{X}$ & $0.95 \pm 0.03$ & 1.01 & $+1.6 \pm 0.2$ & $+6.5 \pm 0.2$ \\
\hline $\mathrm{UO}_{2}-2 \mathrm{wt} \% \mathrm{PuO}_{2}$ & " & 8 & 0.239 & SST & $0.89 \pm 0.04$ & 0.91 & - & $+4.6 \pm 0.2$ \\
\hline $\mathrm{UO}_{2}-2$ wt\% $\mathrm{PuO}_{2}$ & 11 & 8 & 0.239 & Hast-X & $0.90 \pm 0.06$ & 0.90 & - & $+3.7 \pm 0.2$ \\
\hline $\mathrm{UO}_{2}-2 \mathrm{wt} \% \mathrm{PuO}_{2}$ & $"$ & 19 & - & - & 1.09 & 1.13 & $-0.90 \pm 0.2$ & - \\
\hline $\mathrm{UO}_{2}-2$ wt\% $\mathrm{PuO}_{2}$ & $\mathrm{D}_{2} \mathrm{O}$ & 19 & - & - & 0.99 & 1.02 & $-0.02 \pm 0.2$ & - \\
\hline
\end{tabular}


cluster of pelleted $\mathrm{UO}_{2}-2 \mathrm{wt} \% \mathrm{PuO}_{2}$. Twelve additional $\mathrm{UO}_{2}-2$ wt\% $\mathrm{PuO}_{2}$ elements were charged to form a buffer region separating the basic 55 element core and the irradiated elements from earlier PRTR operation that occupied the remainder of the fuel channels in the reactor.

The power test series included: traverse of the peripheral flux chamber thimbles to determine the shape of the flux radially through the $\mathrm{H}_{2} \mathrm{O}$ reflector; axial flux peaking as a function of critical moderator level over the range from 86 to 100 inches (Figure XIII, and Table IX); transient response of the reactor to addition and removal of boron by the chemical shim system (Figure XIV), a detailed examination of the heat removed by each of the reactor coolant systems in order to determine total reactor power (Table $\mathrm{X}$ ); the temperature coefficients of reactivity associated with the fuel + coolant system $\left(-0.019 \mathrm{milli}-\mathrm{k} /{ }^{\circ} \mathrm{F}\right.$ over the range $178-356^{\circ} \mathrm{F}$ ) and the moderator system ( $+0.108 \mathrm{milli-k} /{ }^{\circ} \mathrm{F}$ over the range $92.5-141^{\circ} \mathrm{F}$, with 20 wppm ${ }^{10} \mathrm{~B}$ in the moderator); and measurement of the ratio of the effective delayed neutron fraction to the neutron lifetime, $B / \ell$, at power levels of 250 watts and 1 megawatt, with a sinusoidal reactivity oscillator. The measured ratio was $19.7 \pm 1$, and did not exhibit any significant dependence on reactor power level.

Those power tests which have been completed have, in general, confirmed the predicted operational behavior of the reactor. Further tests are planned to measure growth and decay of fission-product poisoning, and to determine the power coefficient of reactivity.

\section{EBWR Experiment}

An irradiation experiment was conducted in the Experimental Boiling Water Reactor (EBWR) at Argonne National Laboratory (ANL). This experiment is part of a joint ANL-PNL program to demonstrate the utilization of plutonium in a boiling $\mathrm{H}_{2} \mathrm{O}$ power reactor and to obtain useful physics information on the behavior of a plutonium fuel in such a reactor system. Information obtained during this experiment for the plutonium zone will be compared to results of calculations to identify areas of uncertainty in the computation. 


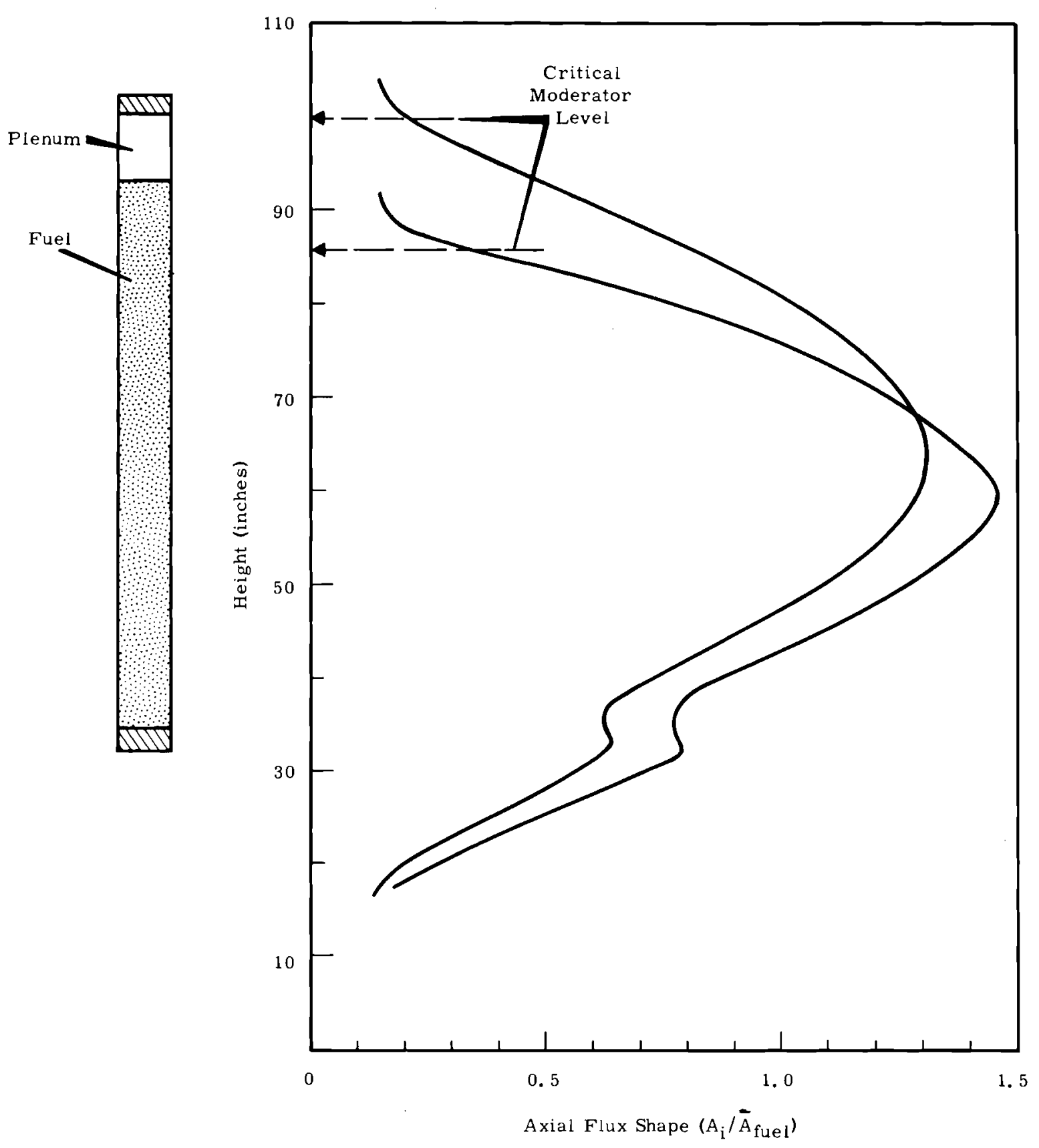

Figure XIII

Axial Flux Shape as a Function of Critical Moderator Height 


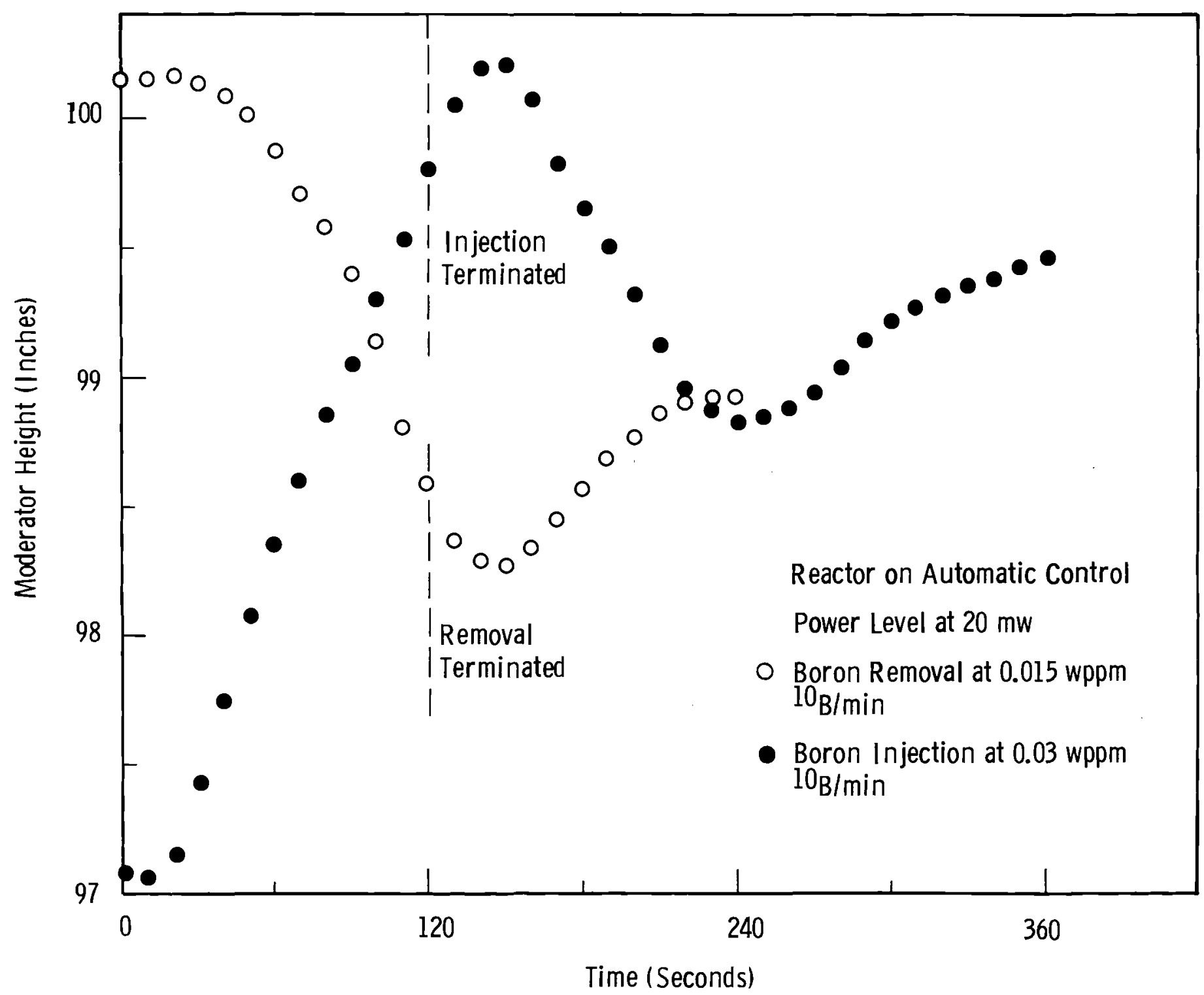


$\underline{\text { Table IX }}$

\section{Axial Flux Peaking}

\begin{tabular}{|c|c|}
\hline $\begin{array}{c}\text { Moderator } \\
\text { Height }\end{array}$ & $\phi_{\text {Max }} / \phi$ ave. \\
\hline 86.0 inches & 1.467 \\
\hline 89.4 & 1.389 \\
\hline 92.0 & 1.357 \\
\hline 95.0 & 1.334 \\
\hline 98.0 & 1.319 \\
\hline 100.0 & 1.312 \\
\hline
\end{tabular}

$\underline{\text { Table X }}$

$\underline{\text { PRTR Power Calculation }}$

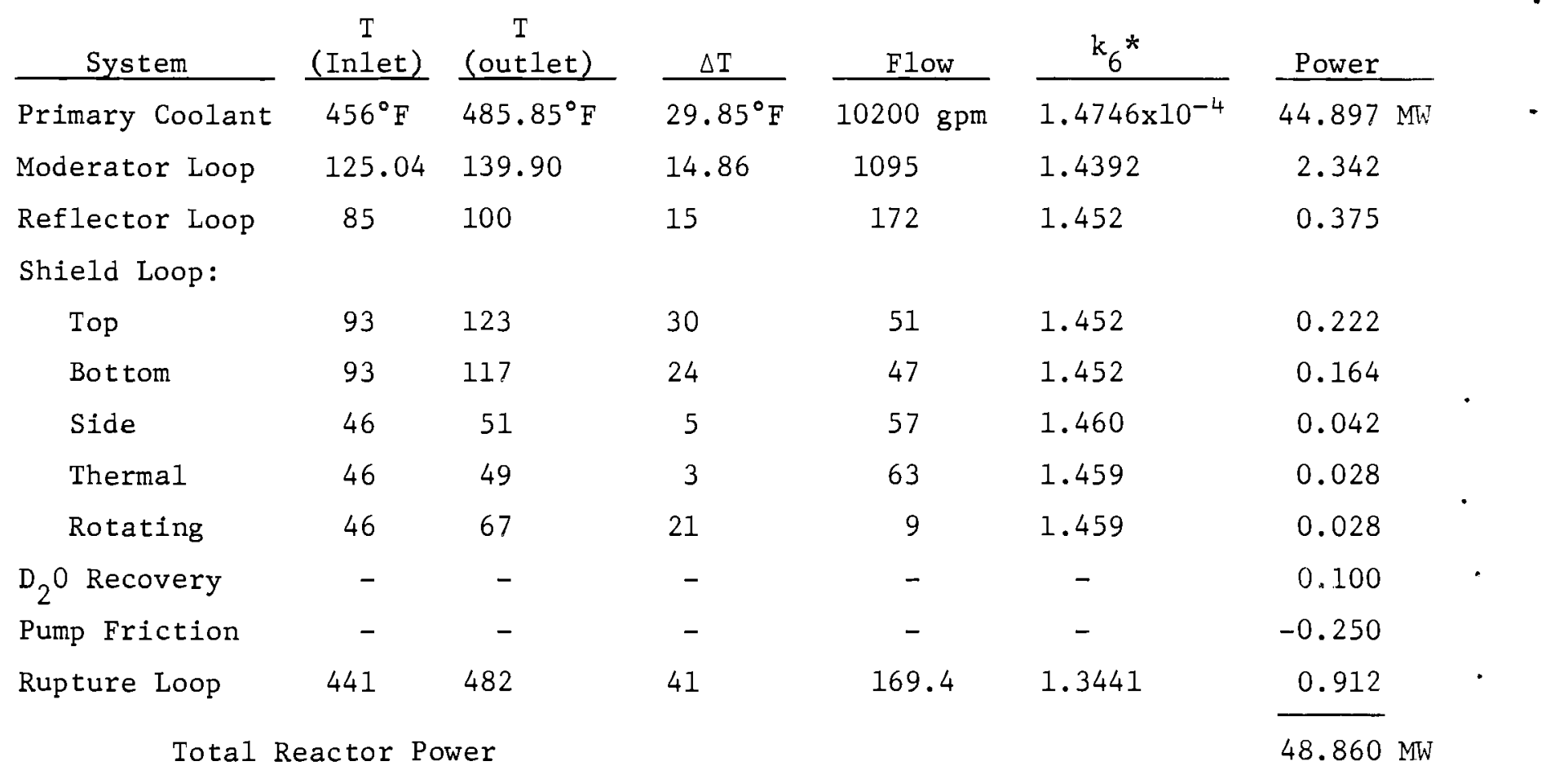

${ }^{*} k_{6}$ is a conversion factor which depends on coolant temperature and density. 
Power Operation History - R. C. Liikala

The power operation of the EBWR is outlined briefly in Table XI. The power operation was terminated on June 29, 1967. The reactor reached $42 \mathrm{MW}$ power level early in November of 1966 and operated until the early part of February, 1967 at this power level. Approvals were received to operate the EBWR at $70 \mathrm{MW}$. During February, experiments were performed to ensure the safe operation of the EBWR at $70 \mathrm{MW}$.

An activation experiment was also performed at the power levels of 42 and $70 \mathrm{MW}$ to aid in determining if a spectral change occurred in this power interval. Power operation at 70 MW was attained during the middle of March and the reactor operated until the end of April at this power level. Intermittent power operation of the EBWR occurred during the month of May due to problems encountered with the EBWR steam system. During the month of June, the reactor was operated at a power level of about 60 MW.

Irradiated Fuel Sampling and Post Irradiation Experiments - R. C. Liikala and U. P. Jenquin

At three stages of burnup of the experiment, a series of rods are removed from the plutonium zone for return to PNL for non-destructive and destructive analysis. The first set of rods were removed in February, 1967 prior to raising the power level to $70 \mathrm{MW}$. The estimated average exposure on these rods is $1300 \mathrm{MWD} /$ tonne. The second series of rods were removed from the EBWR in May, 1967 and the estimated average exposure is 2300 MWD/tonne. The last series of rods is to be removed after the post irradiation experiments are completed. The estimated average exposure of these rods is $2600 \mathrm{MWD} /$ tonne. The series of rods contain the foiding fuels: two $\mathrm{Al}-3.35 \mathrm{wt} \% \mathrm{Pu}$ with one containing $\sim 8 \mathrm{wt} \% \mathrm{Pu}^{2}+0$ and the $\cdots$ iner $-26 \mathrm{wt} \% \mathrm{Pu}^{240}$, one natural $\mathrm{UO}_{2}$, one $\mathrm{UO}_{2}-1.5 \mathrm{wt} \% \mathrm{PuO}_{2}$ with $\sim 26 \mathrm{wt} \% \mathrm{Pu}^{+}+0$, one $\mathrm{UO}_{2}-1.5 \mathrm{wt} \% \mathrm{PuO}_{2}$ with $-20 \mathrm{wt} \% \mathrm{Pu}^{2}-0$, and twelve $\mathrm{UO}_{2}-1.5 \mathrm{wt} \% \mathrm{Pu}$ with $.8 \mathrm{wt} \% \mathrm{Pu}^{240}$. The latter fuel of this series is the normal fuel composition of the EBWR plutonium zone and these rods are selected from various positions in the core so that the spatial distribution of burnup can be obtained from the non-destructive and destructive analysis. 
$\underline{\text { Table XI }}$

Outline of Power Operation EBWR Pu Experiment

\begin{tabular}{|c|c|c|c|}
\hline Date & $\begin{array}{l}\sim \text { Reactor } \\
\text { Exposure } \\
\text { (MWD) } \\
\end{array}$ & $\begin{array}{l}\text { Assumed Power } \\
\text { From Pu Zone } \\
\text { (\% of Reactor Power) } \\
\end{array}$ & $\begin{array}{l}\sim \mathrm{Pu} \text { Zone* } \\
\text { Exposure } \\
\text { (MWD/Tonne) }\end{array}$ \\
\hline Oct. 1966 to Feb. 1967 & 3760 & 35 & 1320 \\
\hline Mar. 1967 to May 1967 & 3140 & 30 & 940 \\
\hline May 1967 & 310 & 25 & 80 \\
\hline \multirow[t]{2}{*}{ June 1967} & 1050 & 25 & 260 \\
\hline & & Total & 2600 \\
\hline
\end{tabular}

* Since there is $\sim$ one tonne of $\mathrm{UO}_{2}-\mathrm{PuO}_{2}$ in the $\mathrm{EBWR}$, the exposures are quoted in megawatt days per metric ton. 
The post irradiation experiments include a determination of boric acid worth, control rod worths, and the rod free-no-boron multiplication for the plutonium zone at room temperature. If the plutonium zone is subcritical (26) the loading is to be augmented with other plutonium fuel assemblies.

Irradiated Fuel Shipments - J. B. Edgar, R. C. Liikala, A. R. Maki, L. D. Williams

A study of utilizing the PRTR shipping cask was made by the PNL Nuclear Safety Specialist to determine if this cask could be licensed for shipping irradiated fuel from ANL to PNL. The study concluded (27) that the PRTR cask could not be modified and approved for interstate shipments of irradiated fuel. Arrangements were made to use the Yankee single element cask ${ }^{(28)}$ for this purpose. A review was made ${ }^{(29)}$ of the hazards associated with using this cask for the irradiated fuel shipments. Approval was granted and the cask has been used for two shipments to date.

The set of pins removed from the EBWR in February were shipped from ANL to PNL in May and the set removed in April were shipped in July. The final shipment of irradiated fuel was made in September. Gamma scanning of the pins are currently underway.

Non-Destructive Analysis - E. S. Murphy and D. E. Christensen

Gamma scanning experiments to determine relative fuel burnup have been irradiated on the set of seventeen EBWR fuel pins which were removed from the reactor in February. The pins are being scanned with a $1-1 / 2$ inch diameter $\mathrm{x} 3$ inch long sodium iodide detector. Two prominent peaks are evident in the gamma spectrum of the pins. One peak at about $500 \mathrm{keV}$ is due mainly to the $513 \mathrm{keV}$ gamma from the decay of ${ }^{106} \mathrm{Rh}$. The other peak

(26) Kier, P. H., private communication.

(27) Letter from C. L. Brown to R. L. Scott, entitled, "Review of PRTR Cask for Off-Site Shipment," November 1, 1966.

(28) James, B., Payne, D. D., and Walchli, H. F., "Experience in the Shipment of Yankee Fuel Assemblies for Post-Irradiation Examination," WCAP-6062, February 1965.

(29) Brown, C. L., "Radiation and Criticality Safety Review of EBWR Fuel Rod Shipments from ANL to PNL," BNWL-CC-1022, 1967. 
at about $750 \mathrm{KeV}$ is due mainly to the 724 and $757 \mathrm{KeV}$ gammas from the decay of ${ }^{95} \mathrm{Zr}$ and the $768 \mathrm{KeV}$ gamma from the decay of ${ }^{95} \mathrm{Nb}$. In the present analysis, the energy threshold of the single channel analyzer is set at $675 \mathrm{KeV}$.

A gamma scan of $\mathrm{UO}_{2}-1.5 \mathrm{wt} \% \mathrm{PuO}_{2}\left(8 \mathrm{wt} \% \mathrm{Pu}^{240}\right)$ fuel pin is shown in Figure XV. The gross count rate has been corrected for background and for the contribution to the total count rate from radioactive zirconium in the cladding. There is a peak in the fuel burnup about 11 inches from the bottom of the fuel. The top ten inches of fuel have experienced very little burnup. This pin is one of the four centermost pins in the plutonium zone of the EBWR. The scan was performed four months after removal of the pin from the reactor. Ganma scan analyses are being made of the other pins removed in February along with those removed from the EBWR in May, 1967.

Analysis of Irradiated Fuels

Non-Destructive Analysis of Fuel Burnup

Underwater Gamma Scanning Facility - D. E. Christensen and E. S. Murphy Introduction

Development of the PNL Gamma Scanner and of the measurement techniques for its use has continued during the past year. Fuel rods of $\mathrm{LO}_{2}, \mathrm{Al}-1.8 \mathrm{wt} \%$ $\mathrm{Pu}$, and $\mathrm{UO}_{2}-0.48 \mathrm{wt} \% \mathrm{PuO}_{2}$ which had been irradiated in the Plutonium Recycle Test Reactor (PRTR) have been examined in course of the development work. More recently, several fuel pins from a fast reactor (described in this report) and selected rods from the fuel burnup experiment in the EBWR have been examined.

Equipment Description

The design of the underwater gamma scanning facility, ${ }^{(30)}$ shown in Figure XVI, permits scanning of irradiated $1 / 2$ inch diameter fuel rods under approximately $6 \mathrm{ft}$. of water in the PRTR basin. The collimator is 105 inches long from source to detector and contains 6 inches of lead

(30) Stringer, J. L., "Gamma Scanner Facility," Quarterly Progress Report Research and Development Program, April, May, June, 1964, HW-83298, $7.1-7.5$ (Nov. 1964). 


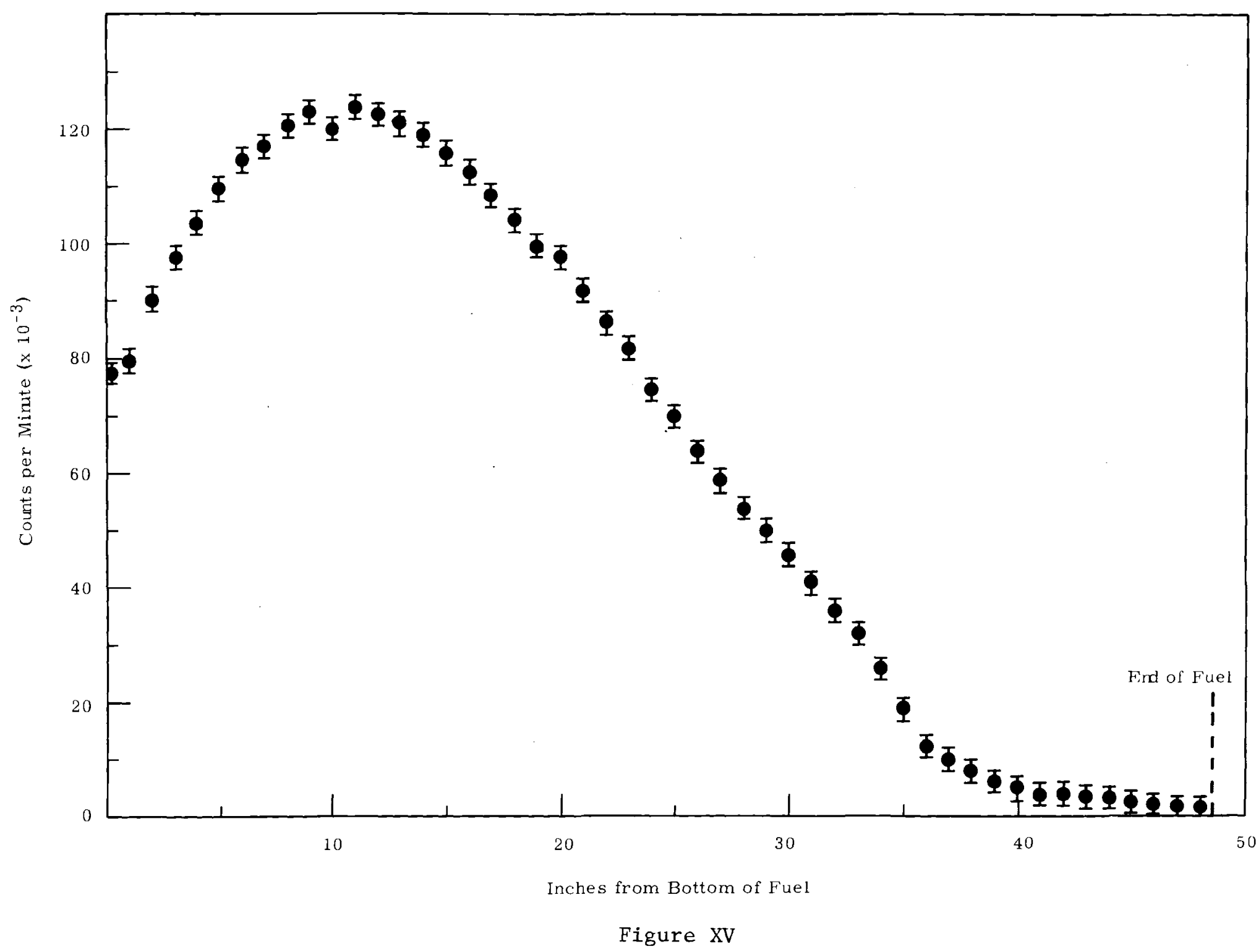

Gamma Scan of EBWR Fuel, Integral Count Above $675 \mathrm{keV}$ 


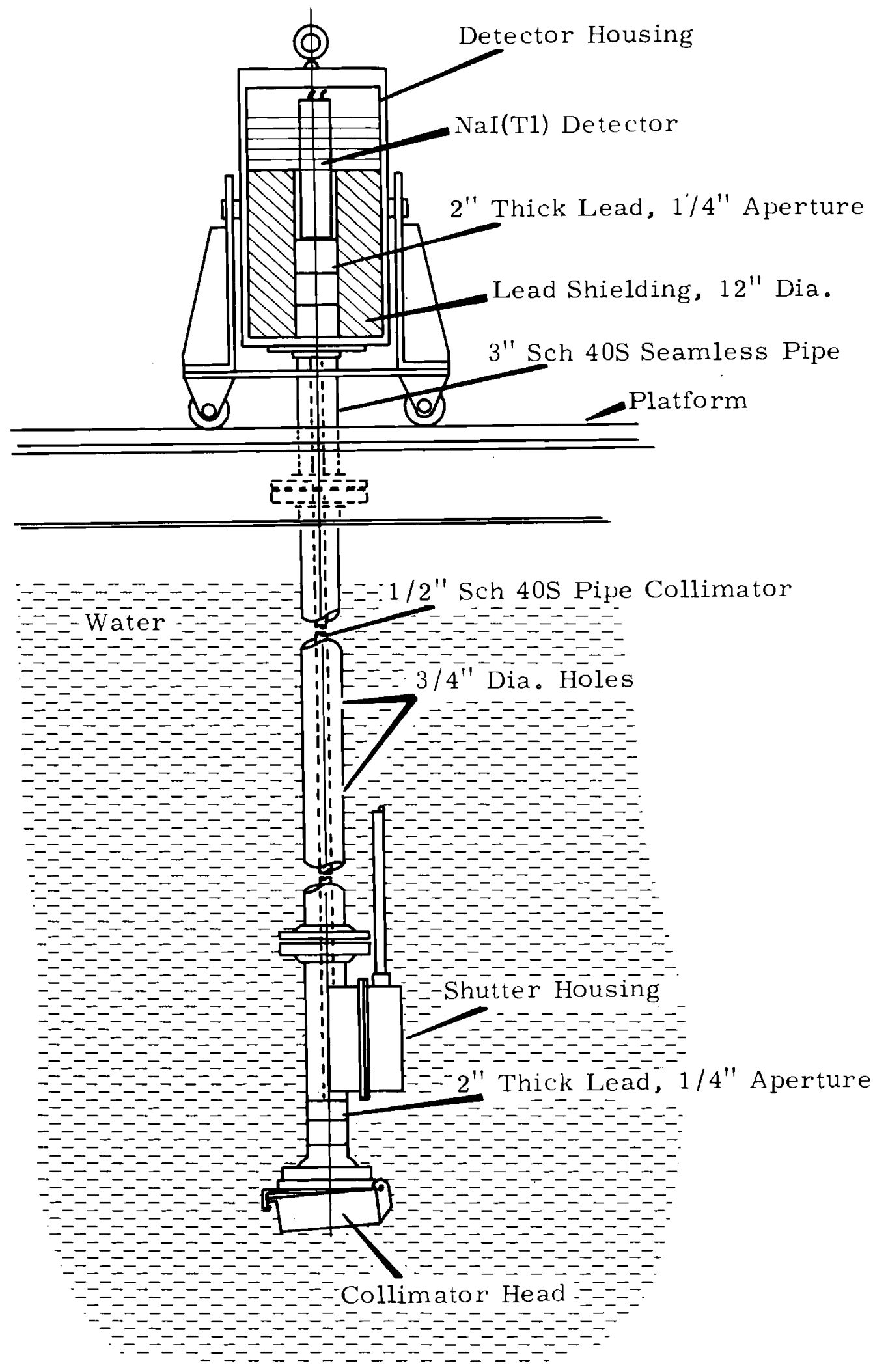

Figure XVI 
near the source and 6 inches of lead next to the detector to collimate the gamma ray beam. At present a $1 / 4$ inch diameter aperture is incorporated in the design with the option of installing a 1/16 inch diameter aperture if desired. The detector, a 1-3/4 inch diameter by 2 inch NaI(T1) crystal, is shielded from background radiation by lead housing 4-1/2 inches thick. The detector and housing are mounted on rails which makes it possible to move the collimator along a fuel rod. The rod is held horizontally in a "V" shaped trough and is raised to be positioned directly beneath the collimator head. A shutter is included near the source to close the aperture and take background readings.

The detecting system, in addition to the NaI(T1) crystal optically coupled to an EMI 9536 B photomultiplier contained in a light-tight assembly, includes a preamplifier (white cathode follower type), a double delay line clipped nonoverloading linear pulse amplifier, a single channel pulse height analyzer which can be made to scan a given energy range, a linear count rate meter, a strip chart recorder, and a scaler. A multichannel analyzer is available to do more detailed energy analysis. Data has been taken to test the stability of the detecting system and the reproducibility of the count rate as a function of position. These data have been shown to be reproducible to $\pm 1.5 \%$.

Measurement Techniques

The longitudinal variation of the gross fission product activities in a fuel rod are determined from a point-by-point traverse along the rod to establish the relative exposure of the fuel. Detailed gamma-ray spectra are determined at selected points with a multi-channel analyzer. Subsequent destructive analysis of $1 / 2$ inch fuel sections then provides data for the absolute determination of the exposure.

Scanning of Irradiated Fue1 Samples

As a demonstration of the measurement techniques and the equipment capabilities, the results of an examination of two fuel pins from a fast reactor are presented here.

The relative distribution of fission products in two $\mathrm{SST}-\mathrm{PuO}_{2}$ cermet fuel pins irradiated in the EBR-II as part of the LMFBR program has been determined. These fuel specimens were fabricated by a coextrusion process 
where high density $\mathrm{PuO}_{2}$ pellets in a 304-SST matrix were coextruded in 304-SST cladding. The core compositions were 30 volume percent and 20 volume percent $\mathrm{PuO}_{2}$ for pins $5 \mathrm{P} 14$ and $5 \mathrm{P} 13$, respectively. The average pin diameters and average core diameters were 0.295 inches and 0.253 inches for pin 5P14 and 0.290 inches and 0.258 inches for pin 5P13. Core lengths of 15.50 inches and 14.62 inches, respectively, were loaded in 40 inch long, 0.375 inch outside diameter EBR-II fuel capsules with a fuel bond of sodium. Between March 26, 1966 and October 20, 1966, the pins were irradiated for varying periods, the total irradiation time being approximately 129 days. The encapsulated pins were available for scanning during March, 1967. Two prominent peaks were evident in the gamma spectrum taken with the NaI(T1) detector, one at about $500 \mathrm{KeV}$ due mainly to the $513 \mathrm{KeV}$ gamma from ${ }^{106} \mathrm{Rh}$ and another at about $750 \mathrm{KeV}$ due mainly to the 724 and $756 \mathrm{KeV}$ gammas from ${ }^{95} \mathrm{Zr}$ and the $765 \mathrm{KeV}$ gamma from ${ }^{95} \mathrm{Nb}$. For these scans, the energy threshold of the single channel analyzer was set at $670 \mathrm{KeV}$. The fuel pins were counted at $1 / 8$ inch invervals and the $1 / 16$ inch aperture was used. The gamma scan traces, Figures XVI and XVII indicate two definite areas of low relative activity in each pin. Comparison of the gamma scans with preirradiation radiographs showed that in each case the low activity regions coincide with pellet interfaces in the extrusion billet. These interfaces appear as a nose-to-tail effect during the extrusion process. (See diagram on Figures XVII and XVIII). There are variations in activity along the length of each pin of the order of 5-10 percent. The statistical accuracy of the data and the difficulty of reproducing the counting geometry on the 0.375 inch diameter rods with equipment designed for 0.5 inch diameter rods would account for variations of the order of 3-4 percent. The larger variations in activity are due, in part, to inhomogenieties in $\mathrm{PuO}_{2}$ concentration. Full length beta-gamma autoradiographs showed considerable nonuniformity. This has been attributed partially to nonuniform distribution of the $\mathrm{PuO}_{2}$ in the pins during fabrication and partially to nonuniform contact of the pins with the film during the exposure of the autoradiograph. (31) These pins are presently being destructively analyzed. Two pieces of fuel are being saved for subsequent gamma-ray spectrum analysis with a $\mathrm{Ge}(\mathrm{Li})$ detector. 


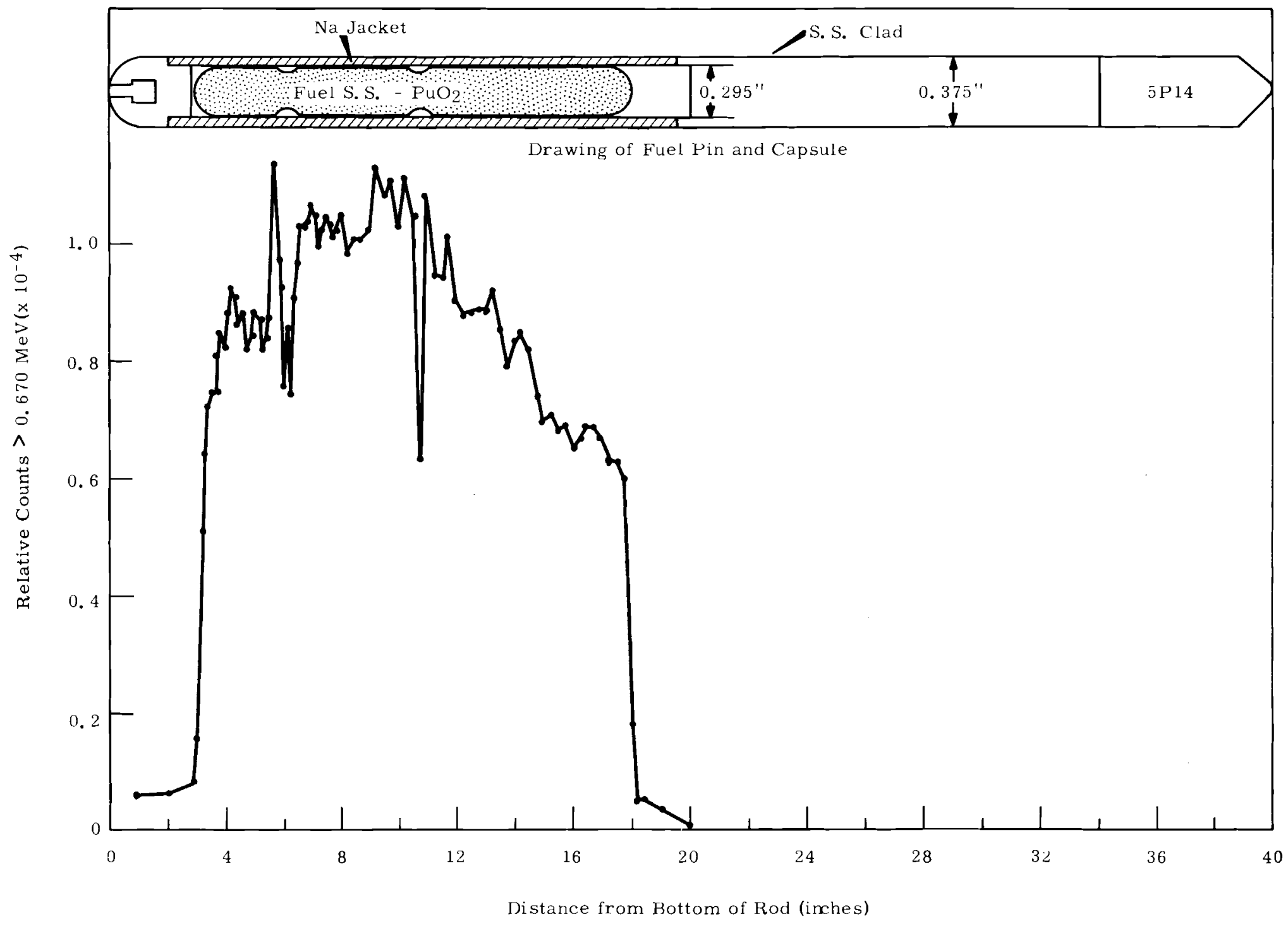

Figure XVII

Relative Gamma Count vs Distance from the Bottom of Fuel Rod 5P14 and a Diagram of the Rod 


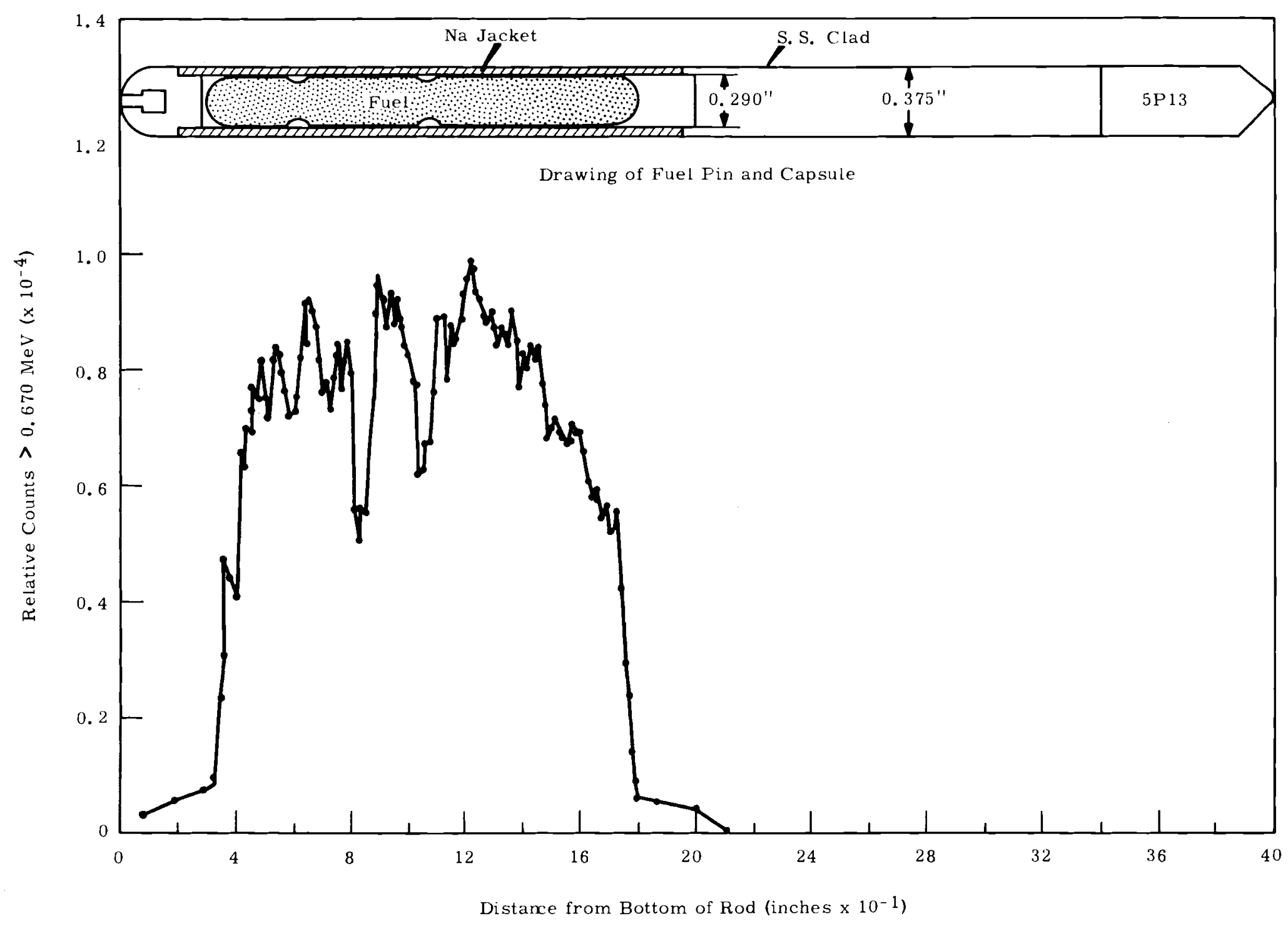

Figure XVIII

Relative Gamma Count vs Distance from the Bottom of Fuel Rod 5P13 and a Diagram of the Rod 


\section{Future Plans}

Work is in progress to develop a fully automated system. This system will include a range of aperture sizes, a high resolution Ge9Li) detector, the associated data collection equipment, and the versatility to scan a variety of fuel geometries. Concurrently, computer programs are being developed which will reduce the complex gamma-ray spectra information to quantitative fuel burnup results.

\section{Destructive Analysis of Fuel Burnup}

Burnup Analysis of Aluminum-Plutonium Fuel Irradiated in the PRTR R. P. Matsen and D. E. Christensen

New methods for analyzing power reactor burnup data have been developed. Our approach is directed toward the extraction of cross section information $f_{1}$ om the experimental data rather than just making the usual comparison of the data with results predicted by reactor burnup codes. This cross section information constitutes a compact set of experimental numbers which should be useful in checking some intermediate steps of reactor burnup codes. Extensive use of least squares techniques is made in the analysis of the data. Least squares fitting codes (programs LEARN and LIKELY), (33) sufficiently versatile for our analysis, have recently been developed at this laboratory.

The experimental data $(34,35)$ were obtained from samples cut from aluminum-plutonium 19-rod elements irradiated in the Plutonium Test Reactor. Samples having the same initial fuel composition and irradiated in approximately the same nuclear surroundings have been analyzed together. resulting in four groups of data:

(32) Schmid, L. C., Christensen, D. E., Duane, B. H., Liikala, R. C., and Matsen, R. P., "Experimental and Theoretical Methods Used for Burnup Analysis at Battelle-Northwest," International Conference on the Physics Problems in Thermal Reactor Design, June 27-29, 1967, to be published.

(33) Duane, B. H., "Maximum Likelihood Nonlinear Correlated Fields (Battelle Northwest Program LIKELY)," BN(WL-390, Pacific Northwest Laboratory, Richland, Wash., September, 1965.

(34) Christensen, D. E., Reppond, E. B., and Reardon, W. A., "Burnup Data From Low Exposure Plutonium-Aluminum Fuel," BNWL-CC-904, Pacific Northwest Laboratory. November, 1966.

(35) Christensen, D. E., Reppond, E. B., and Reardon, W. A., "Burnup Data from High Exposure Plutonium-Aluminum Fuel," BNGL-CC-905, Pacific Northwest Laboratory. December, 1966. 
- LxO - $1.82 \mathrm{wt} \% \mathrm{Pu}$ in Al (6.25\% $\left.{ }^{240} \mathrm{Pu}\right)$ from rods of the 12 -rod outer ring of the elements

- LxMC - 1.82 wt\% Pu in A1 (6.25\% $240 \mathrm{Pu})$ from rods of 6-rod inner and center rods of the elements

- HxO - 2.60 wt\% Pu in A1 (16.45\% $240 \mathrm{Pu})$ from rods of the 12 rod outer ring

- HxMC - 2.60 wt\% Pu in Al (16.45\% $240 \mathrm{Pu})$ from rods of the 6-rod inner ring and center rods.

The maximum exposure of the samples amounted to a plutonium depletion of $50 \%$. The samples were chemically assayed for plutonium and cesium-137. Plutonium isotopic atom ratios were obtained by mass spectrometer analyses.

Two methods of analysis are presently being used. (32) In each, the poorly known flux-time variable has been eliminated from the plutonium transmutation equations used in the analysis. This requires that the cross section information be extracted as ratios of effective (flux-averaged) cross sections rather than as the effective cross sections themselves. However, this is a small price to pay for ridding the analysis of the undesirable flux-time variable.

In the first method (Method $A$ ) the differential transmutation equations are solved for the cross section ratios and applied to each of five burnup increments which together span the full burnup range. In this way variations in the cross section ratios as a function of exposure can be determined. Since the number of cross section ratios exceeds the number of transmutation equations by two, the cross section ratios $\hat{\sigma}_{a}^{41} / \hat{\sigma}_{a}^{49}$ and $\hat{\sigma}_{a}^{42} / \hat{\sigma}_{a}^{49}$ are predetermined in order to determine the remaining ones. In previous work, $\hat{\alpha}^{41}$ was held fixed and $\hat{\sigma}_{a}^{42} / \hat{\sigma}_{a}^{49}$ set equal to zero and therefore the results quoted here are different than those previously reported. (36) The results are presented in Figure XIX, $\left(\hat{\sigma}_{a}^{40} / \hat{\sigma}_{a}^{49}\right)$, and in Table XII. All cross section ratios except $\hat{\sigma}_{a}^{40} / \hat{\sigma}_{a}^{49}$ are constant within their assigned uncertainties and therefore it is the average value of these constant cross section ratios that is quoted in Table XII.

(36) Reardon, W. A., and Christensen, D. E., "Atom Ratios and Effective Cross Section Ratios in Highly Depleted Plutonium-Aluminum Alloy Fuel," Nucl. Sci. \& Eng., 30, 222-232 (1967). 
$\hat{\sigma}_{a}^{40} / \hat{\sigma}_{a}{ }^{49}$ VARIATION FOR PUAI SAMPLES

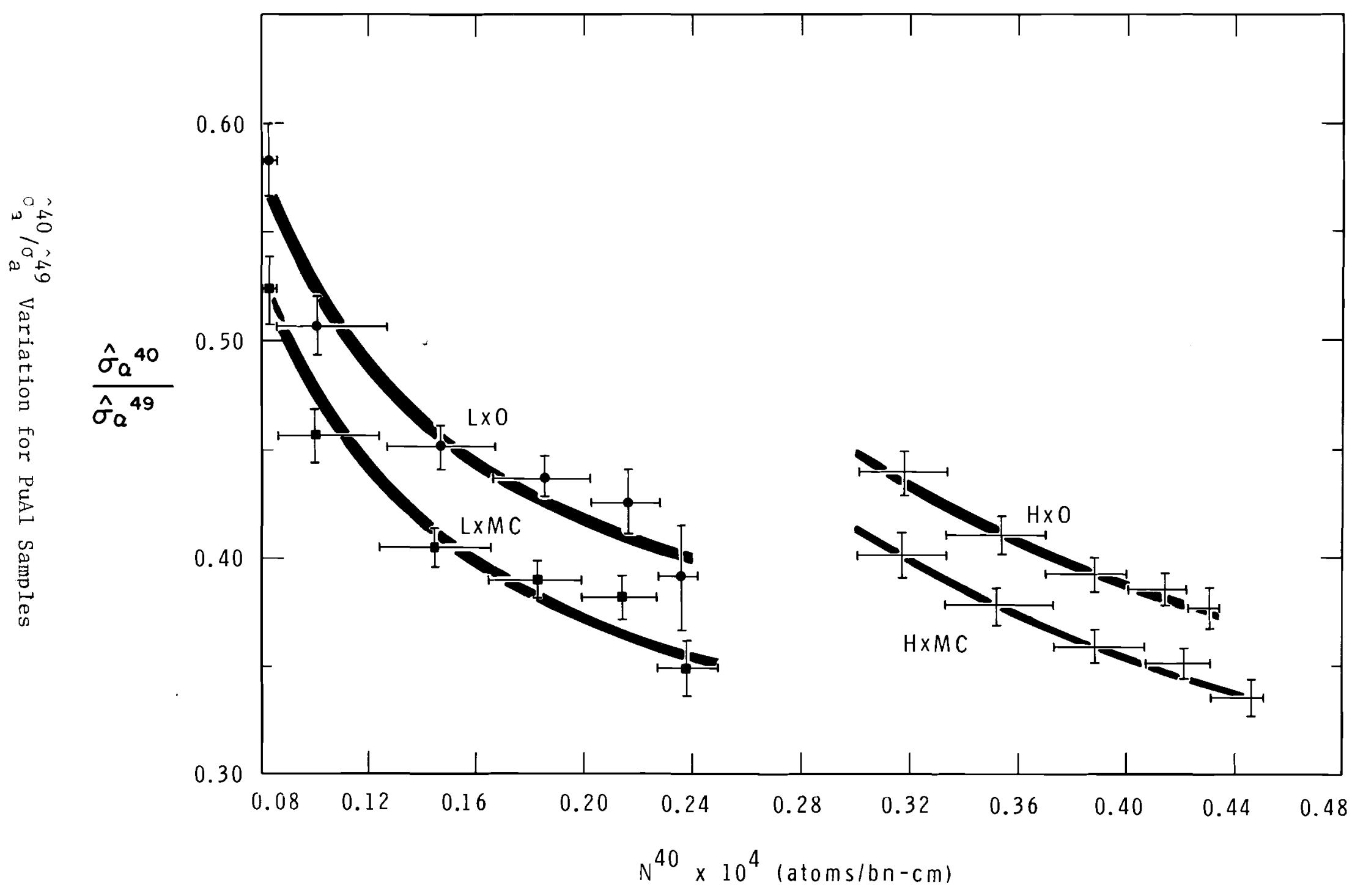

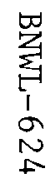

Figure XIX 
Table XII

Cross section ratios for $\mathrm{LxO}$, LxMC, $\mathrm{HxO}$, and $\mathrm{HxMC}$ sets of data

\begin{tabular}{|c|c|c|c|c|c|c|c|c|c|}
\hline \multirow{2}{*}{$\hat{\alpha}^{49}$} & \multirow{2}{*}{$\frac{\text { Method }}{\mathrm{A}}$} & \multicolumn{2}{|c|}{$\mathrm{LxO}$} & \multicolumn{2}{|c|}{ LxMC } & \multicolumn{2}{|c|}{$\mathrm{HxO}$} & \multicolumn{2}{|c|}{$\mathrm{HxMC}$} \\
\hline & & 0.442 & 0.020 & 0.442 & 0.018 & 0.444 & 0.024 & 0.451 & 0.024 \\
\hline & B & 0.439 & 0.015 & 0.436 & 0.015 & 0.442 & 0.014 & 0.447 & 0.014 \\
\hline \multirow{2}{*}{$\hat{c}_{a}^{41} / \hat{o}_{a}^{49}$} & A & 1.150 & (fixed) & 1.150 & (fixed) & 0.150 & (fixed) & 1.150 & (fixed) \\
\hline & B & 1.143 & (fixed) & 1.143 & (fixed) & 1.143 & (fixed) & 1.143 & (fixed) \\
\hline \multirow[t]{2}{*}{$n^{41}$} & A & 0.356 & 0.028 & 0.359 & 0.021 & 0.347 & 0.010 & 0.340 & 0.010 \\
\hline & B & 0.351 & 0.015 & 0.355 & 0.015 & 0.342 & 0.015 & 0.339 & 0.015 \\
\hline \multirow[t]{2}{*}{$?^{42} / \sigma^{49}$} & A & $\begin{array}{r}0.09 \mathrm{t} \\
\text { (fi }\end{array}$ & $\begin{array}{l}0.06 \\
\text { xed) }\end{array}$ & $\begin{array}{r}0.09 \mathrm{t} \\
\quad(\mathrm{f} \mathrm{i}\end{array}$ & $\begin{array}{l}\text { o } 0.06 \\
\text { xed) }\end{array}$ & 0.082 & (fixed) & 0.082 & (fixed) \\
\hline & B & 0.07 & fixed) & 0.07 & fixed) & 0.07( & fixed) & 0.07 & (fixed) \\
\hline
\end{tabular}

In the other method (Method B) the differential transmutation equations e integrated assuming all of the cross section ratios are constant over the entire burnup range as suggested by the results of Method A, with the exception of $\hat{\sigma}_{a}^{40} / \hat{\sigma}_{a}^{49}$ which is assumed to have the form $A+B / N^{40}$. the experimental data is cast in the form of isotopic concentrations $\left(\mathrm{N}^{i}\right.$ in atoms/bn-cm) including their experimental uncertainties. The cross section ratios result from a simultaneous fit of the integrated transmutation equations to the burnup data using the method of least squares (progran LIKELY). In principle, all cross section ratios can be determined from the least squares analysis. In practice, $\hat{\sigma}_{a}^{41} / \hat{\sigma}_{a}^{49}$ an $\hat{\sigma}_{a}^{42} / \hat{\sigma}_{a}^{49}$ must again be predetermined and the remaining ratios obtained from the fitting analysis. 
The fit to the LxO experimental data is shown in Figure XX which is a reproduction of a plot generated by an output subroutine of program LIKELY. The cross section ratio results from the Method $B$ analysis are shown also in Figure XIX and Table XII. In Figure XIX, the points with one standard deviation error flags were determined by Method A. The solid lines are the results of Method $B$. The one standard deviation uncertainties (not shown) of Method B are about the same size as those of Method A. The cross section ratios which were predetermined and held fixed during the analysis are so labeled in Table XII. The remaining ratios are reported with their one standard deviation uncertainties. A comparison of the LxO and LxMC cross section ratio results with computed values is given in Table 3 of reference (32) .

The remarkably good fit of the burnup equations to the experimental data over a wide range of exposure supports the validity of the assumed functional form of the cross section ratios (i.e., constant except for $\left.\hat{c}_{a}^{40} / \hat{\sigma}_{a}^{49}\right)$. The values of $\hat{\sigma}_{a}^{41} / \hat{\sigma}_{a}^{49}$ and $\hat{\alpha}^{41}$ are expected to remain constant for these data. In the energy region 0.0 to $0.1 \mathrm{eV}, \sigma_{a}^{49}(\mathrm{E})$ and $\sigma_{\mathrm{a}}^{41}(\mathrm{E})$ exhibit very similar shapes so that their ratio remains constant and is unaffected by shifts in the thermal spectrum. The capture to fission ratio $\alpha^{41}(\mathrm{E})$ for ${ }^{241} \mathrm{Pu}$ is relatively constant in the thermal energy region, also rendering it insensitive to spectral shifts. On the other hand, $\alpha^{49}(E)$ does vary over the entire thermal region. This leads to the conclusion that changes in the thermal spectrum are either insignificant of if they do occur, the corresponding changes in $\hat{\alpha}^{49}$ are compensated for and therefore masked by adjustments in the $\hat{\sigma}_{a}^{40} / \hat{\sigma}_{a}^{49}$ ratio induced by the least squares fitting routine. Although the computed value of $\hat{\sigma}_{a}^{42} \hat{\sigma_{a}^{4}}$ is not constant as a function of exposure, it is too small to affect the least squares fitting results and therefore has been assumed to be a 


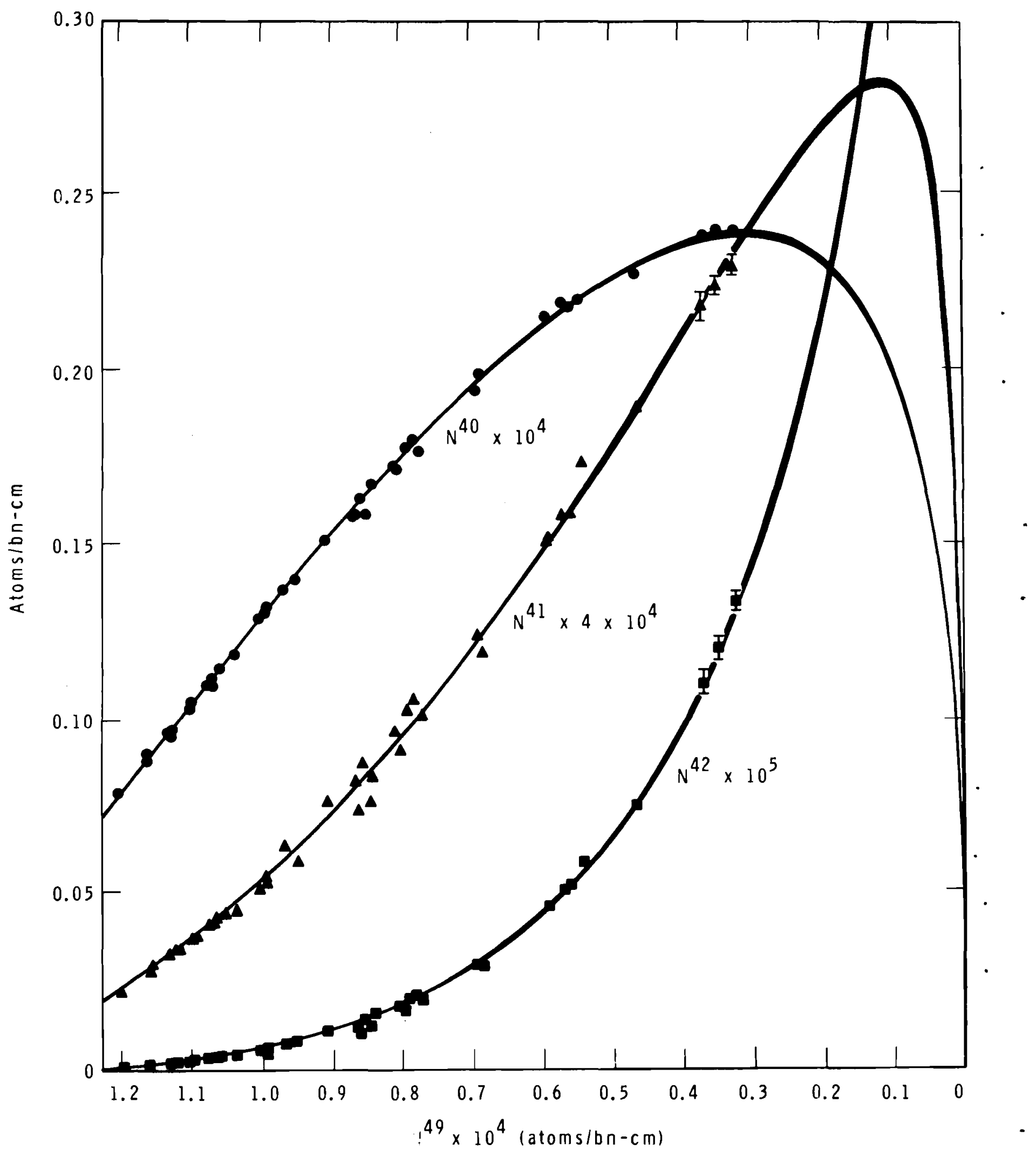

Figure XX

Experimental Isotopic Concentrations and Results of Least Squares Analysis for LxC 
constant. The flux-averaged cross section $\hat{\sigma}_{a}^{49}$ increases markedly during the course of the irradiation due to self shielding changes resulting from a threefold decrease in ${ }^{239} \mathrm{Pu}$ concentration. Since our attention has been focused on cross section ratios rather than the cross sections themselves, this variation in $\hat{\sigma}_{a}^{49}$ has been obscured by the similarities in the shapes of the cross sections making up the ratios. Even the empirical form $\left(a+b / N^{40}\right)$ assumed for $\hat{\sigma}_{a}^{40} / \hat{\sigma}_{a}^{49}$ makes this variation since $1 / N^{40}$ term empirically fuses together the separate ${ }^{239} \mathrm{Pu}$ and $240 \mathrm{Pu}$ self shielding effects.

The burnup methods described above are currently being extended to the transplutonium isotopes ${ }^{234} \mathrm{Am}$ and $2{ }^{24} \mathrm{Cm}$ as well as being applied to the uranium-plutonium fueled systems more typical of thermal power reactors.

\section{Saxton Experiment}

The purposes of the Saxton Plutonium Program ${ }^{(37)}$ is to develop information concerning the use of plutonium enriched fuel in pressurized water power reactor systems. Information on the physics characteristics of these systems obtained during this experiment is compared to analytical results. The purpose of the comparison is to evaluate nuclear design methods by pointing out discrepancies, identifying the reasons for the discrepancies, and illustrate schemes for normalizing the methods to bring about agreement between calculation and experiment.

Analysis of WREC Experiments - G. L. Simmons

As a part of this over-all program, a series of design-oriented critical experiments were conducted ${ }^{(38)}$ at the Westinghouse Reactor Evaluation Center (WREC) using the same fuel rods as those to be used in the Saxton core. These experiments include single zone and two zone loadings of $5.74 \% 5 \% \mathrm{JO}_{2}$ and $\mathrm{UO}_{2}-6.6 \mathrm{wt} \% \mathrm{PuO}_{2}$ fuels in $\mathrm{H}_{2} \mathrm{O}$ moderated lattices. The lattice configurations are square arrays of rods and the assemblies were made critical by adjusting the height of the moderator. Since the cores are

(37) Saxton Plutonium Program Progress Reports, WCAP-3385-1 through 10, Westinghouse Atomic Power Division, Part 1, Penn.

(38) Taylor, E. G., et al., "Saxton Plutonium Program Critical Experiments for the Saxton Particle Plutonium Core," EURAEC-1493/WCAP-3385-54, Westinghouse Electronic Corporation, December, 1965. 
geometrically either rectangles or squares* is was felt that an evaluation of the neutron leakage from these cores was necessary. A systematic evaluation of the effects of neutron leakage on the multiplication, flux distributions and power distributions of these assemblies is being made. Preliminary results of an analytical study aimed at investigating the effects of neutron leakage on multiplication values, $k_{e f f}$, are given here.

The neutronics model used in the analysis of these critical experiments is described in detail in the Methods Evaluation section of this report. Briefly, this model consists of using the codes HRG, (39) THERMOS, (40) and TEMPEST ${ }^{(41)}$ for computing the neutron spectrum in a lattice cell to obtain cell average cross sections. The cell average cross sections obtained are used in a diffusion theory calculation of the neutron leakage from the finite assembly to obtain the effective multiplication factor, $k_{e f f}$. The leakage calculations were made using a point reactor model (zero D), a one-dimensional cylindrical model (1-D), and a two-dimensional square model (2-D) of the reactor. The reactor was assumed to consist of two regions for the 1 and 2-D models, namely a homogeneous core and an $\mathrm{H}_{2} \mathrm{O}$ reflector. The experimental buckling is utilized to account for all leakage in the point reactor model calculations. The measured axial bucklings were used to account for axial leakage in the 1 and $2-D$ reactor model calculations. The cores HFN ${ }^{(42)}$ and EXTERMINATOR ${ }^{(43)}$ were utilized for the 1 and 2-D

* An exception is the 0.52 inch $\mathrm{UO}_{2}$ lattice was a cylindrical configuration.

(39) Carter, J. L., Ir., "Computer Code Abstracts, Computer Code-HRG," Reactor Physics Department Technical Activities Quarterly Report; July, August, September 1966; USAEC Report, BNWL-340, October 15, 1966.

(40) Honeck, H. C., "THERMOS - A Thermalization Transport Theory Code for Reactor Lattice Calculations," BNL-5826, Brookhaven National Laboratory.

(41) Shuddle, R. H. and Dyer, J., NAA Program Description, "TEMPEST - A neutron Thermalization Code," North American Aviation Corporation, 1960.

(42) Lilley, J. R., "Computer Code HFN - Multigroup, Multiregion Neutron Diffusion Theory in One Space Dimension," USAEC Report HW-71545, November, 1961.

(43) Fowler, T. B., Tobias, M., and Vondy, D. R., "EXTERMINATOR - A Multigroup Code for Solving Neutron Diffusion Equations in One and Two Dimensions," ORNL-TM-842, February, 1965. 
computations. The point reactor calculations were made assuming two groups of neutrons ( $10^{7}$ to $0.683 \mathrm{eV}$, and 0.683 to $0.0 \mathrm{eV}$ ), whereas four groups $\left(10^{7}\right.$ to $1.17 \times 10^{4} \mathrm{eV}, 1.17 \times 10^{4}$ to $2.38 \mathrm{eV}, 2.38$ to $0.683 \mathrm{eV}$, and 0.683 to $0.0 \mathrm{eV}$ ) were assumed in the 1 and 2-D calculations.

The adequacy of the 4 group-1D model in predicting values of $k_{\text {eff }}$ for the $\mathrm{UO}_{2}-6.6 \mathrm{wt} \% \mathrm{PuO}_{2}$ cores** is described in the Methods Evaluation section of this report. This same model predicts values of $k_{\text {eff }}$ for the $5.74 \mathrm{wt} \%$ $\mathrm{UO}_{2}$ cores** which range from about $0.5 \%$ low at the tight lattice to about $2.0 \%$ high at the loose lattice.

The differences in calculated values of $k_{\text {eff }}$ for the zero, one, and two dimensional models are shown in Table XIII. Large differences are noted between the zero and one dimensional model whereas small differences are noted between the one and two dimensional model. Part of the differences between the point reactor model and the one dimensional model could be due to the differnt number of neutron energy groups (recalling 2 groups used for the zero D model and 4 groups used for the others). The conclusion that we reach in this analysis is that a one dimensional cylindrical model of the reactor seems adequate from the standpoint of reactivity computations for these single zone lattices.

The Saxton core is a multi-region $\mathrm{UO}_{2} / \mathrm{UO}_{2}-\mathrm{PuO}_{2}$ configuration which may dictate using a two dimensional model. Moreover, the accurate computation of power distributions and core burnup for the Saxton core probably require a two-dimensional reactor model.

\section{Analytical Survey Studies}

Analytical survey studies have been performed to provide information on the physics characteristics for various reactor systems of interest. Results of these studies are directed toward, (a) providing the scope for possible experiments, and (b) providing information on certain physics characteristics of reactor systems in the absence of experimental information. A summary of the results of these studies is given here.

** Extrapolations to a critical fully inumdated cylindrical core, p. A-3 of WCAP-3385-54. 
$\underline{\text { Table XIII }}$ Differences in $k$ eff $\frac{\text { Using A Zero*, One, and Two Dimensiona1 }}{\text { Diffusion Theory Mode1 }}$

$\mathrm{UO}_{2}$

\begin{tabular}{|c|c|c|}
\hline & \multicolumn{2}{|c|}{$\Delta k_{\text {eff }}(\mathrm{mk})$} \\
\hline L.S. (in) & (Zero D to 1D) & (1D to 2D) \\
\hline 0.52 & +15.5 & \\
\hline 0.56 & +29.2 & -1.84 \\
\hline 0.792 & +35.0 & \\
\hline
\end{tabular}

$\mathrm{UO}_{2}-\mathrm{PuO}_{2}$

$\begin{array}{ll}0.52 & +16.7 \\ 0.56 & +28.9 \\ 0.735 & +32.6 \\ 0.792 & +27.1 \\ 1.04 & +12.8\end{array}$

*

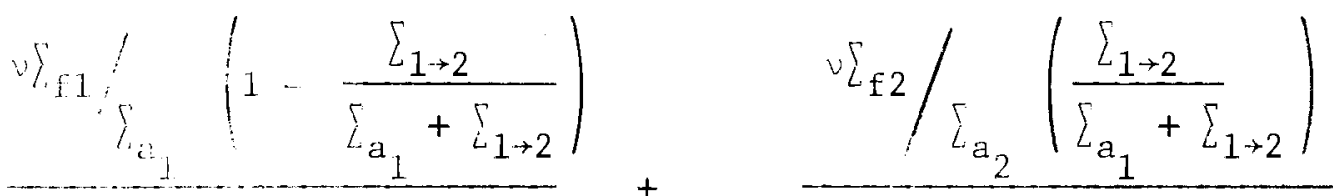

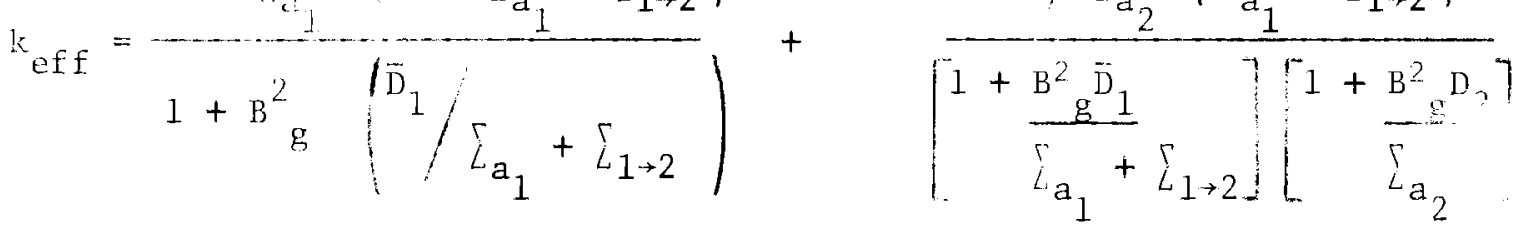

where subscripts 1 and 2 refer to nonthermal and thermal neutron energy groups. 
$\underline{\mathrm{H}}_{2} \underline{\mathrm{O} \text { Moderated Lattices of } \underline{\mathrm{UO}}_{2}-4 \mathrm{wt} \% \text { PuO }} 2$ Fuel $-\mathrm{S}$. Kobayashi ${ }^{\dagger}$ and V. O. Uotinen

Over the last few years experiments have been conducted in $\mathrm{H}_{2} \mathrm{O}$-moderated lattices of $\mathrm{PuO}_{2}-\mathrm{UO}_{2}$ fuel rods in which the concentration of $\mathrm{PuO}_{2}$ was $6.6 \mathrm{wt} \%,^{(44)} 2 \mathrm{wt}^{(45)}$ or $1.5 \mathrm{wt} \%{ }^{(46)}$ The concentration of $\mathrm{PuO}_{2}$ that is expected to be best suited for commercial thermal reactors is between $2 \mathrm{wt} \%$ and $6.6 \mathrm{wt} \%$.

To privide data at an intermediate concentration, a series of experiments in $\mathrm{H}_{2}$-moderated lattices containing $\mathrm{UO}_{2}-4 \mathrm{wt} \% \mathrm{PuO}_{2}$ fuel rods is being planned. (47) Experiments will be conducted to measure critical masses, bukclings, reflector savings, reactivity coefficients, and other detailed properties of these lattices. The experimental program will include approach-to-critical experiments in the Critical Approach Facility (CAF) and critical experiments in the Plutonium Recycle Critical Facility (PRCF). This report describes preliminary calculations which have been performed to help predict critical masses and various lattice parameters for these experiments.

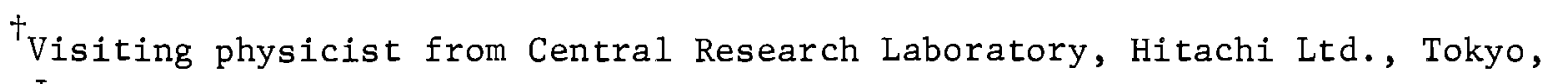
Japan.

(44) Taylor, et al., "Saxton Plutonium Program Critical Experiments for the Saxton Partial Plutonium Core," EURAEC-1493/WCAP-3385-54, westinghouse Electric Corporation, December, 1965.

(45) Liikala, R. C. and Stinson, W. P., "Experimental and Analytical Results for PuO $-40{ }_{2}-\mathrm{H}_{2} \mathrm{O}$ Lattices," Trans. Am. Nucl. Soc., 9, 1:127 (1966), and Uotinen, $V^{2} .0$. and Williams, L. D., "Experiments and Calculations for $\mathrm{H}_{2}$-Moderated Assemblies Containing $40_{2}^{-2}$ wt: $\mathrm{PuO}_{2}$ Fuel Rods," Trans. Am. Nucl. Sac., 10, (1967).

(46) Schmid, L. C., et al, "Critical Masses and Bucklings of $\mathrm{PuO}-\mathrm{UO}_{2}-\mathrm{H}_{2} \mathrm{O}$ Systems," Trans. Am. Nucl. Soc., 1, 2:216 (1964).

(47) Dawson, F. G., et al., "Program Analyses and Plans Plutonium Utilization Program Fy 1967 Through 1970," BNWL-298, July 1966. 
Fuel and Lattice Arrangements

The fuel selected for the calculations contains $4 \mathrm{wt} \% \mathrm{PuO}_{2}$ in $\mathrm{UO}_{2}$, the uranium being natural. Two isotopic compositions of plutonium were considered, the ${ }^{240} \mathrm{Pu}$ content being either $7.65 \mathrm{wt} \%$ or $23.5 \mathrm{wt} \%$ as shown in Table XIV. These isotopic compositions are identical to compositions in existing rods that contain $2 \mathrm{wt} \% \mathrm{PuO}_{2}$ in $\mathrm{UO}_{2} \cdot{ }^{(48)} \mathrm{Also}$, the fuel rod dimensions are identical to the dimensions of the $\mathrm{UO}_{2}-2 \mathrm{wt} \% \mathrm{PuO}_{2}$ fuel rods. The fuel $\left(\mathrm{PuO}_{2}-\mathrm{UO}_{2}\right)$ is 0.505 inches in diameter and 36.0 inches long, is clad with 0.030 inches thick Zircaloy-2, and has a fuel density which is assumed to be $88 \%$ of theoretical $\left(9.2675 \mathrm{~g} / \mathrm{cm}^{3}\right.$ of $\left.\mathrm{PuO}_{2}\right)$.

$\underline{\text { Table XIV }}$

Isotopic Compositions of Plutonium (wt\%)

\begin{tabular}{|c|c|c|c|c|}
\hline & ${ }^{239} \mathrm{Pu}$ & $\begin{array}{l}240 \\
\mathrm{Pu}\end{array}$ & $\begin{array}{l}241 \\
\mathrm{Pu}\end{array}$ & ${ }^{242} \mathrm{Pu}$ \\
\hline$C-I$ & 91.62 & 7.65 & 0.70 & 0.03 \\
\hline C-II & 71.76 & 23.50 & 4.08 & 0.66 \\
\hline
\end{tabular}

(48) Dawson, F. G., et al., "Analys is of Plutonium-Fueled Light water Reactors," IAEA Symposium on the Use of Plutonium as a Reactor Fu??. Brussels, Belgium, March 13-17, 1967. 
Hexagonal lattices with fuel rod spacings of $0.75,0.80$, and 0.85 inches were selected. These lattices have a moderator-to-fuel volume ratio of $1.16,1.49$ and 1.84 respectively. The physical temperature of materials in the lattice was selected at $20^{\circ} \mathrm{C}$.

Calculational Methods

The calculational methods employed are identical to those used in analysis of other plutonium fueled-H, $\mathrm{H}_{2} \mathrm{O}$ critical experiments. $(45,46,48)$ They consist of using the codes HRG, ${ }^{49)}$ THERMOS, $(50)$ and TEMPEST ${ }^{(51)}$ to obtain multigroup cell homogenized cross sections, and $\mathrm{HFN}^{(52)}$ to calculate multiplication.

The critical radius and number of rods for critical are obtained from a one-dimensional, four energy group, diffusion theory calculation (HFN code) assuming a two-region reactor consisting of a homogeneous core and an $\mathrm{H}_{2} \mathrm{O}$ reflector. Axial leakage effects are accounted for with transverse bucklings which are assumed to be $8.550 \times 10^{-4} \mathrm{~cm}^{-2}$ for all cases and for all energy groups. This buckling is based on a reflector savings of $8.0 \mathrm{~cm}$. Cut-off energies for the four energy groups are $1.17 \times 10^{4} \mathrm{eV}, 2.38 \mathrm{eV}$ and $0.683 \mathrm{eV}$. Calculational Results

The critical radius and number of fuel rods at critical obtained from HFN critical search calculations are listed in Table XV. Also shown are the group parameters which describe the thermal and nonthermal characteristics of the

(49) Carter, J. L., Jr., "Effective Cross Sections for Resonances in HRG," and "Computer Code Abstracts," Technical Activities Quarterly Report, July, August, September, 1966, USAEC Report BNWL-340, October 15, 1966.

(50) Honeck, H. C., "THERMOS - A Thermalization Transport Theory Cod for Reactor Lattice Calculations," BNL-5826, Brookhaven National Laboratory, and worden, J. R., Purcell, W. L., and Liikala, R. C., "Modifications to the Computer Code THERMOS, and Comparative Studies on Scattering Kernels," Physics Research Quarterly Report, July. August, September, 1965, BNWL-193, pp.5-15, October 25, 1965.

(51) Shudde, R. H. and Dyer, J., NAA Program Description, "TEMPEST - A Neutron Thermalization Code," North American Aviation Corporation (1960).

(52) Lilley, J. R., "Computer Code HFN-Multigroup, Multiregion Neutron Diffusion Theory in One Space Dimension," USAEC Repart HW-71545, November, 1961. 
$\underline{\text { Table XV }}$

$\underline{\mathrm{UO}}_{2}$ (Nat.) $4 \mathrm{wt} \% \mathrm{PuO}_{2}-\mathrm{H}_{2}$ O Lattices - Preliminary Results

\begin{tabular}{|c|c|c|c|c|c|c|}
\hline \multirow[b]{2}{*}{$\begin{array}{l}\text { Lattice Pitch } \\
\text { (in.) }\end{array}$} & \multicolumn{3}{|c|}{$7.65 \mathrm{wt} \% 240 \mathrm{Pu}$} & \multicolumn{3}{|c|}{$23.5 \mathrm{wt} \%{ }^{240} \mathrm{Pu}$} \\
\hline & 0.75 & 0.80 & 0.85 & 0.75 & 0.80 & 0.85 \\
\hline $\begin{array}{l}\text { Volume Ratio } \\
\mathrm{V}_{\mathrm{M}} / \mathrm{F}_{\mathrm{F}}\end{array}$ & 1.1567 & 1.4891 & 1.8423 & 1.1567 & 1.4891 & 1.8423 \\
\hline $\begin{array}{l}\text { Radius at } \\
\text { Critical }(\mathrm{cm})\end{array}$ & 19.613 & 17.265 & 15.938 & 25.655 & 21.748 & 19.649 \\
\hline $\begin{array}{l}\text { No. of Fuel } \\
\text { Rods at Critical }\end{array}$ & 384.67 & 261.86 & 197.77 & 657.88 & 415.52 & 300.58 \\
\hline $\bar{n} \mathrm{f}_{\text {(thermal) }}$ & 1.7660 & 1.7544 & 1.7392 & 1.6794 & 1.6669 & 1.6508 \\
\hline $\bar{n}$ (thermal) & 1.8333 & 1.8417 & 1.8484 & 1.7477 & 1.7554 & 1.7613 \\
\hline${ }^{f}$ (therma 1$)$ & 0.9633 & 0.9526 & 0.9409 & 0.9609 & 0.9496 & 0.9372 \\
\hline $\begin{array}{l}\text { Disadvantage } \\
\text { Factor (therma1) }\end{array}$ & 1.8562 & 1.8283 & 1.8161 & 1.7616 & 1.7365 & 1.7263 \\
\hline$P_{1}$ & 0.9199 & 0.9336 & 0.9436 & 0.9208 & 0.9344 & 0.9442 \\
\hline $\mathrm{P}_{2}\left({ }^{238} \mathrm{U}\right)$ & 0.6638 & 0.7184 & 0.7598 & 0.6636 & 0.7185 & 0.7600 \\
\hline$P_{3}\left({ }^{240} \mathrm{Pu}\right)$ & 0.8424 & 0.8688 & 0.8883 & 0.7963 & 0.8259 & 0.8491 \\
\hline $\bar{\eta} \mathbf{f}_{1}$ & 1.6279 & 1.6490 & 1.6612 & 1.6057 & 1.6277 & 1.6405 \\
\hline $\bar{n} \mathrm{f}_{2}$ & 0.6796 & 0.6724 & 0.6660 & 0.6326 & 0.6256 & 0.6203 \\
\hline$n f_{3}$ & 0.5328 & 0.5154 & 0.5029 & 0.3305 & 0.3132 & 0.3014 \\
\hline
\end{tabular}


1attice. They are $\bar{n} f, \bar{n}$ and $f$ for thermal parameters, and $\bar{n}_{f_{1}}, \bar{\eta} f_{2}$, and $\bar{n}_{3}$ and resonance escape probability $p$ for nonthermal. The $\bar{n}^{\prime}$ 's are defined as the ratio of the cell averaged cross sections $\nu \bar{\Sigma}_{f}$ to $\bar{\Sigma}_{a}$. The cell averaged value of $\bar{n}$ is the ratio of $\left[\cup \bar{\Sigma}_{f 4}\right]$ fuel to $\left[\bar{\Sigma}_{a 4}\right]$ fuel. The $f$ is the usual thermal utilization, $\bar{n} f / \bar{\eta}$.

Resonance escape probabilities, $p_{i}$, are calculated as the ratio of cell averaged values of $\bar{\Sigma}_{\text {out }}$ to $\bar{\Sigma}_{r_{j}}$, where $i$ refers to particular neutron energy groups and $\bar{\Sigma}_{r}$ is the removal cross section (i.e., $\Sigma_{a}+\Sigma_{\text {out }}$ ).

$\mathrm{p}\left(\mathrm{U}^{238}\right)$ and $\mathrm{p}\left(\mathrm{Pu}^{240}\right)$ are defined so that they correspond to energy groups from $1.17 \times 10^{4}$ to $2.38 \mathrm{eV}$ and from $2.38 \mathrm{eV}$ to $0.683 \mathrm{eV}$, respectively.

The dependence of these parameters on lattice spacing for constant temperature $\left(20^{\circ} \mathrm{C}\right)$ can be summarized as follows. As the lattice spacing increases, (a) $\bar{\eta} f_{\text {thermal }}, \bar{\eta} f_{3}$ and $\bar{n} f_{2}$ decrease, (b) $\bar{\eta} f_{1}$ increases, (c) the $p^{\prime}$ 's increase, and (d) the number of fuel rods for critical decreases.

The 0.75 to 0.85 inch lattice can be considered to be undermoderated; and the changes in critical mass follow the trend in the reciprocal of $p_{i}$. The changes in $\bar{n} f$ for groups 2,3 , and thermal as a function of lattice spacing follow the trend in $f\left(f_{2}=1-p_{2}\right.$ etc.) rather than $\bar{n}$. The change in $\bar{n} f$ for group 1 follows the trend in $n_{1}$ rather than $f_{1}$. It is evident that the balance between the changes in $\eta$ and $f$ values plays an important role in the reactivity behavior of the system.

The difference in ${ }^{240} \mathrm{Pu}$ content (about a factor of three in our case) has a large effect on the values of $\bar{n} f, p$ and $\eta$ in the third and thermal energy groups; the effect in the third energy group is larger than that in the therma1 group. Thus, it is important to investigate experimentally how the characteristic parameters change as the ${ }^{240} \mathrm{Pu}$ content chang i Therma1 Neutron Energy Spectrum

To describe quantitatively the thermal neutron spectrum, activation ratios $A R$, of a non- $1 / \mathrm{v}$ element $\left({ }^{6} \mathrm{Lu}\right)$ to a $1 / \mathrm{v}$ element $\left({ }^{63} \mathrm{Cu}\right) *$, were

* Generally, ${ }^{175} \mathrm{Lu},{ }^{53} \mathrm{Cu}$ or ${ }^{64} \mathrm{Dy}$ is used as a $1 / \mathrm{v}$ detector in the thermal energy region, but ${ }^{164} \mathrm{Dy}$ is not strictly speaking a $1 / \mathrm{v}$ detector, because its cross section deviates downward from the $1 / \mathrm{v}$ cross section near the thermal cutoff energy. ${ }^{63} \mathrm{Cu}$ is selected here as a typical example of a $1 / \mathrm{v}$ detector. 
calculated. The AR, which are roughly proportional to neutron temperature, are calculated by the following equations

$$
A R=\frac{\int_{0}^{E^{*}} \sigma_{L u_{x} \Phi}(\vec{r}, E) d E}{\int_{0}^{E^{*}} \sigma_{1 / v{ }_{x}(\vec{r}, E) d E}} / \frac{\int_{0}^{E^{*}} \sigma_{L u^{\Phi}}(E) d E}{\int_{0}^{E^{*}} \sigma_{1 / v}{ }^{\Phi}(E) d E}
$$

where

$$
\begin{array}{ll}
E^{*} & =\text { thermal cutoff energy. This is taken to be } 0.683 \mathrm{eV} . \\
\sigma_{\mathrm{x}}(\mathrm{r}, \mathrm{E})= & \text { neutron flux at position and energy } \mathrm{E} . \\
\Phi_{\mathrm{r}}(\mathrm{E})= & \text { neutron flux at reference position } \\
\sigma_{\mathrm{Lu}}, \sigma_{1 / \mathrm{V}}= & \text { microscopic absorption cross sections of }{ }^{176} \mathrm{Lu} \text { and } \\
& { }^{63} \mathrm{Cu} \\
\mathrm{x}, \mathrm{r} & \text { notations of position, } \mathrm{r} \text { means reference position }
\end{array}
$$

$\mathrm{AR}_{\mathrm{f}}$ in the fuel region and $\mathrm{AR}_{\mathrm{m}}$ in the moderator region are obtained from THERMOS calculations, and cell averaged activation ratios, $\mathrm{AR}_{\mathrm{c}}$, are calculated as follows:

$$
\mathrm{AR}_{\mathrm{c}}=\frac{\mathrm{AR}_{f}+\frac{\mathrm{V}_{\mathrm{m}}}{\mathrm{V}_{f}}(\mathrm{D} \cdot \mathrm{F}) \cdot \mathrm{AR}_{\mathrm{m}}}{1+\frac{\mathrm{V}_{\mathrm{m}}}{\mathrm{V}_{\mathrm{f}}}(\mathrm{D} \cdot \mathrm{F})}
$$

where, $v_{m}$ and $v_{f}$ are volumes of moderator and fuel regions respectively, and (D.F) is the disadvantage factor.

These thermal spectral parameters are listed in Table XVI. The difference in thermal spectra between $7.65 \mathrm{wt} \%{ }^{240} \mathrm{Pu}$ lattices and $23.5 \mathrm{wt} \%$ $240 \mathrm{Pu}$ lattices is not very large. Spectral differences are expected to be greater in the near thermal region than in the thermal region, because of the large ${ }^{240} \mathrm{Pu}$ resonance at $1 \mathrm{eV}$. Thus, it seems that an experimental study of the epi-thermal neutron spectrum is important.

\section{Two-Group Parameters}

An analytical model that is frequently used in the analysis of exponential ${ }^{(53)}$ and critical ${ }^{(54)}$ experiments is the two-group diffusion

(53) Hellens, R. L. and Honeck, H. C., "Light Water Lattices," IAEA, STI/DOC 10,12, Vienna, 1962.

(54) Strawbridge, L. E. and Jarry, R. F., NSEE 23, 58 (1965). 
Table XVI

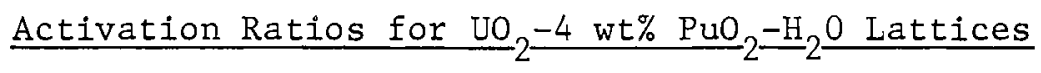

\begin{tabular}{|c|c|c|c|c|}
\hline & $\begin{array}{l}\text { Lattice } \\
\text { Spacing }\end{array}$ & $\mathrm{AR}_{\mathrm{f}}$ & $\mathrm{AR}_{\mathrm{m}}$ & $\mathrm{AR}_{\mathrm{cell}}$ \\
\hline \multirow{3}{*}{$7.65 \mathrm{wt} \%{ }^{240} \mathrm{Pu}$} & 0.75 & 1.4648 & 1.3683 & 1.3990 \\
\hline & 0.80 & 1.4179 & 1.3116 & 1.3402 \\
\hline & 0.85 & 1.3803 & 1.2660 & 1.2923 \\
\hline \multirow{3}{*}{$23.5 \mathrm{wt} \%{ }^{240} \mathrm{Pu}$} & 0.75 & 1.4699 & 1.3767 & 1.4074 \\
\hline & 0.80 & 1.4246 & 1.3201 & 1.3492 \\
\hline & 0.85 & 1.3884 & 1.2741 & 1.3014 \\
\hline
\end{tabular}


theory model as applied to bare reactors. In this model all the leakage effects are accounted for by a measured material buckling, and the effective multiplication factor is given by

$$
k_{\text {eff }}=\frac{\bar{\eta} f_{\text {Fast }}\left(1-P_{\text {Fast }}\right)}{1+B^{2} \tau}+\frac{\bar{\eta} f_{t h} P_{\text {Fast }}}{\left(1+B^{2} \tau\right)\left(1+B^{2} L^{2}\right)} \text {, }
$$

where

$$
\begin{aligned}
\mathrm{P}_{\text {Fast }} & =\left[\Sigma_{\text {out }} / \Sigma_{r}\right]_{\text {Fast }} \\
\tau & =\left[\mathrm{D} / \Sigma_{r}\right]_{\text {Fast }} \\
\mathrm{L}^{2} & =\left[\mathrm{D} / \Sigma_{\mathrm{a}}\right]_{\text {th }} \\
& \nu \Sigma_{f} \\
\eta f_{i} & =\frac{\Sigma_{i}}{\Sigma_{i}} \quad(i=\text { Fast }, \text { th }) .
\end{aligned}
$$

Two-group parameters for the $\mathrm{UO}_{2}-4$ wt\% $\mathrm{PuO}_{2}$ cores are listed in Table XVII. These parameters can be used to estimate critical sizes of these and other $\mathrm{UO}_{2}-4 \mathrm{wt} \% \mathrm{PuO}_{2}$ lattices.

\section{Conclusions}

Calculational results describing the physics behavior of $\mathrm{six} \mathrm{UO}_{2}-$ 4 wt $\% \mathrm{PuO}_{2}-\mathrm{H}_{2} \mathrm{O}$ cores are presented as a survey study.

It is shown that these cores are undermoderated, and that the characteristic parameters such as $n f, f$ and $p$ in the third and thermal energy groups play an important role in the physics behavior of these cores. Thus, it is recommended that the following experiments be done in a wide range of lattice spacings and $2+0 \mathrm{Pu}$ contents:

1. Fast fission, effect, $\delta$,

2. Fission ratios of $235 \mathrm{U}$ to ${ }^{239} \mathrm{Pu}$ and $24 ! \mathrm{Pu}$,

3. Resonance capture ratio, $\rho^{\prime} s$,

4. Epithermal energy spectrum, for example, epithermal index,

5. Disadvantage factor (thermal and epithermal)

6. Power peaking and spectral changes around water gaps (or slots),

7. Temperature coefficient. 
Table XVII

Two Group Parameters for $\mathrm{UO}_{2}=4 \mathrm{wt} \%$ PuO $2=\mathrm{H}_{2}=$ Cores

\begin{tabular}{|c|c|c|c|c|c|c|}
\hline & & 65 wt $\% 2$ & & & $5 \mathrm{wt} \% 240$ & \\
\hline & Latt & e Spacin & (in.) & Latt & Spacing & (in.) \\
\hline & 0.75 & 0.80 & 0.85 & 0.75 & 0.80 & 0.85 \\
\hline $\bar{n} f_{\text {Fast }}$ & 0.8324 & 0.8208 & 0.8120 & 0.7470 & 0.7305 & 0.7180 \\
\hline $\mathrm{P}_{\text {Fast }}$ & 0.5367 & 0.7036 & 0.6562 & 0.5172 & 0.5837 & 0.6367 \\
\hline$\tau$ & 37.289 & 34.997 & 33.397 & 37.247 & 34.956 & 33.359 \\
\hline $\bar{n} \mathbf{f}_{t h}$ & 1.7660 & 1.7544 & 1.7392 & 1.6794 & 1.6669 & 1.6508 \\
\hline $\mathrm{L}^{2}$ & 0.9257 & 0.9793 & 1.0257 & 1.0048 & 1.0592 & 1.1051 \\
\hline $\bar{n} \mathrm{f}_{\mathrm{F}} / \bar{n} \mathrm{f}_{\mathrm{th}}$ & 0.4713 & 0.4679 & 0.4669 & 0.4448 & 0.4382 & 0.4349 \\
\hline & $k_{\text {eff }}$ & $\frac{\text { Fast }^{(1-P}}{1+B^{2} T}$ & ) & $\frac{\bar{n} f_{t h}\left(P_{\text {Fast }}\right)}{\left(1+B^{2} \tau\right)(1+B}$ & & \\
\hline
\end{tabular}

where,

$$
\begin{aligned}
\mathrm{P}_{\text {Fast }} & =\left[\Sigma_{\text {out }} / \Sigma_{r}\right]_{\text {Fast }}, \\
\tau & =\left[D / \Sigma_{r}\right]_{\text {Fast }} \\
\mathrm{L}^{2} & =\left[D / \Sigma_{\mathrm{a}}\right]_{\mathrm{th}} \\
\bar{n} \mathrm{f}_{i} & =\frac{\nu \Sigma_{f_{i}}}{\Sigma_{\mathrm{a}}} \quad(i=\text { Fast, th }) .
\end{aligned}
$$


$\underline{\mathrm{UO}}_{2} \underline{\mathrm{PuO}}_{2}=\mathrm{H}_{2}$ O Systems-Reactivity Coefficients - U. P. Jenquin

A survey study was conducted to determine the approximate magnitude of the various reactivity coefficients for plutonium-fueled light water reactors. The reactor systems were assumed to be idealized fuel-moderator configurations (i.e., uniform lattices) free of structural materials. A previous report (55) gave calculated results of the reactivity coefficients for a variety of plutonium fueled light water reactor systems. The plutonium composition used in the previous study was assumed to be typical of plutonium from a fast reactor blanket or low exposure thermal reactor fuel. As an extension to this study, calculations have been performed for these reactor systems which contain a fuel differing in plutonium composition from that of the previous study. The composition of plutonium assumed for this study is typical of first cycle plutonium fuel from light water reactors.

The previous study was based upon a fuel which contained 92 , and 8 atom percent of ${ }^{239} \mathrm{Pu}$ and $240 \mathrm{Pu}$, respectively. The fuel for this study is assumed to be $62 / 22 / 12 / 4$ atom percent ${ }^{239} \mathrm{Pu} /{ }^{240} \mathrm{Pu} /{ }^{241} \mathrm{Pu} /$ and ${ }^{242} \mathrm{Pu}$, respectively. The fissile atom content was assumed to be equivalent to the $92 / 8$ fuel of the previous study. The effect of fuel rod size on the physics characteristics was also studied. Results of these calculations were given in a recent paper. (48) A brief summary of the results are included here.

\section{Theoretical Methods}

The theoretical methods employed for this study are the same as described in the previous section and consist of using the codes HRG ${ }^{(49)}$ and THERMOS $(50)$ to compute the reaction rates in a representative lattice cell. Cell averaged cross sections were obtained from these calculations to compute the infinite medium multiplication factor, $k_{\infty}$. Control materials and reactor

(55) Liikala, R. C. and Jenquin, U. P., "Physics Survey Calculations for a $\mathrm{PuO}_{2}-\mathrm{UO}_{2}$ Fuel in Idealized $\mathrm{H}_{2} \mathrm{O}$ Power Reactors," BNWL-305, July 1966. 
size (neutron leakage) were not accounted for in this study. Details of the theoretical model are given in Reference (55).

\section{Calculated Results}

The results of the calculations for the $62 / 22 / 12 / 4$ fuel are compared to the values for the $92 / 8 / 0 / 0$ fuel in Figures XXI, XXII, and XXIII.

Figure XXI is a plot of the moderator temperature coefficient versus moderator-to-fuel volume ratio. The data plotted represent the average coefficients from 20 to $225^{\circ} \mathrm{C}$. It is seen that the coefficient is negative but becomes less negative as the moderator-to-fuel ratio increases. There is little difference in the coefficient between the two fuels. The reason for this is that the changes in the nuclear parameters are small and tend to compensate.

Figure XXII shows the calculated Doppler (fuel temperature) coefficient versus moderator-to-fuel volume ratio for the fuel temperature range, 20 to $1020^{\circ} \mathrm{C}$. The coefficient is slightly more negative for the $62 / 22 / 12 / 4$ fue1. Approximately $80-85 \%$ of the Doppler coefficient is due to the ${ }^{238} \mathrm{U}$. Therefore, one would expect Doppler coefficients for plutonium fueled systems to be similar to those observed in uranium fueled systems, with the ones for plutonium fuel being slightly more negative due to the added effect of $240 \mathrm{Pu}$.

An additional reactivity effect for BWR's is due to voiding from coolant boiling. Void effects were represented by uniformly decreasing the moderator density while keeping the moderator temperature at $255^{\circ} \mathrm{C}$ and the fuel temperature at $472^{\circ} \mathrm{C}$.

The reactivity effects due to voiding are similar to those due to increasing moderator temperature, except for the change in the neutron temperature. Since the moderator temperature is held constant, the average neutron temperature changes only slightly; hence $n_{\text {thermal }}$ changes only slightly. The major effects are the increasing of the thermal utilization factor and the decreasing of the resonance escape probabilities. For moderator-to-fuel ratios of interest for BWR designs, the resonance escape effect predominates, resulting in a negative void coefficient. The average coefficient versus moderator-to-fuel ratio is given in Figure XXIII. 


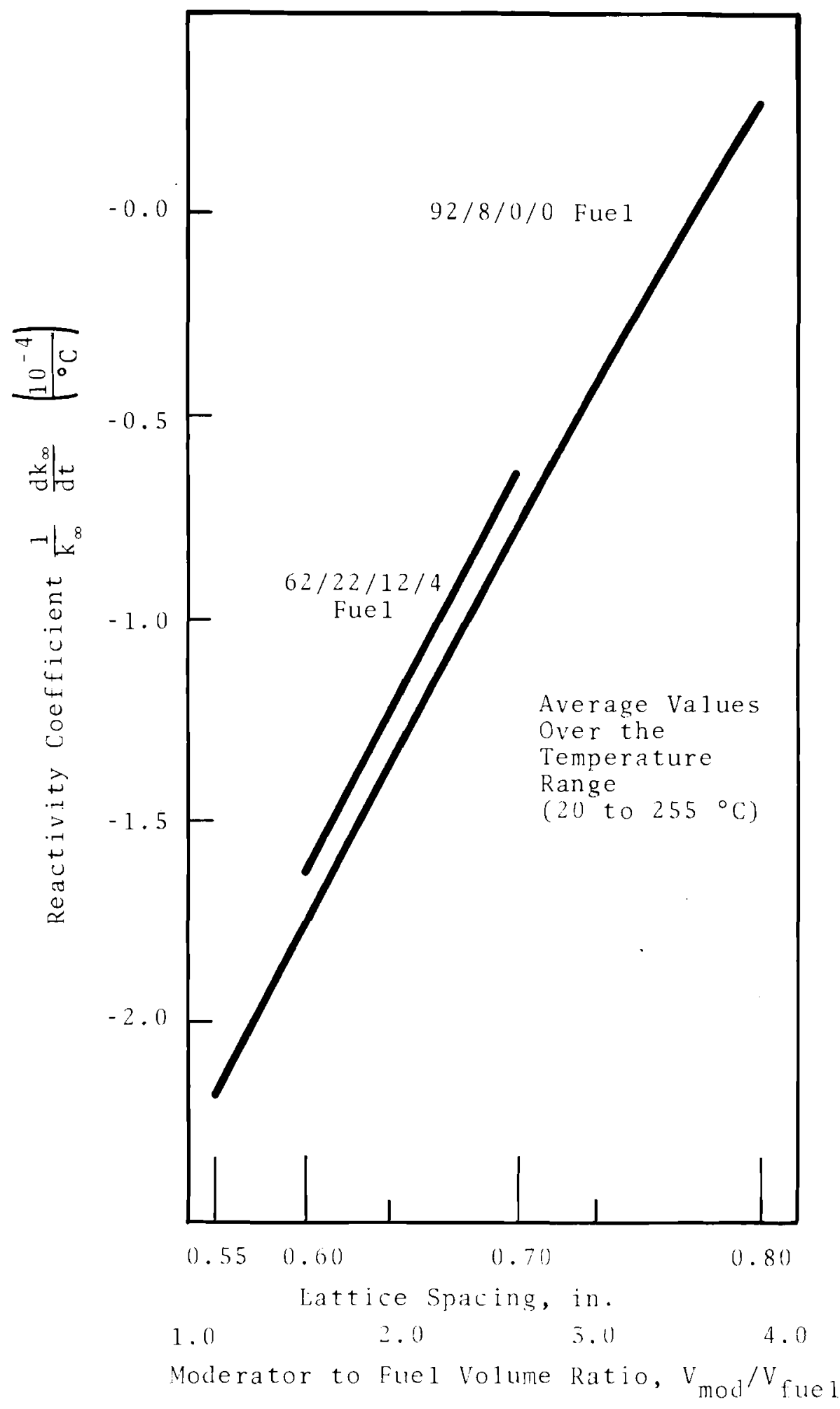

Figure XXI

Moderator Temperature Coefficient of Reactivity 


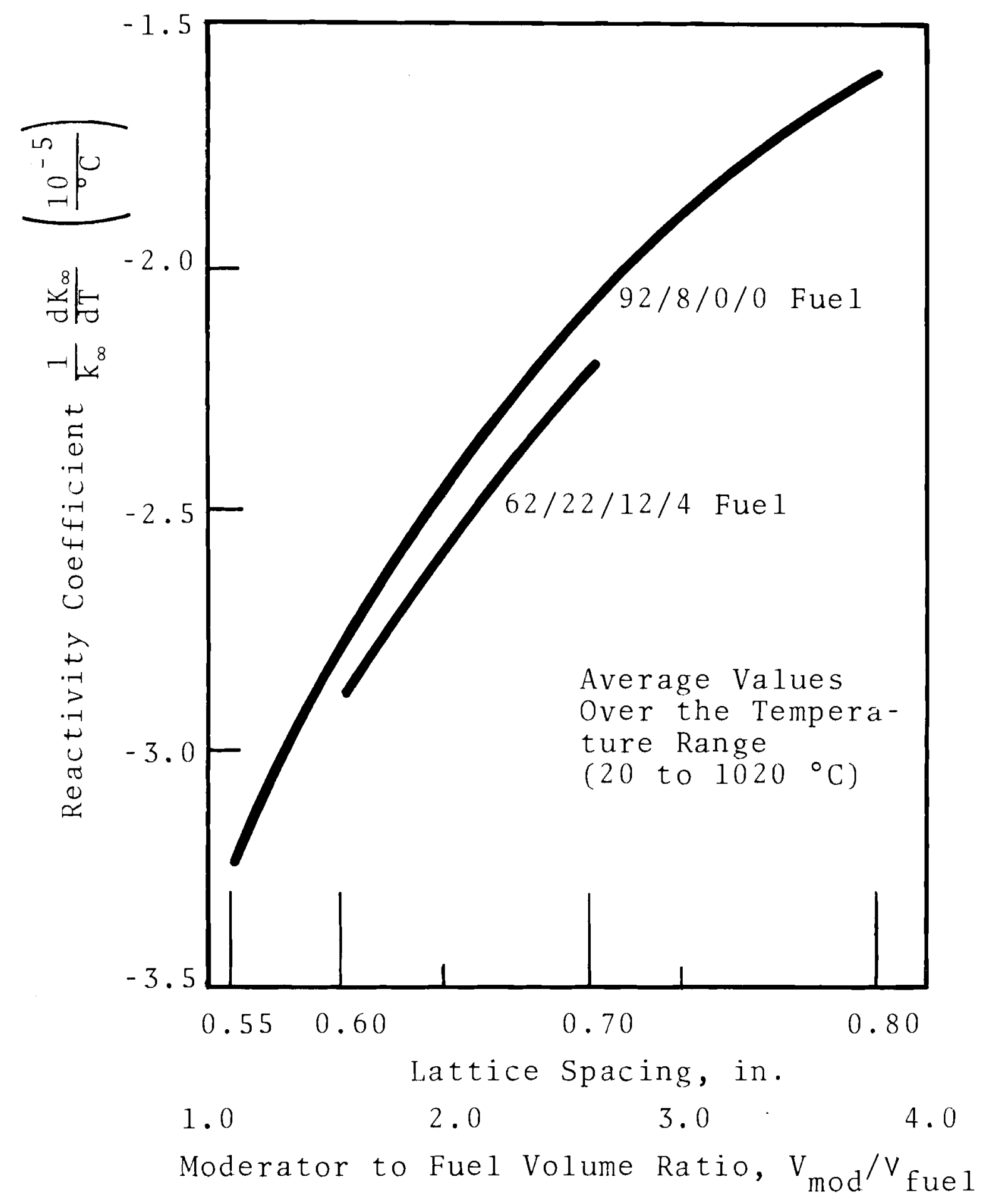

Figure XXII

Fuel Temperature Coefficient of Reactivity 


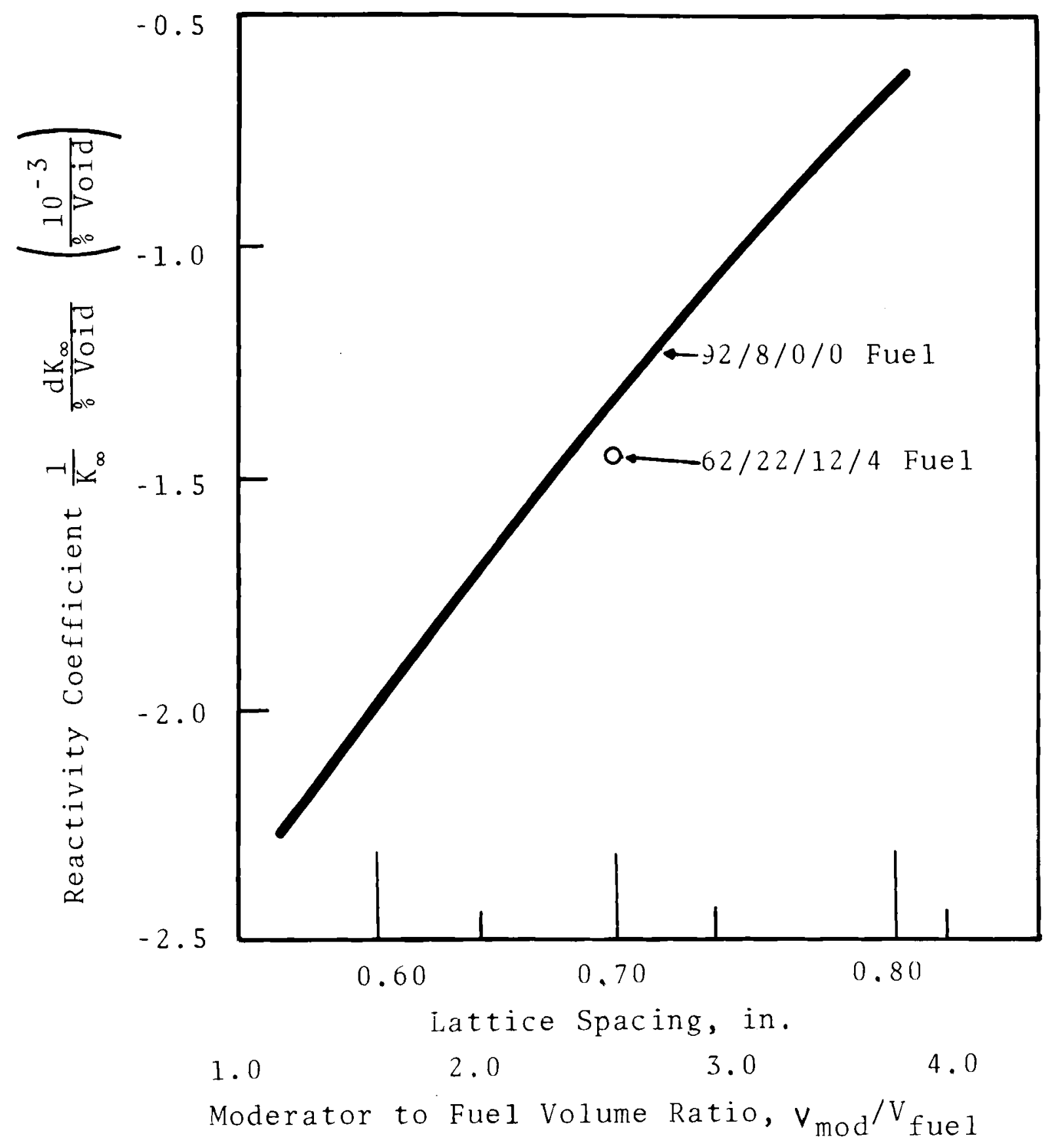

Figure XXIII

Void Coefficient of Reactivity 
for the void range, $0-30 \%$. The coefficient for the $62 / 22$ fuel is slightly more negative than for the $92 / 8$ fuel because of the additional resonance absorption effect of ${ }^{240} \mathrm{Pu}$. The coefficient also becomes more negative with increasing void content.

The effects of fuel rod size on the reactivity coefficients determined for two fuel sizes of interest in current reactor designs. The variation of reactivity coefficients with fuel rod size is shown in Table XVIII. The coefficients are all smaller for the larger size fuel rod.

Photoneutron Calculations for $\mathrm{D}_{2} 0$ Systems - U. P. Jenquin and L. J. Page It is difficult to accurately determine the production of delayed photoneutrons in $\mathrm{D}_{2} \mathrm{O}$ moderated reactor systems. The number of delayed neutrons occurring because of the $(\gamma-n)$ reaction in $\mathrm{D}_{2} 0$ affects the kinetics behavior of these systems.

A study was made to determine the effective delayed photoneutron fraction for some $\mathrm{D}_{2} \mathrm{O}$ moderated reactor systems. Results of calculations are combined with experimentally measured data of the fraction of neutrons produced by a $(\gamma, n)$ reaction from a point source of gamma rays in an infinite medium of $\mathrm{D}_{2} \mathrm{O} \cdot(56,57,58) \quad$ The reactor systems studied were typical of the PRTR $(59)$ configuration.

The number of neutrons produced from the $(\gamma, n)$ reaction in $D_{2} 0$ was calculated for systems containing 19-rod clusters of A1-1.8 wt\% Pu

(56) Bernstein, S., Preston, W. M., wolfe, G., and Slattery, R. E., "yield of Photo-Neutrons from $U^{235}$ Fission Products in Heavy Water," Phys. Rev., 71, pp. 573-581, 1947.

(57) Bernstein, S., Leslie, J. K., McKinney, C. R., Jackson, H. K., "Photoneutrons from $\mathrm{U}^{233}$ and $P \mathrm{u}^{239}$ Fission Products in Heavy Water," J. Appl. Phys. 27, pp. 23-24, 1956.

(58) Keepin, G. R., Wimett, T. F., and Zeigler, R. K., "Delayed Neutrons from Fissionable Isotopes of Uranium, Plutonium, and Thorium," Phys. Rev., 107, pp. 1044-1049, 1957.

(59) Wittenbrock, N. G., walkup, P. C., and Anderson, J. K., "Plutonium Recycle Test Reactor. Final Safeguards Analysis," HW-61236, Sup. 1, October 1, 1959. 
Table XVIII

Comparison of Reactivity Coefficients for Two Rod Sizes at the Same Moderator to Fuel Volume Ratio

$\frac{\text { Fuel Diameter, In. }}{3 / 8}$

Average Moderator Coefficient

20 to $255^{\circ} \mathrm{C}, 1 / \mathrm{k}_{\infty} \mathrm{dk}{ }_{\infty} / \mathrm{dT}\left(10^{-4} /{ }^{\circ} \mathrm{C}\right)$

$-0.74 \quad-0.40$

Average Doppler Coefficient 20 to

$1020^{\circ} \mathrm{C}, 1 / \mathrm{k}_{\infty} \mathrm{dk}_{x} / \mathrm{dT}\left(10^{\left.-5 /{ }^{\circ} \mathrm{C}\right)}\right.$

$-2.20 \quad-1.89$

Average Void Coefficient 0 to $30 \%$

Void, $1 / \mathrm{k}_{\infty} \mathrm{dk} / \%$ Void $\left(10^{-3} / \%\right.$ Void $)$

$-1.45-1.28$


and $\mathrm{UO}_{2}-2 \mathrm{wt} \% \mathrm{PuO}_{2}$ in $\mathrm{D}_{2} \mathrm{O}$, and for an infinite medium of $\mathrm{D}_{2} 0$ containing a point source of gamma rays. The ratio of photoneutrons produced in each reactor loading relative to the number produced in the pure $\mathrm{D}_{2} 0$ system containing the point source is defined as the "photoneutron production efficiency."

To calculate the efficiencies, the space-energy distribution of the gamma rays was determined using the transport theory code, S-XIII. (60) In these calculations a unit lattice cell for an eight inch hexagonal lattice spacing was represented geometrically as concentric cylinders. Isotropic and first order anisotropic cross sections were computed using Program GAMMAX. (61) Values for the $(\gamma, n)$ cross section of deuterium were obtained from Reference (62). The gamma ray energy spectrum was assumed to be the same for both types of fuel.

The calculated efficiencies for producing photoneutrons for the two PRTR systems are listed in Table XIX. Table XIX also lists a result show.ing the effect of replacing the process and shroud tubes with $\mathrm{D}_{2} 0$. Since both systems contain $1 / 2$ inch diameter fuel rods, the differences in calculated efficiencies are a result of differences in fuel composition only.

The calculated efficiencies are combined with the measured photoneutron fractions $(56,57,58,63)$ of pure $\mathrm{D}_{2} 0$ to obtain the effective delayed photoneutron fraction for each system, (the results are given in Table XX). The

(60) Duane, B. H., "Neutron and Photon Transport Plane-Cylinder-Sphere, GE ANPD Program S Variational Optimum Formulation," General Electric, Cincinnati, XDC 59-9-118 (1959).

(61) Page, L. J. and Zwibel, H. S., "Program GAMMAX," Pacific Northwe.t Laboratory, BNWL-CC-773 (1966).

(62) Keepin, G. Robert, Physics of Nuclear Kinetics, Chapter 5, Addison-Wesley Publishing Company, Thc. (1965).

(63) Schmid, L. C., "Delayed Neutron Parameters and Reactivity Measurements in the PRCF," Physics Research Quarterly Report, July, August, September, 1963, H(W-79054, P. 21, Octaber 15, 1963. 
Table XIX

Calculated Efficiency of Al-Pu and UO $2-\mathrm{PuO}_{2}$ Cluster Fuels For Producing Photoneutrons

$\frac{20^{\circ} \mathrm{C} \text { Coolant and Moderator }}{\underline{H}_{2} \underline{0 \text { Coolant }} \quad \underline{D}_{2} \underline{0 \text { Coolant }}} \quad \underline{H}_{2} \underline{0 \text { Coolant }} \quad \underline{D}_{2} \underline{\text { and } 65^{\circ} \mathrm{Colant}}$

Al-Pu (with

process \&

$s$ hroud tubes)

0.2417

0.3477

0.2472

0.3300

Al-Pu (without process \& shroud tubes)
$\mathrm{VO}_{2}-\mathrm{PuO}_{2}$
0.1821
0.2216
0.1838
0.2150

\section{Table XX}

Effective Delayed Photoneutron Fraction For $\mathrm{A} 1-\mathrm{Pu}$ and $\mathrm{UO}_{2}{ }_{2} \mathrm{PuO}_{2}$ Cluster Fuels

\begin{tabular}{|c|c|}
\hline $20^{\circ} \mathrm{C}$ Coolant and $\mathrm{M}$ & $\begin{array}{l}265^{\circ} \mathrm{C} \text { Coolant } \\
\text { and } 65^{\circ} \mathrm{C} \text { Moderator }\end{array}$ \\
\hline$-2 \frac{0 \text { Coolant }}{1}$ & $\underline{\mathrm{H}}_{2} \frac{\mathrm{O} \text { Coolant }}{\mathrm{C}}$ \\
\hline
\end{tabular}

Al-Pu (with process \& $1.096-04$

$1.577-04$

$1.121-04$

$1.497-04$

shroud tubes)

Al-Pu (without process \& shroud tubes)

$\mathrm{UO}_{2}-\mathrm{PuO}_{2}$

$1.037-04$

$1.261-04$

$1.046-04$

$1.223-04$ 
$\mathrm{UO}_{2}-\mathrm{PuO}_{2}$ fueled system contains two fissionable elements, uranium and plutonium. A weighting function which accounts for the fraction of the total fissions occurring in each element was applied in obtaining the effective delayed photoneutron fraction. This fraction was calculated $(64)$ 0.80 and 0.20 for plutonium and uranium respectively.

The calculations could be improved by including a higher order of anisotropy and more angular detail. Because of the absence of experimental cross section values, calculated values were used. The calculated results given above are sensitive to the values of these cross section data.

\section{Cross Section Measurements*}

Slow neutron inelastic scattering cross sections have been reported for $\mathrm{H}_{2} \mathrm{O}$ and $\mathrm{D}_{2} \mathrm{O}$. The double differential cross section and the Egelstaff scattering law have been obtained from measurements for room temperature $\mathrm{H}_{2} \mathrm{O}$ and $\mathrm{D}_{2} \mathrm{O}$ and for $\mathrm{H}_{2} \mathrm{O}$ at five degrees below its freezing point using the Battelle Rotating Crystal time-of-flight Spectrometer. In addition, results of measurements for $\mathrm{H}_{2} \mathrm{O}$ at $95^{\circ} \mathrm{C}$ using the Battelle Triple-Axis Spectrometer have been reported.

The results provide significant information in two areas. One is the area of nuclear reactor design in which a knowledge of the slow-neutron differential scattering cross section is required for accurate calculations of neutron-thermalization effects of moderator and coolant. The second area is the physics of liquids, for which the same scattering cross section provides detailed information on the motions of the hydrogen atoms. The results for $\mathrm{H}_{2} \mathrm{O}$ include the first known observation of well resolved high energy vibrations in liquid water, using the neutron scattering techn ale.

Doubly Differential Cross Sections and the Scattering Law for $\mathrm{H}_{2} \mathrm{O}$ and $\mathrm{D}_{2} \mathrm{O}$ at $299^{\circ} \mathrm{K}$ and for $\mathrm{H}_{2}$ at $268^{\circ} \mathrm{K}$ - 0 . K. Harling

Slow neutron inelastic scattering cross sections have been compiled $(65)$

(64) Worden, J. R., Purcell, W. L., and Schmid, L. C., "Physics Experiment High Power Density Core of the PRTR," BNUL-221, January, 1966.

(65) Harling, 0.K., "Compilation of Doubly Differential Cross Sections and the Scattering Law for $\mathrm{H}_{2} \mathrm{O}$ and $\mathrm{D}_{2} \mathrm{O}$ at $299^{\circ} \mathrm{K}$ and for $\mathrm{H}_{2} \mathrm{O}$ at $268^{\circ} \mathrm{K}$, BNWL-436 June 1967. 
for room temperature $\mathrm{H}_{2} \mathrm{O}$ and $\mathrm{D}_{2} \mathrm{O}$ and for $\mathrm{H}_{2} \mathrm{O}$ at five degrees below its freezing point. The double differential cross section, and from these, the Egelstaff scattering $1_{\mathrm{aw}}{ }^{(66)}$ have been obtained from measurements of scattered neutron spectra using the Battelle Rotating Crystal time-offlight spectrometer. (67) Experimental conditions were designed to provide cross sections over a wide range of energy and momentum transfer space. Maximum energy transfers, by downscattering of $0.6,0.21$ and $0.6 \mathrm{eV}$ with wave vector $(\overline{\mathrm{k}}=\overline{\mathrm{P}} / \overline{\mathrm{n}})$ transfers up to $32,9.5$ and $32 \mathrm{~A}^{-1}$ were used, respectively, with $\mathrm{H}_{2} \mathrm{O}, \mathrm{D}_{2} \mathrm{O}$, and light ice.

The Battelle Rotating Crystal Spectrometer (RXS) was used to provide a small time and energy width burst of slow neutrons on the sample. Timeof-flight (TOF) detectors located around the sample at scattering angles ranging from 15 to $165^{\circ}$ were used to record the TOF spectra of scattered neutrons. Nine or ten detectors were normally used simultaneously to cover the above angular range. Time-of-flight detectors consisted of banks of five, 1 x $10 \mathrm{in.,} 2$ atm ${ }^{10} \mathrm{BF}_{3}$ counter tubes for the $1 \mathrm{~m}$ analyzing flight path and banks of five, $1 \times 15$ in., 8 atm ${ }^{3}$ He counter tubes for the $1.5 \mathrm{~m}$ flight path.

Thin-samples of $\mathrm{D}_{2} \mathrm{O}$ and $\mathrm{H}_{2} \mathrm{O}$ were constructed by stretching two, $0.025 \mathrm{~cm}$-thick high-strength anodized aluminum alloy windows in a rectangular frame. A spacer located between and near the edges of the windows defined the sample thickness.

The energy and momentum transfer range of the $\mathrm{D}_{2} \mathrm{O}$ measurements and the $\mathrm{H}_{2} \mathrm{O}$ ice measurements overlaps and extends to considerably values than most previously reported work. The double differential cross sections clearly exhibit resolved phonon peaks corresponding to both the bending (68)

(66) Egelstaf6. P. A., "The Theory of the Thermal-Neutron Scattering Law," Proceedings of Symposium on Inelastic Scattering of Neutrons in Solids and Liquids, Vienna, pp. 25-37, IAEA, 1960. and Egelstab6. P. A. and Schofield, "On the Evaluation of the Thermal iveutron Scattering Law," Nucl. Sci. and Eng., Vol. 12, pp. 260-270 (1962).

(67) Harling, 0. K., "Phased Rotating Crystal and Chopper for Time-of-Flight Neutron Spectroscopy," Rev. of Sci. Instr. Vol. 37, pp. 697-709, 1966.

(68) Harling, 0. K., "Slow-Neutron Width of 200 meV Vibration Level in Liquid $\mathrm{H}_{2} \mathrm{O}, "$ Phys. Letters, Vol. 22, pp. 15-16, 1966. 
and stretching modes ${ }^{(69)}$ of the water molecule in the liquid and solid phases, as well as the hindered rotation band in the solid.

Examples of double differential cross sections are presented in Figure XXIV, results areshown for water and ice scattering at $15^{\circ}$ and an initial energy of $0.304 \mathrm{eV}$. The structure due to the $\mathrm{H}_{2} \mathrm{O}$ intramolecular bending mode $(-205 \mathrm{eV})$ and the hindered rotational band $(\sim 90 \mathrm{eV})$ is clearly evident in the scattering distributions and is indicative of the high resolution used to obtain the results published in Reference 65.

Values of partial differential cross sections $\frac{\partial^{2} \sigma}{\partial \Omega \partial \mathrm{E}}$, and the scattering law $S(\alpha, \beta)$ are presented in Tables in Reference 65 along with standard deviations. The data are listed for six incident energies between 0.15 and $0.62 \mathrm{eV}$ and 9-10 scattering angles. Such an extensive grid will be useful to accurately represent the scattering kernel for reactor thermalization calculations and to obtain a better understanding of the dynamics and structure of $\mathrm{H}_{2} \mathrm{O}$ and $\mathrm{D}_{2} 0$. A spectral density function, ${ }^{(70)}$ for example, is being obtained from these neutron scattering results.

Neutron Scattering Law for Light Water at $95^{\circ} \mathrm{C}-\mathrm{R}$. B. Smith

Inelastic scattering cross sections for slow neutrons have been presented $^{(71)}$ for $\mathrm{H}_{2} \mathrm{O}$ at $95^{\circ} \mathrm{C}$. The results were obtained from measurements using the Hanford Triple-Axis Spectrometer. (72) Double-differential cross sections were obtained by normalization to the measured scattering from vanadium and were further reduced to the Egelstaff Scattering Law (66) presentation.

(69) Harling, 0. K., "High Resolution Neutron Inelastic Scattering Strdy of water and ICe," BNWL-SA-985A, Presented to the American Crystallograph Association, January 26, 1967.

(70) Egelstaf6. P. A., "The Scattering of Thermal Neutrons by Moderators," Nuc. Sci. and Eng., Vol. 12, pp. 250-259, 1962.

(71) Smith, R. B., "Some Measurements of the Neutron Scattering Law for Light water at 95\% C, "BNWL-345 (1967).

(72) Kottwitz, D. A. and Leonard, B. R., Jr., "The Scattering Law for Room Temperature Water," IAEA Proceedings, Chalk River, Vol.1, pp. 359, 1963. Also issued with tables of the data, as HW-75526, November, 1962. 


\section{$\mathrm{H}_{2} \mathrm{O}$ SCATTERING CROSS-SECTION \\ $E_{O}=0.304 \mathrm{eV}, \theta_{S}=15^{\circ}$}

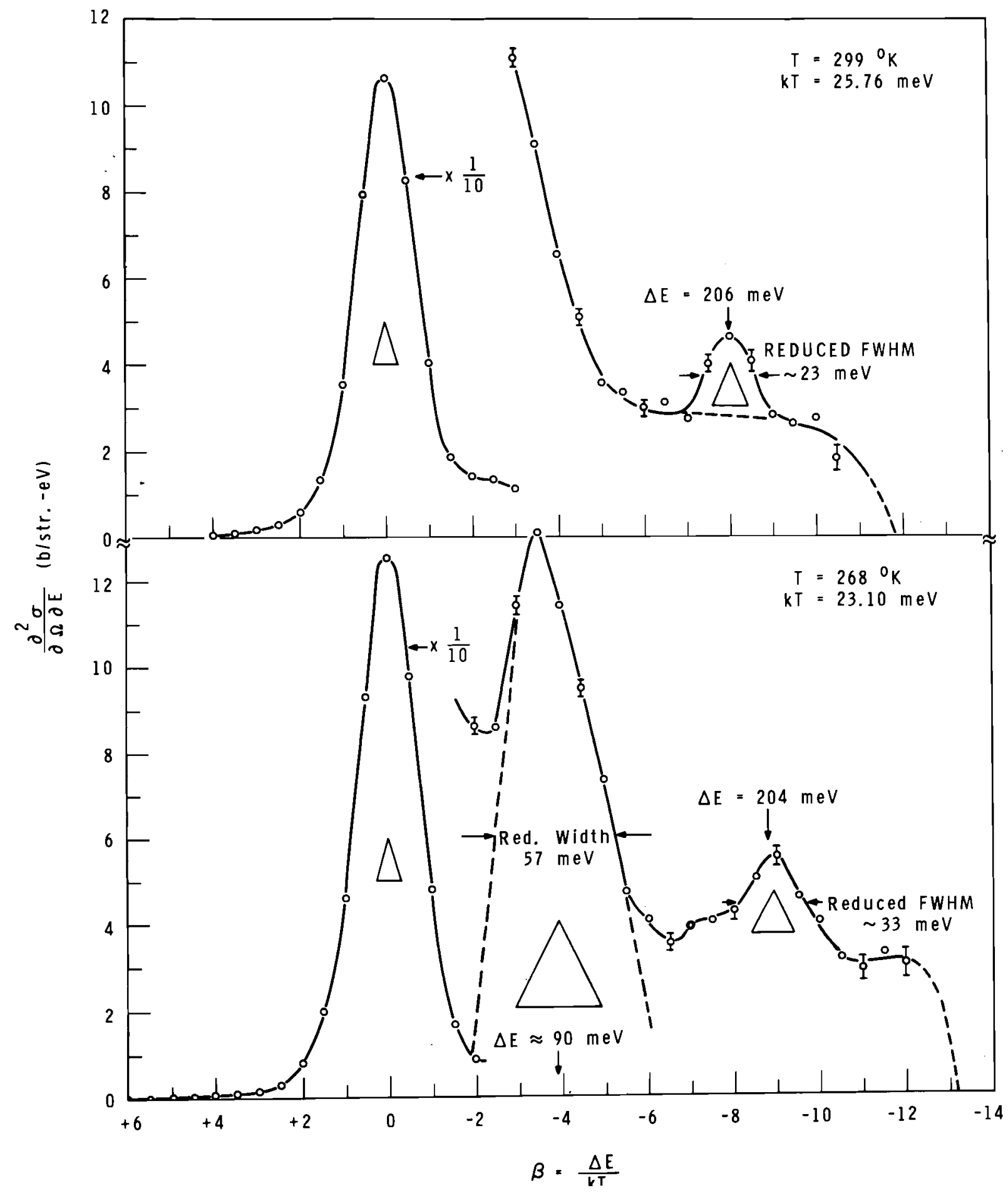

Figure XXIV

Double Differential Scattering Cross Section Measured at $15^{\circ}$ with an Initial Energy of 0.304 $\mathrm{eV}$ for Water and Ice 
The monochromating spectrometer is heavily shielded, and the scattering angle and crystal orientation are set manually at the first axis to provide a monoenergetic beam emergent from the shield. The monochromomator crystal was a beryllium crystal of exceptional uniformity. The neutrons scattered from a sample placed at a second axis were selected in energy by the analyzing spectrometer.

Samples of water were confined in a heated holder assembly between two layers of stretched aluminum foil. The sample region was 2 in. diameter and nominally 0.033 in. thick. The geometry was such that scattering angles up to $70^{\circ}$ could be used without the frame of the sample holder interfering with the scattered beam.

The analyzing spectrometer was the subject of greatest change from a configuration previously used. (72) Initially, it differed only in the use of a 1 inch diam, $8 \mathrm{~atm}, \mathrm{He}^{3}$ proportional counter for the third arm detector. The analyzing crystal was the same $1 / 4$ inch thick beryllium slab parallel to the (0002) planes. These planes, in reflection geometry, were the only ones of sufficient reflectivity for making these measurements. Subsequent observations indicated that the use of these planes in this manner could result in systematic errors in some of the data and motivated a change to a copper analyzer crystal. The copper (200) planes were used in transmission geometry. Partly for the same reasons, a change was made in the detector. An end window ( 2 inch diam), 1 atm $\mathrm{BF}_{3}$ proportional counter was used in a larger and more effective cylindrical shield.

The analyzer collimators also had removable cadmium collimating strips which permitted a choice of energy resolution. The available values of $\Delta \theta$ in Bragg angle were $0.48,0.77$ and $1.05^{\circ}$.

Neutron spectra of inelastically scattered neutrons were obtainet with a beryllium analyzer crystal and with a copper crystal. Results were obtained for neutron energy changes of 40 to $175 \mathrm{meV}$ and scattering angles between 4 and 70 degrees. The initial energy values ranged from 100 to 377 meV.

Data are presented $(71)$ as graphs of the scattering law $S(\alpha, \beta)$ versus $\alpha$ for several values of $B$ and in tabular form. Also included in the tables are values of the double-differential scattering cross section. 
Several sources of systematic errors in triple-axis spectrometer measurements were investigated. These include the effect of spatial nonuniformities in the neutron beam intensity and in analyzer sensitivity as well as multiple diffraction in beryllium monochromator crystals (simulated (0003) reflections were noted). The magnitudes of these effects and methods of minimizing their contributions are discussed in Reference 71 . Also described is a copper monochromator crystal in which mosaic was increased by mechanical deformation.

Many measurements were made to check on the accuracy and reproducibility of the results. The scattering law for some values of $\alpha$ and $\beta$ was obtained under a. fferent conditions of initial and final neutron energy as well as under different resolutions for the same energy values. These measurements showed inconsistencies in the magnitude of $S(\alpha, \beta)$ to often be 10 to $15 \%$ and cocasionally 20 to $25 \%$.

The principal explanation for these discrepancies was found to lie in th geometry of the incident beam, its intensity distribution over the sample, and similarly, the sensitivity of the analyzer over the sample area. It was assible to minimize much of the discrepancy originally observed, but it is appareit. that there are inherent limitations to the accuracy of intensity measurements made with crystal spectrometers. Some of the limitation is due to the use of multiple-slit Soller collimators.

Although it is reasonable to assume the cross section varies slowly with energy and scattering angle, the same cannot be said for $S(\alpha, \beta)$. Because of an exponential factor, $e^{\beta / 2}$, the value of $S(\alpha, \beta)$ is very sensitive to changes and uncertainties in the energy change, $B$, especially at large values. Thus, on a fractional basis, variations $\delta \beta$, through the exponential factor alone, give rise to variations $\delta S$ of

$$
\frac{\delta S}{S}=B^{2} / 2 \frac{\delta B}{B}
$$

For this reason the statistical errors, uncertainties in normalization, and other errors evidenced by comparison of different measurements may not represent the largest uncertainty in the values stated for $S(\alpha, \beta)$. For example, a value of $\beta=5$, known with an accuracy of $5 \%$, results in an 
uncertainty of $60 \%$ in the value of $S(\alpha, \beta)$. This sensitivity to $\beta$ is of consequency when comparisons are made between theoretical models and experimental results. Measured intensity is not very sensitive to errors in energy, and the exponential factor does not influence comparisons between different experimental results--even those obtained with different apparatus. For this reason it is suggested that for many purposes experimental results could be presented, compared, and discussed as a function of the form $\left[e^{-\beta / 2} \cdot S(\alpha, \beta)\right], i$ e, the scattering law with the exponential factor removed. This form retains many of the advantages of $S(\alpha, \beta)$, being still a function of the two dimensionless variables, $\alpha, \beta$, and no other external variables. The uncertainty in the value of $\beta$ could be stated separately, and its effect would remain distinct from other sources of error until a conversion to $S$ is made for comparison with theoretical results,

Completion of Fast-Neutron Iotal-Cross-Section Measurements - D. G. Foster, Jr. and D. W. Glasgow

The final block of measurements for the total-cross-section program (73) was taken in October and November, 1966. The run encompassed 48 samples, and provided approximately $1 / 5$ of the entire body of raw data. Data-reduction has now been completed, and the results are ready for publication and distribution.

The complete set of final results include neutron total cross sections from 2.25 to $15 \mathrm{MeV}$ for the following samples:

(1) Seventy-eight naturally-occurring elements (the only omissions are the noble gases and the highly-radioactive elements he than bismuth);

(2) Fourteen isotopically-enriched or artifically-produced samples: $\mathrm{D}, \mathrm{Li}^{6}, \mathrm{Li}^{7}, \mathrm{Ca}^{42}, \mathrm{Ca}^{+4}, \mathrm{Cr}^{53}, \mathrm{Tc}^{99}, \mathrm{Pm}^{147}, \mathrm{~W}^{182}, \mathrm{~W}^{186}, \mathrm{~Pb}^{206}$, $\mathrm{U}^{233}, \mathrm{U}^{235}$, and $\mathrm{Pu}$; the results for $\mathrm{Li}^{6}, \mathrm{Ca}^{+2}, \mathrm{Ca}^{44}, \mathrm{Cr}^{53}$, $\mathrm{W}^{382}, \mathrm{~W}^{36}, \mathrm{~Pb}^{206}, \mathrm{U}^{233}$, and $\mathrm{U}^{235}$ have been further enriched algebraically by combining the results from more than one isotopic mixture;

(73) Foster, D. G., Ir. and Glasgow, D. W. "Method for Measuring Total Cross Sections wxth Neutrons Having Energies from 2.5 to $15 \mathrm{MeV}, "$ Nucl. Instr. and Math, 36, $1: 1965:$. 
(3) Algebraic enrichments of 5 is topes which dominate their natura1 isotopic mixtures: $\mathrm{Ca}, \mathrm{Cr}^{5}, \mathrm{~W}^{-8}$ (to $68 \mathrm{at} \%$ ) $\mathrm{Pb}^{2 J 8}$ (to $70 \mathrm{at} \%$ ), and $U^{? ? 2}$; and,

(4) Two common abnormal jsotopic mixtures, radiogenic lead (89at\% $\mathrm{Pb}^{206}$ ) and enriched uranium (93at\% $\mathrm{U}^{2} 35$ ).

Thus, there are 99 records in the final list, comprising 24,112 data points.

Three severe instrumental problems which were present in the apparatus at the end of 1965 were eliminated before the final run. The first of these, electronic loss of stored data in memory or during output, was eliminated by replacing the home-made 400-channel analyzer with a PDP-8 computer. The second, unreliable punching of the paper-tape output, was eliminated by replacing the old tape perforator with a Tally P-120 perforacor with a parity-checking attachment (however, the entire 1966 run was punched out without a single parity fault!). The third, a counting-rate-dependent instability in the zero point of the trme-of-flight scale, was not positively diagnosed until the end of 1965, when the over-all stability of the apparatus became good enough to permit unambiguous diagnosis. It was cured (albeit rather reluctantly) by replacing the vernier chronotron with a combination of a commercial time-to-pulse height converter and a commercial analog-todigital converter. The latter had been furnished with the computer. The former was purchased from Edgerton, Germeshausen, and Grier along with the necessary auxiliary modules to provide logical control. The new apparatus was interfaced to the computer as a single system, using the modules manufactured by Digital Equipment Corp., which also manufactured the PDP-8 computer and built the interface equipment for the analog-to-digital converter.

A supervisory program (TOFDAD) for taking time-of-flight data on th= PDP-8 was prepared by modifying S. N. Samsky's Dual One-Dimensional Ana" : $^{\text {, }}$ and Display program (DODAD) ${ }^{(74)}$. The major modifications included:

(1) Inclusion of the necessary commands for the time-of-flight interface circuits;

(74) Samsky, D. N. "Dual One-Demensional Analyses and Desplay Program," BNWL-299, Parefec Northwest Laboratory. Richland, Washengton, September, 1966. 
(2) Conversion to 500 channels of double-precision storage in quadrants 2 and 3 of the 4096-inord memory, with memory protection of the fourth quadrant (which contained the overflow of the program; DODAD is written entirely in the first quadrant);

(3) Modification of the display routines to accommodate doubleprecision words from 63 counts to 8195 counts full-scale;

(4) Punchout with paxity checking and error correction on the P-120 tape perforator, in Friden 8-level code, with automatic run-number incrementation and inclusion of the special characters required for reading by the paper-tape-to-card program TCS,

(5) Incorporation of $a$ routine to calculate centroids of peaks in double precision including subtraction of background; and,

(6) Zero suppression in the decimal printout routines.

In addition, two independent utility programs were stored in the fourth quadrant, a test program for the tape perforator (written by C. N. Greenwell), and a Flexowriter-simulation program (originally written by R. E. Draper) to convert the paper-tape output into typewritten pages.

The performance of the new equipment amply justified the effort expended in making the changes. There was, however, one major instrumental problem which seriously threatened the run. A minor instability in the performance of che detector, which we have suspected for several years but never identified, becan: conspicuous when the pulse-shape discrimination of the detector abruptly disappeared, After a lengthy search, the cause was traced to some unstable parameter in the 58 AVP photomult.plier, which could not be detected .... iny operating characteristic except the manner in which space charge in tre collector region is formed and dissipated following a large pulse. Thus, tt affected the pulse-shape discrimination which rejects photon-induced background without changing the pulse-height discrimination which determines the threshold of the detector. The problem was cured by replacing the faulty photomultiplier.

After rebuilding the detector the vuer-all stability of the time-of- 
flight system justified the performance of another experiment, following the completion of the scheduled transmission measurements. The additional experiment consisted of gathering further (probably conclusive) evidence for the nonexistence of a supposed level in the $B$ nucleus at $2.86 \mathrm{MeV}$. If such a level exists, it should produce a discrete neutron group in the time-of-flight spectrum of the $B^{3}(\mathrm{~d}, \mathrm{n}) \mathrm{B}$ ? reaction, which we use for calibrating the time scale of our equipment. Accordingly, we spent several hours optimizing the time resolution and background rejection of the apparatus, and removing all possible extraneous scattering material from the neighborhood of the beryllium target and then accumulated the spectrum from a target 89 $\mathrm{keV}$ thick until the height of the ground-stare peak reached 10,000 counts/ channel. Four successive measurements were so dearly identical in time scale that they could be combined into a single moasurement without degradation of the resolution. The peak/background ratio relative to the ground-state group was $650 / 1$. We found no evidence for the $2.86 \mathrm{MeV} \mathrm{level,} \mathrm{and} \mathrm{set} \mathrm{an}$ upper limit for the intensity of a transition to this level of one-third percent, relative to the two transitions which flank it in energy. A paper describing this work has been published. (75)

Processing of the transmisston data to obtain total cross sections followed the sequence devised earlier in the program. The punched paper tape was converted to punched cards (program TCS), and the cards used for entry into the primary data-reduztion program (BIG NED), usually by way of a magnetic tape coded in NTRAN records for the UNIVAC 1107 computer. The output from BIG NED consists of total cross sections for a particular sample, using all of the data acquiced under purportedly identical experimental conditions. A second program (LI'L NED) then serves to prepare combined results for several measurements taken under different conditions. BIG NED contaín: routine for compensating the counting-rate-dependenc shift in time zero. This procedure removes most of the resulting spurious structure in the cross sections above $11 \mathrm{MeV}$, but only at the expense of introducing some covariance

(75) Glasgow, D. $w$, and Foster, D. G., Jr., "Beid, $n ! \cdot{ }^{\circ} B$ Reaction and the Exustence of the ?.86 MeV Level in B." "Nucl. Phys., A99, 170 (1967). 
into the results. The covarlance is enhanced when runs are combined, so both BIG NED and LI'L NED must use fully covariant calculations,

The amount of residual spurious structure which remains depends partly on the severity of the original insrability, which varied with time, and partly on the slope and curvature of the cross section in the critical energy range, which varies with mass number. Since the total cross section is given by

$$
\tau_{T}=\Sigma \ln \mathrm{R},
$$

where $C$ depends on the thickness of the sample and $1 / R$ is its transmission, the error in the total cross section saused by a snall shift in time zero is given by

$$
\mathrm{d}=-\mathrm{C} \frac{\mathrm{d} R}{\mathrm{R}},
$$

and hence is proportional to the relative slope, d: /, of the source spectrum. Since the relative slope is easily determined to depends only on deuteron energy and effective resolution width), cocrections for the residual error can be made by subtracting from the apparent cross section a sultable multiple of the relative slope.

The actual prosedure used was to subtract est mated correstions from the data abore $11.5 \mathrm{MeV}$, using the contaminant-subtraction routine in LI'L NED, and generate punched cards with the resulting adjusted cross sections. These cards were then entered into the short covariant-least-squares fitting program COVFT, which was originally wricten for the analysis of the deuterium cross section near the di-neutron threshold, in order to determine the chi-square for fitting a second-degree polynimial to the cross section above $11.5 \mathrm{MeV}$ (the deuterium analysis has been published $(76)$ ). The behavior of -3 -aguare near the corrert value of slope-error contamination is aqadratic, $\cdots$ at the correct amounc of contamination to subtract can be detarmined from the uncorrected data and two estimated correzions. A correztion determined in this manner was applied orex $\mathrm{rhe}$ ent re energy range to approximately $1 / 3$ of the elements; for the others the amplicude of the spurtous structure was already less than $1,5 \%$ and no additjonal correction was deemed necessary. The shape of the relative-slope error is so characteristic that this

(76) Glasgow, D (i. and Foster, D. G., Ir., "n-d Total Cross Section, Thre2Nucleon Problem, and the De-neutron," Phys. Rev., 57, $764.1967 !$. 
correction scheme works even for the light elements, such as nitrogen and carbon, in which there is genuine structure in the cross section at these energies.

A few miscellaneous errors were also removed during the final stages of data processing. Several samples which had been prepared in powdered form were found to exhibit the characteristic structure of the oxygen cross section. By comparing these cross sections to those of neighboring elements (or of other isotopes of the same element) as templates, it was easy to determine whether the actual contamination was due to elemental oxygen (as in our $W^{186}$ sample) or to water vapor (which appeared as a fixed contaminant in Te, but increased with time in $\mathrm{As}$ and $\mathrm{Re}$ ), and to determine the magnitude of the contamination within a few tenths atom-percent. Comparison between our older measurements and those on new - and more carefully prepared - samples of $\mathrm{Li}, \mathrm{Na}$, and $\mathrm{K}$ revealed (as anticipated) errors in the densities ascribed to the older samples. Similarly, our first measurements on $\mathrm{C}, \mathrm{S}$, and $\mathrm{Ca}$ all had errors in energy scale, which can be traced to the fact that our earliest work used the interval between the upswing and downswing bursts in the beam-pulsing system to calibrate the time scale. We then assumed that this interval was equal to one-half the period of the deflection oscillator, instead of calibrating against the full period of the oscillator as in all of our later work. The length of the two half-cycles frequently differs by as much as $1 \%$. In these three cases we used our newer measurements to determine the correct average channel width in the older measurements by matching the pronounced fine structure in the respective cross sections, and repeated the original data reduction using the corrected channel width.

Because of the press of other work, progress on the publication of this work has been slow. The results have been compared with the existing literature, . using LI'L NED, primarily by working from a magnetic-tape excerpt of the Livermore library prepared by R. J. Howerton, supplemented by additions and corrections of our own. Numerous errors in the Livermore library were discovered during the comparison process, and these remain to be corrected. Various tabular summaries of the comparisons are partly completed. A program for plotting isometric projections of the data on the Benson-Lehner plotter has been written, but the plotting has not been carried out. Tabulations of the 
complete set of data will be prepared as a BNW formal reporc, since they are tos bilky for fublication in an archive journal. In themeantime, a numerical copy of the final results has been sant to the Sigma Center ar Brookhaven, from whach it wil enter the international coeperative neutron data compilation system, Copses arealso being sent, on request, to the local compilation groups at the major AEC laboratories.

The Dineutron and n-d Total Cross Secrion - D. W. Glasgow and D. G. Foster, jr. Detailed knowledge of nuclear interactions is obrained from studies of very simple nuclear systems. Such a simple system is obcained by bombarding deuterium with neutrons.

The n-d total sross section was measured at 241 diffarent energies to a precision of $5.7-1.0 \%$ and an energy resolution of $2.0-5.1 \%$ for $2.25=E_{n}$ $=15.0 \mathrm{MeV}$. The results support the correctness of present three-body calculations, and exhibit no evidence for a wigner cusp near the predicted threshold ror dineutron production. In the absence of suh a cusp, an expa ment of this type furnishes very little information regarding the existerce the dineutron, or wolat oos of cha:ge independen

The Existenze of the 2.86 MoV State in B - D. W. Glasgow and D. G. Fos:en,

The intense gamma ray thash and the neutron group resilting from the nuclear reaztion " $\mathrm{Be} d, n, \cdots B$ have been used for calibrating the energy siale and datermining the form of whe resolution funtion for the experimentally measured neutron rotal cross sections. There has been a controversy, for

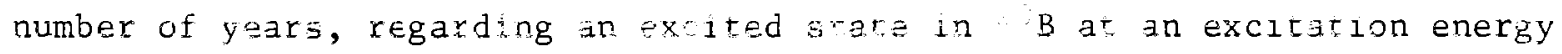
of $2.86 \mathrm{MeV}$. In order to resolue this controversy, z detailed stud was mat of the Beld, n; B reation, is,

The stud, pranted ns exdence for the existence of an excited trats 1.1

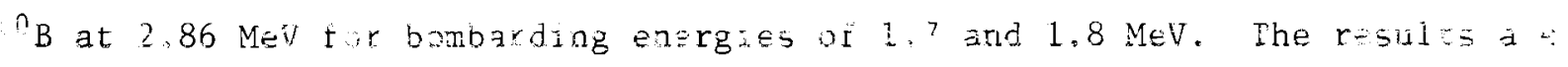

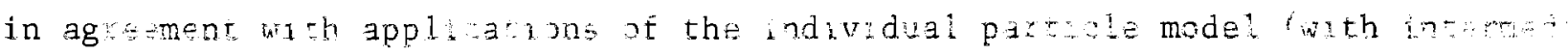
coupline to the nutea, lp-she!l.

(77) Glasgw, D. Wh and F tor, D, G, 3i. "n-d Total cross Secteon, ThreeNuleon Problem, and the Dineutron", Physical Revew, :57, $764: 19671$.

178, Glasgow, $D$, $W$ and Foter, $D$ G, Jn., "Be $d, n$ B Reaction and the Exstonge 06 the? 86 MeV State in "B". Naclear Physes, A99, 10 96? 


\section{Methods Development}

Calculation of Thermal Neutron Scattering Cross Sections - C. W. Lindenmeier and A. G. Gibbs

Knowledge of the Legendre moments of moderator scattering cross sections is required to analyze thermal reactors. In the Egelstaff-Schofield formalism the Legendre moments of the scattering cross section can be computed in two different ways: The scattering law $S(\alpha, \beta)$ can first be computed, and the moments of the cross section obtained by integrating $S(\alpha, \beta)$ over angles,

$$
\sigma_{n}\left(E \rightarrow E^{\prime}\right)=\frac{\sigma_{b}}{2 K T}\left(E^{*} / E\right) \frac{1}{2} e^{-\beta / 2} S(\alpha, \beta) \operatorname{Pn}(\mu) d \mu
$$

where

$$
\begin{array}{ll}
S(\alpha, \beta)=\frac{1}{\pi} \int_{0}^{\infty} e^{-\alpha \omega(t)} \cos B t d t \\
B=\frac{E^{-}-E}{K T} & \alpha=\frac{E^{\prime}+E-2 \mu \sqrt{E^{\prime}}}{A K T}
\end{array}
$$

or alternatively, the integral representation of $S(\alpha, \beta)$ can be integrated analytically over angles to provide a representation of the $n^{\text {th }}$ moment of the cross section as a cosine transform:

$$
\begin{aligned}
\sigma_{n}\left(E-E^{\prime}\right)= & \frac{\sigma_{b}}{k T}\left(\frac{E^{*}}{E}\right)^{\frac{1}{2}} e^{-B / 2} \\
& \int_{0}^{\infty} \cos B t e^{-B \omega(t)} i_{n}(C \omega(T)) d t .
\end{aligned}
$$

Here, $B=\left(E+E^{\prime}\right) / A k T, C=2 \sqrt{E E^{\prime}} / A k T$, and $\omega(t)$ is the time-dependent $N^{\prime} r$ function, determined from experiment or model calculations.

Both of the above approaches are being developed (Program SCTMOM and SMOMFT), since each has advantages in certain applications.

In either calculation of the moments Eq. (1) or Eq. (2) a special treatment for the large time contribution has been developed. (79)

(79) Gibbs, A, G, and Lindenmecer, C. W., "Analytical Evaluation of the Large Time Contribution to Neutron Scattering Cross Sections," IAEA Symposium on Thermalization and Reactor Spectra, University of Michigan, July 1967, to be published! 
Since $\omega(t)$ has a simple asymptotic form at large $t\left(\omega(t) \sim J t^{2}+K / 4\right.$ for the present BNW water model) it is advantageous, when $\beta$ is small, to subtract out the large $t$ contribution and evaluate it analytically. The results can be expressed in terms of exponentials and error functions, and are generalizations of the ideal gas results. The remaining contribution must still be evaluated numerically, but it can be computed more rapidly and accurately than the original integral.

The analytical treatment of the large $t$ contribution is also useful for the calculation of the integrated cross sections

$$
\sigma_{n}(E)=\int_{0}^{\infty} \sigma_{n}\left(E \rightarrow E^{\prime}\right) d^{\prime}
$$

The large $t$ contribution gives rise to the quasi-elastic peak in which $\sigma_{n}\left(E \rightarrow E^{\prime}\right)$ is rapidly varying, and if this contribution is evaluated analytically the numerical evaluation of the remaining contribution in Eq. (3) requires only a few energy points. The integration of the large $t$ contribution to $\sigma_{0}\left(E \rightarrow E^{\prime}\right)$ over final energies has been successfully carried out, and an expression for the integral of the large $t$ part of $\sigma_{1}\left(\mathrm{E} \rightarrow \mathrm{E}^{\prime}\right)$ obtained as a power series in $\mathrm{J}$, which is a small parameter for water.

Since the numerical contribution in Eq. (2) is evaluated by summing contributions from successive half-cycles of Cos $\beta t$, a special treatment was required for $\beta=0$, and this point is now handled properly by a straightforward numerical technique in calculating the elastic cross section $\sigma_{n}\left(E \rightarrow E^{\prime}\right)$.

Practical calculations of the scattering law $S(\alpha, \beta)$ and its angular moments require developing accurate approximations which will increas? the speed of the calculations. As $\beta$ increases in size the contrib-ion to $S(\alpha, \beta)$ due to low energy resonances in the frequency spectrum can be treated by replacing a certain sum over a binomial distribution by an integral over a gaussian distribution, which can be evaluated analytically. The results is an expression for $S(\alpha, \beta)$ identical in form to Eq. ( 1 ) but with a simpler $\omega(t)$. Thus, this approximation can also be used implicitly in SMOMFT by replacing the actual $w(t)$ by the new approximate form. 
An altexnative approximatun, which can also be "1sed in both codes, treats the part of wit) due ro bo energy resonances by a short time expansion and the part dio to high energy resonanzes by a large time expansion. The azsuracy of the shor: time expansion is greatly improved by expanding $w(t)$ about $t=-/ 2$ rather than about $t=0$, since this insures that the first few Placzek mom=nrs of the rosos section will be exact.

The final version SMOMF $T$ w 11 offer the user the oprion of calculating $S(\alpha, \beta)$ or $n\left(E \rightarrow E^{\prime}\right)$ with the exact $j(t)$, or of reductng the computation time by using one of the above approximations. To reduce computer time to a practical linit, the short time expansion of wt, is intinsically programmed into SCTMOM, as is the assumption that the time-dependent width function $w(t)$ can be represented as a sum of Gaussians.

Both methods of calculating Iegendre moments of the scattering cross section have been successfully programmed, and the resulting programs give agreement with expected a:curazy for the same v(t).

On the basis of available experimental data, an appropriate wht for generating scattering moments for water is currently being evaluated.

Space-Angle Synthesis - H. S. Zwibel

Space synthesis has proven to be $a$ useful approximation to the multidimensional diffusion equarion. Spare-angle synthesis approximations to the transport equation may prove to be equally useful. In several siudies related to space-angle synthesis, Kaplan, et $a l^{(80)}$ have found that a significant improvement over Pl cheory is possibie even though the spaceangle synthesis used by them is mathemacically equivalent to P1 theory,

As a further test of spare-angle synthesis, H. S. Zwibel (81) has analyzed the critical slab problem.

The starting point for space-angle synthesis is a varjational expression for the zharanteristic of interast, whoh in che case of the critical slab is "c", the mean number of secondarigs per zollision necessary to achieve criticality. The variational functional used is:

(80) Kaplan, S., Daves, J, A., Natels:n, M., "Angle-Space Synthesis - An. Approash to Transport Approximation:,"NSEE, Vol. 28, No. 3 IJune 1967.

(81) Zwebel, H. S., "An Angilar Synthess Approximation Appleed to Thin Critisal Slabs," Trans. Am Nual. Sic, '0, : June 967 :. 


$$
\begin{aligned}
& c_{t}=2\left\{\int_{-a}^{a} d x \int_{-1}^{1} d \mu f_{t}(x,-\mu)\left[\mu \frac{\partial}{\partial x} f_{t}(x, \mu)+f_{t}(x, \mu)\right]+\int_{0}^{1} d \mu \mu f_{t}(-a,-\mu)\right. \\
& \left.f_{t}(-a,-\mu)-\int_{-1}^{0} d \mu \mu f_{t}(a, \mu) f_{t}(a,-\mu)\right\}\left[\int_{-a}^{a} d x \int_{-1}^{1} d \mu f_{t}(x,-\mu) \int_{-1}^{1} d \mu^{\prime} f_{t}\left(x, \mu^{\prime}\right)\right]-1
\end{aligned}
$$

where " $a$ ' is the slab half-thickness; $f_{t}(x, \mu)$ is the trial flux function; and $c_{t}$ is the resulting approximate "c".

The trial function used in this report is

$$
f_{t}(x, \mu)=\cosh \times g_{1}(\mu)+\sinh x g_{2}(\mu),
$$

where $k, g_{1}(\mu)$, and $g_{2}(\mu)$ are to be chosen such that $c_{t}$ is stationary with respect to small variations to these quantities.

Note that spatial trial functions are chosen. The angular functions are then obtained by solving a pair of coupled integral equations. (Kaplan chose angular trial functions and solved the resulting "P1-like" equations for the spatial functions.)

The results for several cases (presented below in Table XXI) are quite encouraging. For comparison, P1 theory yields $c=2.4$ for "a" $=.3108$, which is in error by $20 \%$; whereas $c_{t}$ is in error by only .4\%. A significant improvement over P1 theory is achieved by space-angle synthesis for the critical slab problem.

$\underline{\text { Table XXI }}$

\begin{tabular}{c|l|c}
\multicolumn{1}{c}{$a$} & \multicolumn{1}{c}{$c_{t}$} & $c($ exact) \\
\hline 5.6655 & 1.020031 & 1.02 \\
2.1134 & 1.10047 & 1.10 \\
1.2893 & 1.2013 & 1.20 \\
.7366 & 1.4032 & 1.40 \\
.512 & 1.6049 & 1.60 \\
.3887 & 1.8067 & 1.80 \\
.3108 & 2.0088 & 2.00
\end{tabular}

(82) Sargis, D. A., "Orthogonal Polynominal Solutions to the Integral Transport Equation," Trans. Am. Nucl. Soc., 10, 1 (June 1967). 
Effective Cross Sections for Resonances in HRG - J. L. Carter

One of the distinguishing features of the GAM-i calculational scheme for determining the energy spectrum of epithermal neutrons is the method of treating resonance contributions of the principal resonance absorbers. The resonance integrals of individual resonances are found and these are converted into effective fine group cross sections by dividing by a fine energy group flux. GAM and HRG until recently, has used a $1 / \mathrm{E}$ flux for this conversion. This procedure has not correctly allowed for spatial and energy self-shielding effects. A recent revision in HRG (Hanford Revised Gam) has modified this : eff calculat: on by using, instead of the $1 / \mathrm{E}$ flux, an approximation of the flux used in the resonance integral calculation itself. It was also assumed that unbroadened cross sections and the Wigner rational approximation to the collision probability could be used. The resulting divisor of the resonance integral, instead of the value 0.25 previously used, becomes

$$
n d E \phi(E)=0.25-\frac{N_{c e 11}}{N_{\text {fue } 1}} \frac{b}{\left.(b+1) !+c^{2}\right)} \quad\left[0.25+2 c \tan ^{-i} 0.1243530 c\right]
$$

with

$$
\begin{array}{rlr}
b & =\frac{\sigma_{0}}{\partial_{p}+i_{i}} & \text { NR } \\
& =\frac{i a}{i} \frac{\sigma_{0}}{i_{m}+\sigma_{\ell}} \quad I M \\
c & =\frac{2 E_{i}}{i(b+1) / / 2}
\end{array}
$$

and other quantities as defined $\pm n$ the GAM-I dosument, GA-1850.

Numerical evaluation of Equation (1) in representative cases of a moderate concentration of $\mathrm{Pu}$ ? Gives a revised eff for the strong 1,056 eV ressnance $5 \%$ to $10 \%$ larger than the unrevised value in a usual homogenized cell calculation, and $20 \%$ to $40 \%$ larger in a one-region calculation for the fuel rod itself. The accuray of thase calculations was $0.5 \%$ to $1 \%$ and $3 \%$ 
to $4 \%$ in the respective cases, when compared to a form of the flux integral in which exact collision probabilities and Doppler broadened cross sections were used.

These comparisons show that the HRG modifications to $\sigma_{\text {eff }}$ can be appreciable for strong resonances and can be calculated with acceptable accuracy. The effect of the revised $\sigma_{\text {eff }}$ on the nuclear parameters of the cell depends, of course, on the flux spectrum. Since the corrections are largest for the strong, low energy resonances of isotopes such as $\mathrm{U}^{238}$ and $\mathrm{Pu}^{240}$, their influence is strongest for thermal or near thermal reactors. For such reactors, calculated changes in reactivity of 10-15 mk are typical. The revisions have also improved the correlation between HRG calculations and Hellstrand's experimental measurements of resonance integrals.

Zodiac - D. D. Matsumoto and R, H. Holeman

ZODIAC2, the burnup chain for the IBM 7090, was modified and enlarged to increase its burnup capabilities. The superior epithermal cross-sections averaging code HRG was added as an optional alternative to GAM. Both independent and related changes were made to the COMBO, TEMPEST, SIGMA-3H, and REFIRE portions for the chain.

Libraries for the codes TEMPEST, HRG (GAM), and SIGMA-3H were reorganized and expanded to the extent that existing Composite Library Tapes (CLT's) were imcompatible with the current versions of these codes. Both current and obsolescent versions of the three codes are included on the program tape, giving rise to the name ZODIAC $(2+2)$.

Documentation supplementary to the ZODIAC2 User's Manual ${ }^{(83)}$ was published. (84)

ZODIAC3, an improved version of ZODIAC for the Univac 1108, reinins largely incomplete. A significantly larger version of the diffusion code

(83) Matsumato, D. D. and Busselman, G. J., "ZODIAC2 User's Manual," HW-83577, Oct. i, $\$ 964$.

(84) Holeman, R. H. and Matsumato, D. D., "ZODIAC $(2+2)$ : Revision to ZODIAC2," BNWL-459, May 1967. 
HFN was prepared for the ZODIAC3 and is also available as an independent code. Identical in operation to the standard $\mathrm{HFN}$, the new code utilizes the larger core of the Univac machines for additional in-core library space, thus relieving the greatest restriction to HFN capabilities.

The clerical cross-section processing link, CLERK, and the isotope transmutation portion, ALCHEMY, are in transition to ZODIAC3.

HRG Data Tapes - J. L. Carter

A new series of HRG data tapes has been started which departs in several respects from the series previously used. Data on these tapes reflect the large amounts of new data added to the BNW Master Library in the past few months. Data for 83 nuclides have been revised or added. Multiple versions of ${ }^{233} \mathrm{U},{ }^{235} \mathrm{U},{ }^{239} \mathrm{Pu}$, and ${ }^{2+j} \mathrm{Pu}$ are present, to provide data compatible with several recommended self-consistent sets of thermal parameters for these nuclides. These sets are designated as the Leonard, $(85,86)$ Westcott, (87) Sher-62 ${ }^{(88)}$ and Sher-65 ${ }^{(89)}$ sets. An extensive rearrangement of nuclide identification numbers has been made, placing the most frequently used nuclides near the front of the tape. Materials--currently $\mathrm{H}_{2} 0, \mathrm{D}_{2} \mathrm{O}$, and 304SS--appear as nuclides for the first time; these are simply convenient combinations of nuclides which also appear separately elsewhere on the tape. Tentative data for $\mathrm{Tm}^{169}$ and data for two pseudo fission products have been added. Also added is a synthetic nuclide, Unit $1 / \mathrm{v}$, with a $2200 \mathrm{~m} / \mathrm{sec}$ absorption cross section of 1 barn and no scattering, for possible use in simulating data for nuclides not present. Data are presented for a total of 240 nuclides.

(85) Leonard, B. R., Ir., "Survey of the Status of Low Energy Cross Sections of Fissile Nuclides," Neutron Physics. Proceedings of Symposium held at Renssalaer Polytechnic Institute, 196!, edited by M. L. Yater. Academic Press, New York, 1962, pp. 3-33. Also HW-69342. April, 1961.

(86) Leonard, B. R., Jr., "Plutonium Physics: Contribution to Plutonium Handbook," HW-72947, March, 1962.

(87) Westcott, C. L., et al, "A Survey of Values of the $2200 \mathrm{~m} / \mathrm{sec}$ Constants for Four Fissile Nuclides," Atomic Energy Review 3, 2, 3-60, July, 1965.

(88) Sher, R. and Felderbaum, J., "Least Squares Analys is of the $2200 \mathrm{~m} / \mathrm{sec}$ Parameters of $U^{233}, U^{235}$ and $P U^{239}, " B N W L-722$, June 1962.

(89) Sher, R. and Felderbaum. J., "Least Squares Analysis of the $2200 \mathrm{~m} / \mathrm{sec}$ Parameters of $U^{233}, U^{235}$, and Pu' ${ }^{239}$. Final Report," BNWL-918, March 1965. 
Revisions in BARNS-II - J. L. Carter

BARNS-II is a computer code designed to process neutron cross section data from the BNW Master Libraxy into point or group cross sections. In general one of four possible energy variations of the flux can be selected for each group in calculating the group values: constant, $1 / E$, fission, or maxwellian. An exception to this general capability has been in the resonance region of certain isotopes, for which the cross sections have been calculated as superpositions of contributions of Breit-Wigner single level resonances; in this combination, only a $1 / \mathrm{E}$ flux has been used and group cross sections have been calculated analytically with no doppler broadening. This limitation has been removed by recent revisions to the code, which permit cross sections in this resonance region to be calculated optionally by Simpson's rule integration. In other revisions, flexibility has been introduced by providing for a convenience routine DOCTOR, to manipulate the results into non-standard form. For example, versions of DOCTOR have been produced which permit multiple lower limits of an epithermal group, or mutliple temperatures and supper limits of maxwellian groups, to be calculated as a single case.

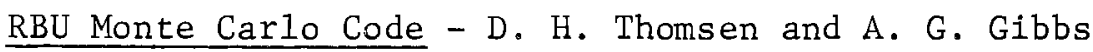
An extensive evaluation of the RBU Monte Carlo Code ${ }^{(90)}$ has been made. The purpose of the evaluation was to check the formulation and coding of the code and to provide a base of problems to help in the selection of future applications of RBU. The test problems were selected to specifically test the various routines (fission, resonance, thermalization, geometry, etc.) contained in RBU. An improved kernel for use in the thermalization routine has been incorporated into the code. A summary of the evaluation studies $(91,92,93,94)$ are given here.

(90)Triplett, Jr., Merrill, E. T. and Burr, J. R., "The RBU Reactor Burrup Code: Formulation and Operating Procedures," HW-70049, July 196.

(91)Thomsen, D. H, and Gibbs, A. G., "New Analytical Results from SlowingDown Theory and Their Application to a Check Out of the RBU Slowing-Down Routine, BNWL-307.

(92)Thomsen, D. H., "Thermalization Calculational Study-Comparison of Results obtained Using the RBU Monte Carlo, THERMOS, and Program S-XIII Codes," quarterly Technical Activities Report - July, August, September, 1966, BNWL-34!

(93)Thomsen, D. H., "Cell Calculations Using the RBU Monte Carlo Code, "Reactor Physics Department Technical Activities Quarterly Report, October, November, December, 1966, BNWL-400.

(94)Thomsen, D. H., "Analysis of a $110-19$-Rod Cluster Experiment with the RBU Monte Carlo Code," Trans. Am. Nucl. Soc., 10, 238 (June 1967). 


\section{Checkout of Scattering and Boundary Routines}

An analytical study $(91)$ was made of the neutron slowing down process in a pure scattering medium, of constant cross section, and whose constituent atoms scatter neutrons isotropically in the center-of-mass system. The analytical results were compared to results obtained using the RBU Monte Carlo Code. The comparison of results provides a check of the elastic scattering and boundary routines contained in the code. The comparison indicates that the RBU slowing-down routine is working properly.

Checkout of Slowing Down Routine

The energy distribution of neutrons slowing down from a fission source to thermal energies was computed using the RBU and $\mathrm{HRG}^{(95)}$ codes. An infinite homogeneous aqueous medium containing plutonium, aluminum and zirconium was used for the test problem. The purpose of this calculation was to examine the RBU Monte Carlo slowing down routines for errors.

HRG is a neutron slowing down code which calculates the neutron flux distribution by solving the time-independent Boltzman equation assuming the $\mathrm{P}_{1}$ or $\mathrm{B}_{1}$ approximation. Sixty-eight quarter lethargy groups between 0.414 and $10^{7} \mathrm{eV}$ are used. The flux within each group and the source of neutrons into each group are considered to have 1/E distribution.

The RBU used the same 68 energy groups as HRG. Cross sections for both codes were obtained from the same BNW Master Library ${ }^{(96)}$ and averaged over each group assuming a constant flux distribution. The fission source used in HRG was obtained by integrating the fission spectrum that RBU samples from over each energy group. The HRG calculation was made using the $\mathrm{P}_{1}$ approximation with a leakage of $10^{-10}$.

Figure XXV shows the calculated flux shape using RBU along with the one calculated using HRG. The RBU and HRG fluxes were normalized using ine total flux integrals. The RBU flux values with a lethargy greater than 1.5 have a statistical spread of $\sim 2 \%$. Even though the agreement between the two flux spectrums is not complete it appears to exclude the possibility of any large errors in the RBU Monte Carlo slowing down routines.

(95) Carter, J. L., Ir., "Computer Code Abstracts, Computer Code-HRG," Reactor Physics Department Technical Activities Quarterly Report - July, August, September, 1966, USAEC Report BNWL-340, October 15, 1966.

(96) Stewart, K. B., "BNW Master Library," USAEC Report BNWL-CC-325, September 1965. 


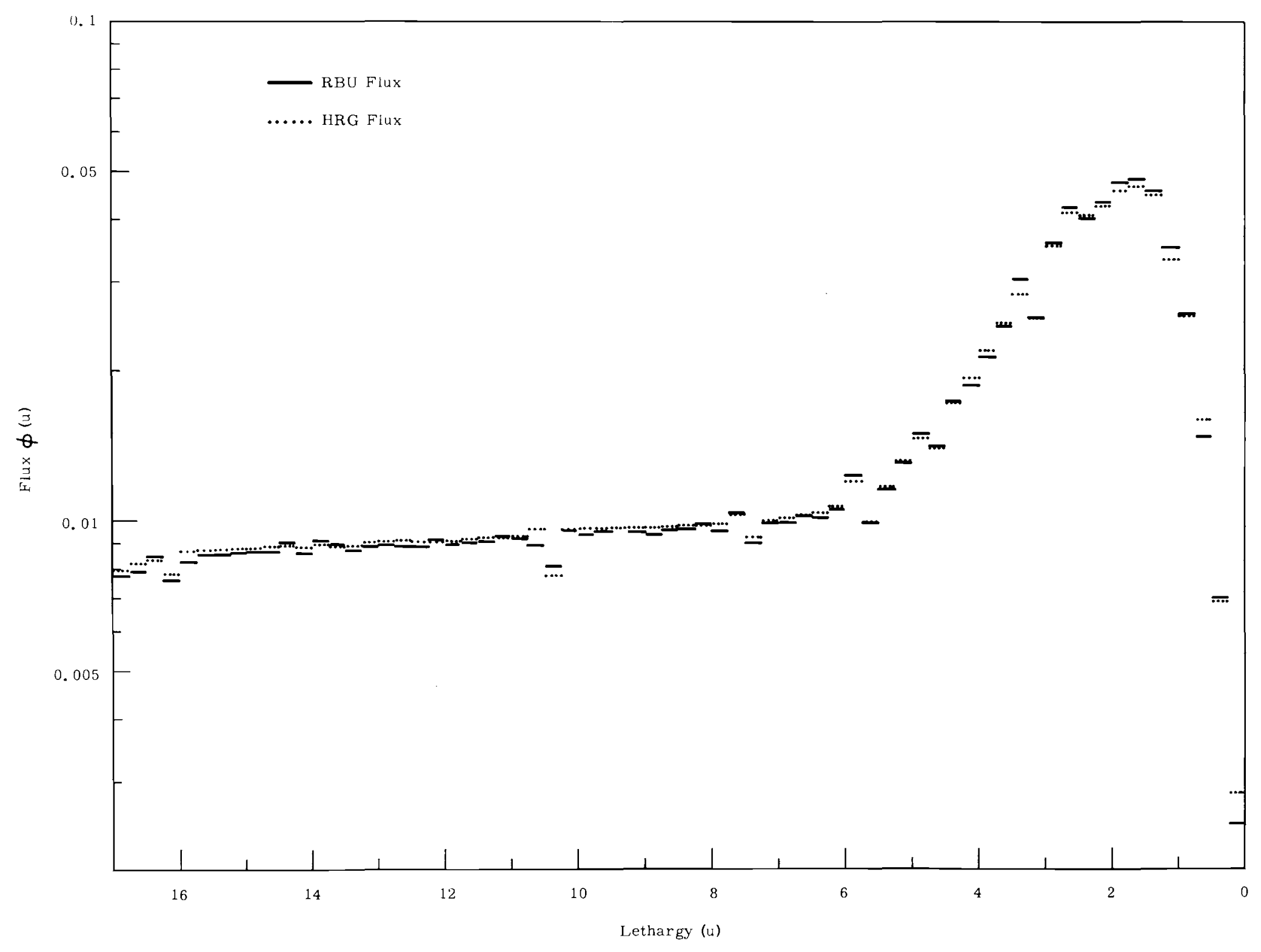

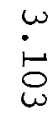

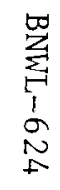

Figure XXV

Calculated Flux versus Lethargy 
There is a slightly greater slope in the RBU fluxes than in the HRG fluxes. This was examined by obtaining the ratio of the flux above a lethargy of 6.25 to the flux below 6.25. A value of $1.569 \pm 0.024$ was obtained from the RBU fluxes while a value of 1.529 was calculated from the HRG fluxes. The greater slope in the RBU fluxes thus appears to be real but it is not statistically distinct from the slope in the HRG fluxes.

Group average cross sections for 15 broad energy groups were obtained using the $\mathrm{RBU}$ and $\mathrm{HRG}$ flux spectrums. The results for $\mathrm{Pu}^{239}$ capture and fission are compared in Table XXII. Similar disagreements were observed in the other average cross sections that were compared.

The effect on $k_{\infty}$ of the variation in the flux spectrums calculated with the two codes was examined even though thermal parameters were not obtained. $\mathrm{k}_{\infty}$ can be defined as

$$
\mathrm{k}_{\infty}=\frac{v \Sigma_{\mathrm{fl}}}{\Sigma_{\mathrm{a} 1}+\Sigma_{12}}+\frac{\Sigma_{12}}{\Sigma_{\mathrm{a} 1}+\Sigma_{12}} \frac{v \Sigma_{\mathrm{f} 2}}{\Sigma_{\mathrm{a} 2}}
$$

using two group slowing down theory. $\nu \Sigma_{f}$ is the fission neutron production cross section, $\Sigma_{a}$ is the absorption cross section, and $\Sigma_{12}$ is the transfer cross section for neutrons slowing from group 1 to group 2 . The values of $\Sigma_{a 1}, \Sigma_{12}$, and $v \Sigma_{f l}$ were averaged down to $0.683 \mathrm{eV}$ using HRG. First, the HRG flux spectrum was used to perform the averaging, and then the RBU flux spectrum was read into HRG and the averages made. Using the HRG fluxes $k_{\infty}=0.05983+$ $0.89502 v \Sigma_{\mathrm{f} 2} / \Sigma_{\mathrm{a} 2}$ while $\mathrm{k}_{\infty}=0.06016+0.89321 v \Sigma_{\mathrm{f} 2} / \Sigma_{\mathrm{a} 2}$ using the RBU fluxes. A good number to compare is the value of $\nu \Sigma_{f 2} / \Sigma_{a 2}$ for which $k_{\infty}=1.0 . \mathrm{RBU}$ requires $\nu \Sigma_{f 2} / \Sigma_{a 2}$ to be 1.0522 while HRG requires $\nu \Sigma_{f 2} / \Sigma_{a 2}$ to equal 1.0504 .

The fluxes calculated by RBU and HRG did not agree exactly; however this should be expected when the differences between the two codes are considered. The agreement that was observed indicates that the portions of the RBU Monte Carlo code tested by this calculation are free from gross coding or formulation errors.

Checkout of Thermalization Routine

A calculational study ${ }^{(92)}$ was made of the neutron thermalization process in an $\mathrm{H}_{2} \mathrm{O}$ moderated cell. Thermalization calculations for a simple cell were 
$\underline{\text { Table XXII }}$

Comparison of Average Cross Sections From RBU and HRG

\begin{tabular}{|c|c|c|c|c|c|c|}
\hline \multirow[b]{2}{*}{$\begin{array}{c}\text { Min. Energy } \\
(\mathrm{eV}) \\
\end{array}$} & \multicolumn{3}{|c|}{ Pu239 Capture } & \multicolumn{3}{|c|}{$\mathrm{Pu}^{239}$ Fission } \\
\hline & $\begin{array}{r}\mathrm{R}] \\
(\mathrm{Ba}) \\
\end{array}$ & & $\begin{array}{c}\text { HRG } \\
\text { (Barns) } \\
\end{array}$ & $\begin{array}{r}\mathrm{RI} \\
(\mathrm{Bal}\end{array}$ & & $\begin{array}{c}\text { HRG } \\
\text { (Barns) } \\
\end{array}$ \\
\hline $1.35 \times 10$ & 0.01350 & 0.00007 & 0.01335 & 2.0048 & 0.0009 & 2.0047 \\
\hline $9.39 \times 10$ & 0.05779 & 0.00014 & 0.05769 & 1.7442 & 0.0004 & 1.7443 \\
\hline $3.88 \times 10$ & 0.12134 & 0.00015 & 0.12150 & 1.6799 & 0.0001 & 1.6799 \\
\hline $1.83 \times 10$ & 0.18766 & 0.00016 & 0.18846 & 1.6574 & 0.0001 & 1.6570 \\
\hline $1.11 \times 10$ & 0.23073 & 0.00003 & 0.23069 & 1.7279 & 0.0003 & 1.7275 \\
\hline $5.25 \times 10$ & 0.25775 & 0.00018 & 0.25795 & 1.8421 & 0.0003 & 1.8422 \\
\hline $1.17 \times 10$ & 0.65205 & 0.00090 & 0.65250 & 1.8391 & 0.0005 & 1.8396 \\
\hline $3.35 \times 10$ & 1.1581 & 0.0011 & 1.1581 & 2.2921 & 0.0015 & 2.2921 \\
\hline $9.61 \times 10$ & 1.9554 & 0.0069 & 1.9625 & 3.3222 & 0.0107 & 3.3332 \\
\hline $1.30 \times 10$ & 10.220 & 0.034 & 10.238 & 15.590 & 0.048 & 15.584 \\
\hline 29.0 & 50.434 & 0.176 & 50.118 & 44.392 & 0.207 & 44.146 \\
\hline 8.32 & 53.047 & 0.363 & 53.042 & 74.636 & 0.480 & 74.519 \\
\hline 2.38 & 18.913 & 0.265 & 19.178 & 26.069 & 0.256 & 26.339 \\
\hline 0.683 & 6.9478 & 0.0426 & 6.8209 & 31.972 & 0.103 & 31.720 \\
\hline 0.414 & 94.918 & 0.458 & 94.569 & 199.10 & 0.87 & 198.43 \\
\hline
\end{tabular}


performed using the RBU Monte Carlo, ${ }^{(90)}$ THERMOS, ${ }^{(97)}$ and Program S-XIII $(98)$ codes and the results compared. The purpose of the comparison was to check the formulation and numerics of the RBU Monte Carlo thermalization routine.

The problem was to compute the thermalization within a two region cylindrical cell consisting of a boron aluminum rod in light water. The energy range studied was from 0.0 to $0.683 \mathrm{eV}$. The cell source and boundary conditions were the same for all codes with one exception, a spatially dependent source was used in RBU and THERMOS whereas a flat source was used in Program S-XIII and THERMOS. Other details of the problem are given in Table XXIII for each code. The space points in Program S-XIII were distributed at closer intervals near the interface of the two regions while the THERMOS calculation used a uniform spatial mesh in each region. To speed up Program S-XIII convergence three axial angles were used for the first iterations and then five axial angles were used in a restart to obtain the final values.

The initial analysis was based upon the gas model to account for neutron scatter-transfers. Results of these calculations are compared in Table XXV The calculated quantities are flux averaged* cross section values and the disadvantage factor, $\phi_{\mathrm{H}_{2}} / \phi_{\mathrm{B}}$. A statistical analysis was made for the results obtained from the RBU Monte Carlo Code.

The effects of anisotropy in the hydrogen scattering and the spatial source were evaluated separately. Program S-XIII calculations were made using zeroth moment scattering $\left(P_{0}\right)$ and zeroth plus first moment $\left(P_{0}+P_{1}\right)$ scattering. Comparison of results obtained from these cases, labelled 2 and 3 in Table XXIV show the disadvantage factor changes by about $10 \%$. THERMOS calculations were made using a spatially constant source and a space dependent source. Comparing the results of these calculations, cases 4 and 5 in Table XXIV, shows tae disadvantage factor changes by about $1 \%$.

(97) Honeck, H. C., "THERMOS - A Thermalization Transport Theory Code for Reactor Lattice Calculations," BNL-5826, Brookhaven National Laboratory.

(98) Duane, B. H., "Neutron and Photon Transport Plane-Cylinder-Sphere GE-ANPD Program S Variational Optimum Formulation, XDC 59-9-118, January 9, 1959.

* $\bar{\sigma}=\frac{\int \sigma(E) \phi(E) d E}{\int \phi(E) d E}$ 
Table XXIII

Comparison of Problem Input for RBU, Program $S$ and Thermos

$\begin{array}{lcccc} & \frac{\text { RBU }}{} & & \text { Program S } & \text { Thermos } \\ \text { Total Number of Energies } & 63 & 30 & 30 \\ \text { Number of Energies Below 0.683 eV } & 58 & 30 & 30 \\ \text { Number of Space Points in Boron Rod } & & 15 & 7 \\ \text { Number of Space Points in Water } & 14 & 13 \\ \text { Number of Polar Angles } & & 2 & \\ \text { Number of Axial Angles } & 3 \text { or 5 }\end{array}$

Table XXIV

Comparison of Calculated Results Using the Gas Model

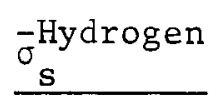

1. RBU Monte Car1o

2. $\mathrm{Sn}, \mathrm{P}$ Scattêring, Flat Source

3. $S n, P_{0} \& P_{1}$ Scattêring, Flat Source

4. THERMOS, Flat Source

5. THERMOS, Non-flat 27.57 Source
27.49

0.2638

2611

2.609

27.57

0.2657

2615

2.964

0.2657

2623

2.987 
The disadvantage factors obtained using RBU and Program S-XIII, case 3 , agree to within $3 \%$. Correcting the Program S-XIII value for the spatial source effect would bring them into even better agreement.

The comparison of the results from RBU and Program S-XIII show that the RBU Monte Carlo ideal gas routine is both formulated correctly and free from detectable numerical error. However, a gas model does not accurately describe neutron scatter-transfers from molecular and crystalline bound moderators. A method of treating the scattering in water more accurately was devised for use in the RBU Code. (93)

This approximate model was suggested by Dr. C. W. Lindenmeier and uses the ideal gas model for the energy transfer and a fictitious heavy mass isotope to provide a correct transport cross section. The fictitious transport cross section, $\sigma_{\mathrm{TR}} f$ is calculated as

$$
\sigma_{T R} f(E, T)=\sigma_{T R}{ }^{\mathrm{H}_{2} \mathrm{O}}(\mathrm{E}, \mathrm{T})-\sigma_{\mathrm{TR}} \text { Ideal Gas }_{(\mathrm{E}, \mathrm{T})} \cdot
$$

To calculate the transport cross section for light water it is first assumed that the scattering from oxygen is treated exactly by the ideal gas model. The average cosine of the scattering angle $(\bar{\mu})$ for hydrogen in light water was calculated using the Nelkin Model. The angular distribution of the scattering for the fictitious heavy isotope is treated as isotropic in the laboratory system by the RBU code. The scattering cross section for the fictitious isotope can now be calculated as

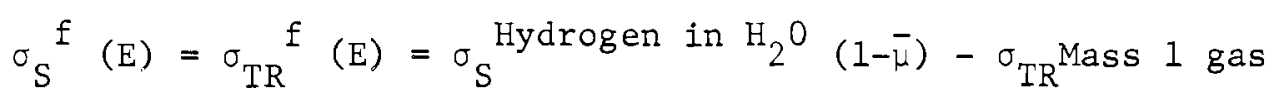

The cell calculation was repeated using this model in RBU and the results compared in Table XXV to values obtained using Program S-XIII and THERMOS with the Nelkin model for $\mathrm{H}_{2} \mathrm{O}$.

The comparison of TBU calculations using the ideal gas and the approximate $\mathrm{H}_{2} \mathrm{O}$ model shows large differences in average cross sections and fluxes. The results obtained using the approximate model agree fairly well with those obtained using Program S-XIII and THERMOS. If we assume that the results obtained from the Program S-XIII calculation are correct then we can conclude that this approximate model represents an improvement in the RBU thermalization routine for light water systems. 
$\underline{\text { Table XXV }}$

Comparison of Calculated Results Using Approximate $\mathrm{H}_{2} \mathrm{O}$ Model in $\mathrm{RBU}$ and the Nelkin Model in Program S-XIII and Thermos

\begin{tabular}{|c|c|c|c|c|c|}
\hline & $\bar{\sigma}_{s}^{H}$ & & $\sigma_{\mathrm{a}}^{\mathrm{H}}$ & $\bar{\sigma}_{\mathrm{a}}^{\mathrm{B}}$ & $\phi_{\mathrm{H}_{2}} \mathrm{O}^{/ \phi}$ Boron Rod \\
\hline $\begin{array}{l}\text { RBU Monte Carlo } \\
\text { (Approx. } \mathrm{H}_{2} \mathrm{O} \text { Model) }\end{array}$ & 27.52 & 0.2646 & \pm 0.0018 & $2549 \pm 25$ & $2.955 \pm 0.060$ \\
\hline $\begin{array}{l}\text { Program S-XIII } \\
\text { (Nelkin)* }\end{array}$ & 27.47 & 0.2637 & & 2543 & 2.952 \\
\hline THERMOS $($ Nelkin $) * *$ & 27.45 & 0.2645 & & 2551 & 3.032 \\
\hline RBU Monte Carlo & 27.43 & 0.2625 & \pm 0.0009 & $2613 \pm 13$ & $2.684 \pm 0.034$ \\
\hline
\end{tabular}

* Includes Po and Pl kernels.
** Transport corrected kernel. 
This approximate model can be extended to other liquid moderators by simply computing a new fictitious scatterer from Equation (1). Theory-Experiment Correlation Study

The RBU Monte Carlo Code (RBU) was used to perform a theoretical analysis of a 19-rod $\mathrm{UO}_{2}$ cluster cell. A paper ${ }^{(94)}$ on this analysis was presented at the June meeting of the American Nuclear Society in San Diego. This analysis is the last in a series of calculations $(91,92,93)$ designed to test the RBU code. Part of the analysis included testing the RBU resonance routine. Several problems were uncovered and corrected. Final tests indicate that the RBU resonance routine is working correctly.

Table XXVI compares experimental $(99,100)$ are calculated values of various lattice parameters for the final calculation of this analysis. The results are given after 300,000 neutron collisions and after 500,000 neutron collisions. The error bars given with the calculated values are for one statistical standard deviation. All of the earlier RBU calculations gave results consistent with the values at 300,000 collisions.

Table XXVI

Calculated and Experimental Lattice Parameter Values

\begin{tabular}{|c|c|c|c|}
\hline \multirow[b]{2}{*}{ Parameter } & \multirow[b]{2}{*}{ Experiment } & \multicolumn{2}{|c|}{ Calculated } \\
\hline & & $300 \mathrm{k}$ Collisions & $500 \mathrm{k}$ Collisions \\
\hline $\mathrm{k}_{\infty}$ & $1.052 \pm 0.003$ & $1.026 \pm 0.008$ & $1.039 \pm 0.006$ \\
\hline $\mathrm{f}(1 / \mathrm{v})$ & $0.896 \pm 0.003$ & $0.896 \pm 0.001$ & $0.896 \pm 0.001$ \\
\hline $\mathrm{p}$ & $0.868=0.009$ & $0.859 \pm 0.006$ & $0.869 \pm 0.005$ \\
\hline$\varepsilon$ & $1.018=0.002$ & $1.025 \pm 0.003$ & $1.024 \pm 0.002$ \\
\hline$k$ (tallies) & & $1.07=0.23$ & $1.11 \pm 0.18$ \\
\hline
\end{tabular}

(99) Lilley, J. R., "Correlation of Data on Heavy-water Moderated Cluster Lattices," HW-60275

(100) Oakes, T. J., "Determination of Lattice Parameters for a 19-Rod Cluster," Nuclear Research Quarterly Report, January, February, March, 1958, Hw-55879. 
The change between the results for $p, k_{\infty}$ and $k$ (tallies) at 300,000 collisions and 500,000 collisions uncovered a mathematical problem in the RBU Monte Carlo code mathematics. Because of the way absorption is treated in RBU, one extra degree of statistical freedom is introduced. Neutron absorption is tied to the random number selections. This is unnecessary and can introduce a small error into the calculation. Even with the possibility of this small error the calculated values are probably valid within their quoted uncertainties. It is seen from Table XXVII that the calculated value of $k_{\infty}$ is too low by about $2 \%$ while the values of $\mathrm{f}, \mathrm{p}$, and $\varepsilon$ each seem to agree with the experimental value. It is felt that the resonance absorption is too large but this could not be proven.

The results of this analysis and the previous test calculations indicate that the RBU Monte Carlo Code is free of gross programming errors and gives reliable results.

Program Gammax - L. J. Page and H. S. Zwibe1

Program GAMMAX is a cross section calculation program which computes gamma cross sections for pair production and Compton scattering. The pair production calculations are those of the General Electric program GAMM-2 and are described in document SDC 60-3-67. The Compton scattering equations were recoded from the document APEX 487. This code was used extensively in computing cross sections for use in a calculational study ${ }^{(101)}$ of photoneutron production in $\mathrm{D}_{2} \mathrm{O}$ systems.

The code has been written in Fortran-IV for use on the UNIVAC-1107 computer.

Program Beta - A Reactor Kinetics Code - L. J. Page

The purpose of this code is to permit the extraction of delayed neutron parameters from experimental data. Prompt neutron lifetime, delayed neutron fractions and the corresponding decay constants are computed from least squares

(101) Jenquin, U. P., "Plutonium Calculations for D, O Systems," Reactor Physics Department Technical Activities Report - January, February, March, 1967, BNWL-472, April 15, 1967. 
fitted data of flux vs. time after negative reactivity insertion.

This code has been written in Fortran-IV for use on the UNIVAC-1107 computer.

Program DANCOF - W. L. Purcell and G. L. Simmons

The calculation of resonance reaction rate parameters in lattice of absorber rods requires the consideration of the net reduction of the flux incident on the surface of an absorber rod due to the shadowing effect of adjacent rods. Alternatively one might consider the effect of the ficticious rediction in the surface area of the absorber rod due to the adjacent rods in the lattice. The correction for this effect was first proposed by Wigner and was calculated in the geometry of neighboring infinite, parallel cylindrical rods by Dancoff and Ginsburg, ${ }^{(102)}$ hence the name Dancoff correction. Sauer ${ }^{(103)}$ has also derived an expression for this correction for both hexagonal and square arrays of rods. Although the Dancoff correction for the surface resonance absorption term is only an approximation, it has been demonstrated by experiment ${ }^{(104)}$ and by comparison with Monte Carlo calculations that the application of such a correction gives resonably good results.

These two methods (Dancoff-Ginsburg and Sauer) have been incorporated into a computer program, DANCOF, written in Fortran-IV for use on the UNIVAC-1107 and UNIVAC-1108 computers.

(102) Dancof6. S. M. and Ginsburg, M., "Surface Resonance Absorption in a Closed Packed Lattice," CP-2157, (1944).

(103) Sauer, A., "Approximate Escape Probabilities," Nucl. Sci. E Eng., 16, $329(1963)$.

(104) Pettus, W. G. and Dayton, I. E., "Mutual Shielding of Lattice Pins in the Resonance Energy Region," Nucl. Sci. \& Eng., 4, 522 11958).

(105) Chernick, J., "Studies of Neutron Capture of $U^{238}$ Resonances," Proceedings of the Brookhaven Conference on Resonance Absorption of Neutrons in Nuclear Reactors (BNL-433), 1956. 
Program NOISE - G. D. Seybold and L. C. Schmid

A computer program entitled NOISE has been developed for use in the analysis of data from reactor noise experiments. The analysis is accomplished in two steps. First the amplitude data of the frequency spectrum of reactor noise is put in a form amenable to comparison to the theoretical function. In the second step, parameters are obtained from the experimental data by fitting the theoretical functions to the data using improved least squares fitting techniques.

Noise analysis is a method whereby random variables are used to describe physical phenomena of a system. To be useful the random variable must be describable by probability theory. The analysis is accomplished by determining what effect, as a function of frequency, the random variable has on the gain or power spectrum at the output of the system. As a result of the analysis the frequency response or transfer function of the system is obtained.

Data analysis is accomplished with a Program NOISE written in Fortran-IV for the UNIVAC-1107 and 1108 computers. Frequency analyzed data are converted to data amenable to least squares fitting methods. Then the parameters which best fit the transfer function are obtained utilizing a new least squares fitting technique, Program LEARN. (106)

Cross Section Evaluation Working Group - B. R. Leonard and K. B. Stewart The initial organizational meeting of the Cross Section Evaluation Working Group (CSEWG) was held at Brookhaven National Laboratory on June 9-10, 1966. At that meeting, the Battelle-Northwest representative accepted the responsibility for furnishing nuclear data for ten isotopes for th. Evaluated Nuclear File/B (ENDF/B). For two of the isotopes, hydroger and deuterium, a complete set of data was requested for neutron energies up to an undefined maximum of 10 - to $-20 \mathrm{MeV}$. For the remainder; $\mathrm{Xe}^{135}, \mathrm{Sm}^{149}$,

(106) Duane, B. H., "Machine Analysis Abstract -- Maximum Likelihood Nonlinear Vector Fields - - Battelle-Northwest Program Likely," pp. 1-3, BNWL-284, Physics Research Quarterly Report, Jan.-Feb.-Mar. 1966. 
Eul51, $\mathrm{Eu}^{153}, \mathrm{Dy}^{164}, \mathrm{Lu}^{175}, \mathrm{Lu}^{176}$, and $\mathrm{Au}{ }^{197}$ only the nuclear data near thermal neutron energies was requested since the primary application of these isotopes is in thermal reactors. For four of the isotopes; $\mathrm{H}, \mathrm{D}, \mathrm{Xe}{ }^{135}$, and $\mathrm{Au}^{197}$, there existed rather up-to-date evaluations which were adapted with minor modifications and additions into the ENDF/B format. For the rare-earth isotopes, new evaluations were required. In order to perform the evaluation it was necessary to acquire a complete program to perform a rigorous BreitWigner resonance calculation. The program UNICORN ${ }^{(107)}$ which does the requisite calculation including resonance-resonance scattering interference was acquired and put into operation. It was found desirable to alter the calculated energy mesh of UNICORN to provide a finer mesh. The evaluations of the ten isotopes were completed and the ENDF/B data along with preliminary documentation were furnished at the November 14-16, 1966 meeting of the CSEWG as requested. At this meeting, the BNW representatives were requested to complete for fast neutrons the data files of the isotopes for which thermal data had been furnished. In order to perform this task it was necessary to perform extensive optical model calculations because of the paucity of fastneutron data for the rare-earth isotopes. Accordingly, the computer program ABACUS-2 (108) was put into operation. In the performance of these calculations, it was discovered that optical-model parameters which had been derived by others did not give an adequate description of the existing total crosssection information. Thus, it was necessary to derive new energy-dependent parameters based primarily on the 2.5 - to 15 - MeV total cross section data (109) for elemental samarium, europium, dysprosium, and lutetium. In order to provide Legendre coefficients to describe elastic scattering, transformation matrices, and the quantities $\mu$ and $\xi$, the computer program

(107) Otter, J. M., NAA-SR-11980, Vol. VI. June 1966.

(108) Auerbach, E. H., BNL - unpublished.

(109) Foster, D. G., Ir. and Glasgow, D. W., Battelle-Northwest - unpublished data (1966). 
CHAD $^{(110)}$ was acquired and put into operation. It was discovered that for neutron energies above about $10 \mathrm{MeV}$ for these isotopes the angular distributions reconstituted from the Legendre coefficients derived by CHAD were badly in error. A Lagarangian interpolation scheme was added to CHAD which expanded the input angular distribution to a finer mesh (501 points). This modified version of CHAD was found to give satisfactory angular distributions to energies at least as high as $20 \mathrm{MeV}$. For $\mathrm{Xe}^{\mathrm{3} 35}$, it was decided to limit the nuclear data to energies below $1 \mathrm{keV}$. For the remainder of the isotopes, the evaluated nuclear data was completed up to $20 \mathrm{MeV}$. The ENDF/B data files and summary documentations of the evaluations for the ten isotopes were essentially completed by July 1, 1967, and have been transmitted to Brookhaven National Laboratory.

ENDF/B Neutron Cross Section Library System - B. R. Leonard and K. B. Stewart Adaption of the national ENDF/B cross section library system for use at BNW continued. Two distinct phases are involved-adapting the processing programs and developing the data tape.

The following processing programs have been received and are being debugged and converted to the UNIVAC 1108:

1. ETOE - produces a library tape for $\mathrm{MC}^{2}$;

2. ETOM - calculates MUFT 4 or 5 libraries for use in HAMMER;

3. FLANGE II - calculates THERMOS cross sections;

4. GAND - calculates cross section input for use in GAF and GAR.

The cross section library has significant defects in some of the major isotopes. Many of the defects have been corrected in the BNW version. However, there are some isotopes remaining that can be modified effectively only by the original evaluators.

BNW Master Cross Section Library - K. B. Stewart

Numerous isotopes contained in the BNW Master Library (BNWL-CC-325) were updated the past year. The changes that will most affect reactor physics

(110) Berland, R. F., NAA-SR-11231. December 1965. 
calculations were the introduction of a new or more recently measured resonance parameters and addition of more accurate and complete data in the fast energy region for some reactor and foil materials.

The following isotopes were modified:

$\begin{array}{ll}\text { B10 } & \text { Eu-151, 153 } \\ \text { C12 } & \text { Ta-181 } \\ \text { N14 } & \text { Tm-169 } \\ \text { F-19 } & \text { Lu-175, 176 } \\ \text { Na-23 } & \text { Hf-174, 176-180 } \\ \text { Mn-55 } & \text { W-183 } \\ \text { Fe-54, 56, 58 } & \text { Au-197 } \\ \text { Co-59 } & \text { Th-228, 230, 232, 234 } \\ \text { Cu-63, 65 } & \text { Pu-231, 233 } \\ \text { Rh-103 } & \mathrm{U}-232,233,234,235,236,237,238 \\ \text { Ag-107, 109 } & \text { Np-237 } \\ \text { In-115 } & \text { Pu-238, 239, 240, 241, 242, 243, 244 } \\ \text { I-127 } & \text { Am-241, 243 } \\ \text { Pr-141 } & \text { Cm-243, 244 } \\ \text { Sm-147, 149, 151 } & \end{array}$

\section{Methods Evaluation}

Theoretical studies have been directed toward developing a mathematical physics model which accurately predicts the observed physics behavior of power reactor systems. The model consists of a theory of the neutron slowing down and thermalization processes coupled with cross sections. The theoretical methods are based upon approximate solutions of the neutron transport equation. The cross sections are dilutions of differential cross section data to group average quantities. A measure of the validity of the mathematical model is obtained by comparing measured and calculated integral parameters such as reactor multiplication, $k_{\text {eff }}$ and effective (burnup) cross sections, $\hat{\sigma}$. Frequently, the results of comparisons of this type are in such good agreement that the effects of uncertainties in the model are never considered in determining the model's figure of merit. Moreover, the model may fail to reproduce other measured integral parameters (e.g., neutron 
age, spectra, disadvantage factors, etc.) which are a part of $k_{\text {eff }}$ and $\hat{\sigma}$. Good agreement in calculated and measured values of $k_{\text {eff }}$ may be due to cancellation of errors with the result that an optimistic estimate is made concerning the state of the art.

Almost all of the uncertainties that are present in the mathematical models used for analyzing clean lattice experiments are present in the model used for the analysis of the power reactor system. The only exception is perhaps the manner in which the model accounts for leakage from the reactor system, since the clean lattice experiments are generally smaller systems physically than are the power reactor systems. However, the power reactor systems are much more complicated geometrically (control rod gaps, etc.) and this adds significantly to the over-all uncertainty in the calculated results.

Analytical studies have been performed of the physics characteristics of numerous plutonium-fueled systems along with some uranium-fueled systems. These studies are aimed at evaluating a mathematical model which is used extensively at PNL for performing reactor calculations.

The model is based upon the use of the HRG, (95) THERMOS (97) and HFN (111) computer codes and the basic cross sections contained in the BNW Master Library. (96) The neutron distributions in space and energy within a representative region of the reactor are computed using the multigroup transport theory codes, HRG and THERMOS. The behavior of neutrons slowing down to thermal energies is computed using the HRG code. The neutron flux and current spectra are computed assuming 68 groups of neutrons with a constant group width of lethargy $=0.25$. Corrections for heterogeneity, Doppler broadening, and leakage are included.

The thermal neutron spectrum is computed using the THERMOS code. The THERMOS code in use at PNL is flexible as to the number of energy groups (up to 50), space points (up to 30 ) and mixtures (up to 6) such that the code can be tailored to the specific problem to be solved. The data tapes for this program have available numerous scattering models to describe the

(111) Lilley, J. R., "Computer Code HFN-Multigroup, Multiregion Neutron Diffusion Theory in One Space Dimension," USAEC Report HW-71545, November, 1965. 
neutron scatter-transfer from molecular and crystalline bound moderators. A11 cross section data for the HRG and THERMOS codes are obtained from the BNW Master Library.

The evaluation of the mathematical model is based upon theory-experiment correlation studies which are described below. We present results of studies on clean lattices and burnup.

\section{Clean Lattice Studies}

Comparison of Calculated and Measured Multiplications, $k$ f, for Some Uranium and/or Plutonium Fueled $\mathrm{H}_{2}$ O Lattices - R. C. Liikala and W. L. Purcell

The type of plutonium fuel receiving the most consideration in commercial thermal reactor power programs is a mixture of uranium dioxide and plutonium dioxide $\left(\mathrm{UO}_{2}-\mathrm{PuO}_{2}\right)$. It is expected that the physics analysis of reactors fueled with $\mathrm{UO}_{2}-\mathrm{PuO}_{2}$ would be inherently more difficult than a system fueled with either uranium alone or plutonium alone. This is so because the uncertainties present in the analysis of systems containing only uranium or plutonium are also present in $\mathrm{UO}_{2}-\mathrm{PuO}_{2}$ systems. Thus, in performing a physics analysis of uniform $\mathrm{H}_{2}$-moderated lattice experiments fueled with either $\mathrm{UO}_{2}, \mathrm{UO}_{2}-\mathrm{PuO}_{2}$ or $\mathrm{Al}-\mathrm{Pu}$, it is expected that the uncertainties in the model would be largest for the $\mathrm{UO}_{2}-\mathrm{PuO}_{2}$ fueled system.

\section{Calculational Method}

The neutron distributions in space and energy within a representative lattice cell are computed using the multigroup transport theory codes, HRG and THERMOS. The multigroup cross sections obtained are collapsed to group constants for four energy groups as shown in Table XXVII. These constants are used in a diffusion theory calculation (code HFN) of the leakage fwom the reactor system to obtain the effective multiplication factor, $k_{\text {eff }}$

$\underline{\text { Table XXVII }}$

Neutron Energy-Group Boundaries

\begin{tabular}{cccc} 
Group & \multicolumn{2}{c}{ Upper Energy } & Lower Energy \\
\cline { 2 - 4 } 1 & 10 & $\mathrm{MeV}$ & $11.7 \mathrm{keV}$ \\
2 & $11.7 \quad \mathrm{keV}$ & $2.38 \mathrm{eV}$ \\
3 & $2.38 \mathrm{eV}$ & $0.683 \mathrm{eV}$ \\
4 & $0.683 \mathrm{eV}$ & 0
\end{tabular}


The representative lattice cell was assumed to consist of three regions: 1) fuel, 2) cladding, and 3) moderator.

Macroscopic cross sections for a homogeneous cell for the three nonthermal groups were computed using the HRG code and for the thermal group using the THERMOS code.

The options utilized in the HRG calculations were: the ${ }^{239} \mathrm{Pu}$ fission spectra, the B-1 approximation using the measured geometrical buckling as the leakage parameter, and Doppler broadening and spatial self shielding corrections for ${ }^{235} \mathrm{U},{ }^{238} \mathrm{U},{ }^{239} \mathrm{Pu}$, and ${ }^{240} \mathrm{Pu}$ in the resonance region. The spatial corrections (Dancoff factors) were obtained from published tables.

The problem as described to the THERMOS code was: 20 space points describing the three region cell, 30 energy groups spanning the range 0.0 to $0.683 \mathrm{eV}$, reflecting cell boundary conditions, the Nelkin kernel (113) for $\mathrm{H}_{2} \mathrm{O}$ with an approximate correction for anisotropy, (114) and the gas kernel for all other materials.

The lattice description used in the HFN calculation was a one dimensional cylindrical reactor consisting of two regions, namely a homogeneous core and $\mathrm{H}_{2} \mathrm{O}$ reflector. A transverse buckling was used to account for axial leakage. Comparison with Experiment

The adequacy of this model is predicting $k_{\text {eff }}$ is shown in Tables XXVIII through XXXI which summarize calculated and experimental results for $\mathrm{UO}_{2},(115,116)$

(112) ANL-5800, Second Edition, pp. 283-291.

(113) Nelkin, M., "The Scattering of Slow Neutrons by water," Phys. Res.. Vol. 19, p. 791 (1960).

(114) Honeck, H. C., "The Calculation of Thermal Utilization and Disadvantage Factor in Uranium/water Lattices," Nucl. Sci. Eng., Vol. 18, p. 49, 1964.

(115) Grob, V. E., et al., "Results of critical Experiments in Loose Lattices of $\mathrm{UO}_{2}$ Rods in $\mathrm{H}_{2} \mathrm{O}$," USAEC Report WCAP-1412, westinghouse Electric Corp., Marok:0

(116) Davison, P. W., et al., "yankee critical Experiments - Measurements on Lattices of Stainless Steel Clad Slightly Enriched Uranium Dioxide Fuel Rods in Liaht water," USAEC Report YAEC-94, Westinghouse Electric Corp., April 1959. 


\section{Table XXVIII}

$\underline{\text { Calculated Multiplications } \mathrm{k}}$ eff for UO ${ }_{2}-\mathrm{H}_{2} \underline{0 \text { Criticals }}(115,116)$

Lattice Pitch*

(in.)

0.405

0.435

0.470

0.573

0.615

0.665

*Square pitch

\section{Volume Moderator}

Volume Fue1

1.048

1.405

1.853

3.357

4.078

4.984 $\underline{\left.\mathrm{k}_{\text {eff }} \text { (Experiment }=1.000\right)}$

0.973

0.979

0.983

0.989

0.989

0.988 


\section{Table XXIX}

Calculated Multiplications, $\mathrm{k}$ eff For A1-Pu-H 2 O Criticals $(117,118,119)$

\begin{tabular}{|c|c|c|c|c|}
\hline \multirow[b]{2}{*}{$\begin{array}{l}\text { Lattice Pitch* } \\
\text { (in.) } \\
\end{array}$} & \multirow[b]{2}{*}{$\begin{array}{c}\text { Volume Moderator } \\
\text { Volume Fue1 } \\
\end{array}$} & \multirow[b]{2}{*}{$\begin{array}{l}\mathrm{A} 1-1.8 \mathrm{wt} \% \mathrm{Pu} \\
\sim 6 \text { at } \% 240 \mathrm{Pu} \\
\end{array}$} & \multicolumn{2}{|c|}{$k_{\text {eff }}($ Experiment $=1.000)$} \\
\hline & & & $\begin{array}{l}\mathrm{A} 1-2.0 \mathrm{wt} \% \mathrm{Pu} \\
\sim 17 \mathrm{at} \% 240 \mathrm{Pu}\end{array}$ & $\begin{array}{l}\mathrm{A} 1-5 \mathrm{wt} \% \mathrm{Pu} \\
6 \text { at } \% 240 \mathrm{Pu} \\
\end{array}$ \\
\hline 0.75 & 1.20 & 1.033 & 1.044 & 1.029 \\
\hline 0.80 & 1.54 & 1.029 & 1.048 & -- \\
\hline 0.85 & 1.91 & 1.024 & 1.043 & 1.028 \\
\hline 0.90 & 2.29 & 1.022 & 1.052 & 1.017 \\
\hline 0.95 & 2.70 & 1.019 & 1.038 & -- \\
\hline 1.00 & 3.13 & -- & -- & 1.022 \\
\hline 1.10 & 4.06 & -- & -- & 1.021 \\
\hline 1.20 & 5.07 & -- & -- & 1.021 \\
\hline 1.30 & 6.17 & -- & -- & 1.014 \\
\hline
\end{tabular}

*Hexagonal pitch 
Table XXX

Calculated Multiplications, $\mathrm{k}_{\mathrm{eff}}$ for $\mathrm{UO}_{2}-1.5 \mathrm{wt} \% \mathrm{PuO}_{2}$ (EBWR Fue1) $-\mathrm{H}_{2}$ O Criticals (121)

\begin{tabular}{ccc}
$\begin{array}{c}\text { Lattice Pitch* } \\
\text { (in.) }\end{array}$ & $\begin{array}{c}\text { Volume Moderator } \\
\text { Volume Fuel }\end{array}$ & keff \\
\cline { 2 - 3 } 0.55 & 1.10 & 0.993 \\
0.60 & 1.56 & 0.992 \\
0.71 & 2.71 & 0.997 \\
0.80 & 3.79 & 0.997 \\
0.90 & 5.14 & 0.998 \\
0.93 & 5.58 & 1.000 \\
$*$ Hexagonal pitch & &
\end{tabular}

$\underline{\text { Table XXXI }}$

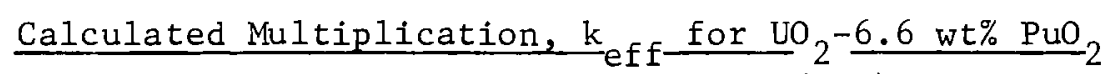
(Saxton Fuel) $-\mathrm{H}_{2} \mathrm{O}$ Criticals $(122)$

$\begin{array}{ccc}\begin{array}{c}\text { Lattice Pitch** } \\ \text { (in.) }\end{array} & \begin{array}{c}\text { Volume Moderator } \\ \text { Volume Fuel }\end{array} & \text { k eff } \\ 0.52 & 1.68 & 1.011 \\ 0.56 & 2.16 & 1.009 \\ 0.735 & 4.70 & 1.012 \\ 0.792 & 5.67 & 1.013 \\ 1.04 & 10.80 & 1.027 \\ * * \text { Square pitch } & & \end{array}$




\section{Table XXXII}

Calculated Multiplications, $k$ eff for $\mathrm{UO}_{2}-2.0 \mathrm{wt} \% \mathrm{PuO}_{2}-\mathrm{H}_{2} \underline{\mathrm{OCriticals}}^{(120)}$

\begin{tabular}{|c|c|c|c|c|}
\hline \multirow{2}{*}{$\begin{array}{l}\text { Lattice Pitch* } \\
\text { (in.) }\end{array}$} & \multirow{2}{*}{$\begin{array}{c}\text { Volume Moderator } \\
\text { Volume Fuel } \\
\end{array}$} & \multirow[b]{2}{*}{$\sim 8$ at\% ${ }^{240} \mathrm{Pu}$} & \multicolumn{2}{|c|}{$\mathrm{k}_{\text {eff }}$ (Experiment $=1.000$} \\
\hline & & & $\simeq 16$ at $\%{ }^{240} \mathrm{Pu}$ & $\simeq 24$ at $\%{ }^{240} \mathrm{Pu}$ \\
\hline 0.80 & 1.49 & 0.992 & -- & 0.996 \\
\hline 0.93 & 2.45 & 1.002 & 1.003 & 1.000 \\
\hline 1.05 & 3.47 & 0.997 & 1.000 & 1.004 \\
\hline 1.143 & 4.35 & 1.007 & 1.008 & 1.008 \\
\hline 1.32 & 6.21 & 1.009 & 1.008 & 1.006 \\
\hline 1.386 & 6.97 & 1.007 & 1.004 & 1.004 \\
\hline 1.611 & 9.85 & 0.992 & - & -- \\
\hline
\end{tabular}


$\mathrm{A} 1-\mathrm{Pu}(117,118,119)$ and $\mathrm{UO}_{2}-\mathrm{PuO}_{2}(120,121,122)$ fueled $\mathrm{H}_{2} \mathrm{O}$ lattices. The calculated results given here differ somewhat from values published previously. $(120,121,123,124,125)$ A host of changes in both the theory and microscopic data utilized have been made in the interim. However, the major differences are due to cross section changes in the thermal energy region for the fissile nuclides and a change in the resonance integral calculation in the HRG code. (126) The $2200 \mathrm{~m} / \mathrm{sec}$ values recommended by the International Atomic Energy Agency (IAEA) survey ${ }^{(127)}$ for the fissile nuclides were used for normalizing the thermal cross section data (96) for the results shown in Tables XXVIII through XXXII.

(117) Stinson, W. P., Marks, J. A., and Schmid, L. C., "Subcritical Measurements With 2.0 wt: Pu-Al Rods in Light water," Physic's Research quarterly Report, July, August, September, 1963, USAEC Report H(w-79054, pp. 43-46, October T963.

(118) Neeley, V. I., Lloyd, R. C., and Clayton, E. D., "Newtron Multiplication Measurement with Pu-Al Alloy Rods in Light Water," USAEC Report HW-70944, August, 1961.

(119) Stinson, W. P. and Schmid, L. C., "Subcritical Measurements with 1.8 wt: Pu-Al Rods in Light water," Physics Research Quarterly Report, July, August, September, 1963, USAEC Report H(W-79054, pp. 17-24, July, 1962.

(120) Liikala, R. C. and Stinson, W. P., "Experimental and Analytical Results for $\mathrm{PuO}_{2}-\mathrm{UO}_{2}-\mathrm{H}_{2} \mathrm{O}$ Lattices," Trans. Am. Nucl. Soc. 9, 1: 127 (1966).

(121) Schmid, L. C., et al. "Critical Masses and Bucklings of $\mathrm{PuO}_{2}-\mathrm{UO}_{2}-\mathrm{H}_{2} \mathrm{O}$ Systems," Trans. Am. Nucl. Soc. 1, 2: 216 (1964).

(122) Taylor, E. G., et al., "Sacton Plutonium Program Critical Experiments for the Saxton Partial Plutonium Core," USAEC-1493, WCAP-3385-54, Westinghouse Electric Corporation, December, 1965.

(123) Liikala, R. C., worden, J. R., and Reardon, W. A., "An Analysis of Uranium Fueled Light Water Moderated Critical Experiments," Physics Research Quarterly Report, January. February, March, 1964, H(w-81659. pp. 26-32, April 15, 1964.

(124) Worden, J. R., Liikala, R. C., and Reardon, W. A., "An Analysis of Plutonium Light water Critical Experiments," Physics Research Quarterly Report - January, February, March, 1964, Hi-81659, pp. 33-34, April 15, 1964.

(125) Dawson, F. G., "Physics Design Aspects of Plutonium Recycle," BNWL-232, May, 1966.

(126) Carter, J. L., Ir., "Effective Cross Sections for Resonances in HRG," Reactor Physics Department Technical Activities Report, July, August, September, 1966, USAEC Report BNWL-340, October 15, 1966.

(127) Westcott, C. H., et al., "A Survey of Values of the $2200 \mathrm{~m} / \mathrm{s}$ Constants for Four Fissile Nuclides," Atomic Energy Review, 3, 2 (1965). 
The calculated multiplications shown in Table XXIX for the $\mathrm{UO}_{2}$-fueled $\mathrm{H}_{2} \mathrm{O}$ critical experiments are all low compared to experimental values. Comparing calculated values of $k_{\text {eff }}$ with experiment for aluminum-plutonium alloy fueled experiments shows (Table XXIX) the calculated values of $k_{\text {eff }}$ are all high. The same comparison for $\mathrm{UO}_{2}-\mathrm{PuO}_{2}$ fueled experiments is shown in Tables XXX, XXXI, XXXII, and the calculated values of $k_{\text {eff }}$ are shown to be in reasonable agreement with experiment. Of all the experiments considered in the above analysis, the aluminum-plutonium fueled lattices should be the least difficult to compute accurately. The resonance escape probability is much larger for the Al-Pu fueled systems compared to the systems containing uranium, and the fast effect is very much smaller. The agreement between calculation and experiment for $\mathrm{UO}_{2}-\mathrm{PuO}_{2}$ fueled systems is probably due to compensating errors in the mathematical model since errors are evident in the model when used for analysis of $\mathrm{UO}_{2}$ and $\mathrm{Al}-\mathrm{Pu}$ fueled systems. Evaluations of Sources of Discrepancy

The discrepancies between calculated and measured values of $k_{\text {eff }}$ are due to inadequacies in both theory and cross section data. We next evaluate the effect of uncertainties in microscopic cross section data.

In evaluating what effect uncertainties in the microscopic cross section data have on the calculation of $\mathrm{k}_{\mathrm{eff}}$, only the cross section data for resonance and thermal neutron energies are considered.

A brief summary of cross section information for the more important uranium and plutonium isotopes which are pertinent to this study are shown in Tables XXXIII and XXXIV.

While the list is by no means complete, it provides a basis upon which to estimate the uncertainty in the data. The resonance data on which ou. calculations are based is listed as "our data."

To estimate the uncertainty in the fission integrals for ${ }^{235} \mathrm{U},{ }^{239} \mathrm{Pu}$, and $2+\mathrm{Pu}$, we use the results of Feiner's study for $23{ }^{5} \mathrm{U}$ and $23{ }^{9} \mathrm{Pu}$ and Hardy, et al for $24 \mathrm{Pu}$. The estimates of the uncertainty in the absorption integrals for $235 \mathrm{U},{ }^{238} \mathrm{U}$, and ${ }^{240} \mathrm{Pu}$ are those listed as Feiner, BNL-325 Recommended and Tattersall, respectively. The value and the uncertainty in the absorption integral for ${ }^{239} \mathrm{Pu}$ and $24 \mathrm{Pu}$ are simply based upon the mean value between the 
Table XXXIII

Summary of Cross Section Data for ${ }^{235} \mathrm{U}$ and ${ }^{238} \mathrm{U}$

Resonance Integra1, $I_{\infty}$ for Infinite Dilution

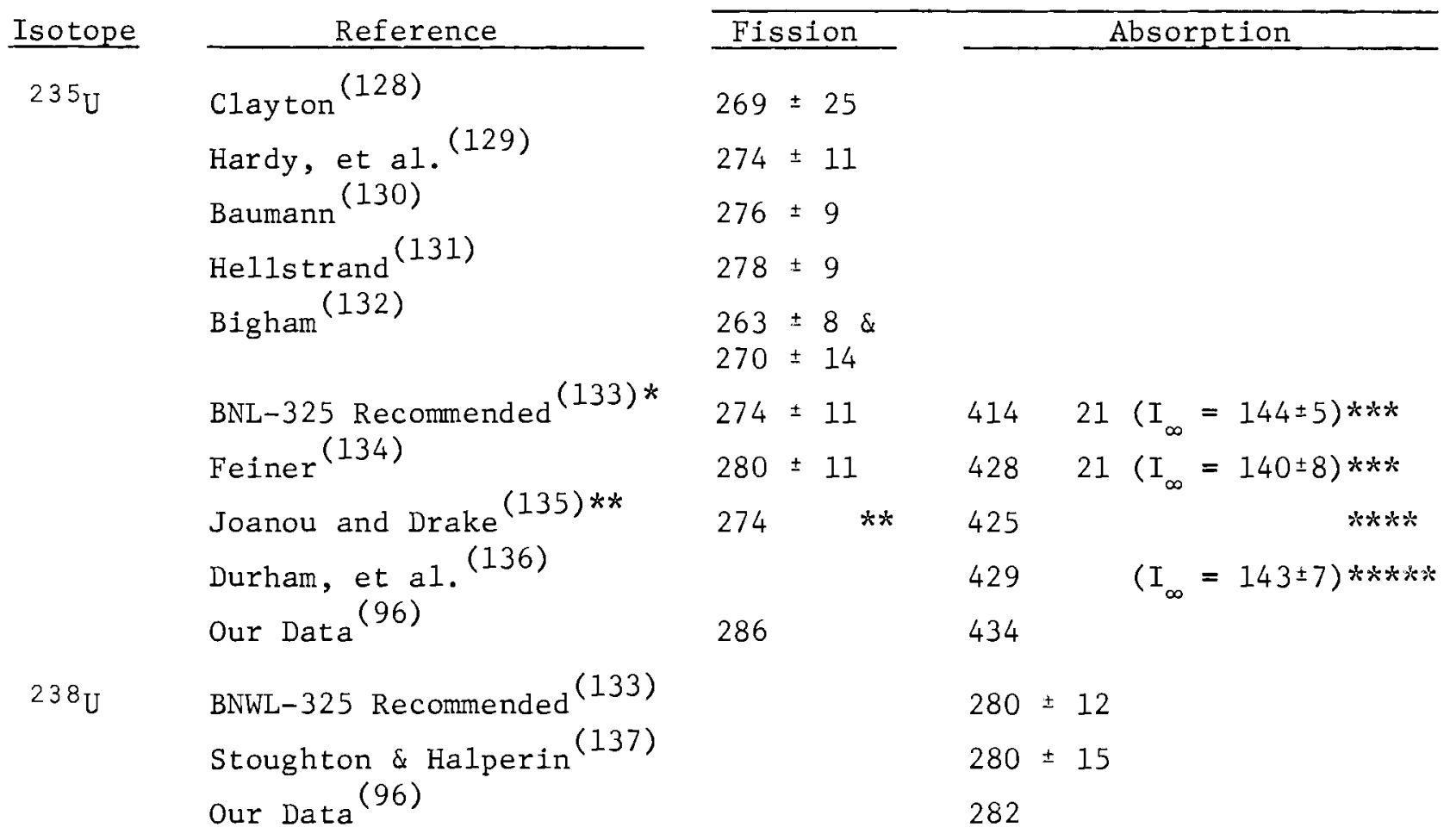

\section{$2200 \mathrm{~m} / \mathrm{sec}$ Capture Cross Section}

Isotope $238 \mathrm{U}$
Reference

$$
\begin{aligned}
& \text { Stoughton and Halperin (137) } \\
& \text { BNL-325 Recommended (133) } \\
& \text { Our Data (96) }
\end{aligned}
$$

$\sigma_{c(b)}$
$2.72 \pm 0.05$
$2.73 \pm 0.04$
2.72

* The low energy cutoff is not stated for the recommended resonance integrals.

** An 18 barn contribution was subtracted from the value given in Table II of Reference 135 to correspond to a $0.5 \mathrm{eV}$ cutoff.

$* * *$ Added $\mathrm{I}_{\infty}$ for capture and fission and assumed that the errors on each were not correlated.

***** A 20.3 barn contribution was subtracted from the value given in Table II of Reference 135 to correspond to a $0.5 \mathrm{eV}$ cutoff.

$* * * * *$ The value obtained assuming $\bar{\alpha}$ epithermal $=0.5$ and the measured capture integral of 143 barns. 


\section{Table XXXIV}

Summary of Cross Section Data for Pu Isotopes

Resonance Integra1, $I_{\infty}$ for Infinite Dilution

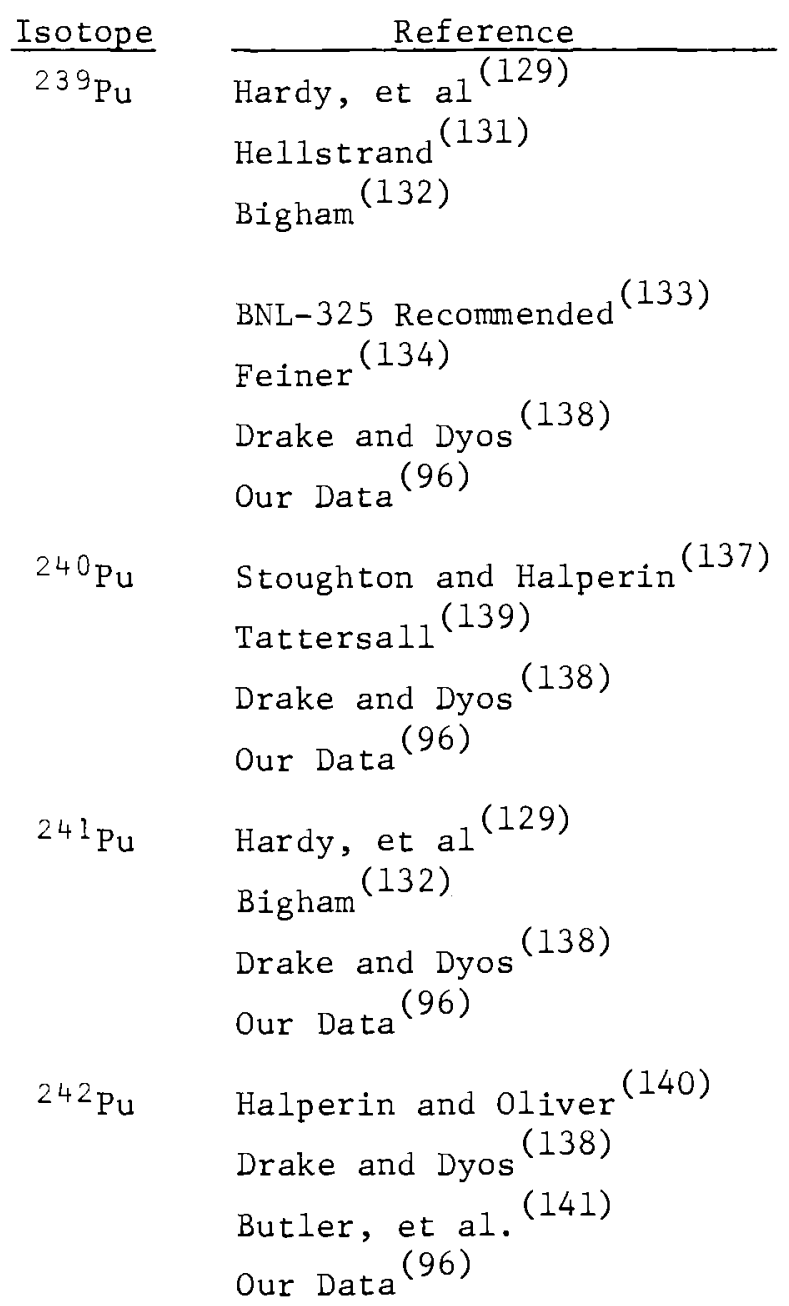

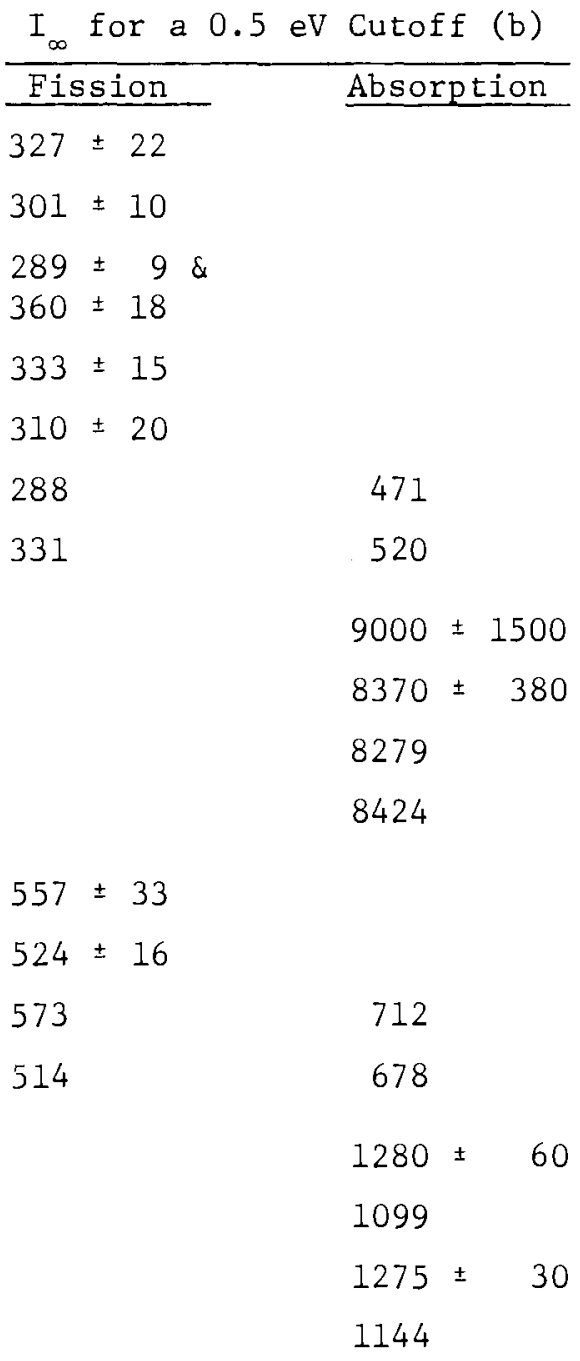

\section{$2200 \mathrm{~m} / \mathrm{sec}$ Capture Cross Section}

$\frac{\text { Isotope }}{240 \mathrm{Pu}}$

$242 \mathrm{Pu}$

\section{Reference}

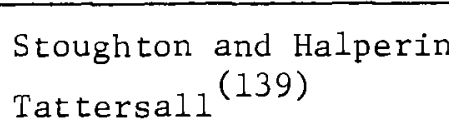

$$
\text { Butler, et al. (141) }
$$$$
\text { Halperin and Oliver (140) }
$$$$
\text { Fields, et al. (142) }
$$$$
\text { Drake and Dyos (138) }
$$$$
\text { Our Data }(96)
$$

\begin{tabular}{|c|}
\hline$\sigma_{c}(b)$ \\
\hline $280 \pm 20$ \\
\hline $290 \pm 9$ \\
\hline 279 \\
\hline 282 \\
\hline
\end{tabular}

$18.6 \pm 0.8$

$24.4 \pm 4.0$

30.0

18.6

30.0 
(128) Clayton, E. D., "Epi-cadmium Fission in U235," AECD-4167 (1955).

(129) Hardy, J., Klein, D., and Smith, G. G., "The Resonance Fission Integrals of $\mathrm{U}^{235}, \mathrm{Pu}^{239}$, and $\mathrm{Pu} \mathrm{u}^{241}$, Nucl. Sci. E Engr. 9: 341 (1961).

(130) Baumann, N. P., "Resonance Integrals and Shelf-Shielding Factors for Detector Foils," DP-817 (1963).

(131) Hellstrand, Eric, "Studies of the Fission Integrals, of $U^{235}$ and $P u^{239}$ With Cadmium and Boron Filters," AE-181, April, 1965.

(132) Bigham, C. B., "Fission Resonance Integrals of $\mathrm{U}^{235}, \mathrm{U}^{239}, \mathrm{Pu}^{239}$ and Pu'24," CRRP-1183, February, 1964.

(133) Stehn, J. R. et al., "Neutron Cross Sections," BNL-325, 2nd Ed., Supplement No. 2, Vol. III, February, 1965.

(134) Feiner, F. and Esch, L. J., "Survey of Capture and Fission Integrals of Fissile Materials," Proceedings of ANS Topical Meeting: Reactor Physics in the Resonance and Thermal Regions, San Diego, California, February 7-9, 1966.

(135) Joanou, G. D. and Drake, M. K. "Neutron Cross Sections for U235," NASA-CR-54263, GA-5944, December 10, 1964.

(136) Durham, R. W., et al., "The Ratio of Capture-to-Fission in $U^{235}$ and Pu"39," Proceedings of Conference on Nuclear Data - Microscopic Cross Sections and Other Basic Data, Paris, October 17-21, 1966.

(137) Stoughton, R. W. and Halperin, J., "Heavy Nuclide Cross Sections of Particular Interest to Thermal Reactor Operation: Conventions, Measurements and Preferred Values," Nucl. Sci. and Eng. 6:100.

(138) Drake, M. K. and Dyos, M. W., "A Compilation and Evaluation of the Nuclear Data Available for the Major Plutonium Isotopes," GA-6576, July 30, 1965.

(139) Tattersall, R. B., "Thermal Cross Section and Resonance Absorption Integral of $P u^{240}$," AEEW-R-115, March, 1962.

(140) Halperin J. and Oliver, J. H., "The Thermal-Neutron Capture Cross Section and Resonance Integral of ${ }^{242} \mathrm{Pu}$," Chemistry Division Annual Progress Report for Period Ending June 20, 1964, USAEC Report, ORNL-3679, September (1964)

(141) Butler, J. P., et al., "The Neutron Capture Cross Sections of $P 1^{2} 38$ $\mathrm{Pu}^{242}$, and $\mathrm{Am}^{243}$ in the Thermal and Epicadmium Regions," Can. J. If Phys... . $35,147(1957)$.

(142) Fields, et al., "Pile Neutron Cross Sections of the Heavier Plutonium Isotopes," Nucl. Sci. and Eng. 1, 62 (1956). 
data compilation of Drake and Dyos and the value of the BNW Master Library. We estimate a 200 barn uncertainty in a value of 1100 barns for ${ }^{242} \mathrm{Pu}$ absorption.

The assumed uncertainty in the $2200 \mathrm{~m} / \mathrm{sec}$ values for the fissile nuclides ${ }^{235} \mathrm{~J},{ }^{239} \mathrm{Pu}$, and ${ }^{241} \mathrm{Pu}$ are those quoted in the IAEA survey for ${ }^{238} \mathrm{U}$ the BNWL-325 Recommended values are used. We estimate a $5 \%$ uncertainty in 2200 $\mathrm{m} / \mathrm{sec}$ value for ${ }^{240} \mathrm{Pu}$ by assuming a value of $282 \pm 15$ and an $18 \%$ uncertainty for $240 \mathrm{Pu}$ by assuming a value of $1100 \pm 200$.

The sensitivity of the multiplication to changes in the resonance and thermal cross section data were previously calculated ${ }^{(143)}$ for the $\mathrm{UO}_{2}, \mathrm{Al}-\mathrm{Pu}$, and some of the $\mathrm{UO}_{2}-\mathrm{PuO}_{2}$ lattices. The multiplication sensitivity factors are combined with the cross section uncertainties to determine their effect on the calculated multiplication constant. The corresponding uncertainties in the multiplication constant are listed in Table XXXV for the $\mathrm{UO}_{2}$, the $\mathrm{Al}-5 \mathrm{wt} \% \mathrm{Pu}$, and the $\mathrm{UO}_{2}-2 \mathrm{wt} \% \mathrm{PuO}_{2}\left(8 \% \mathrm{Pu}^{240}\right)$ fueled systems at two moderator-to-fuel volume ratios.

The results show that for any individual nuclide, the resonance cross section uncertainties lead to larger uncertainties in $k_{\text {eff }}$ than do the thermal data. Uncertainties in resonance data have a larger effect on $k_{\text {eff }}$ at tight lattices whereas the effect due to thermal data is independent of lattice spacing. The over-all uncertainty in $k_{\text {eff }}$ arising from uncertainties in resonance and thermal data is difficult to assess since we do not know how all of the individual uncertainties are correlated. If, for each lattice, the sum of individual values of $\Delta \mathrm{k}_{\text {eff }}$ is taken as the over-all uncertainty, then the largest uncertainty in $k_{\text {eff }}$ would be $\sim 2.5 \%,-2.0 \%$, and $\sim 3.0 \%$ for the $\mathrm{UO}_{2}, \mathrm{Al}-5 \mathrm{wt} \% \mathrm{Pu}$, and $\mathrm{UO}_{2}-2 \mathrm{wt} \% \mathrm{PuO}_{2}$ fueled systems respectively. Assuming these individual values of $\Delta \mathrm{k}_{\mathrm{eff}}$ are not correlated, then one standard deviation in $k_{\text {eff }}$ is $\sim 1 \%$ for each system. Probably, the correct uncertainty value lies somewhere between these two values. The discrepancies in the calculated $k_{\text {eff }}$ for the tight lattices of the $\mathrm{UO}_{2}$ and $\mathrm{Al}-5 \mathrm{wt} \% \mathrm{Pu}$

(143) Liikala, R. C., Purcell, W. L. and Worden, J. R., "Sensitivity of Reactor Multiplication Values to Cross Section Uncertainties for Thermal Systems," Proceedings of the Conference on Neutron Cross Section Technology, March 22-24, 1966, CONF-660303. 


\section{Table XXXV}

Multiplication Uncertainty, $\Delta \mathrm{k}$ ef Due to Cross Section Uncertainties for Various $\mathrm{H}_{2}$ O Moderated Lattices

$\underline{2.7 \mathrm{wt} \% \text { Enriched UO }} 2$

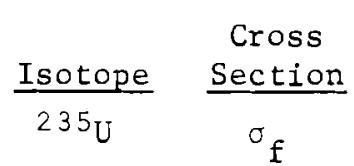

"1

"1

$238_{U}$

1111

$235_{\mathrm{U}} \sigma_{\mathrm{f}}$ or $v$

11
Energy Region Resonance

11

11

11

Thermal

11

11

Resonance

${ }^{2}{ }^{9} \mathrm{Pu}$

"1

"1

$240 \mathrm{Pu}$

II

$239^{\mathrm{Pu}} \sigma_{\mathrm{f}}$ or $v$

11

$$
\sigma_{a}
$$

$\frac{\mathrm{UO}}{2} 2 \frac{-2 \mathrm{wt} \%}{35 \mathrm{PuO}} 2$

11

11

$23{ }^{8} \mathrm{U}$

$239_{\mathrm{Pu}}$

11

11

$240 \mathrm{Pu}$

11

$238 \mathrm{U}$

$235 \mathrm{U}$

11

$\sigma_{a}$

$239 \mathrm{Pu} \quad v$ or $\sigma_{\mathrm{f}}$

$\sigma_{a}$

* $1 \mathrm{mk}=0.1 \%$ in $k_{\text {eff }}$

\section{Thermal}

11

11

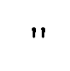

11

11

"1

11

Thermal

11

11

11

"1

in

\begin{tabular}{cc}
$\frac{\Delta \mathrm{k}_{\text {eff }}(\mathrm{mk}) *}{\mathrm{~V}_{\text {Mod }} / \mathrm{V}_{\text {Fuel }}=1.0}$ & \multicolumn{2}{c}{$\mathrm{V}_{\text {Mod } / \mathrm{V}_{\text {Fuel }}}=4.0$} \\
\hline 5 & 2 \\
1 & $<1$ \\
5 & 2 \\
8 & 3 \\
2 & 2 \\
3 & 4 \\
2 & 2
\end{tabular}

Resonance

$<1$

" 5

$"<5$

1

$<1$

$<1$

$<1$

1

$<1$

$<2$

$<1$

1

$<1$

2

$<1$

2

$<1$

1

5

3

4

2

1

1

$<1$

$<1$

4

3
1

1

1

$<1$

4

3 
systems are around $3 \%$. Thus it appears that the cross section uncertainties investigated do not account for the observed discrepancies in calculated $k_{\text {eff }}$ 's. However, it is concluded that computing $k_{\text {eff }}$ to better than say 1.5 or $1 \%$ of experiment is a fortituous result because of uncertainties in cross section data.

Evaluations of the theoretical methods have also been made. Calculational studies have been performed investigating the areas of lattice reaction rates (fast effect, resonance absorption, and thermalization) and neutron leakage. The results of the studies concerning lattice reaction rates are somewhat nebulous because of the lack of experimental information on the lattice fine structure of plutonium fueled- $\mathrm{H}_{2} \mathrm{O}$ lattices. Perhaps it serves more purpose to outline those areas of the theoretical method where we have know errors along with the assumptions that may be a source of error.

We have neglected spatial effects in computing the reaction rates for fast neutrons (>0.1 MeV) in the lattice cell. The error incurred in calculating $k_{\text {eff }}$ is largest for the systems containing the most ${ }^{238} \mathrm{U}$. We estimate this error to be less than $1 \%$ (probably around $0.5 \%$ ) for the systems investigated and the effect of the error is to lower $k_{\text {eff. }}$. This is probably a very small error for the Al-Pu fueled systems.

There are numerous approximations made in the resonance theory of the HRG code. The more significant of these are the use of the narrow resonance approximations for absorbers and moderators, neglecting $\mathrm{p}$ wave resonance absorption, and neglecting resonance overlap. More fundamental than these are the use of the Breit-Wigner single level formulism and neglecting crystalline effects in Doppler broadening for the cross section computations and the use of a quarter lethargy group structure. No estimates are made here of these effects on $k_{\text {eff }}$ calculations.

Another known source of error ${ }^{(144)}$ in our calculational method is in neglecting thermal neutron upscattering to energies above $0.683 \mathrm{eV}$. The effect of neglecting upscattering is to overpredict $k_{\text {eff }}$ for the plutonium fueled system because upscattering increases absorption in the ${ }^{240} \mathrm{Pu}$ and ${ }^{242} \mathrm{Pu}$ resonances at 1.056 and $2.5 \mathrm{eV}$. We estimate that for the lattices considered in this study the effect would probably be no larger than $1 \%$ in $k_{\text {eff }}$.

(144) Robkin, M. A., private communication. 
Neutron reflecting boundary conditions for a cylindrical cell were used in the above analysis. Results of a thermalization study (145) for some of these lattices show the effect on $k_{\text {eff }} \mathrm{o-}$ an approximate correction for these boundary condition limitations. Assuming the correction is valid then the use of the reflecting cell boundary condition is a small $(>0.3 \%)$ error in calculated $k_{\text {eff }}$.

The calculation of neutron leakage from the finite assemblies are also based upon a host of assumptions. Studies have been made of the adequacy of three non-thermal neutron energy groups in describing the leakage. Results of these studies show that the calculated values of $\mathrm{k}_{\text {eff }}$ are relatively independent of the number of groups in excess of four using the same scheme described above. Studies are being made to determine the adequacy of: one thermal neutron group, one dimensional flux calculation, two region reactor description, and diffusion theory itself, in predicting $k_{\text {eff }}$ for these lattices.

Conclusions

We have probably overlooked numerous other approximations and/or theory limitations. However, even this short review indicates that the need to improve the theoretical methods utilized in this study is as acute, if not more so, than the need for accurate cross section data. Evaluations of many of these effects will be made by comparison with Monte Carlo calculations. Forthcoming experimental data on the lattice fine structure will also help in narrowing the uncertainty in predicting $k_{\text {eff }}$ for plutonium fueled lattices.

$\frac{\text { Analytical Correlations of } \mathrm{UO}}{\text { V. O. Uotinen and S. Kobayashi } 2 \frac{-2}{*} \mathrm{wt} \% \mathrm{PuO}_{2}=\mathrm{H}} 2 \frac{0 \text { Moderated Critical Experiments }}{-}$

A summary of the results of critical experiments performed in the Plut inium Recycle Critical Facility (PRCF) ${ }^{(146)}$ for $\mathrm{H}_{2} \mathrm{O}$ moderated $\mathrm{UO}_{2}-2 \mathrm{wt} \% \mathrm{PuO}_{2}$ fueled

*Visiting Physicist from Hitachi Ltd., Tokyo, Japan.

(145) Liikala, R. C. and Purcell, W. L., "Results of Thermalization Calculations for PuO $-40{ }_{2}-\mathrm{H}_{2} \mathrm{O}$ Lattices," Reactor Physics Department Technical Activities Report, July, August, September, 1966, BNWL-340, October 15, 1966.

(146) Bennett, R. A. and Schmid, L. C., "Approach to Critical and Calibration Experiments in the Plutonium Recycle Critical Facility," H(w-80206, July 1964. 
systems are reported in another section* of this report. The results of preliminary analytical correlations are reported here.

The calculational results that are presented constitute a preliminary evaluation of the standard calculational results that are presented constitute a preliminary evaluation of the standard calculational scheme that is used at BNW for reactor physics design calculations. This scheme has been evaluated in the preceeding section for its ability to predict critical masses and multiplications. We are also evaluating its ability to predict other properties of Pu-fueled, $\mathrm{H}_{2} \mathrm{O}$ moderated cores. The work reported here is a step in this direction.

The same calculational methods and basic cross section data used and described in the previous section are used in this analysis. The only exception is that in the analysis of temperature coefficient experiments the scattering in hydrogen was assumed to be isotropic (i.e., no correction to the kernel to account for anisotropy). The comparisons of calculated and measured quantities of $k_{\text {eff }}$, reflector savings, bucklings; spatial distribution of copper activity and power density; worth of fuel, moderator void, and moderator level; kinetics parameters; and temperature coefficient are described below. $\underline{k}_{\text {eff }}$, Reflector Savings, and Bucklings

The calculated results of $k_{\text {eff }}$, bucklings, and reflector savings are shown in Table XXXVI. Calculated bucklings and reflector savings are obtained by fitting the appropriate functions (i.e., cosine, and $J_{0}$ Bessel) to calculated distributions of power density and thermal flux. The measured buckling (radial or axial) was used in HFN to account for transverse leakage. To obtain values for the axial direction, calculations on slab geometry were performed using the HFN code. Discrepancies between calculated and measured $k_{e f f}$ ' and reflector savings are noted. Spatial Copper Activation Distributions

Calculations were made of the thermal copper activation distribution in the radial direction in a single zone core and a two zone core. These distributions are compared to measured distributions of sub-cadmium copper activity in Figures XXVI and XXVII. The thermal activation cross sections

* Page 3.10 of the section on Critical and Subcritical Experiments. 


\section{Table XXXVI}

Measured and Calculated $\mathrm{k}_{\text {eff }}$ Bucklings and Reflector Savings

\begin{tabular}{|c|c|c|c|c|c|c|c|c|c|c|c|c|c|}
\hline \multirow{2}{*}{$\begin{array}{l}\text { Fuel } * x \\
\text { Type } \\
\end{array}$} & \multirow{2}{*}{$\begin{array}{c}\text { Calculated } \\
\mathrm{k} \\
\end{array}$} & \multicolumn{3}{|c|}{$\begin{array}{c}\text { Radial } \\
\text { Reflector } \\
\text { Savings }(\mathrm{cm})\end{array}$} & \multicolumn{3}{|c|}{$\begin{array}{c}\text { Radial } \\
\text { Reflector } \\
\text { Savings (cm) }\end{array}$} & \multicolumn{3}{|c|}{$\begin{array}{l}\mathrm{B}_{\mathrm{r}}^{2} \\
\left(\mathrm{~m}^{-2}\right)\end{array}$} & \multicolumn{3}{|c|}{$\begin{array}{l}\mathrm{B}_{\mathrm{axia} 1}^{2} \\
\left(\mathrm{~m}^{-2}\right)\end{array}$} \\
\hline & & & Exp. & Calc. & & $\operatorname{Exp}$ & Calc. & & Exp. & Calc. & & $\operatorname{xp}$ & Calc. \\
\hline 1 & 0.989 & 8.55 & \pm 0.53 & 6.70 & 6.96 & \pm 0.25 & 6.87 & 82.2 & \pm 3.3 & 90.86 & 8.89 & \pm 0.09 & 8.92 \\
\hline 3 & 0.991 & 7.75 & \pm 0.33 & 6.85 & 6.32 & \pm 0.20 & 7.02 & 63.3 & \pm 1.4 & 64.14 & 9.11 & \pm 0.07 & 8.87 \\
\hline $3-1$ & 0.990 & & - & - & 6.96 & \pm 0.28 & - & & - & - & 8.89 & \pm 0.10 & - \\
\hline $2-3$ & 0.990 & & - & - & 6.38 & \pm 0.30 & - & & - & - & 9.09 & \pm 0.11 & - \\
\hline $3-2$ & 0.990 & & - & - & 6.79 & \pm 0.36 & - & & - & - & 8.95 & \pm 0.12 & \\
\hline
\end{tabular}

$* \mathrm{k}_{\text {eff }}-$ Experiment $=1.000$

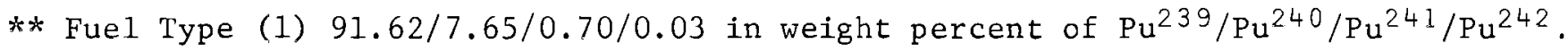

(2) $81.11 / 16.54 / 2.15 / 0.20$ in weight percent of $\mathrm{Pu}^{239} / \mathrm{Pu}^{240} / \mathrm{Pu}^{241} / \mathrm{Pu}^{242}$.

(3) $71.76 / 23 / 50 / 4.08 / 0.66$ in weight percent of $\mathrm{Pu}^{239} / \mathrm{Pu}^{240} / \mathrm{Pu}^{241} / \mathrm{Pu}^{242}$. 
Relative Thermal Copper Activity

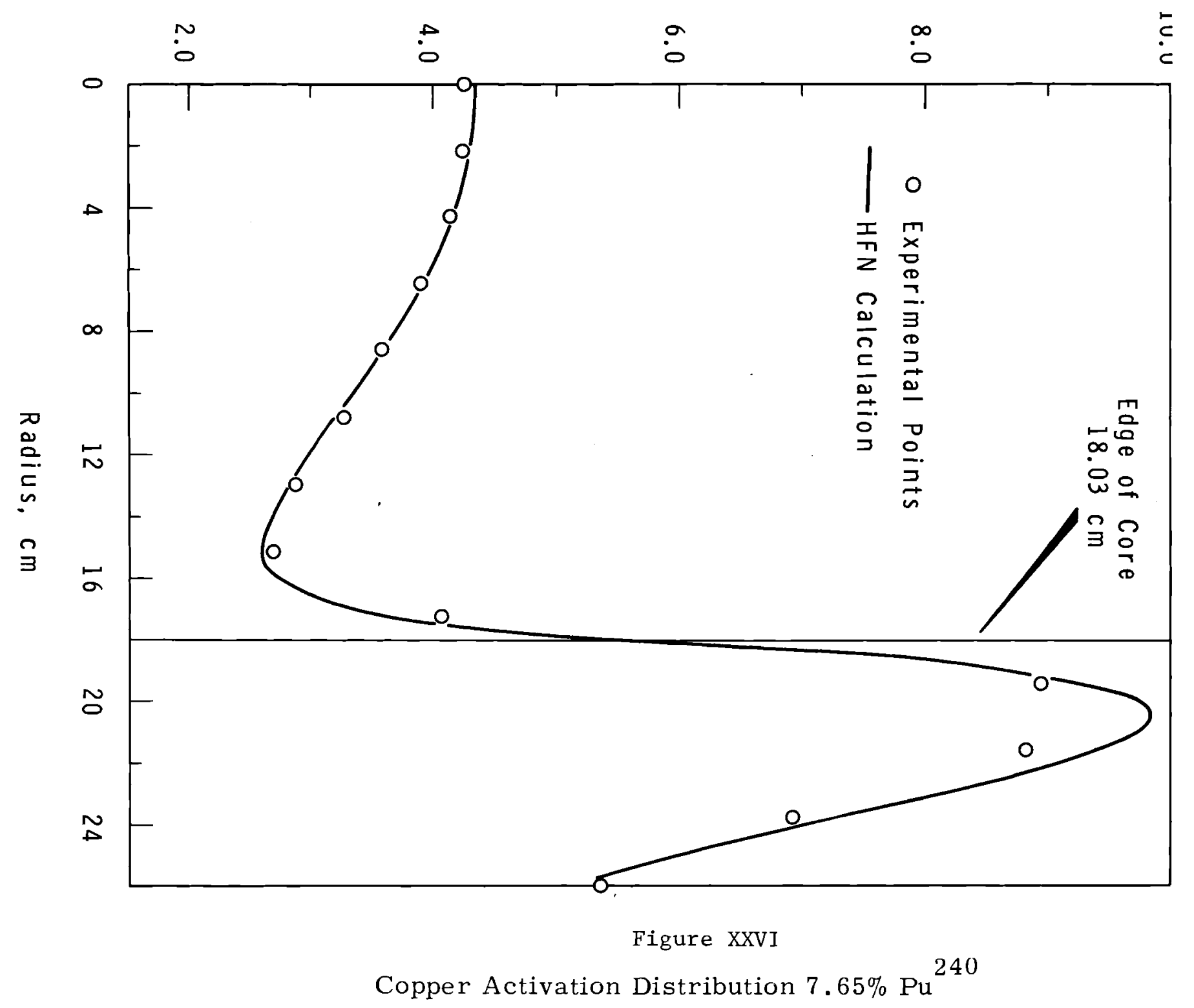

Copper Activation Distribution $7.65 \% \mathrm{Pu}^{240}$ 


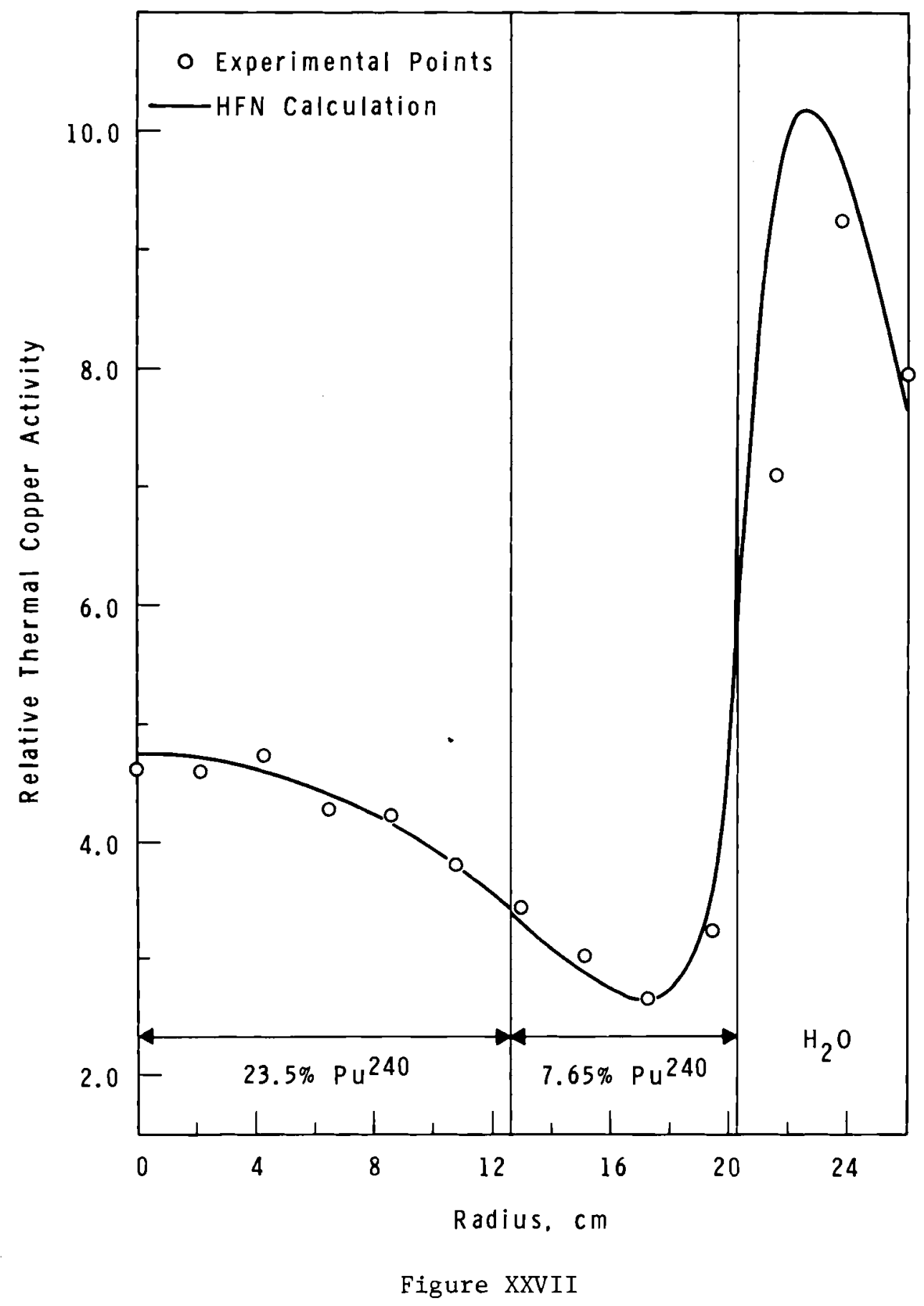

Copper Activation Distribution in Two-Zone Core Inner Zone 23.5\% $\mathrm{Pu}^{240}$; Outer Zone $7.65 \% \mathrm{Pu}^{240}$ 
used in the HFN calculations for various zones are cell-averaged values. The core radius was the effective cylindrical radius based on the actual number of fuel rods present during the experiment. Calculated and measured distributions were normalized using normalization factors that were averaged for the positions two, three, and four lattice units from the center.

The agreement between calculation and experiment is considered good except near the core reflector boundary and near the center of the core. The disagreement at the center is due to a flux depression which was measured at the center of each core. The disagreement in the boundary region between core and reflector is probably due to neglecting the changing spectrum in this region. Attempts are being made to obtain better agreement in this region by taking into account the changes in spectrum near the boundary. Spatial Power Density Distribution

Calculations were made of the power density in the radial direction using the HFN code for a single zone and a two zone core. The results are compared to measurement in Figures XXVIII and XXIX. The core radius was the effective cylindrical radius based on the number of fuel rods present during the experiment. Each experimental point represents the average power density over the thickness of a fuel rod, and is plotted at the effective cylinderized radius for the fuel rod. The calculated curves were normalized to an average power density of unity; the measured points were normalized to the calculated curve using average normalization factors as explained in the preceding section.

As in the case of activation distributions, the agreement between calculation and experiment is reasonably good, except near the core-reflector boundary and at the center of the core. Calculated and measured power sharing factors in zoned cores (ratio of power density in a fuel rod to power density in a fuel rod of the other type at the same radius) agree in all cases to within $2 \%$.

\section{Power Peaking}

Radial distributions of relative power density were measured in the two single-zone cores with a water hole in the center; the water hole was formed by removing the central fuel rod. Calculated local-to-average power peaking 


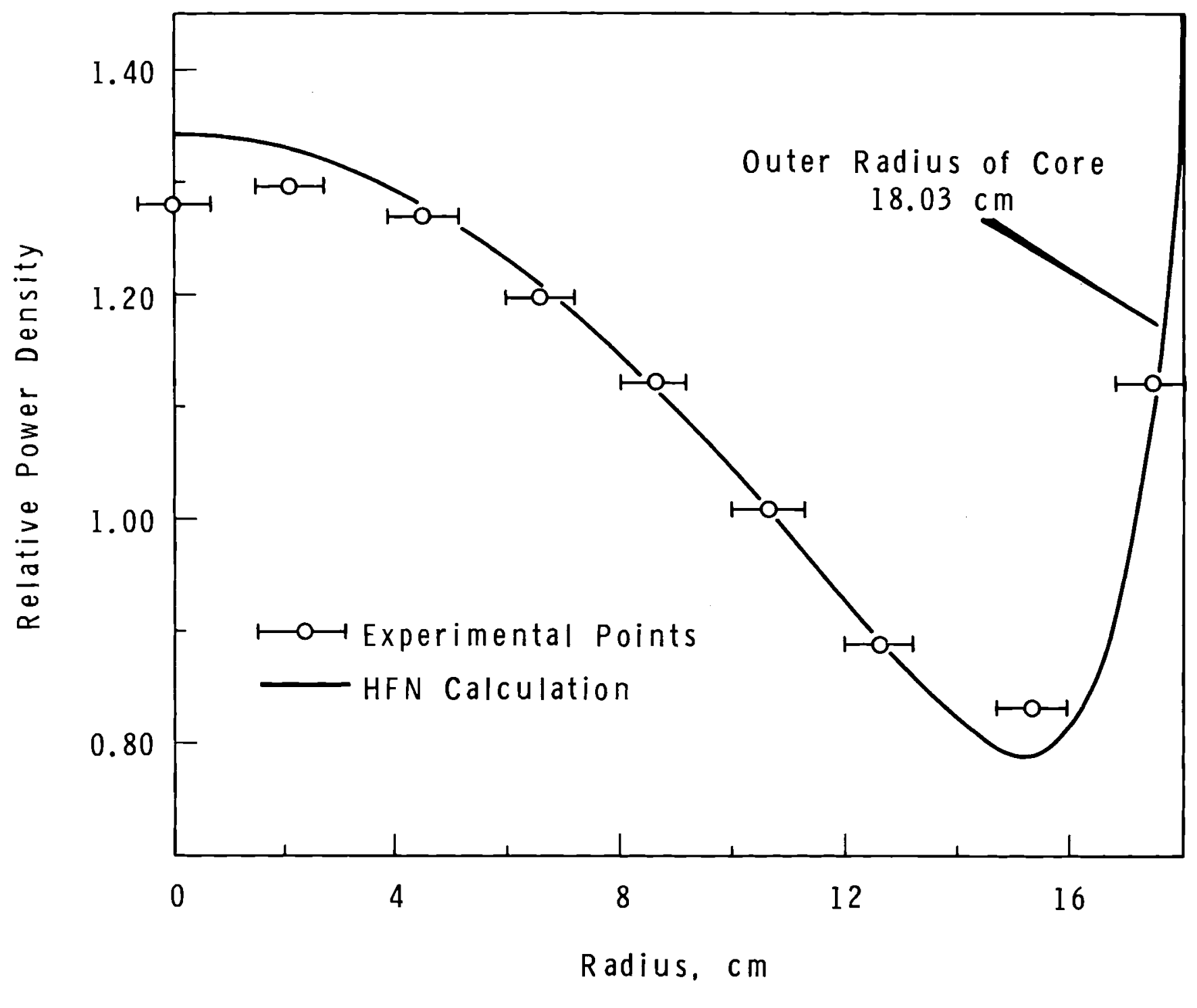

Figure XXVIII

Power Density Distribution $7.65 \% \mathrm{Pu}^{240}$ 


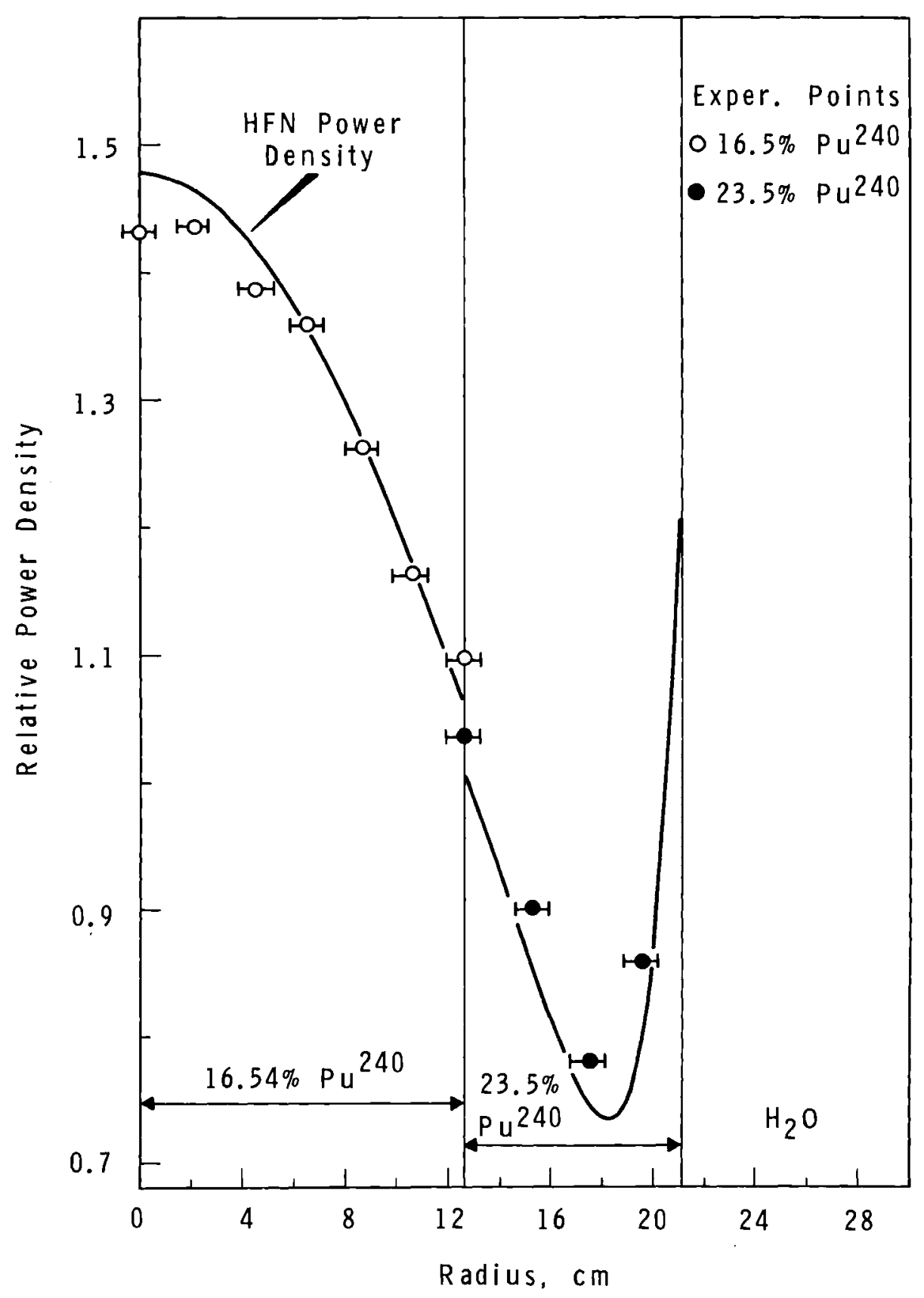

Figure XXIX

Power Density Distribution in Two-Zone Core Inner Core $16.54 \% \mathrm{Pu}^{240}$; Outer Zone $23.50 \% \mathrm{Pu}^{240}$ 
factors in rods adjacent to the water hole are greater than measured values by $\sim 5-6 \%$. However, calculated ratios of (av. power in rod adjacent to $\mathrm{H}_{2} \mathrm{O}$ hole)/(av. power in same rod with no $\mathrm{H}_{2} \mathrm{O}$ hole present) agree with measured values to better than $1 \%$.

Fuel Rod Worth

The difference in $k_{\text {eff }}$ when a fuel rod replaces water in the center and at the periphery of the core was calculated with the code HFN. Calculated worths of fuel rods in the center and on the periphery of the reactor are compared with measured worths in Table XXXVII.

Calculated fuel rod worths depend on what lattice constants are chosen to represent water. In our case, the constants were those for an infinite water medium. Better agreement with experimental results would be expected if one would take into account the changes in spectrum near core-water boundaries.

Moderator Voiding

Calculations were performed of the change in $\mathrm{k}_{\text {eff }}$ produced by a $14 \%$ void in the central cell, and by a $14 \%$ voiding of the entire moderator for the two single zone cores. The results are compared to values inferred from experiment in Table XXVIII. The calculated values of the average void coefficient are about $20-30 \%$ higher than the measured values.

Moderator Level Reactivity Coefficient

Calculations of moderator level worth have been performed using the diffusion theory code HFN with slab geometry. The four-group lattice constants were the same as for the radial calculations. For water heights below the top of the fuel the effect of dry (unmoderated) fuel above the homogenized core was neglected. Calculated values of moderator level worth are $20-25 \%$ greater than measured values.

Kinetics

The calculated kinetics parameters are compared to measurement in Table XXXIX. The calculations were performed using the transport theory code, PROGRAM S-III. (147) The calculated and measured values of $B / \ell$ differ by about $12 \%$.

(147) Duane, B. H., "Neutron and Photon Transport, Plane-Cylinder-Sphere, GE-ANPO Program S, Variational Optimum Formulation," XDC 59-9-118 General Electric Aircraft Nuclear Propulsion Department, 1959. 
Table XXVII

Calculated and Measured Fuel Rod Worth, Cents

(For a Fuel Rod Replacing Water)

\begin{tabular}{|c|c|c|c|c|}
\hline \multirow{2}{*}{$\begin{array}{l}\text { Fue1 } \\
\text { Type }\end{array}$} & \multicolumn{2}{|c|}{ Central Fuel Rod } & \multicolumn{2}{|c|}{ Peripheral Fuel Rod } \\
\hline & Exp. & Calc. & Exp. & Calc. \\
\hline 1 & $-23.2 \pm 0.2$ & -34.8 & $21.0 *$ & 22.0 \\
\hline 3 & $-15.3 \pm 0.2$ & -23.0 & $10.2 *$ & 10.2 \\
\hline
\end{tabular}

* Read off curves of experimental data, at effective radius of core. The estimated uncertainty is $\pm 5 \%$.

\section{Table XXVIII}

Calculated and Measured Void Worth

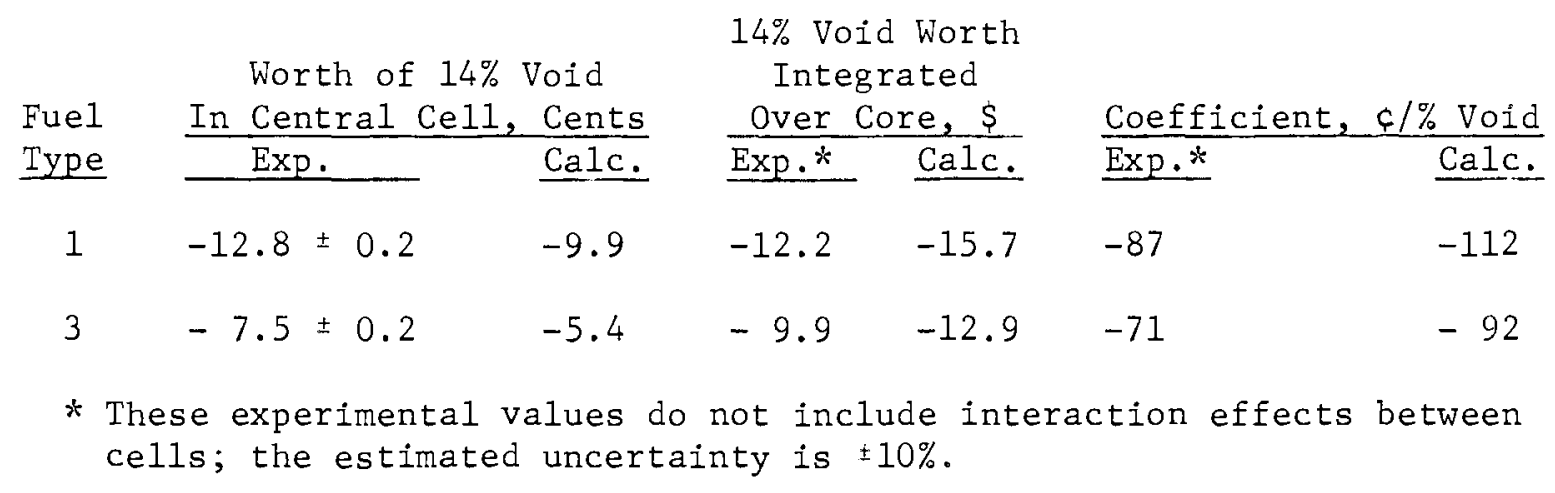

Table XXXIX

Comparison of Measured and Calculated Kinetics Parameters

\begin{tabular}{|c|c|c|c|c|}
\hline \multirow{2}{*}{$\begin{array}{l}\text { Fue1 } \\
\text { Type }\end{array}$} & \multicolumn{3}{|c|}{ Calculated } & \multirow{2}{*}{$\begin{array}{l}\text { Meas } \\
\underline{B} / \ell, \sec ^{-1}\end{array}$} \\
\hline & $\beta$ & $\ell$ & $\beta / \ell, \sec ^{-1}$ & \\
\hline 1 & $3.447 \times 10^{-3}$ & $3.064 \times 10^{-5}$ & 112.5 & $127 \pm 11$ \\
\hline 3 & $3.732 \times 10^{-3}$ & $2.944 \times 10^{-5}$ & 126.8 & $114 \pm 15$ \\
\hline
\end{tabular}




\section{Temperature Coefficient}

The temperature coefficient of reactivity was measured in the two singlezone cores over the temperature range between $\sim 20^{\circ} \mathrm{C}$ and $\sim 50^{\circ} \mathrm{C}$. The moderator was heated (or cooled) in a storage tank and was pumped in and out of the reactor vessel between measurements.

Calculations of multiplication at several temperatures were performed using temperature-dependent lattice constants for both core and reflector, taking into account also the change in transverse leakage with temperature. One other effect that needs to be included in the calculation is the expansion of the lucite lattice plates. New lattice constants were calculated, taking into account the increase in lattice pitch with temperature. Multiplications were then calculated using these new lattice constants and a temperaturedependent core radius. The calculated temperature coefficients are compared to measurement in Figures XXX and XXXI.

Summary

The results of this evaluation show that, in many cases the preliminary calculational techniques need to be refined. The techniques for analyzing each individual experiment are being developed, and more detailed analyses will be reported later.

\section{Correlations of Burnup Data}

Another measure of the validity of the mathematical model is obtained by comparison of calculated and experimental isotopic concentrations and effective $(\hat{\sigma})$ cross sections. Two approaches to evaluating the theory and cross sections are being used at PNL.

In one, a computation of the equilibrium neutron spectrum is made at various time intervals to obtain flux integrated cross sections for use in burnup calculations. Each burnup calculation is made assuming the neutron flux is constant during the time interval. The effects of fission product cross sections are eplicitly accounted for in the calculations by including the yield per fission of each product and the appropriate decay chains. As a result of these calculations, isotopic concentrations and cross section ratios are obtained as a function of exposure. Comparison of the calculated values with experimental values allow conclusions to be made about the burnup calculations. The calculation can be made for either a single cell of the reactor or the whole reactor. 
TEMPERATURE COEFFICIENT 7.65 WT. $\%$ Pu $^{240}$

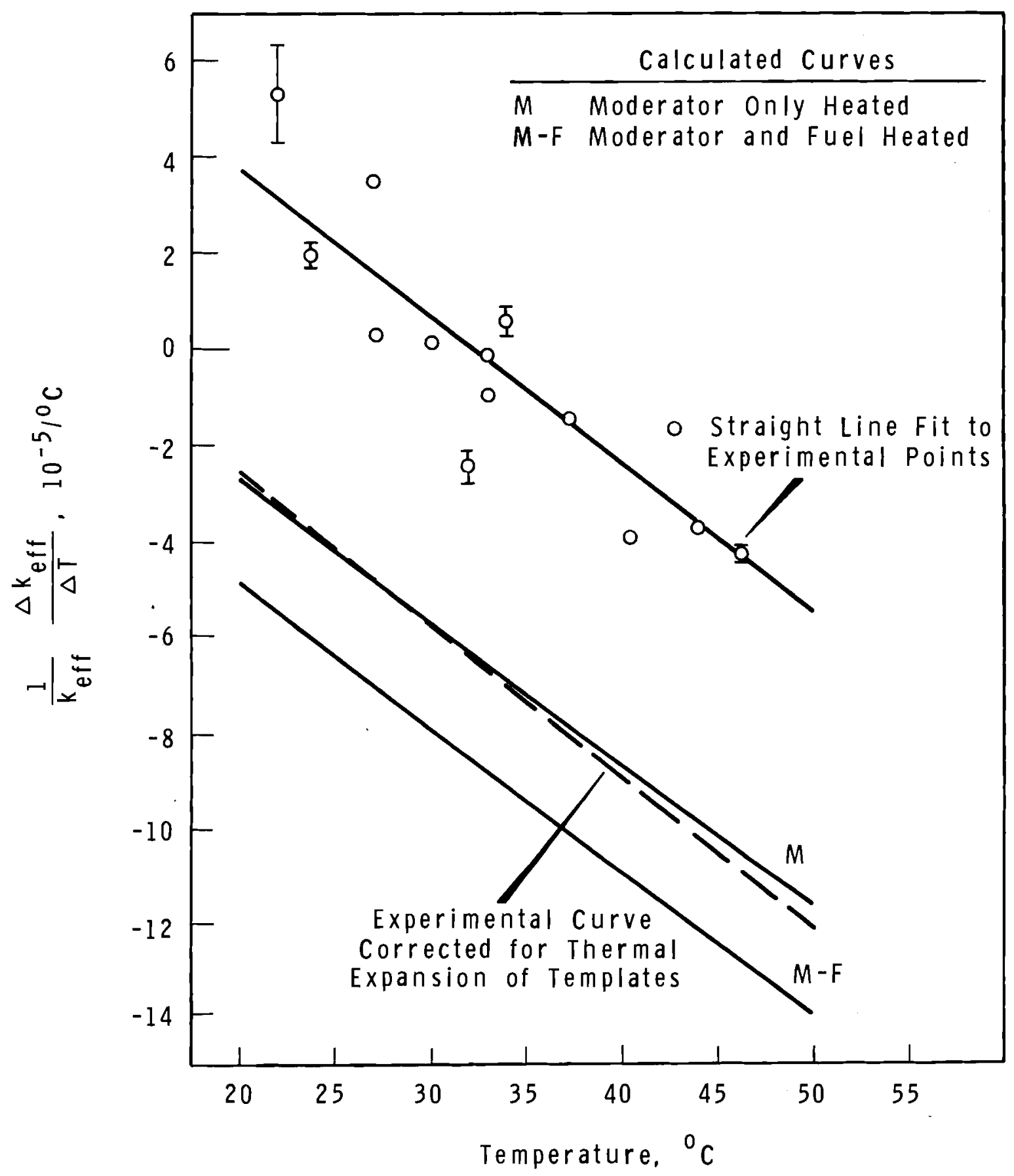

Figure XXX 
TEMPERATURE COEFFICIENT 23.5 WT. \% Pu 240

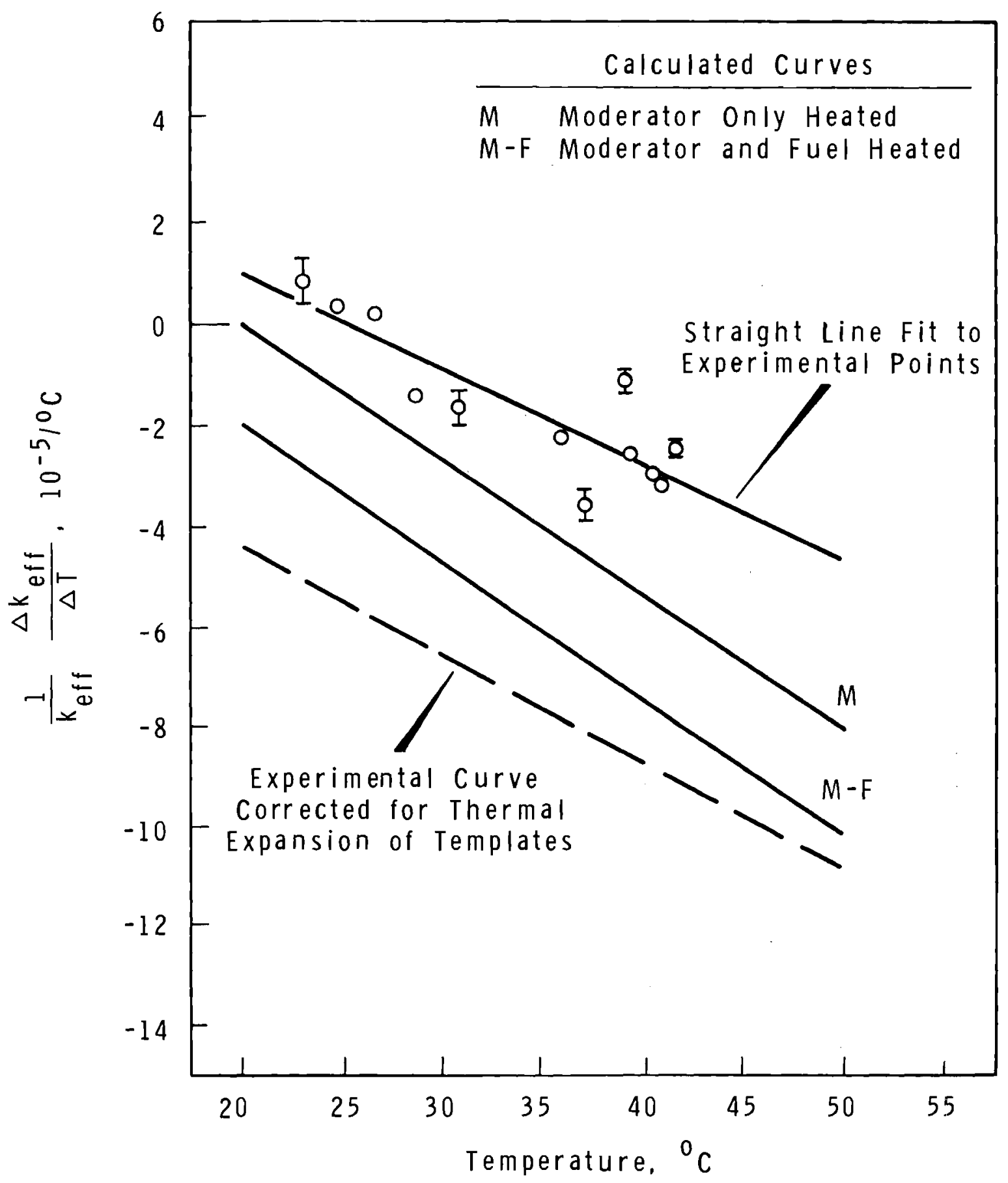


The second approach uses measured isotopic concentrations in a computation of the neutron spectrum and effective cross sections within a representative cell of the reactor at various exposure. The neutron spectrum is computed using thermal cross section data which have been normalized to the results of various evaluations of the $2200 \mathrm{~m} / \mathrm{sec}$ values. Average cross sections obtained from these calculations are used in obtaining effective values $\hat{\sigma}^{i}, j$ for each region $j$. The effective values are compared to values derived from the least squares analysis of the experimental data. The merit of this approach is (a) the same assumptions are used in the experimental and the theoretical analysis, (b) it determines which normalization of thermal data results in the best fit to the experimental data, (c) it provides a measure of the sensitivity of calculated results to uncertainties in the thermal data, and (d) the effects of various perturbations on the neutron spectrum such as fission products, leakage, etc., are easily compared to experimental results obtained from irradiations of aluminum-1.8 wt\% plutonium fuels included in a previous paper ${ }^{(148)}$ along with details of the experimental analysis.

Correlation of Effective Cross Sections - R. C. Liikala and W. L. Purcell Analytical Procedures

The effective values are defined as

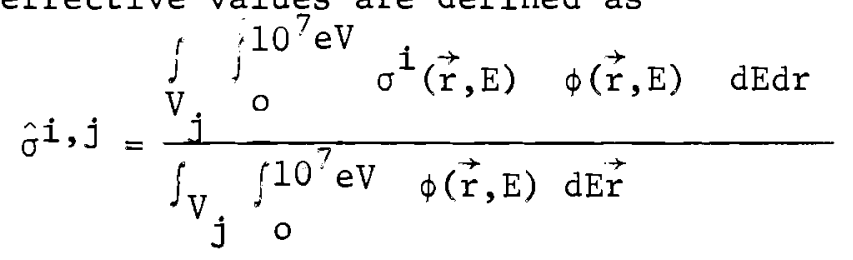

where the spatial integration is over the fuel volume $v_{j}$ of interest. Separating the energy integrals in numerator and denominator into thermal ( 0.683 to $\left.10^{7} \mathrm{eV}\right)$ and thermal $(0.0$ to $0.683 \mathrm{eV})$ terms and $\mathrm{Is} / \mathrm{g}$ the spatial integral of the flux above 0.683 is constant allows Equation

(148) Schmid, L. C., et al., "Experimental and Theoretical Methods used for Burnup Analys is at Battelle-Northwest," British Nuclear Energy Society International Conference on Physics Problems of Thermal Reactor Design, London, England, June 27-29, 1967. 
(1) to be written as

$$
\hat{\sigma}^{i, j}=\frac{\bar{\sigma}_{1}^{i} \phi_{1}+j_{V_{j}} j^{0.0683} \sigma^{i(\vec{r}, E) \phi(r, E) d E d \vec{r}}}{\phi_{1}+\int_{V_{j}} j^{0.0683} \phi(\vec{r}, E) d E d \vec{r}}
$$

where subscript 1 refers to the nonthermal neutron energy group. The second term of the numerator can be written as the product of the average thermal cross section, $\sigma_{2}^{i, j}$ and the total thermal neutron flux $\phi_{2}^{j}$ in the fuel region of interest. Subscript 2 refers to the thermal neutron energy group. The second term in the denominator is just the total thermal neutron flux $\phi_{2}^{j}$ in fuel region $j$. Thus, Equation (2) becomes

$$
\hat{\sigma}^{i, j}=\left(\bar{\sigma}^{i, j} \phi_{1}^{j}+\bar{\sigma}_{2}^{i, j} \phi_{2}^{j}\right) /\left(\phi_{1}^{j}+\phi_{2}^{j}\right) \text {. }
$$

The fluxes $\phi_{1}^{j}$ and $\phi_{2}^{j}$ are normalized assuming that all neutron scattered from group 1 to group 2 are absorbed in group 2. Thus

$$
\phi_{1}^{\mathrm{c}} \bar{\Sigma}_{1 \rightarrow 2}^{\mathrm{c}}=\phi_{2}^{\mathrm{c}} \overline{\bar{\Sigma}}_{\mathrm{a} 2}^{\mathrm{c}} \text {, }
$$

where $\phi_{1}^{c}$ and $\phi_{2}^{c}$ are the total flux in the cell for group 1 and 2 . Now $\phi^{c}$ is related to the total flux in the fuel by

$$
\begin{aligned}
& \phi_{1}^{j}=\phi_{2}^{c}\left(V^{j} \bar{\phi}_{1}^{j}\right) /\left(V^{c} \bar{\phi}_{1}^{c}\right) \text { and } \\
& \phi_{2}^{j}=\phi_{2}^{c}\left(v^{j} \bar{\phi}_{2}^{j}\right) /\left(V^{c} \quad \bar{\phi}_{2}^{c}\right)
\end{aligned}
$$

where $V$ refers again to volume and $\bar{\phi}$ is the average flux. Assuming $\phi_{1}^{j} / \bar{\phi}_{1}=1$, substituting Equations (5) and (6) in Equation (4) and solving for the ratio $\phi_{1}^{j} / \phi_{2}^{j}$ and then using this normalizing condition in Equation (3), the expression for the effective cross section becon:

$$
\hat{\sigma}^{i, j}=\frac{\sigma_{1}^{i, j} \bar{\Sigma}_{a 2}^{c} / \bar{\Sigma}_{1 \rightarrow 2}^{c}+\bar{\sigma}_{2}^{i, j} \bar{\phi}^{j} / \bar{\phi}_{2}^{c}}{\bar{\Sigma}_{2 a}^{c} / \bar{\Sigma}_{1 \rightarrow 2}^{c}+\bar{\phi}_{2}^{j} \bar{\phi}_{2}^{c}}
$$

The quantities $\bar{\sigma}_{1}^{j}$ and $\bar{\Sigma}_{1 \rightarrow 2}^{c}$ are obtained from cell calculations using the HRG code and all other quantities are obtained from calculations using the THERMOS code. 


\section{Experiment}

The experimental data ${ }^{(149)}$ on the burnup of Al-1.8 wt\% Pu fuel were obtained from PRTR irradiations. (150) The fuel element was a 19-rod cluster. (151) The isotopic concentrations versus irradiation time were used as the basis for analysis ${ }^{(148)}$ to obtain ratios of effective cross sections. It is these data that we attempt to correlate. Neutron Spectrum Computations

The neutron spectrum is computed at various exposures utilizing the experimental atom concentration of the plutonium isotopes. The average physical temperatures of the fuel, coolant, and moderator were assumed to be $343,260,59^{\circ} \mathrm{C}$ respectively. These are the average inferred fuel temperature during irradiation, the average of the observed inlet and outlet temperatures for the moderator and coolant.

The slowing down of neutrons is computed using the HRG code. The options utilized in the current study are: the P-I approximation for zero leakage, the ${ }^{239} \mathrm{Pu}$ fission spectra, and Doppler broadening and spatial corrections for ${ }^{239} \mathrm{Pu},{ }^{240} \mathrm{Pu}$, and ${ }^{241} \mathrm{Pu}$. The mean chord length ( $\left.\bar{l}\right)$ for the cluster was obtained from the relationship $\bar{l}=4 \mathrm{~V} / \mathrm{S}$ eff where $\mathrm{V}$ is the volume enclosed by a rubber band stretched around the cluster and $\mathrm{S}_{\text {eff }}=$ $1.23 \mathrm{x}$ rubber band surface area. The admixed moderator scattering cross section per absorber atom was computed for a single rod of the 19-rod cluster, (i.e., Al as the admixed moderator in the fuel). This procedure for obtaining the spatial correction parameters evolved from analytical correlations of experiments for similar cells fueled with natural $\mathrm{UO}_{2}{ }^{-}$ 19-rod clusters.

The thermal neutron spectrum is computed using the THERMOS code. Thirty neutron energy groups were used to describe events occurring

(148) Schmid, L. C., et al., "Experimental and Theoretical Methods used for Burnup Analysis at Battelle-Northwest," British Nuclear Energy Society International Conference on Physics Problems of Thermal Reactor Design, London, England, June 27-29, 1967.

(149) Christensen, D. E., Reppond, E. B., and Reardon, W. A., "Burnup Data from Low Exposure Plutonium-Aluminum Fuel," BNaL-CC-904 (1966).

(150) Smith, R. I. and Peterson, R. E., "Experience with the Plutonium Recycle Test Reactor," Proceedings Plutonium As a Power Reactor Fuel, Hw-75007, December, 1962.

(151) Freshley, M. D., "Plutonium Spike Fuel Elements for the PRTR - Part I The Mark I-G," H(W-69200 Pt. 1 (1961). Sharp, R. E., "Plutonium Spike Fuel Elements for the PRTR Part II - The Mark I-H," HW-69200 Pt. 2 (1961). 
below $0.683 \mathrm{eV}$. A concentric cylinder model of the cluster obtained by preserving atom concentrations and volumes were used. The cell is described in seven regions with 30 square points. The Brown-St. John kernel for $\mathrm{D}_{2} \mathrm{O}^{(152)}$ was used. Reflecting cell boundary conditions were also utilized.

\section{Cross Sections}

We have considered here only four of the more recent evaluations of the most probable values of the $2200 \mathrm{~m} / \mathrm{sec}$ constants. Leonard reviewed (153) the information concerning the low energy cross sections of the fissile nuclides in 1961 . The $2200 \mathrm{~m} / \mathrm{sec}$ values 1 isted for ${ }^{241} \mathrm{Pu}$ resulted from a 1962 review. (154) Sher undertook an evaluation to arrive at "best" values for the $2200 \mathrm{~m} / \mathrm{sec}$ constants and gave early results (155) in March, 1962 and revised results in March, 1965. (156) Westcott, et al., have made the most recent study of these probable values. Preliminary results were presented ${ }^{(157)}$ in a paper at the Third Geneva Conference and the final results given in a report ${ }^{(127)}$ which followed shortly thereafter. This evaluation included $24 \mathrm{Pu}$ (independent from the other three nuclides). The results of all four of these evaluations are given in Table XL.

The resonance data for the plutonium isotopes on which our calculations are based are those listed in the previous section as are the $2200 \mathrm{~m} / \mathrm{sec}$ values for $240 \mathrm{Pu}$ and $242 \mathrm{Pu}$.

(152) Brown, H. and St. John, D., "Neutron Energy Spectrum in $D_{2} 0, "$ USAEC Report DP-33, (1954).

(153) Leonard, B. R., Jr., "Survey of the Status of Low Energy Cros. Sections of Fissile Nuclides," Neutron Physics, Proceedings of Symposium Held at Rensselaer Polytechnic Institute, 1961, pp, edited by M. L. Yeater, Academic Press, New York, N. Y. 1962, also HEW-69342, April 22, 1961.

(154) Leonard, B. R., Ir., "Plutonium Physecs" Contribution to Plutonium Handbook," HW-72947, March 9, 1962.

(155) Sher, R. and Felberbaum, J., "Least Squares Analysis of the $2200 \mathrm{~m}$, seo Parameters of $U^{233}, U^{235}$, and $P u^{238}$," USAEC Report, BNL-722, June 1962.

(156) Sher, R. and Felberbaum, J., "Least Squares Analysis of the $2200 \mathrm{~m} / \mathrm{sec}$ Parameters of $U^{233}, U^{235}$, and Pu'38," USAEC Report BNL-918, March 965 .

(157) Westcott, C. H., et al., P. A. Conference 28,P/717, Proceedings of the Third United Nations International Conference, "Peaceful uses of Atomic Energy," Geneva (1964). 
Table XL

Evaluation of $2200 \mathrm{~m} / \mathrm{sec}$ Constants for $\mathrm{Pu}^{239}$ and $\mathrm{Pu} 24 \mathrm{I}$

\section{Isotope}

$\mathrm{Pu}^{239}$

$\mathrm{Pu}^{241}$

\begin{tabular}{|c|c|c|}
\hline $\begin{array}{c}\text { Cross } \\
\text { Section } \\
\end{array}$ & Leonard & $(153,154)$ \\
\hline$\sigma_{a}$ & 1008 & \pm 6 \\
\hline$\sigma_{f}$ & 754 & \pm 9 \\
\hline$\sigma_{c}$ & 254 & \\
\hline$\nu$ & 2.89 & \pm 0.05 \\
\hline$\alpha$ & 0.337 & \pm 0.017 \\
\hline$\eta$ & 2.16 & \pm 0.05 \\
\hline$\sigma_{\mathrm{a}}$ & 1370 & \pm 15 \\
\hline$\sigma_{f}$ & 1030 & \pm 8 \\
\hline$\sigma_{c}$ & 340 & \pm 16 \\
\hline$\nu$ & 3.03 & \pm 0.05 \\
\hline$\alpha$ & 0.330 & \\
\hline$n$ & 2.278 & \\
\hline
\end{tabular}




\section{Comparison of Results}

The ratios obtained from results of cell calculations and Equation (7) for various $2200 \mathrm{~m} / \mathrm{sec}$ cross section sets are compared to values obtained from the least squarter analysis of experimental data ${ }^{(148)}$ in Table XLI.

The calculated values of $\alpha^{+9}$ obtained using the Leonard normalization compare favorably with experiment (ranging from 0 to $\sim 2-1 / 2 \%$ low). The values for the Westcott, et al., normalization are all within one standard deviation of the experimental value. The Sher sets give values differing from experiment by one to two standard deviations.

The values of $\hat{\alpha}^{4}$ calculated using the Leonard and Westcott, et al., normalizations are both larger than the experimental value. The Leonard set giving a result differing from experiment by less than one standard deviation and the Westcott set result bring slightly greater than one standard deviation of the experimental value.

The calculated values of $\hat{\sigma}_{a}^{40} / \hat{\sigma}_{a}^{49}$ are all $\sim 20 \%$ lower than the experimental values. Such a discrepancy was not unexpected considering all the approximations made in computing the effective cross section of $\mathrm{Pu}^{240}$. The HRG code assumes; quarter lethargy groups (i.e., 5 groups spanning the $1.056 \mathrm{eV}$ resonance of $\mathrm{Pu}^{240}$ ) with all absorption occurring in oen of these groups. Narrow Resonance (NR) approximation for all non fuel materials $\left(D_{2} 0\right)$ as well as the material admixed with fuel (A1), Narrow Resonance Infinite Absorber (NRIA) approximation for $\mathrm{Pu}^{2}+0$, and a homogeneous cell. In addition, we have neglected upscattering from thermal energies. An ad hoc prescription to resolve this discrepancy would be to force the data to agree via the spatial correction (mean shord length, $\bar{l}$ ) term in the HRG calculation. Once a value of $\bar{l}$ has been determined which provides th? fit, possibly a phenomenological recipe could be developed to compute he value of $\bar{\ell}$.

Areas of Uncertainty in the Analysis

The results of this analytical study are based upon numerous assumptions. Since assumptions frequently lead to errors, studies are being conducted to evaluate the effects these assumptions have on the calculated results.

We have neglected leakage and fission products in the neutron spectrum calculations. Some preliminary calculations have been made to determine the sensitivity of the neutron spectrum and the effective cross sections to leakage and fission products. Results of these calculations indicate that the ratios of effective cross sections are relatively insensitive to each. 
Table XLI

Comparison of Calculated Ratios of Effective Cross Sections to Values Obtained from Least Squares Analysis of Experimental Data for Lx Pu-Al Clusters

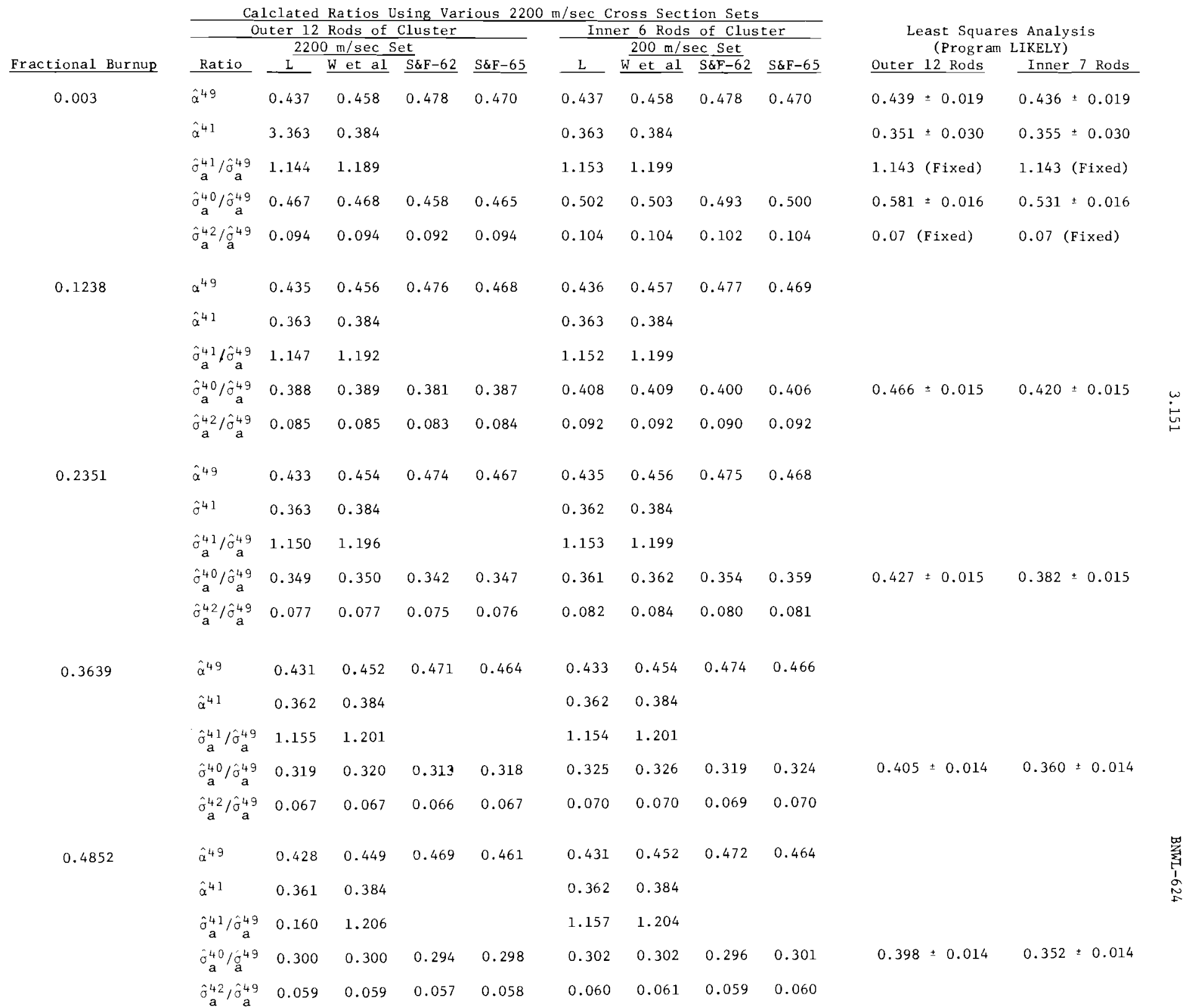


Likewise, the thermalization calculations were performed using the Brown and St.John (BSJ) model for the $\mathrm{D}_{2} \mathrm{O}$ scattering kernel. Models are available $(158,159)$ which better describe the neutron scattering from deuterium in $\mathrm{D}_{2} \mathrm{O}$. Calculations were made using the Honeck-Nelkin model ${ }^{(159)}$ for $\mathrm{D}_{2} \mathrm{O}$ in the THERMOS code. Results of these calculations are given in Table XIII along with those obtained using the BSJ model. The ratios of effective cross sections are essentially the same irrespective of the scattering kernel.

Results of more detailed analysis concerning these effects will help to firm up these areas of uncertainty in the analysis. Conclusions

We have evaluated the adequacy of a calculational method as applied to burnup determinations by comparing calculated ratios of effective cross sections to values deduced from experiment. The comparison is "best" when the thermal cross sections for $\mathrm{Pu}^{239}$ and $\mathrm{Pu}$ are normalized to the $2200 \mathrm{~m} / \mathrm{sec}$ values of Leonard's evaluation. However, the calculated values using the Westcott, et al., normalization are within one standard deviation of the experimental value for $\hat{a}^{+9}$ very nearly within the experimental uncertainty for $\hat{\alpha}^{41}$. The constants of the Westcott, et al., evaluation have been temporarily accepted for the normalization of data in the ENDF/B data file. Thus, if we assume these $2200 \mathrm{~m} / \mathrm{sec}$ values as the most probable, we would conclude that the "best" comparison is a result of errors in the theoretical methods that were used and/or inaccurate cross section data (e.g., resonance data, shape of the thermal cross sections, etc.).

Correlations of Effective Cross Section Ratios and Isotopic Concentrations L. J. Page and L. C. Schmid

A theoretical analysis ${ }^{(160)}$ of the burnup has been performed for tins

(158) Koppel, J. U., Triplett, J. R., and Nalibojf, Y. D., "Gasket: A Unefied Code for Thermal Neutron Scattereng," GA-74/7, Sept. 22, 1966.

(159) Honeck, H. C., "An Incoherent Thermal Scattering Model for Heavy water," Trans. Am. Nucl. Soc., Vol. 5, No. 1, 1962.

(160) Page, L. J., "Theory Experment Correlation of Burnup Data from Al 1.8 wt: Pu Fuel Initially 6 at: $P u^{2}+01, "$ USAEC Report BNWL-393, July 1967. 


\section{Table XLII}

Effect of $\mathrm{D}_{2} \mathrm{O}$ Scattering Kernel on Ratios of Effective Cross Sections

Ratio

\begin{tabular}{|c|c|c|c|c|c|c|}
\hline $\mathrm{D}_{2} \mathrm{O} \quad$ Temp. & Coolant & Moderator & $\hat{\alpha}^{49}$ & $\hat{\sigma}^{41}$ & $\begin{array}{c}\hat{\sigma}_{a}^{41} / \hat{\sigma}^{49} \\
{ }^{2}\end{array}$ & $\hat{\sigma}_{a}^{40} / \hat{\sigma}^{49}$ \\
\hline \multirow[t]{3}{*}{ Operating } & BSJ & $\mathrm{BSJ}$ & 0.458 & 0.384 & 1.189 & 0.468 \\
\hline & $\mathrm{H}-\mathrm{N}^{*}$ & BSJ & 0.456 & 0.384 & 1.198 & 0.465 \\
\hline & $\mathrm{H}-\mathrm{N} *$ & $\mathrm{H}-\mathrm{N}^{*}$ & 0.455 & 0.384 & 1.191 & 0.464 \\
\hline \multirow[t]{3}{*}{ Room } & BSJ & BSJ & 0.435 & 0.383 & 1.225 & 0.465 \\
\hline & $\mathrm{H}-\mathrm{N} *$ & $\mathrm{H}-\mathrm{N}^{*}$ & 0.430 & 0.385 & 1.244 & 0.469 \\
\hline & $\mathrm{H}-\mathrm{N}^{* *}$ & $\mathrm{H}-\mathrm{N} * *$ & 0.430 & 0.385 & 1.245 & 0.468 \\
\hline
\end{tabular}

* No correction for anisotropy in the kernel.

** Includes a correction for anisotropy. The diagonal elements of the kernel (matrix) are corrected such that the kernel sums to the transport cross section. 
same Al-Pu fuel cluster in the PRTR using the first approach. The calculations were made using the codes HRG, THERMOS, and PROGRAM S-XIII (147) for four energy groups of neutrons. Cross sections for the two higher energy groups were obtained from cell calculations using the HRG* code. The cross sections for the two lower energy groups were obtained from cell calculations using the THERMOS code. These four group cross sections were then used in the PROGRAM S-XIII code to compute isotopic concentrations, cross section ratios and eigenvalues as a function of burnup. A one dimensional. model of the cluster was used in the burnup calculation (PROGRAM S-XIII) and the average cross sections for the regions were computed at approximate

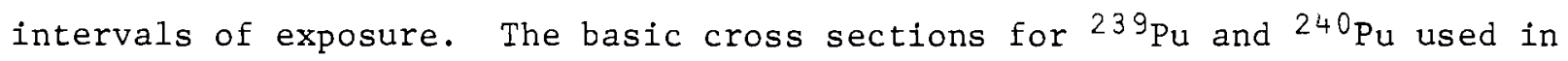
this study are the same (Leonard normalization) used in the analysis described in the previous section. The ratios of effective cross sections obtained using this approach (Method A) and those of the other Section (Method B) are compared in Table XLIII. The results of Method A do not show the trend in $\hat{\alpha}^{49}$ with burnup that Method $B$ does. A significant difference is noted in the ratio $\hat{\sigma}_{a}^{40} / \hat{\sigma}_{a}^{49}$ between the two methods. This difference is a result of using THERMOS to compute resonance absorption in the energy interval containing the large $240 \mathrm{Pu}$ resonance (i.e., 0.683 to $2.38 \mathrm{eV}$ ).

Since the vast majority of experimental data is in form of isotopic concentrations are determined by mass spectrometer analysis, primary importance is put on correlation of those data. Concentrations of the plutonium isotopes are shown in Figure XXXII, XXXIII, and XXXIV as a function of percent depletion of the initial plutonium for each of the three fuel regions of the 19-rod cluster. Burnup is defined as the amount of plutonium (all isotopes) fissioned or decayed divided by the initial amount of plutonium. All experimental numbers and errors came from data in reference (149), The experimental uncertainty quoted on burnup values ranges from $4.2 \%$ at $10 \mathrm{w}$ depletion to $2.1 \%$ at $50 \%$ depletion. The uncertainties on the experimental concentrations are $1 \%$ for ${ }^{239} \mathrm{Pu}, 1-1 / 2 \%$ for ${ }^{240} \mathrm{Pu}, 2 \%$ for ${ }^{241} \mathrm{Pu}$, and $2-1 / 2 \%$ for ${ }^{242} \mathrm{Pu}$. When these uncertainties are taken into account, the calculated

* Since this study was made changes have been made to the HRG code. (95) The changes reflect improvement in theory (126) and cross section data. (161)

(161) Carter, J. L., "HRG Data Tape," Reactor Physics Department Technical Activities Report, October, November, December, 1966. BNWL-400, April 15, 1967. 
Table XIIII

\section{Comparison of Calculated Ratios of Effective Cross Sections}

\begin{tabular}{|c|c|c|c|c|c|c|}
\hline \multirow{3}{*}{$\begin{array}{c}\text { Fractional } \\
\text { Burnup } \\
\end{array}$} & \multicolumn{2}{|c|}{$\hat{\alpha}^{49}$} & \multicolumn{4}{|c|}{$\begin{array}{c}\hat{\sigma}^{40} / \hat{\sigma}^{49} \\
a\end{array}$} \\
\hline & \multicolumn{2}{|c|}{ (Outer 12 Rods) } & \multicolumn{2}{|c|}{ (Outer 12 Rods) } & \multicolumn{2}{|c|}{ (Inner 6 Rods) } \\
\hline & Method A & Method B & Method A & Method B & Method A & Method \\
\hline 0.003 & 0.439 & 0.437 & 0.516 & 0.467 & 0.496 & 0.502 \\
\hline 0.2351 & 0.439 & 0.433 & 0.415 & 0.349 & 0.364 & 0.361 \\
\hline 0.4852 & 0.436 & 0.428 & 0.386 & 0.300 & 0.285 & 0.302 \\
\hline
\end{tabular}




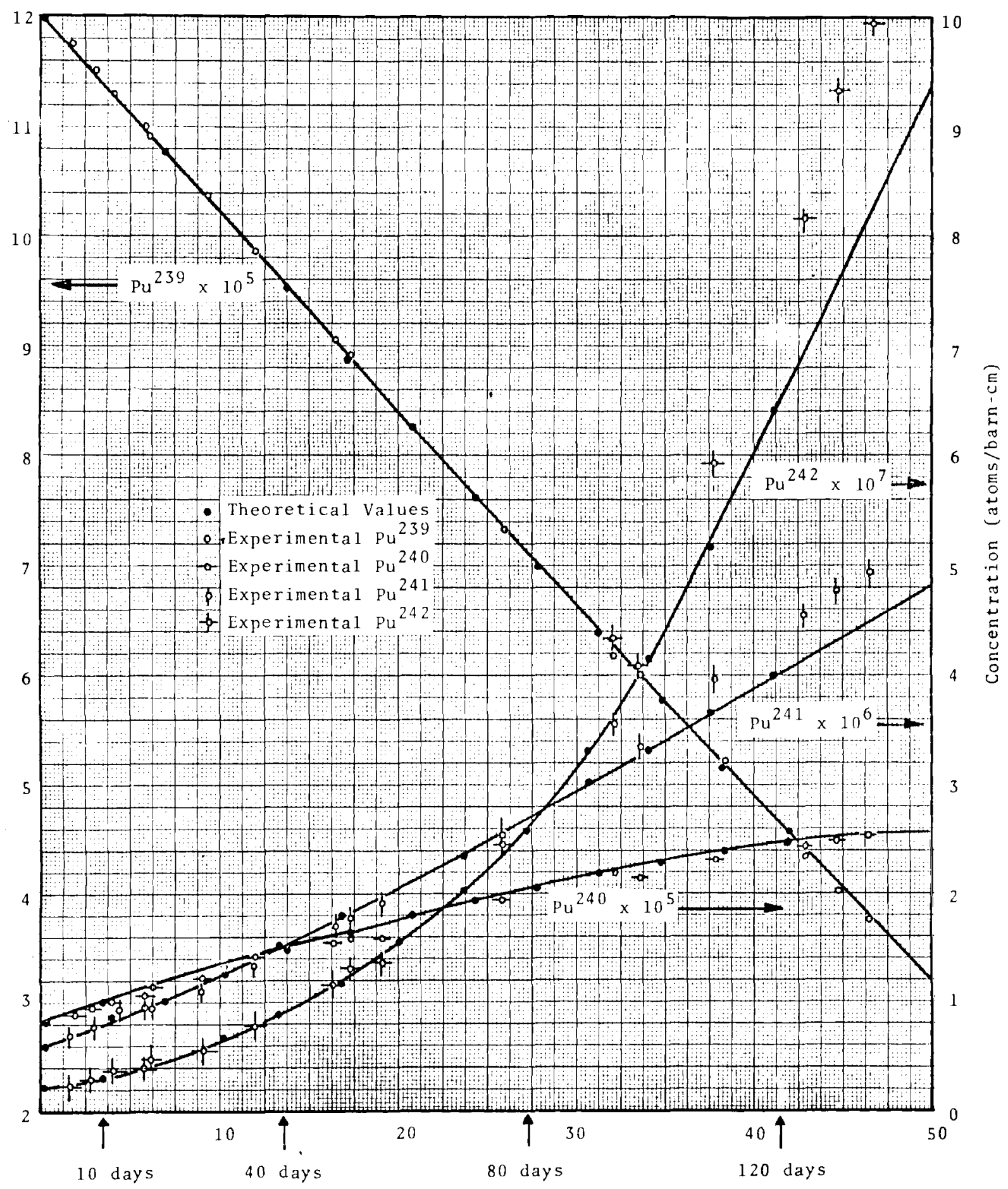

Percent Burnup

Figure XXXII

Isotopic Concentrations for

the center Rod of a PuAl Cluster 


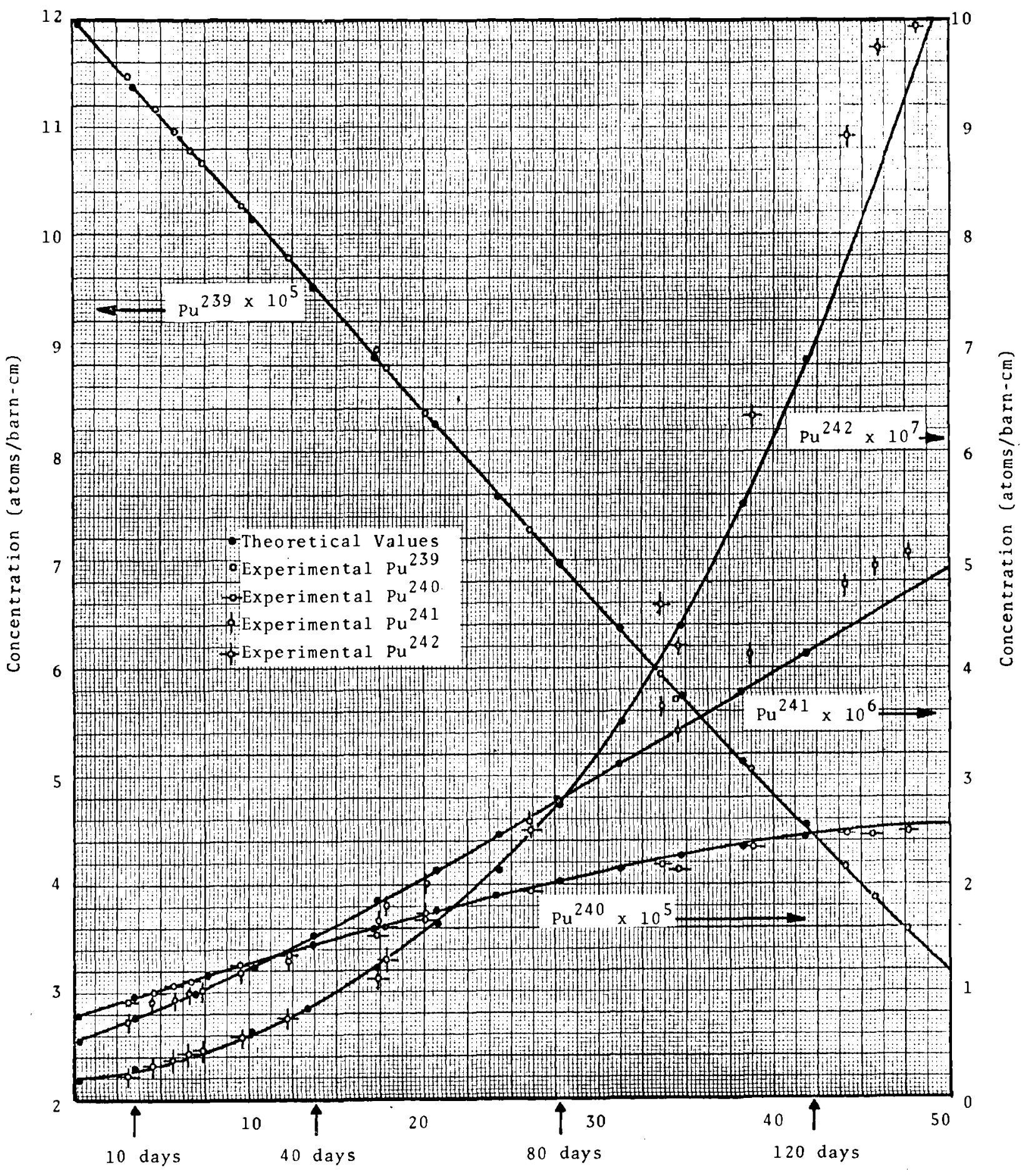

Percent Burnup

Figure XXXIII

1sotoprc lioncentrations for

Fuel in the Middle Ring of a PuAl Cluster 


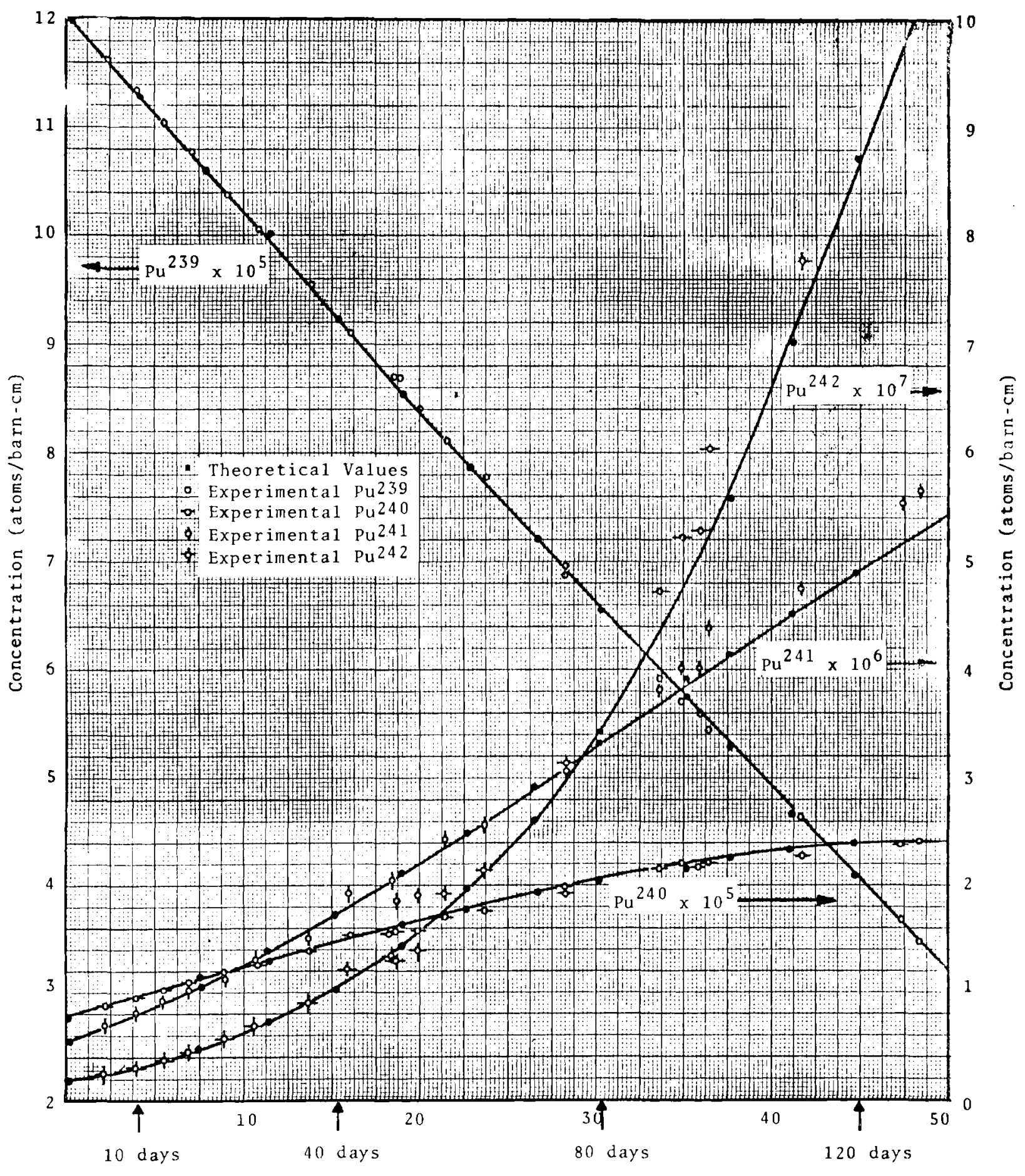

Percent Burnup

Figure XXXIV 
values agree with the experimental values for ${ }^{239} \mathrm{Pu}$ and ${ }^{240} \mathrm{Pu}$ over the entire burnup range studied. The experimental and calculated values for the other isotopes agree up to approximately $33 \%$ burnup.

Conclusions

As a result of this correlation study we conclude that the combination of cross sections and theoretical methods used in this analysis does adequately predict experimental isotopic concentrations and effective cross section ratios for aluminum-1.8 wt\% plutonium fuel containing initially 6 at $240 \mathrm{Pu}$. Analytical results agree with experimental results up to approximately 33\% burnup; and it is felt that the discrepancies for larger values of burnup may be attributed to the fact that program THERMOS as used in this calculation is not adequate for cross section calculations involving the ${ }^{240} \mathrm{Pu}$ resonance. 
, 


\section{PLUTONIUM UTILIZATION STUDIES}

Optimized Lattices for Plutonium Utilization - J. H. Nail

Several possibilities have been examined ${ }^{(1)}$ for modifying the fuel lattice design of a uranium oxide fueled reactor so that plutonium is burned more efficiently, that is, the plutonium value is increased over that resulting from direct substitution in a lattice designed for slightly enriched uranium. These modifications can be done in several ways and the ones considered here are varying fuel density, lattice spacing, and fuel rod diameter. If an existing reactor is to be converted to plutonium fueling, any of these changes must be made with a minimum perturbation of the original core design. The studies reported are for an optimized reactor for plutonium recycle with plutonia in natural or only slightly enriched urania. The reference uranium cell that was used has a pitch of 0.50 inches and a clad rod diameter of 0.40 inches, and is a PWR similar to YANKEE reactor design.

Table I shows the advantages and disadvantages of the three optimization methods considered. First, if the fuel density is reduced, heat transfer area is maintained, and therefore reactor power can be maintained. No modification of the fuel assembly is necessary and the reactor inventory might be decreased to even smaller quantities than the density change requires because of possible higher specific powers resulting from the use of a high conductivity matrix material. The two disadvantages are (1) the fabrication cost, being a function of the loading in each tube, may increase with decreasing density, and (2) the spectral effect is less pronounced than for the other two methods since the water content or he cell does not change.

If optimization is accomplished by reducing rod sizes while maintaining the kilowatts per foot, higher specific powers are possible. No modification of the fuel assembly over-all dimensions is necessary and a rather large range of spectrum changes is available. The reduction in heat transfer area

(1) Nail, J. H, and Deonigi, D. E., "Economically Optimum Plutonium Lattices for Water Reactors," Paper for American Nuclear Society Meeting, Pittsburgh, Pennsylvania, October 37-November 3, 1966., BNWL-SA-738. 
Table I

Advantages and Disadvantages of Severa1 Methods of Lattice Optimization

Basic Variation

Reducing Fuel Density

Reducing Rod Size

Increasing Pitch

\section{Advantages}

1. Maintains heat transfer area.

2. No modification of pitch or assembly.

3. Higher specific power (for high thermal conductivity of matrix material when used).

4. Lower inventory.

1. Higher specific power. (Avoiding melting by using thinner rods.)

2. No modification of pitch or assemb1y.

3. Large range of change in spectrum.

1. No change in fabrication cost.

2. Large range of spectrum change (but at discrete $M / F$ values).
Disadvantages

1. Fabrication cost my increase.

2. Less rapid spectral change.

1. Reduced heat transter area.

2. Fabrication cost increases.

1. Assembly requires modification.

2. Reduced heat transfer area in a fixed vessel size. 
is somewhat offset by the decrease in rod $\Delta \mathrm{T}$. The fabrication charges per kilogram will increase with decreasing tube size.

If the lattice is optimized by increasing the lattice pitch, there is no fabrication cost penalty. Also, there is a rather large range of spectrum changes available at discrete moderator-to-fuel values. Two disadvantages are (1) the lattice optimization requires that the assembly be internally modified, and (2) the heat transfer area for a fixed assembly volume is reduced so that the total reactor power must be degraded or a slight increase in power rating for the fuel must somehow be obtained or the reactor core volume increased. The results presented here do not reflect any penalty for modification of the lattice pitch.

Reoptimizing of the reactor lattice for plutonium fuels will usually result in softening the neutron spectrum. The optimum lattices therefore require a lower fuel inventory but in doing this the conversion ratio is decreased. As a result, in the optimization process it is necessary to balance these two effects.

Table II is the first of several showing the results of the optimization study. For the cases where fuel density and rod diameter are varied, the optimization is carried out at several lattice pitches, representing variations in lattice design. The data in the tables show a comparison between fuel cycle cost with plutonium recycle with and without optimization for each of the lattices. Table II shows the results for fuel density optimization. Two plutonium compositions are considered. The results, in the first four rows are for variations in lattice pitch and show improvement in fuel cycle cost of up to $0.1 \mathrm{mills} / \mathrm{kWh}$ when the density is optimized. The fifth row shows that a small increase in uranium enrichment has 1 re influence on fuel cycle cost and optimum fuel density. The first ro can be directly compared with the reference lattice which has a fuel cycle cost of $1.84 \mathrm{mills} / \mathrm{kWh}$ when fueled with slightly enriched uranium.

The calculations were performed using the fuel cycle analysis chain currently in use at Pacific Northwest Laboratory. For this study the following cost data were assumed: $\$ 100 / \mathrm{kg}$ fabrication; $\$ 32 / \mathrm{kg}$ reprocessing; $10 \%$ interest on both fuel inventory and fuel cycle, and $\$ 10 / g$ fissile 
Table II

Fue1 Cycle Cost for Optimum Fuel Density

\begin{tabular}{|c|c|c|c|c|c|c|}
\hline \multirow[b]{3}{*}{$\begin{array}{l}\text { Lattice } \\
\text { Pitch, } \\
\text { Inches } \\
\end{array}$} & \multicolumn{6}{|c|}{ Plutonium Composition } \\
\hline & \multicolumn{3}{|c|}{$62-17-16-5(a)$} & \multicolumn{3}{|c|}{$50-16-19-15^{(a)}$} \\
\hline & $\begin{array}{l}\text { Cost For } \\
95 \% \text { Density } \\
\text { Mills / kWh } \\
\end{array}$ & $\begin{array}{c}\text { Optimum } \\
\text { Cost } \\
\text { Mi11s/kWh }\end{array}$ & $\begin{array}{c}\text { Optimum } \\
\text { Density } \\
\% \text { of } \\
\text { Theoretica1 } \\
\end{array}$ & $\begin{array}{l}\text { Cost For } \\
95 \% \text { Density } \\
\text { Mills / kWh } \\
\end{array}$ & $\begin{array}{c}\text { Optimum } \\
\text { Cost } \\
\text { Mills } / \mathrm{kWh} \\
\end{array}$ & $\begin{array}{c}\text { Optimum } \\
\text { Density } \\
\% \text { of } \\
\text { Theoretical }\end{array}$ \\
\hline 0.50 & 2.06 & 1.96 & 71 & 2.38 & 2.19 & 49 \\
\hline 0.54 & 1.95 & 1.91 & 76 & 2.12 & 2.05 & 74 \\
\hline 0.59 & 1.97 & 1.93 & 80 & 2.07 & 2.03 & 76 \\
\hline 0.65 & 2.02 & 2.01 & 80 & 2.14 & 2.09 & 76 \\
\hline $0.50^{(b)}$ & 2.06 & 1.96 & 71 & -- & 2.19 & 49 \\
\hline
\end{tabular}

(a) Percent $\mathrm{Pu}^{239}, \mathrm{Pu}^{240}, \mathrm{Pu}^{241}$, and $\mathrm{Pu}^{242}$, respectively

(b) One percent enriched uranium assumed for this case, others contained natural uranium. 
plutonium credit. For these conditions the reference uranium lattice has a fuel cycle cost of $1.84 \mathrm{mills} / \mathrm{kWh}$. The required cost increases for variations in density or rod size are described in some detail in BNWL-SA-738.

Table III shows the optimum cost for optimum rod size at each lattice spacing. It is seen that the rod size decreases for the plutonium composition having the higher $\mathrm{Pu}^{240}$ content. This is a result of the higher inventories required to achieve the desired fuel lifetimes, so that these fuels are more sensitive to any method which will reduce the fissile inventory or enrichment, in this case softening the neutron spectrum. All cases are for a constant specific power except the last one in the table. There the kilowatts per foot of fuel rod was assumed constant, thus requiring an increase in surface heat flux. In this case the saving was due to the decrease in fuel inventory as the specific power increased, and the optimum rod size shifted to an even softer spectrum. The 0.35 inch rod diameter corresponds to a moderator-to-fuel ratio of about 2.4 with 0.50 inch pitch.

Table IV shows the cost at optimum pitch for three plutonium compositions and for two rod sizes. The costs reflect a constant ratio of megawatts per tonne, which is to say a constant inventory of fuel. As the lattice pitch changes, this means a change in core size. Again, no penalty was applied to lattice pitch increases. Such a penalty, however, would tend to drive the optimums to smaller pitches. For the first case the cost for the 94-5-1-0 plutonium is the same as for plutonium in a uranium lattice because it optimizes at the reference lattice. For the 62-17-16-5 composition there is a significant improvement of $0.1 \mathrm{mills} / \mathrm{kWh}$ in the optimum cos over that for plutonium in the reference lattice. The 50-16-19-15 composition shows an even better improvement of $0.3 \mathrm{mills} / \mathrm{kWh}$. When the rod diameter is increased to 0.42 inches, the optimum lattice pitch yields still greater improvement in the fuel cycle cost. For all cases, except the first, it is necessary to increase the lattice pitch in arriving at an optimum cost. Again the largest pitch, meaning the sotest neutron spectrum, is required for the plutonium composition having the highest $\mathrm{Pu}^{242}$ content. 
$\underline{\text { Table III }}$

Fuel Cycle Cost for Optimum Fuel Rod Diameter

\begin{tabular}{|c|c|c|c|c|c|c|}
\hline \multirow[b]{3}{*}{$\begin{array}{l}\text { Lattice } \\
\text { Pitch, } \\
\text { Inches }\end{array}$} & \multicolumn{6}{|c|}{ Plutonium Composition } \\
\hline & \multicolumn{3}{|c|}{$62-17-16-5(a)$} & \multicolumn{3}{|c|}{$50-16-19-15^{(a)}$} \\
\hline & $\begin{array}{l}\text { Cost For } \\
\text { Ref. Rod } \\
\text { Mills } / \mathrm{kWh}\end{array}$ & $\begin{array}{c}\text { Optimum } \\
\text { Cost } \\
\text { Mills } / \mathrm{kWh} \\
\end{array}$ & $\begin{array}{l}\text { Optimum } \\
\text { Rod } \\
\text { Diameter, } \\
\text { Inches }\end{array}$ & $\begin{array}{l}\text { Cost For } \\
\text { Ref. Rod } \\
\text { Mills/kWh }\end{array}$ & $\begin{array}{c}\text { Optimum } \\
\text { Cost } \\
\text { Mills } / \mathrm{kWh} \\
\end{array}$ & $\begin{array}{c}\text { Optimum } \\
\text { Rod } \\
\text { Diameter } \\
\text { Inches }\end{array}$ \\
\hline 0.50 & 2.06 & 2.02 & 0.37 & 2.38 & 2.19 & 0.35 \\
\hline 0.54 & 1.95 & 1.95 & 0.40 & 2.12 & 2.11 & 0.39 \\
\hline 0.59 & 1.97 & 1.88 & 0.45 & 2.07 & 2.04 & 0.43 \\
\hline 0.65 & 2.02 & 1.82 & 0.47 & 2.14 & 1.92 & 0.46 \\
\hline $0.50^{(\mathrm{b})}$ & 2.06 & 1.92 & 0.35 & -- & -- & -- \\
\hline
\end{tabular}

(a) Percent $\mathrm{Pu}^{239}, \mathrm{Pu}^{240}, \mathrm{Pu}^{241}$, and $\mathrm{Pu}^{242}$, respectively.

(b) Assumed $\mathrm{kW} / \mathrm{ft}$ a constant, other cases assumed constant specific power. 
Table IV

\section{Fuel Cycle Cost for Optimum Lattice Pitch}

\begin{tabular}{|c|c|c|c|c|}
\hline Composition ${ }^{(a)}$ & $\begin{array}{c}\text { Rod } \\
\text { Diameter } \\
\text { Inches } \\
\end{array}$ & $\begin{array}{c}\text { Cost for } \\
\text { Ref. Lattice } \\
\text { Pitch } \\
\text { Mills/kWh } \\
\end{array}$ & $\begin{array}{l}\text { Cost For } \\
\text { Optimum } \\
\text { Pitch } \\
\text { Mills/kWh } \\
\end{array}$ & $\begin{array}{l}\text { Optimum } \\
\text { Pitch, } \\
\text { Inches } \\
\end{array}$ \\
\hline \multirow[t]{2}{*}{$94-5-1-0^{(b)}$} & 0.40 & 1.83 & 1.83 & 0.50 \\
\hline & 0.42 & 1.83 & 1.77 & 0.54 \\
\hline \multirow[t]{2}{*}{$62-17-16-5^{(b)}$} & 0.40 & 2.06 & 1.95 & 0.55 \\
\hline & 0.42 & 2.11 & 1.90 & 0.60 \\
\hline \multirow[t]{2}{*}{$50-17-19-15^{(b)}$} & 0.40 & 2.38 & 2.07 & 0.57 \\
\hline & 0.42 & 2.52 & 2.01 & 0.63 \\
\hline
\end{tabular}

(a) In natural uranium.

(b) Percent $\mathrm{Pu}^{239}, \mathrm{Pu}^{240}, \mathrm{Pu}^{241}$, and $\mathrm{Pu}^{242}$, respectively. 


\section{8}

BNWL -624

Additional improvements in the fuel cycle cost can be obtained by using a combination of the three variables. Studies have shown that with the cost functions assumed, the rod size-pitch combination is better than the densitypitch combination. However, new data regarding the cost of fabricating reduced density fuel could change this conclusion.

It should be noted that the magnitude of the fuel cycle cost reduction are sensitive to the chosen reference case and that more recent PWR designs cal1 for pitches of 0.55 inches which Table IV indicates is also optimum for a typical plutonium bearing fuel.

To summarize, there is an economic incentive for reoptimizing the lattices of reactors originally designed for uranium fuel to utilize plutonium fuel. The magnitude of the saving is dependent on both the method of changing the lattice and the plutonium composition. The three methods examined were reduced fuel density, reduced rod size, and increase lattice pitch. Of these and under the economic conditions assumed the reduced rod size and increased pitch showed more savings (up to $0.2 \mathrm{mills} / \mathrm{kWh}$ ) with the rod size reduction possibly being technologically the more desireable.

Power Peaking With Plutonium Recycle - R. T. Thompson

In the previous section, the reactor was assumed to be refueled and enriched above natural completely with plutonium that was assumed to be available to the reactor owner. This section discusses the power distribution problems that arise when a reactor is partially reloaded with fresh fuel assemblies containing recycle plutonium. The quantities of plutonium assumed were equivalent to that available from the uranium elements at the end of the first cycle.

Two loading schemes were considered. The first was to recycle the plutonium in al1 rods of a 16 x 16 rod assembly which was surrounded by the original uranium fueled assemblies exposed to 14,000 MWd/t. The total fissile enrichment was held constant at $2.8 \mathrm{wt} \%$ except when the fuel density was varied. Then the enrichment was selected to give equal fissile content per tube. The plutonium concentration was about 0.5 wt\% for both the first cycle and for the steady state recycle condition. 
For the steady state recycle, the $16 \mathrm{x} 16$ rod assembly was surrounded by results of a $16 \times 16$ rod first recycle assembly burned to 14,000 MWd/t. The second loading scheme considered was to load the same total quantity of plutonium in only a fraction of the rods. The incentive here is to reduce the fabrication cost penalty associated with adding plutonium to a fuel rod as well as improve power flattening by lowering the effective $\mathrm{Pu}$ cross section through increased self shielding. The remainder of the $16 \times 16$ rod assembly, the center section, was loaded with enriched uranium. Again the total assembly was surrounded by the burned original uranium assemblies. The reference lattice had a rod diameter of 0.43 inches, a lattice pitch of 0.59 inches, and a fuel density of $90 \%$ of theoretical.

Table $V$ depicts the power characteristics obtained with various lattice parameters with the plutonium loaded uniformly throughout the assembly. The power ratio is the power generated with the plutonium assembly divided by the power that would be obtained from a purely ${ }^{235} \mathrm{U}$ enriched assembly. The first column is the ratio when the assembly is first inserted in the reactor and shows an average power of about 1.20 times the uranium assembly for the reference lattice. This has dropped to 1.01 after an exposure of 10,000 $\mathrm{MWd} / \mathrm{t}$, indicating that the plutonium burns out more quickly than the uranium because of its considerably higher cross section. It can be seen from the last two columns in the table that steady state plutonium recycle, that is when the surrounding assemblies initially contained recycle plutonium instead of only uranium, the power peaking is less severe. This is because the fission cross sections of the two zones are more nearly matched. Variations in lattice parameters are shown which correspond to the range of parameters foind optimum in the previous section of the report. It can be seen that lactice optimization (for minimum power cost) by rod diameter reduces the power peaking problem whereas lattice optimization by pitch increases the power peaking problem.

Table VI shows how the power density in the plutonium fueled rods increases as the plutonium is refueled in various fractions of the total rods in the assembly. The U/Pu rod ratio indicates that fraction, e.g., 
Table V

Power Characteristics for Various PWR Lattice Parameters

Power Ratio

Plutonium Assembly/Uranium Assembly

\begin{tabular}{|c|c|c|c|c|c|}
\hline \multicolumn{2}{|c|}{$\begin{array}{c}\text { Lattice Parameter } \\
\text { Variations }\end{array}$} & $\begin{array}{l}\text { First Recycle } \\
\text { (Zero Exposure) }\end{array}$ & $\begin{array}{l}\text { First Recycle } \\
(10,000 \mathrm{MWd} / \mathrm{t}) \\
\end{array}$ & $\begin{array}{c}\text { Steady State } \\
\text { Recycle, } \\
\text { (Zero Exposure) }\end{array}$ & $\begin{array}{c}\text { Recycle, } \\
(10,000 \mathrm{MWd} / \mathrm{t}) \\
\end{array}$ \\
\hline Fuel & $90 \% *$ & 1.20 & 1.01 & 1.13 & 1.00 \\
\hline Density & 70 & 1.33 & 1.08 & 1.24 & 1.04 \\
\hline$\%$ Theo. & 50 & 1.49 & 1.17 & 1.39 & 1.13 \\
\hline Rod & 0.50 & 0.96 & 0.91 & 0.90 & 0.91 \\
\hline Pitch, & 0.55 & 1.14 & 1.02 & 1.07 & 1.00 \\
\hline Inches & $0.59 *$ & 1.20 & 1.01 & 1.13 & 1.00 \\
\hline Rod & $0.418 *$ & 1.20 & 1.01 & 1.13 & 1.00 \\
\hline Diameter, & 0.386 & 1.15 & 0.95 & 1.08 & 0.93 \\
\hline Inches & 0.354 & 1.05 & 0.84 & 0.98 & 0.82 \\
\hline
\end{tabular}

* Lattice parameters for reference lattice. 


\section{Table VI}

Effect of Test Assembly Zoning on Power Peaking*

U/Pu Rod Ratio: $0 / 1 \quad 1 / 1 \quad 2 / 1 \quad 3 / 1 \quad 4 / 1 \quad 5 / 1$

Pu Zone/Total Assembly

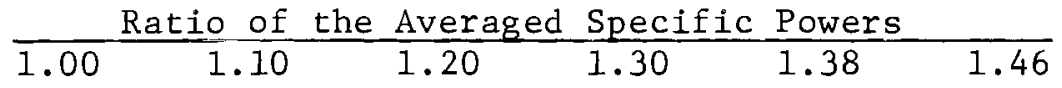

$235 \mathrm{U}$ Zone/Total Assembly

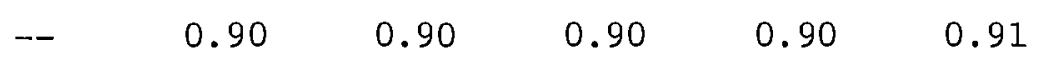

Total Assembly/235 U Refuel Assembly

1.20

1.15

1.13

1.12

$1.11 \quad 1.11$

*Enrichment in each rod of assembly is $2.8 \mathrm{wt} \%$. 
$0 / 1$ indicates $100 \%$ of rods containing plutonium, $1 / 1$ indicates $50 \%$, etc. It is seen that the power peaking within the assembly is considerably increased as the number of plutonium bearing rods is reduced. This is because the plutonium is more concentrated in the fewer rods. However, because of the greater concentration, the average neutron flux in the plutonium zone is reduced. This causes a smaller increase in the average specific power in the subassembly over that would be obtained with a $235 \mathrm{U}$ enriched assembly. This effect is seen in the bottom row of Table VI.

In Table VII it can be seen that the peaking is apparently not affected by varying the plutonium composition while holding the fissile plutonium fraction constant. However, Table VII does show an improved power flattening within the assembly by decreasing the amount of $235_{\mathrm{U}}$ in the Pu bearing rods. The displaced $235 \mathrm{U}$ then is placed in the reamining rods of the refuel assembly. Although the peaking within the assembly has decreased, the total peaking of the assembly has increased slightly.

Also shown in Table VII is the effect of bundle size on power peaking. From this variation, it can be seen that as the recycle amount of plutonium is introduced into the core, the power peaking is much less severe for small bundles ( 1.06 for $8 \times 8$ as opposed to 1.12 for $16 \times 16$ rod bundles). This improvement is countered partially by a slight increase in power peaking within the assembly. From this analysis it appears that special attention will have to be given to placement of plutonium fueled assemblies in a reactor primarily fueled with uranium. These results do indicate that the power peaking between assemblies can be improved by decreasing the rod pitch, decreasing the rod diameter, isolating the plutonium into a fraction of the rods, using smaller sized bundles, or possibly some combination of the above. Another possible solution to the problem is indicated by the large decrease in flux in the plutonium as it is concentrated into certain rods.

An extension of this concept would be to place small spheres or grains of full density plutonium oxide in a matrix of uranium oxide to take maximum advantage of the self shielding of resonances and the thermal flux depression. Monte Carlo studies of this configuration were commenced 
Table VII

Effect of Enrichment Distribution, Pu Composition and Bundle Size on Power Peaking and $k_{\infty}$ for A 3/1 Zoned Assembly at $2.8 \%$ Fissile Enrichment

\begin{tabular}{|c|c|c|c|c|}
\hline & $\begin{array}{c}\begin{array}{c}\text { Pu-Enr } \\
\text { Rods/Assy }\end{array} \\
\end{array}$ & $\begin{array}{l}\mathrm{U}^{235}-\operatorname{Enr} \\
\text { Rods/Assy } \\
\end{array}$ & $\begin{array}{c}\text { Assy/U } \mathrm{U}^{235} \\
\text { Enr Refuel Assy }\end{array}$ & $\begin{array}{l}\mathrm{k}_{\infty} \text { of } \\
\text { Mode1 }\end{array}$ \\
\hline $94 \% 239,5 \% 240,1 \% 241$ & 1.30 & .90 & 1.12 & 1.236 \\
\hline $70 \% 239,20 \% 240,8 \% 241$ & 1.30 & .90 & 1.12 & 1.224 \\
\hline $61 \% 239,24 \% 240,12 \% 241$ & 1.30 & .90 & 1.12 & 1.226 \\
\hline 2.8 wt\% Fissile in All Rods* & 1.30 & .90 & 1.12 & 1.224 \\
\hline 2.5 wt\% Fissile in Pu Rods & 1.22 & .93 & 1.14 & 1.229 \\
\hline 2.2 wt\% Fissile in $\mathrm{Pu}$ Rods & 1.14 & .95 & 1.15 & 1.229 \\
\hline $16 \times 16$ Rod Bundle & 1.30 & .90 & 1.12 & 1.224 \\
\hline $12 \times 12$ Rod Bundle & 1.34 & .89 & 1.09 & 1.238 \\
\hline $8 \times 8$ Rod Bundle & 1.37 & .88 & 1.06 & 1.230 \\
\hline
\end{tabular}

* For these three cases the average assembly enrichment is held to $2.8 \mathrm{wt} \%$. 
near the end of this year, but due to limited available computer time, statistically valid results were not obtained.

Another simple solution to the recycle problem would be to place plutonium bearing assemblies in low flux areas of the reactor.

\section{$\underline{\text { Plutonium Core Comparison Studies and Calculation Integration }}$}

\section{Introduction}

From fuel cycle studies (performed at PNL under PUP) over a wide range of design and operating parameters, general conclusions have been reached about optimum utilization of plutonium in thermal, water moderated power reactors. Because of the wide range of parameters, and consequent proliferation of cases, these studies were of a survey nature. It is necessary to translate these general conclusions into specific core designs for optimum utilization of plutonium in Boiling Water Reactors (BWR's) and Pressurized Water Reactors (PWR's) typical of those that will be operating during the decade 1970-1980. These studies will assist in determining potential problem areas associated with plutonium recycle and hence provide information for program direction.

As a first step in these optimization studies, a digital computer code, REPP, has been written which enables the user to design a core for Boiling Water and Pressurized Water Reactors based on heat removal requirements. From input specified by the user, such as hot channel factors, fuel melting temperature, safety margin from DNB, and reactor power, calculations are made of fuel rod size, lattice spacing, core size, pressure drops and heat fluxes within the core. This code has been integrated with a fuel cycle code to provide a design survey code (callec FULCYC) for water moderated reactors.

A detailed description of REPP is contained in a formal report to be published. The present report contains a general description of input requirements for the code and the results of a sample design problem (Connecticut Yankee Reactor) used to test the code. 


\section{Input Requirements}

There are several options in specifying input to REPP. For example, the total reactor power and fuel rod size can be specified and the code will calculate core size and lattice spacing. Conversely, core size can be specified and total reactor power will be calculated. No attempt will be made in the present discussion to cover all of these options but in general input requirements include some combination of the following items:

1) Model and hardware assumptions which may be specified from manufacturing capabilities and techniques.

a) lattice geometry (square or hexagona1)

b) size of fuel boxes

c) spacing between fuel boxes (water gaps and control rods)

d) fuel rod diameter and clad thickness

e) core void fraction defined as (1 minus fuel fraction)

f) fuel density

g) core volume

h) type and number of fuel element support grids and their axia1 location.

2) Entrant coolant conditions

a) coolant temperature and pressure at core inlet

b) inlet pressure drop

c) coolant mass flow rate (total core)

d) entrance length (unheated)

3) Exit coolant conditions

a) exit pressure drop

\section{Sample Case}

Ordinarily, the output from REPP would consist of rod size and lattice spacing for a heat transfer limited core. By varying rod size, a different lattice spacing would be found and in this way, a curve of rod size versus lattice spacing could be drawn, each point on the curve representing a potential candidate for final design of the reactor. The choice will generally be made on the basis of comparative economics. 
As a check on the methods used in REPP, input data corresponding to the Connecticut Yankee Reactor was supplied the code. In this case, the radius of the rod was provided as input so that the key check is to determine if the proper lattice spacing is calculated. The input data was as follows:

Total thermal power $\left(\mathrm{MW}_{\mathrm{t}}\right)$

1540

Coolant inlet temperature $\left({ }^{\circ} \mathrm{F}\right)$

Coolant inlet pressure (psi) 2050

Clad thickness including .00225 in gap (in) 0.01825

Coolant mass flow rate $\left(1 \mathrm{~b} / \mathrm{hr}-\mathrm{ft}^{2}\right) \quad 1.96 \times 10^{6}$

Fuel diameter (in) 0.375

Active core length ( $f t) \quad 10$

Hot channel peaking factor (Fq) 3.25

DNB ratio 2

The results from REPP compared to the original design values are as follows :

\begin{tabular}{|c|c|c|}
\hline & $\begin{array}{c}\text { Connecticut } \\
\text { Yankee } \\
\end{array}$ & REPP \\
\hline Lattice spacing (in) & 0.553 & 0.558 \\
\hline Average specific heat (BTU/hr-ft $\left.{ }^{3}\right)$ & $0.203 \times 10^{8}$ & $0.210 \times 10^{8}$ \\
\hline Number of fuel pins in core & 33805 & 34700 \\
\hline Exit coolant temperature $\left({ }^{\circ} \mathrm{F}\right)$ & 592 & 593 \\
\hline Maximum heat flux (BTU/hr-ft) & $4.37 \times 10^{5}$ & $4.53 \times 10^{5}$ \\
\hline
\end{tabular}
design data is seen to be quite good. Some uncertainty exists in the input data. For example, the total thermal power used in the REPP calculation is $1540 \mathrm{MW}_{\mathrm{t}}$ which was determined from a power profile over the core. The iesign value is $1473 \mathrm{MW}_{t}$ or about $5 \%$ lower. If this lower value were used as input, the agreement shown in the above table would be even better. 
BNWL- 624

5.1

\section{PLUTONIUM RECYCLE TEST REACTOR (PRTR)}

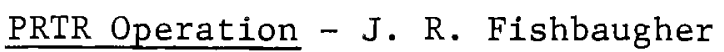

Recovery from the CY 1965 FERTF Incident

The major part of the recovery work was accomplished in FY 1966 so that by July 16, 1966, fuel elements could again be introduced into the PRTR for critical testing at essentially zero power. After completing critical testing for the new fuel loading, the PRTR shut down to await safeguards approval for operation at power. The delay extended through December. Cleanup and restoration of the FERTF, other modification work, and additional critical tests were completed during the delay period.

The Fuel Element Rupture Test Facility (FERTF) was returned to service in March, 1967, concurrent with the start of batch core power tests.

Incident recovery was effective as measured by equipment performance and lack of radiological contamination and activation following resumption of operation.

Nuclear Critical Tests

Critical tests for the batch core experiment were begun in July 1966. The tests were essentially complete in september but continued intermittently through December. Critical tests included the critical core size for boron concentrations ranging from zero to about 21 parts per million by weight (wppm) of ${ }^{0}{ }_{B}$ in $D_{2} 0$ moderator level coefficients of reactivity over a 25-inch range of critical moderator heights at several boron concentrations, moderator void worths, reflector worth, and thermal neutron flux distributions axially and within a lattice cell. The effect of loss of coolant from the core was measured, with both $\mathrm{D}_{2} \mathrm{O}$ and $\mathrm{H}_{2} \mathrm{O}$ coolants. K netics parameters were measured using a reactivity oscillator.

Initial critical tests of the proposed fuel elements for FERTF experiments were started in December 1966 and completed in March 1967. The critical tests were performed to measure the relative power generation between various six- and eight-rod fuel elements and adjacent high power density 19-rod clusters. The relative power generation was measured by gamma scanning new fuel rods irradiated for short times at very low powers in the 


\section{2}

BNWL-624

reactor core. In addition to the power generation measurements, fuel element and coolant reactivity worth measurements were made for several of the FERTF fuel element variables.

Batch Core Power Tests

Batch core power tests and a series of tests to evaluate the maximum fuel rod power permitted by the operating safety limits were conducted. Reactor fuel loading began in January 1967. Power testing began in April and was largely completed during that month. The power tests established the validity of calculated values of operational parameters. Additional physics data were taken during the loading of previously irradiated fuel elements into the fringe tubes on the perimeter of the batch core. Neutron flux and thermal power instruments were calibrated and their performance verified. Tests of the temperature and power coefficients of reactivity, and tests of the operational behavior of new systems (chemical shim, traveling flux monitor) at increased reactor fuel loadings and power levels were conducted. Neutron flux peaking aspects of reactor operation at reduced moderator levels were measured. The reactor kinetics measurement using the oscillator was repeated at a low power level. Eight of the nine power tests were completed. The measurement of the transient fission product poisoning (Xe buildup and decay) from full reactor power was postponed until maximum reactor power was attained.

The maximum fuel rod power tests were begun in April and continued through year end. The PRTR was operated at several ascending power levels to produce brief fuel irradiations. Following each power level increment, fuel sample(s) were removed and subjected to destructive metallurgical examination to determine fuel centerline temperature from observed metallurgical structures. Irradiations were completed at powers of $16.8,17.0,17.9,18.6$, and $20.0 \mathrm{kw} / \mathrm{ft}$. Preliminary results indicate that centerline melting can be expected at 19.4 to $20.3 \mathrm{kw} / \mathrm{ft}$.

\section{Fuels Testing}

At the end of the fiscal year, the PRTR loading consists of 80 fuel elements. The FERTF test section is located in the central channel. Around the FERTF, the central $55 \mathrm{UO}_{2} 2 \mathrm{wt} \% \mathrm{PuO}_{2}-19$-rod cluster HPDC fuel 
elements constitute the batch core. An additional 16 of these elements constitute a buffer zone for a total of 71 batch core elements. Included in the 71 were two instrumented fission gas pressure measuring fuel elements. The maximum exposure for the HPDC fuel elements is about 840 $\mathrm{MWd} / \mathrm{Tu}$.

The remaining fuel elements in the PRTR are: One $\mathrm{UO}_{2} \mathrm{FE}$ with an exposure of $9,180 \mathrm{MWd} / \mathrm{Tu}$ Three $\mathrm{UO}_{2} 0.5 \mathrm{wt} \% \mathrm{PuO}_{2} \mathrm{FE}$ 's with an exposure of $10,790,9,990$, and $7,450 \mathrm{MWd} / \mathrm{Tu}$, respectively

Three $\mathrm{UO}_{2} 1.0 \mathrm{wt} \% \mathrm{PuO}_{2} \mathrm{FE}^{\prime}$ 's with an exposure of $7,900,6,295$, and $6,120 \mathrm{MWd} / \mathrm{Tu}$, respectively

One $\mathrm{UO}_{2} 1.5 \mathrm{wt} \% \mathrm{PuO}_{2} \mathrm{FE}$ (EBWR) with an exposure of 3,490 $\mathrm{MWd} / \mathrm{Tu}$ One $\mathrm{UO}_{2} 2.0 \mathrm{wt} \% \mathrm{PuO}_{2} \mathrm{FE}$ (pelleted) with an exposure of 927 MWd/Tu is being irradiated in the FERTF (PC 1550)

The general loading pattern is shown in Figure 2.

\section{Reactor Operation}

Significant events and daily MWd operation are shown in Figure 1. Approximately 1,410 MWd were produced from the 80 fuel elements during FY 1967 at a maximum reactor power of $66 \mathrm{MW}$.

Use of a boron solution in the moderator as a chemical shim has been successful. Changes of boron concentrations to compensate for xenon transients are accomplished routinely with negligible perturbations of reactor control.

Operation of the primary system coolant at a neutral $\mathrm{pH}$ has produced no significant problems. Some "crud" formation has been evident from fuel element and process tube inspections and from examination of the primary system crud filters; but normal water quality control practices have provided adequate crud control for the system.

A leak rate check of the containment vessel was made in November. The leak rate of 10 psig was $0.43 \pm 0.026$ per cent of free volume for 24 hours which is about one-half of the limit 

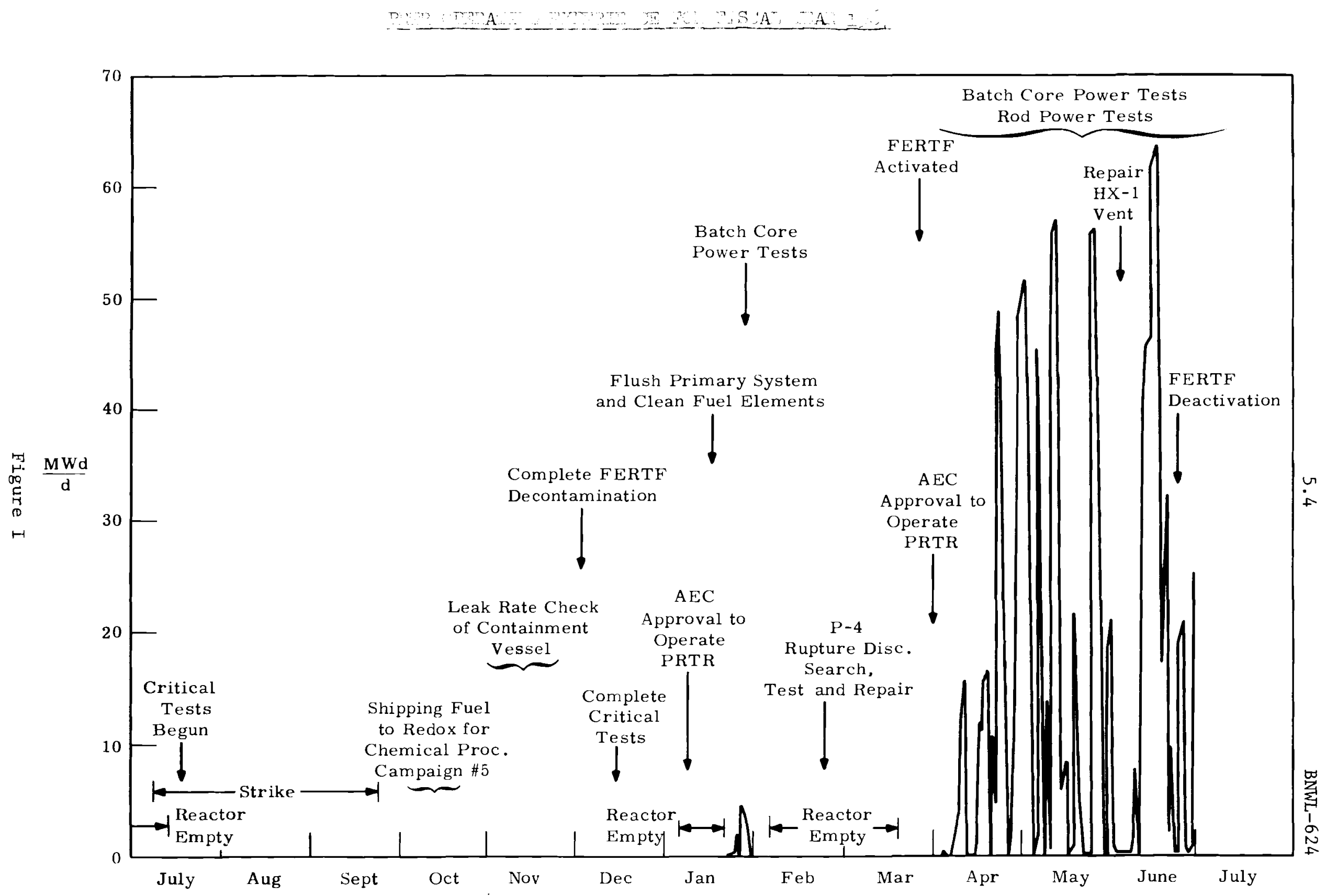


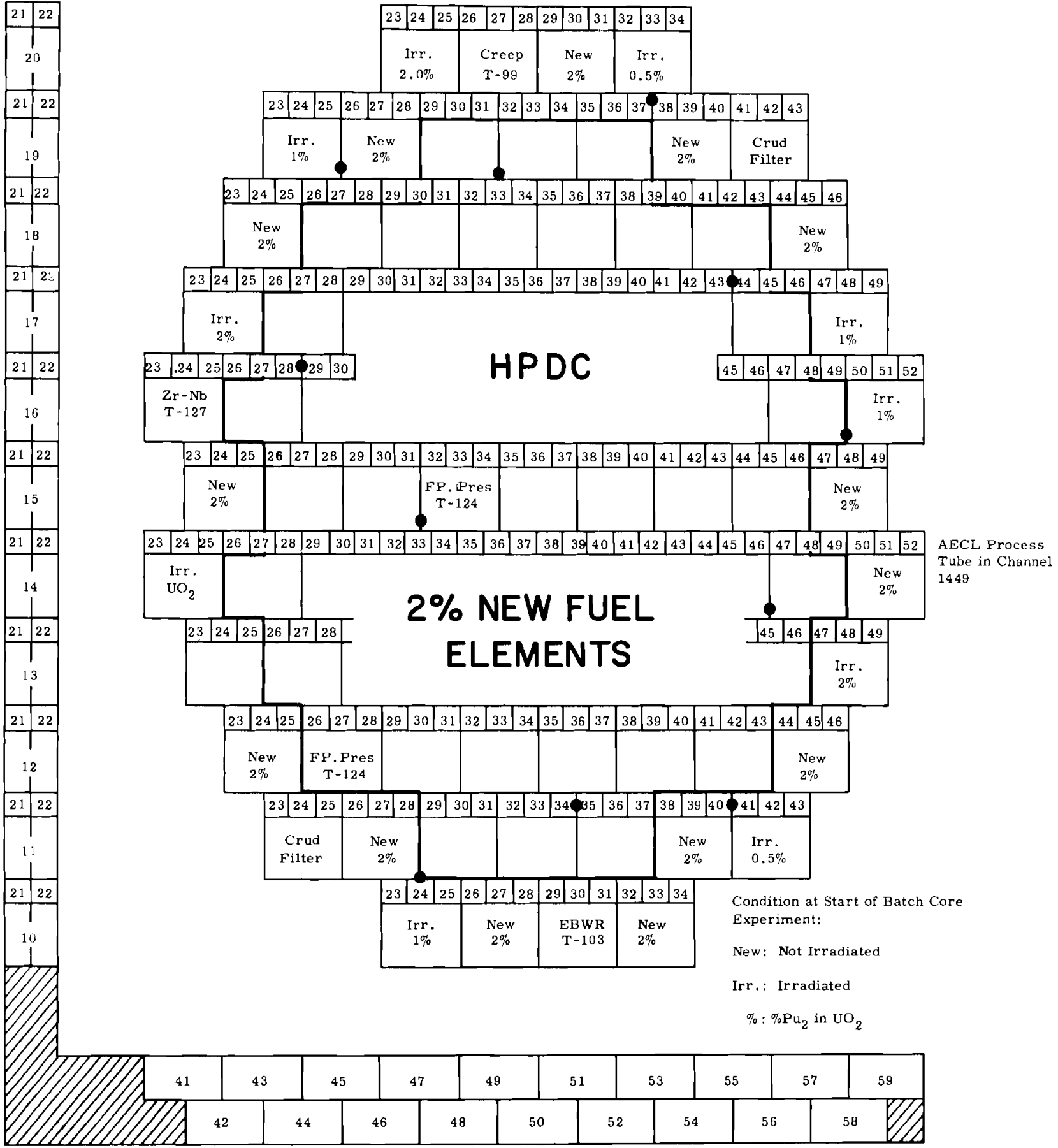

Figure II

PRTR Loading At End of FY 1967 
Equipment Problems

The main primary system shutoff valve $(\mathrm{P}-4)$ is located in the 14" $\mathrm{D}_{2} \mathrm{O}$ line between the reactor and the primary heat exchanger $(\mathrm{HX}-1)$. The rupture disc is installed in the gate of the valve to prevent flow stoppage in the case of inadvertent closure of the P-4 valve. The rupture disc was found to be ruptured on December 16, 1966 and again on February 6, 1967. In each instance, the disc material was lodged in the inlet of the heat exchanger. From this point, it broke up slowly and was distributed throughout the primary system. The PRTR was defueled and extensive flushing and filtering was done to the primary system to remove the recoverable rupture disc particles. Corrective actions were taken to minimize the chances for $\mathrm{P}-4$ rupture disc failure in the future.

On June 2, 1967, a crack developed in an elbow of one of the three wide vent lines on the secondary side of the primary heat exchanger. The heat exchanger and associated secondary coolant piping were inspected and no other problem areas were found. Three new vent lines were installed and the system returned to service.

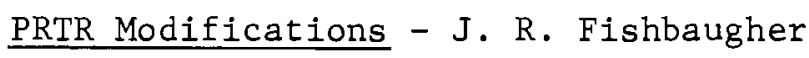

Project $\mathrm{CBB}-001$ - Increased Power Level

Project CBB-001 planned to increase the capacity of the various reactor systems as necessary to permit operation at $100 \mathrm{MW}$ thermal. Included in the changes were the chemical shim, increased size of the steam control valve S-80, deaerator modification, primary system flow redistribution, and power calculator changes. These items were completed. Other items including moderator heat exchanger changes, an additional boiler feed pump, and an additional boiler safety valve were dropped from the project when it became evident that foreseeable programs would not require $100 \mathrm{MW}$ capability. Present maximum power level capability is approximately $85 \mathrm{MW}$. Project BCP-007 - Waste Handling

Project BCP-007 provided for improved handling of wastes generated during a reactor incident and for improved control of reactor systems during such an incident. Significant items included larger sump pumps, electrical 
readout of primary conditions, waste tank bypass piping, remote operation of critical primary system valves, remote $\mathrm{D}_{2} 0$ addition, and the rupture loop bypass. This work was completed during the fourth quarter FY 1967. Reflector Change to Light Water

Physical changes and additions were made to isolate the reflector from other heavy water systems and permit its change to light water thereby reducing the heavy water inventory and potential losses from the reflector.

\section{Primary System Filters}

Filters have been installed in two empty process tubes to control crud levels in the primary system. Initial filters were five-micron pore size.

New Instrument Power Supply

The capacity of the DC power system has been increased by installation of batteries and control equipment procured from excess. Safety Circuit Modifications

The safety circuit has been rearranged to minimize the vulnerability to "live shorts" and several components have been added to increase reliability. Components included an additional primary system overpressure switch and an additional scram circuit. Complete duplication of the safety circuit is currently underway.

Boiling Burnout Limits for 8-Rod Element in FERTF - J. K. Anderson

Experimental and analytical studies were performed to determine operating limits for an 8-rod fuel element to be irradiated in the $F^{n n} \mathrm{R}$ Fuel Element Rupture Test Facility (FERTF). The purpose of these siudies was to determine limits of tube power, coolant flow rates, and coolant temperatures which will prevent either film boiling (boiling burnout) or bulk coolant boiling in the reactor.

The FERTF fuel assembly consists of eight 0.565 in. diameter fuel rods arranged in a circle around a central 0.983 in. diameter non-heat spacing between adjacent fuel rods and between fuel rods and the central 
rod is $0.100 \mathrm{in.}$ The basket tube is provided with a removable inner sleeve, or liner. The purpose of this liner is to reduce the quantity of water in the pressure tube. In-reactor experiments may be performed either with or without the liner in place. With the liner installed, the minimum spacing between fuel rods and liner will be 0.100 in. With it removed, the minimum spacing between fuel rods and basket tube will be 0.214 in.

No boiling burnout data are presently available for this particular fuel geometry. However, its configuration is similar in certain respects to both rod bundle fuel elements and to tubular fuel elements contained in unheated flow tubes. Therefore, boiling burnout information on the FERTF element can be obtained by examining available boiling burnout conditions for these similar configurations. Literature on boiling burnout was searched to obtain experimental data applicable to the FERTF element. Applicable data at about 1000 psia pressure and mass velocities ranging from 1 to 2 million $1 \mathrm{~b} / \mathrm{hr}-\mathrm{ft} \mathrm{t}^{2}$ were found for $\operatorname{rod}$ bundles $(1,2,3)$ with spacings from 0.074 to 0.112 inches and annuli $(4,5,6)$ with spacings from 0.090 to 0.125 inches. Plots of the boiling burnout heat flux versus coolant enthalpy from the data of these two geometries agreed quite well.

(1) Matzner, Bruce, "Critical Heat Flux for Large Diameter Internally Heated Annuli in Forced Convection Boiling at 1000 psia," Topical Report No. 6, Task XVI of Contract AT (30-3)-187. Columbia University Department of Chemical Engineering, New Vork, September, 1965.

(2) Barnett, P. G., "A Correlation of Burnout Data for Uniformly Heated Annuli and Its Use for Predicting Burnout in Uniformly Heated Rod Bundles," AEEW-R463. United Kingdom Atomic Energy Authority, Atomic Energy Establishment, Winfrith, Dorchester, Dorset, England, Sept., 1966.

(3) Neill, J. S., "Heat Transfer Studies for the D, 0 Power Reactor Program," DP-1024. duPont, Savannah River Lab., Aiken, South Carolina, Aug., 1966.

(4) Lee, D. H., "Burnout in a Channel With Non-Uniform Circumferential Heat Flux," AEEW-R477. United Kingdom Atomic Energy Authority, Atomic Energy Establishment, Winfrith, Dorchester, Dorset, England, March, 1966.

(5) Janssen, E. and Kervinen, J. A., "Burnout Conditions for Single Rod in Annular Geometry, Water at 600 to 1400 psia," GEAP-3899. General Electric Co., Atomic Power Equipment Department, San Jose, California, Feb. 1963.

(6) Levy, S., Polomik, E. E., Swan, C. L., and McKinney, A. W., "Eccentric Rod Burnout at 1000 psia With Net Steam Generation," GEAP-3148. General Electric Company, Atomic Power Equipment Department, San Jose, California, April 6, 1959. 
Since most of the experimental data were obtained under bulk boiling conditions, it was necessary to extrapolate the data into the subcooled region which is of principal interest for the FERTF. A linear extrapolation was made by drawing a line through the data but shifted down to the lower extreme of the data points. Since this extrapolation is subject to some error, it was desirable to apply a large burnout safety margin. Consequently, a second set of curves was drawn at heat fluxes $1 / 3$ lower than the boiling burnout heat flux curves (safety margin of 1.5). These lower curves were used as boiling burnout limits. Calculations were then performed to determine outlet subcoolings which would allow fuel at some axial position to just reach, but not exceed the established boiling burnout limits. These calculations produced linear plots of limiting tube power versus outlet subcooling for different mass velocities.

Since there is no reactor instrumentation installed for measuring for coolant flowing inside the basket tube, boiling burnout limits must be expressed in terms of quantities that can be measured. Therefore, further calculations were performed to express limiting tube powers as functions of the measured mass velocity and inlet subcooling. In some instances the burnout limits would allow undesired bulk boiling of coolant inside the basket tube. Therefore, another set of calculations was performed to decermine limiting conditions to prevent bulk coolant boiling. The combined results of the two calculations gave the required limits for FERTF operating conditions.

When determining the operating limits of the FERTF, the mass velocity inside the basket tube was the coolant flow parameter. However, a cne reactor, only the total flow rate to the FERTF pressure tube is messured. This total flow includes both the coolant flowing inside the basket tube and that flowing in the annulus between the basket tube and the pressure tube. In order to apply the operating limits properly, it is necessary to know the fraction of the total measured flow passing inside the basket tube, Because of the complex geometry of the supports and other hardware in the assembly, this fraction cannot be calculated accurately. Therefore, 
measurements were made at the Pacific Northwest Laboratories' ThermalHydraulics Laboratory to determine this fraction experimentally.

Four series of tests were performed to determine the effects of two different types of spacers on the flow split and the influence of a basket tube liner:

$$
\begin{aligned}
& \text { I - original spacers - basket tube liner installed } \\
& \text { II - original spacers - no basket tube liner } \\
& \text { III - modified spacers - basket tube liner installed } \\
& \text { IV - modified spacers - no basket tube liner }
\end{aligned}
$$

In each series of tests, measurements were made of flow splits over a range of total flowrates at water temperatures of $50^{\circ} \mathrm{F}$ and $200^{\circ} \mathrm{F}$. The results showed that the flow splits were independent of flow and only slightly dependent on coolant temperature. The results are summarized in the following table:

\begin{tabular}{ccc} 
Series & $\begin{array}{c}\text { Flow Ratio* } \\
\text { at } 50^{\circ} \mathrm{F}\end{array}$ & $\begin{array}{c}\text { Flow Ratio } \\
\text { at } 200^{\circ} \mathrm{F}\end{array}$ \\
\cline { 2 - 2 } I & 0.688 & 0.674 \\
II & 0.785 & 0.772 \\
III & 0.685 & 0.675 \\
IV & 0.785 & 0.772
\end{tabular}

Results of these flow experiments were incorporated in the burnour limit calculations to specify the limits in terms of measurable parameters.

Thermal-Hydraulic Limits for PRTR Thorium Loading - J. K. Anderson

Calculations were performed to evaluate various fuel element designs proposed for a thorium loading for the PRTR. One of the proposed designs consists of an 18-rod cluster of $\mathrm{ThO}_{2}$ rods enriched with $\mathrm{U}^{235}$. This rod 
bundle is comparable to the present 19-rod cluster with the center rod removed.

The design called for $3 / 8$ in. fuel diameter and an average power density of 64 watts per gram of fuel. Calculations indicated that some melting would occur at the centers of fuel rods. Maximum surface heat fluxes would be on the order of $900,000 \mathrm{Btu} / \mathrm{hr}-\mathrm{ft}^{2}$. Although a thorough study of boiling burnout conditions has not been made, the possibility of operating at such heat fluxes was judged to be questionable.

Two possible methods were suggested for maintaining maximum core temperatures below the melting point of $\mathrm{ThO}_{2}$ and for reducing the maximum surface heat flux to a value nearer to present operating values. These were:

1. Use the proposed geometry and dimensions, but reduce the average power density to about 45 watts per gram.

2. Substitute a bundle of 36 rods (by adding an 18-rod outer ring) with a fuel rod diameter of about $1 / 4 \mathrm{in.}$ for the proposed 18-rod element, and maintain the 64 watt per gram power density.

Another proposed design consisted of two concentric fuel tubes made of Zircaloy-clad $U^{235}$ enriched metallis thorium. Design dimensions and operating conditions for such a loading are still being investigated. Equations were developed for determining temperature distributions within the fuel tubes and heat fluxes at each surface (inner and outer surface of each tube).

These equations will be used to examine the suitability of the designs from the thermal-hydraulic standpoint when dimensions and desired $c_{2}$ ting conditions become better defined.

\section{Physics Analysis for PRTR Thorium Loading - U. P. Jenquin}

Physics calculations were performed to determine the feasibility or a thorium loading in the PRTR. The physics characteristics of two different types of fuel elements were investigated along with the variation in enrichment and rod size. 
The fuel elements considered in the study were a metallic fuel comprised of nested cylinders of $\mathrm{Th}-4 \mathrm{wt} \% \mathrm{U}^{235}$, and ceramic $\left(\mathrm{ThO}_{2}-\mathrm{U}^{235} \mathrm{O}_{2}\right)$ fuels in clusters of rods.

The calculations were performed using the computer codes THERMOS, HRG, and HFN. The physical model of the clusters and the techniques utilized for the analysis are similar to those used in analyzing the $\mathrm{PuO}_{2}-\mathrm{UO}_{2}$ Batch Core Experiment.

Some of the more important physics characteristics of the various fuel elements considered in the study are shown in Table I. Comparing results for 18 and 19 rod clusters, we note that the effect of the central rod of the cluster is small for all parameters listed. The effect of rod size is more pronounced. Decreasing the rod size results in an increase in $k_{\infty}$ and a decrease in the conversion ratio. The comparison of thermal power ratios show the power density in the $3 / 8 \mathrm{in}$. rod cluster is flatter than in the $1 / 2 \mathrm{in}$. rod cluster. The metallic fuel element has a flatter power density than any of the ceramic fuel elements, and also a higher conversion ratio. However, all conversion ratios are small.

The PRTR loadings assumed were 55 elements, five feet long, surrounded fully by $\mathrm{D}_{2} \mathrm{O}$. Survey calculations for these loadings were made with the ALTHAEA code. (7) Results indicate that the 4 wt\% metallic elements and the $5 \mathrm{wt} \%$ ceramic elements, $3 / 8 \mathrm{in}$. rods, could attain an average exposure of 20,000 Megawatt days. Since this is about the exposure of interest, further reactivity calculations for these two systems were made. The $\mathrm{U}^{235}$ in $\mathrm{U}$ content was assumed as $100 \%$ in the calculation. In reality the most enriched uranium that can be produced is about $93 \%$ $\mathrm{U}^{235}$. The fuel compositions were changed to reflect this for the additional reactivity calculations. The physics parameters change slightly so the remainder of the calculations are not entirely consistent with the previous calculations. The leakage for a loading of 55 fuel elements in the PRTR is worth about $-15 \% \Delta k / k$ in reactivity. Values of the multiplication, $k_{e f f}$, are summarized in Table II.

(7) Merrill, E.T., et al., (unpublished data) 


\section{Table I}

Physics Characteristics of Various Fuel Elements

\begin{tabular}{|c|c|c|c|c|c|}
\hline & $\begin{array}{c}\mathrm{U}^{235} \\
\text { Enrichment, } \\
\text { wt\% } \\
\end{array}$ & $\mathrm{k}_{\infty}$ & $\begin{array}{c}\text { Conversion } \\
\text { Ratio* }\end{array}$ & $\begin{array}{c}\text { Resonance } \\
\text { Escape } \\
\text { Probability } \\
\end{array}$ & $\begin{array}{c}\text { Thermal Power } \\
\text { Density Ratio** } \\
\text { Inner Ring } \\
\text { Outer Ring }\end{array}$ \\
\hline Metallic Nested Cylinders*** & 4.0 & 1.424 & 0.346 & 0.801 & 0.71 \\
\hline $\begin{array}{l}\text { Oxide Clusters of Rods***** } \\
19 \text { rods, } 1 / 2 \text { in. O.D. }\end{array}$ & 5.0 & 1.460 & 0.310 & 0.725 & 0.49 \\
\hline 18 rods, $1 / 2$ in. O.D. & 5.0 & 1.466 & 0.306 & 0.737 & 0.54 \\
\hline 19 rods, $3 / 8$ in. O.D. & 5.0 & 1.499 & 0.278 & 0.833 & 0.66 \\
\hline 18 rods, $3 / 8$ in. O.D. & 5.0 & 1.510 & 0.274 & 0.836 & 0.69 \\
\hline 18 rods, $3 / 8$ in. $0 . \mathrm{D}$. & 7.0 & 1.597 & 0.204 & 0.808 & 0.63 \\
\hline
\end{tabular}

* Absorptions in $\mathrm{Th}^{232} /$ absorptions in $\mathrm{U}^{235}$.

* For the 19 rod clusters: Thermal Power in the 6 Rods Adjacent to the Center Rod *** Density of $11.7 \mathrm{~g} / \mathrm{cc}$.

**** Density of $8.5 \mathrm{~g} / \mathrm{c}$. 
Table II

Multiplication Calculations for a Loading of 55 Fuel Elements in the PRTR

\begin{tabular}{|c|c|c|}
\hline \multirow[b]{2}{*}{ Reactor Conditions } & \multicolumn{2}{|c|}{ Multiplication, $\mathrm{k}_{\text {eff }}$} \\
\hline & Th-4 wt\% U Tubes & $\mathrm{ThO}_{2}-5 \mathrm{wt} \% \mathrm{UO}_{2}$ Cluster \\
\hline Room Temperature & 1.207 & 1.271 \\
\hline Room Temperature, $100 \mathrm{ppm}$ Boron* & 1.046 & \\
\hline Room Temperature, 120 ppm Boron* & & 1.049 \\
\hline Operating Temperatures & 1.178 & 1.239 \\
\hline Operating Temperatures with $\mathrm{H}_{2} \mathrm{O}$ Coolant & 1.153 & 1.181 \\
\hline Operating Temperatures with no coolant & & 1.217 \\
\hline
\end{tabular}


The boron necessary to control the excess reactivity is in the range which has been previously used in the PRTR. (8) The over-all temperature coefficient of reactivity (Doppler, moderator and coolant) is large and negative. The loss of coolant results in a loss in reactivity if $\mathrm{D}_{2} 0$ is the coolant, but a gain in reactivity if $\mathrm{H}_{2} \mathrm{O}$ is the coolant.

A refined burnup calculation on the metallic loading was performed using Program ZODIAC. (9) The lifetime of a 55 element core was calculated to be 220 days, assuming 70 MW operation, at which point the average exposure would be 14,000 MWd/Tonne; peak exposure would be 27,000 MWdTonne; and $5.0 \mathrm{~kg}$ of $\mathrm{U}^{233}$ would exist in the core. At this exposure the $\mathrm{U}^{235}$ will have been depleted to $55 \%$ of its original density.

Interest has been expressed in obtaining additional exposure on some of the $\mathrm{UO}_{2}-2 \mathrm{wt} \% \mathrm{PuO}_{2}$ Batch Core elements. Calculations were made for various PRTR loadings consisting of thorium-uranium and uranium-plutonium fuels. The $\mathrm{UO}_{2}-\mathrm{PuO}_{2}$ elements were assumed to have an exposure of 13,000 MWd/Tonne of oxide. Static calculations of reactivity and power distribution are summarized in Table III at room temperature conditions, 100 ppm boron, and no exposure on the Th-U fuel elements.

A burnup calculation with ZODIAC was performed for the arrangement of $19 \mathrm{UO}_{2}-\mathrm{PuO}_{2}$ fuel elements (13,000 MWd/Tonne) surrounded by $66 \mathrm{Th}-\mathrm{U}$ fuel elements. The lifetime of this core is calculated to be about 300 days at a $70 \mathrm{MW}$ power level. The Th-U metal would attain an average exposure of $12,000 \mathrm{MWd} /$ Tonne while the $\mathrm{UO}_{2}-\mathrm{PuO}_{2}$ would attain an additional exposure of 6,500 MWd/Tonne.

(8) Smith, R. I., Kutcher, J. W., and Lauby, J. H., "Critical Experwients with the $100^{-2}$ wt: PuO Batch Core in the PRTR," Trans. Am. Nucl. Soc., Vol. 10, No. 1, p. 185 (1967).

(9) Holeman, R. H. and Matsumoto, D. D., "ZODIAC (2+2): A Revision of ZODIAC 2" BNWL-459, May 1967. 
Table III

Multiplication and Power Distributions for Various

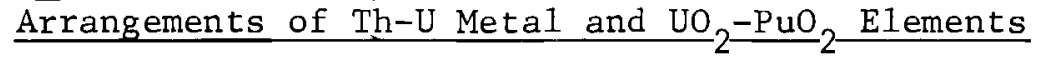

Power Density Relative to

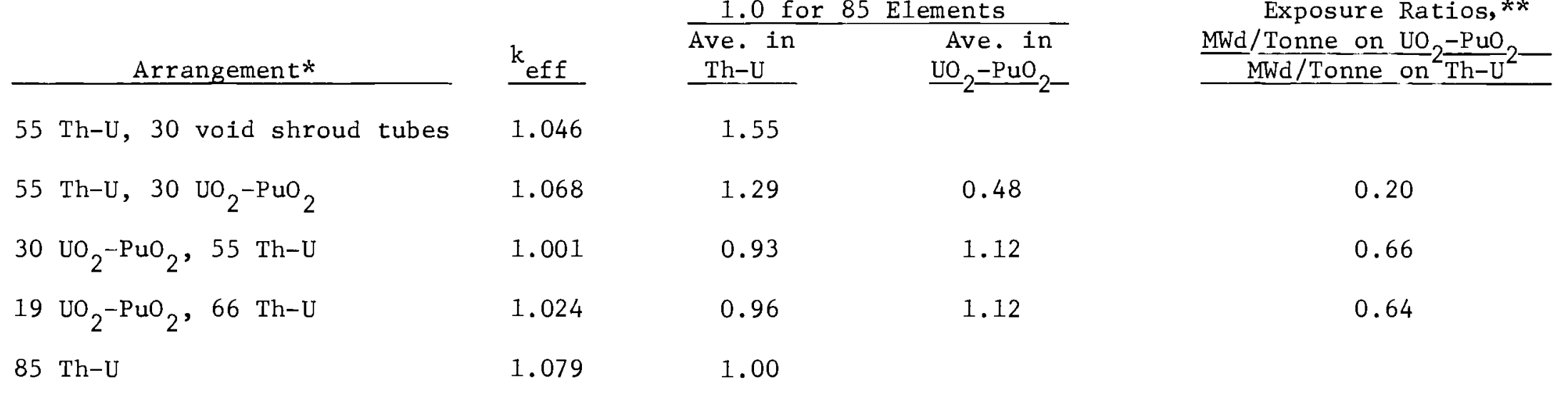

* Cold, 100 ppm boron.

** The volume and mass of fuel is not the same for both fuel elements; the factor to calculate this no. is . 55 . 


\section{MATERIALS}

Although the materials development efforts are primarily to insure safe and continued operation of the PRTR, many of the results are of value to general reactor technology. The results of the studies are given in this section.

Effects of Flux on the Alloys in the PRTR

Corrosion and Hydriding of Tubular Zircaloy-2 and Zircaloy-4 SpecimensA. B. Johnson, Jr., B. Griggs, and H. C. Bowen

Sixty Zircaloy-2 and Zircaloy-4 tubular corrosion specimens were arranged on a rod and exposed in the Plutonium Recycle Test Reactor (PRTR) at a position normally occupied by a fuel rod. A description of the assembly was published previously. (1) Conditions of exposure are summarized in Table I.

\section{Table I}

\section{Conditions of Exposure for PRTR Corrosion Specimens}

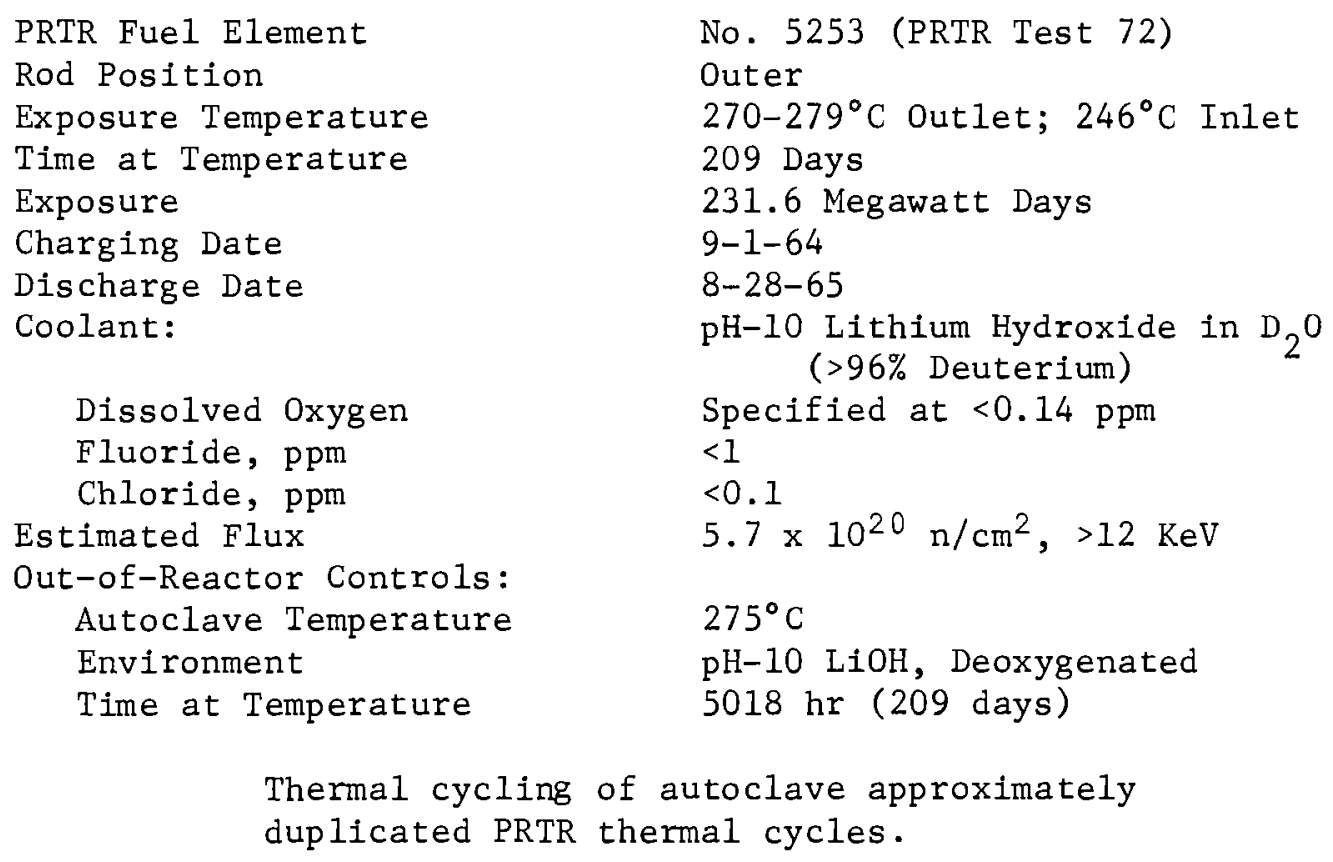

Thermal cycling of autoclave approximately duplicated PRTR thermal cycles.

(1) Cadwell, J. J., "Quarterly Progress Report, Metallurgy Research Operation, July, August, September, 1964," HW-84281, p. 5.29, October, 1964. 
The tubular Zircaloy-2 and Zircaloy-4 specimens were 0.505-0.510 in. ID, 0.559-0.576 in. OD and 1.000 $\pm 0.005 \mathrm{in.} \mathrm{long.} \mathrm{The} \mathrm{specimens} \mathrm{were}$ exposed in three surface conditions: as-etched, autoclaved pretransition,* and autoclaved posttransition, $*$ Each type of sample appeared on the rod at ten positions, providing comparisons of oxidation and hydriding as a function of flux level. Identical tubular specimens were exposed out-of-reactor in an autoclave (See Table I). The specimens were decontaminated in an oxalic acid-ammonium citrate solution before oxide weight gains were determined.

In-Flux and Out-of-Reactor Corrosion

In-reactor and out-of-reactor weight gains for specimens exposed 209 days are summarized in Table II. The in-flux data are arranged in sets of six specimens exposed in close proximity along the rod. Each set of data represents the two alloys in each of three surface conditions. The bottom of the rod was at the coolant inlet temperature, while the top of the rod was at the outlet temperature. The maximum flux occurred near the center of the rod, with low fluxes at each end. Summarizing the data:

- For each alloy and surface treatment, the in-flux weight gains follow the flux profile, indicating that flux accelerated the oxidation.

- On etched specimens, the effect of flux was slight; weight gains at the highest flux were only a factor of 1.2 greater than corresponding out-of-reactor weight gains. At the low temperature $\left(246^{\circ} \mathrm{C}\right)$, low-flux position, weight gains were consistently less than the corresponding out-of-reactor weight gains obtained at $275^{\circ} \mathrm{C}$.

- On specimens with pretransition autoclave films, weight gains were markedly affected by flux. Weight gain ratios (in-flux/out-of-flux) were 4.0 to 6.2 for Zircaloy-2 and 2.0 to 4.8 for Zircaloy-4.

* $72 \mathrm{hr}$ in steam of $400^{\circ} \mathrm{C}$ and $1500 \mathrm{psi}\left(17.4-19.6 \mathrm{mg} / \mathrm{dm}^{2}\right)$

** $644 \mathrm{hr}$ in steam at $425^{\circ} \mathrm{C}$ and $1500 \mathrm{psi}\left(57.0-72.0 \mathrm{mg} / \mathrm{dm}^{2}\right)$ 
Table II

In-Flux and Out-of-Reactor Weight Gains on PRTR Zircaloy Corrosion Specimens

\begin{tabular}{|c|c|c|c|c|c|c|c|}
\hline $\begin{array}{c}\text { Sct } \\
\text { Number } \\
\end{array}$ & $\begin{array}{l}\text { Position } \\
\text { on Rod }\end{array}$ & Temperature & Flux & Alloy & $\begin{array}{c}\text { As- } \\
\text { Etched } \\
\underline{\mathrm{mg} / \mathrm{dm}^{2}} \\
\end{array}$ & $\begin{array}{c}\text { Pre- } \\
\text { Transition } \\
\text { Prefilm } \\
\mathrm{mg} / \mathrm{dm}^{2} \\
\end{array}$ & $\begin{array}{c}\text { Post- } \\
\text { Transition } \\
\text { Prefilm } \\
\mathrm{mg} / \mathrm{dm}^{2} \\
\end{array}$ \\
\hline 1 & Top & $\begin{array}{c}270-279^{\circ} \mathrm{C} \\
\left(518-532^{\circ} \mathrm{F}\right)\end{array}$ & Low & $\begin{array}{l}\text { Zircaloy }-2 \\
\text { Zircaloy }-4\end{array}$ & $\begin{array}{l}10.5 \% \\
12.7\end{array}$ & $\begin{array}{l}17.3 \\
14.4\end{array}$ & $\begin{array}{l}16.9 \\
14.2\end{array}$ \\
\hline 2 & & & & $\begin{array}{l}\text { Zircaloy }-2 \\
\text { Zircaloy }-4\end{array}$ & 16.5 & $\begin{array}{l}21.9 \\
20.4\end{array}$ & $\begin{array}{l}18.2 \\
17.5\end{array}$ \\
\hline 3 & & & & $\begin{array}{l}\text { Zircaloy }-2 \\
\text { Zircaloy }-4\end{array}$ & $\begin{array}{l}15.6 \\
17.6\end{array}$ & $\begin{array}{l}22.7 \\
22.8\end{array}$ & $\begin{array}{l}20.4 \\
16.8\end{array}$ \\
\hline 4 & & & & $\begin{array}{l}\text { Zircaloy-2 } \\
\text { Zircaloy-4 }\end{array}$ & $\begin{array}{l}15.9 \\
17.1\end{array}$ & $\begin{array}{l}24.9 \\
25.1\end{array}$ & $\begin{array}{l}20.3 \\
21.3\end{array}$ \\
\hline 5 & & & & $\begin{array}{l}\text { Zircaloy-2 } \\
\text { Zircaloy } 4\end{array}$ & $\begin{array}{l}16.4 \\
16.4\end{array}$ & $\begin{array}{l}26.0 \\
23.6\end{array}$ & $\begin{array}{l}24.2 \\
18.4\end{array}$ \\
\hline & & & High & & & & \\
\hline 6 & & & & $\begin{array}{l}\text { Zircaloy-2 } \\
\text { Zircaloy }-4\end{array}$ & $\begin{array}{l}12.9 \\
14.0\end{array}$ & $\begin{array}{l}23.3 \\
21.4\end{array}$ & $\begin{array}{l}20.8 \\
18.0\end{array}$ \\
\hline 7 & & & & $\begin{array}{l}\text { Zircaloy }-2 \\
\text { Zircaloy-4 }\end{array}$ & $\begin{array}{l}12.7 \\
12.4\end{array}$ & $\begin{array}{l}21.6 \\
20.2\end{array}$ & $\begin{array}{l}18.5 \\
12.7\end{array}$ \\
\hline 8 & & & & $\begin{array}{l}\text { Zircaloy-2 } \\
\text { Zircaloy-4 }\end{array}$ & $\begin{array}{l}10.7 \\
10.3\end{array}$ & $\begin{array}{c}18.5 \\
--\end{array}$ & $\begin{array}{l}19.1 \\
20.0\end{array}$ \\
\hline 9 & & & & $\begin{array}{l}\text { Zircaloy-2 } \\
\text { Zircaloy-4 }\end{array}$ & $\begin{array}{l}10.8 \\
10.9\end{array}$ & $\begin{array}{l}18.4 \\
15.2\end{array}$ & $\begin{array}{l}17.9 \\
14.3\end{array}$ \\
\hline 10 & Bottom & $246^{\circ} \mathrm{C}\left(475^{\circ} \mathrm{F}\right)$ & Low & $\begin{array}{l}\text { Zircaloy-2 } \\
\text { Zircaloy-4 }\end{array}$ & $\begin{array}{l}10.2 \\
11.1\end{array}$ & $\begin{array}{l}17.1 \\
10.1\end{array}$ & $\begin{array}{l}15.2 \\
15.1\end{array}$ \\
\hline \multicolumn{2}{|c|}{ Out-of-Reactor } & $275^{\circ} \mathrm{C}\left(527^{\circ} \mathrm{F}\right)$ & & $\begin{array}{l}\text { Zircaloy- } 2 \\
\text { Zircaloy }-4\end{array}$ & $\begin{array}{l}14.0 \\
14.3\end{array}$ & $\begin{array}{l}4.2 \\
5.2\end{array}$ & $\begin{array}{l}16.1 \\
13.8\end{array}$ \\
\hline
\end{tabular}

* As-etched specimen highly scratched.

** As-etched specimen scuffed in machining when removed from rod. 
- In-flux weight gains on specimens with posttransition films were slightly lower than weight gains on specimens with pretransition films. However, in-flux/out-of-flux ratios were much smaller for posttransition samples (up to 1.5 for Zircaloy-2 and Zircaloy-4), due to relatively large weight gains on out-of-flux specimens. The large out-of-flux weight gains are likely the result of a memory phenomenon from the $425^{\circ} \mathrm{C}$ posttransition autoclave treatment.

\section{In-Flux and Out-of-Reactor Hydriding}

Hydrogen analyses were performed on four of the ten sets of in-flux specimens and on specimens from the out-of-reactor autoclave. Two hydrogen samples were cut from each specimen. Analyses were performed by a hot vacuum extraction method. Results of the hydrogen analyses appear in Table III.

Summarizing the results:

- Hydrogen (deuterium) absorption was low on all specimens of both alloys exposed as-etched.

- Zircaloy-2 specimens exposed with a pretransition oxide film. showed a surprising tendency for in-flux hydrogen absorption. Values up to $438 \mathrm{ppm}$ occurred on in-flux specimens, equivalent to absorption of up to $120 \%$ of the corrosion product hydrogen. Hydrogen absorption was lower on corresponding Zircaloy-4 specimens and out-ofreactor Zircaloy-2 specimens.

- In-flux hydrogen absorption on specimens with posttransition films was generally lower than the hydrogen absorption on corresponding samples with pretransition films. However, some uncertainty must be attached to the hydrogen pickup values for posttransition samples, since their hydrogen blank values were not known with precision.

- The percentage of the corrosion deuterium absorbed was less than $40 \%$ For as-etched specimens of both alloys. The percentage was higher for posttransition films but with one exception (Zircaloy-2, set No. 1) was less than $25 \%$. Highest percentage pickups in-flux occurred for Zircaloy-2 specimens with pretransition oxides. Values up to $120 \%$ were observed. Percentage pickups in the out-of-reactor autoclave were less than $40 \%$ for all specimens. 
Table III

In-F1ux and Out-of-Reactor Hydrogen* Pickups

\begin{tabular}{|c|c|c|c|c|c|c|c|c|c|c|}
\hline \multirow{2}{*}{$\begin{array}{c}\text { Set } \\
\text { Number }\end{array}$} & \multirow{2}{*}{$\begin{array}{l}\text { Position } \\
\text { on Rod }\end{array}$} & \multirow[b]{2}{*}{ Temperature } & \multirow[b]{2}{*}{ Flux } & \multirow{2}{*}{$\begin{array}{c}\text { Surface } \\
\text { Condition }\end{array}$} & \multicolumn{3}{|c|}{ Zircaloy-2 } & \multicolumn{3}{|c|}{ Zircaloy -4} \\
\hline & & & & & $\mathrm{ppm}$ & $\mathrm{mg} / \mathrm{dm}^{2}$ & $\% \dot{x}$ & $\overline{\mathrm{ppm}}$ & $\mathrm{mg} / \mathrm{dm}^{2}$ & $\% * *$ \\
\hline \multirow[t]{3}{*}{1} & Top & $270-279^{\circ} \mathrm{C}$ & Low & As-etched & 24 & 0.4 & 16 & 16 & 0.2 & 6 \\
\hline & & $\left(518-532^{\circ} \mathrm{F}\right)$ & & Pretransition & 144 & 2.2 & 52 & 70 & 1.0 & 26 \\
\hline & & & & Posttransition & 226 & 3.6 & 86 & 122 & 1.8 & 48 \\
\hline \multirow[t]{3}{*}{4} & & & & As-etched & 40 & 0.6 & 16 & 28 & 0.4 & 10 \\
\hline & & & & Pretransition & 276 & 4.0 & 64 & 76 & 1.2 & 20 \\
\hline & & & & Posttransition & 118 & 1.8 & 36 & 76 & 1.2 & 22 \\
\hline \multirow[t]{3}{*}{6} & & & High & As-etched & 18 & 0.2 & 8 & 14 & 0.2 & 8 \\
\hline & & & & Pretransition & 326 & 5.2 & 120 & 68 & 1.0 & 38 \\
\hline & & & & Posttransition & 92 & 1.4 & 36 & 26 & 0.4 & 10 \\
\hline \multirow[t]{3}{*}{10} & Bottom & $246^{\circ} \mathrm{C}\left(475^{\circ} \mathrm{F}\right)$ & Low & As-etched & & & & & & \\
\hline & & & & Pretransition & & & & & & \\
\hline & & & & Posttransition & & & & & & \\
\hline \multirow{3}{*}{\multicolumn{3}{|c|}{ Out-of-Reactor (autoclave) }} & & As-etched & 4 & 0.06 & 2 & 6 & 0.1 & 3 \\
\hline & & & & Pretransition & 16 & 0.2 & 40 & 10 & 0.2 & 30 \\
\hline & & & & Posttransition & \multicolumn{6}{|c|}{ Not Available } \\
\hline \multirow{3}{*}{\multicolumn{4}{|c|}{ Hydrogen Blank Values: }} & As-etched & 15 & & & 12 & & \\
\hline & & & & Pretransition & 35 & & & 27 & & \\
\hline & & & & Posttransition & $175^{*}$ & & & $120 \%$ & & \\
\hline
\end{tabular}

* In-flux hydrogen absorption refers to the deuterium isotope. Out-of-reactor absorption refers to ordinary hydrogen. A11 values in the table refer to net hydrogen absorbed in the reactor or in the out-of-reactor test.

** Percent refers to the percentage of the corrosion $\mathrm{D}_{2}$ or $\mathrm{H}_{2}$ absorbed.

*** Estimated from out-of-reactor autoclave data. 
- As a function of alloy, there was little difference between Zircaloy-2 and Zircaloy-4 in the as-etched condition. However, hydrogen pickups were markedly higher for prefilmed Zircaloy-2 than for prefilmed Zircaloy-4 specimens.

- Hydrogen pickups increased with increasing flux for specimens with as-etched and pretransition surface conditions. No consistent flux-hydrogen pickup trend occurred for posttransition specimens of either alloy. However, for both alloys, actual hydrogen pickups were higher in-flux than in the autoclave.

\section{Discussion}

Two aspects of the test results have particular significance. First, the oxidation rate was clearly accelerated by the flux, but the effect was more pronounced on prefilmed than on etched specimens. The second principal observation was that prefilming contributed to relatively high total hydrogen contents, particularly for Zircaloy-2: the pretransition film samples absorbed up to $438 \mathrm{ppm}$ in the reactor exposure, the posttransition film samples pickup $\sim 175 \mathrm{ppm}$ (Zircaloy-2) and $120 \mathrm{ppm}$ (Zircaloy-4) hydrogen in the prefilming operation.

The presence of accelerated flux-induced corrosion and the adverse affect of prefilming are not surprising. The corrosion behavior of Zircaloy-2 and Zircaloy-4 in the G-7 loop of the Engineering Test Reactor yielded similar results ${ }^{.(2)}$ From the ETR tests, oxygen level in the coolant appears to be a significant factor in the in-flux corrosion mechanism. The most recent G-7 loop environment was $\mathrm{pH}-10 \mathrm{NH}_{4} \mathrm{OH}<0.05 \mathrm{ppm} \mathrm{O}_{2}$. The PRTR coolant is not routinely monitored for dissolved oxygen. However, oxygen in the cover gas is routinely monitored by gas chromatography. Experimental correlations of cover gas and coolant oxygen concentrations indicate that the PRTR coolant oxygen level is normally an order of magnitude below the specified maximum of $0.14 \mathrm{ppm}$. The corrosion behavior of the PRTR

(2) Johnson, A. B. Ir., "In-Reactor Oxidation of Zirconium Alloys in pH$10 \mathrm{LiOH}$ and $\mathrm{pH}-10 \mathrm{NH}_{4} \mathrm{OH}, " \mathrm{BNWL}-\mathrm{SA}-822$, presented at the 23rd Annual Meeting, National Association of Corrosion Engineers, Los Angeles, March, 1967. 
Zircaloy corrosion specimens is consistent with expected results in a lowoxygen system.

The possibility that fissionable contamination contributed to the accelerated corrosion cannot be ruled out, since the release of fissionable contamination to the PRTR coolant is known to have occurred from time to time. The role of fissionable species in in-reactor corrosion mechanisms is a subject of considerable controversy. A "clean loop" experiment is planned to be conducted in the Battelle-Northwest water loop of the Advanced Test Reactor (ATR) to resolve the question of whether or not fissionable species are a significant factor in the corrosion mechanism. Effect of Alloy

The comparable corrosion properties of Zircaloy-2 and Zircaloy-4 specimens in the test are consistent with the general behavior of the two alloys. The superior resistance of zircaloy-4 to hydrogen absorption also is typical of the comparative behavior of the two alloys. Effect of Prefilming

The fact that etched specimens performed much better than prefilmed specimens in-flux has practical implications, since prefilming reactor components is a standard practice. Evidence is mounting that prefilming is deleterious to the in-flux corrosion resistance. (2) Hydrogen absorption also was increase by prefilming of the PRTR specimens.

There is evidence from work at Harwell (3) that flux accelerates the onset of transition. Thus, the specimens with pretransition oxides were accelerated through transition by the flux, while the etched specimens did not reach the oxide thickness for transition. The etched specimens did undergo a slight flux-induced acceleration which may be the result of easy path generation in the oxide from fast neutron damage.

The situation is more complicated on specimens with posttransition oxides. It is evident from the out-of-reactor data that the posttransition

(3) Asher, R. C., Davies, D., Hall, A., Kirstein, T.B.A., Marriot, J. W., and White, P. J., "Effects of Radiation on the Oxidation and Hydrogen Absorption of Zirconium Alloys in Steam," J. Electrochem. Tech., 4, No. 5-6, pp, 231-26 (1966) May-June. 
samples corroded rapidly due to a "memory effect"(4) as a result of the $425^{\circ} \mathrm{C}$ autoclave treatment. An additional acceleration can be attributed to the flux, but it was smaller than the effect occurring on pretransition samples.

Hydrogen absorption as a function of surface condition has certain interesting aspects. The etched specimens were least susceptible to hydriding, indicating that the relatively thin oxide which formed in-reactor was an effective barrier against radiolytic hydrogen. Also, the low percentage pickup indicates that flux did not accelerate the hydrogen absorption mechanism on the specimens with thin oxides.

Regarding effects of prefilming, in-flux hydrogen absorption was more pronounced on pretransition than on posttransition samples, which at first seems anamolous, since percentage hydrogen pickups are generally higher after transition than before transition. However, at some point in the PRTR exposure the pretransition oxides apparently became posttransition oxides. Thus, the most rapid portion of posttransition oxidation occurred in-reactor, while on prefilmed posttransition samples part of the rapid oxidation occurred in the autoclave before the specimens were placed inreactor.

Hydrogen pickups in the PRTR pretransition Zircaloy-2 samples were considerably higher than were hydrogen pickups in prefilmed Zircaloy-2 exposed in the ETR G-7 1oop. (5) Experience has shown that hydrogen pickup varies considerably as a function of Zircaloy-2 lot. Lot differences may account for differences in hydriding behavior for prefilmed PRTR and G-7 loop specimens.

The growing evidence that prefilming adversely affects in-flux corrosion resistance should prompt a re-evaluation of proof testing practices on Zircaloy components. While the magnitude of the accelerated oxidation and hydriding has not yet reached critical proportions, the reasons for going to the trouble and expense of prefilming seem of doubtful validity in view of the deleterious effects. Alternative prefilm

(4) Thomas, D. E. and Kass, S., "Effect of Prior Corrosion History on the Corrosion of Zircaloy-2 in High Temperature Water," J. Electrochem. Soc., 103, p. 478, (1956).

(5) Johnson, A. B., Ir. and Irvin, J. E., "Radiation-Enhanced Oxidation of Zircaloy-2 in pH-10 LiOH and $\mathrm{pH}^{-10} \mathrm{NH}_{4}-\mathrm{OH}, \mathrm{BNWL}-463, \mathrm{July}, 1967$. 
procedures may be more satisfactory than the standard $400^{\circ} \mathrm{C}$ steam treatment used at many sites. A two-stage prefilm treatment has proved beneficial from the standpoint of hydrogen pickup in out-of-reactor tests. (6) This pretreatment will be tested in a PRTR in-flux test now being prepared.

\section{Corrosion Behavior as a Function of Flux}

The array of sixty coupons presents a substantial opportunity to evaluate in-flux corrosion as a function of flux level. Weight gains followed the flux profile for both alloys in all three surface conditions. The weight gain maxima occurred slightly above the core center line (Table II). Low weight gains, below those of the autoclave controls, occurred at the low-flux, low-temperature position. However, the relatively low weight gain spread and the presence of some experimental scatter compromised the evaluation of flux-temperature interactions. Nevertheless, a computer analysis of the data is being attempted using the program LEARN.

\section{Conclusions}

1. The corrosion rate of Zircaloy-2 and Zircaloy-4 was accelerated by flux in the $\mathrm{pH}-10$ LiOH PRTR environment.

2. The magnitude of the acceleration varied with initial surface condition as follows:

\begin{tabular}{lll}
\multicolumn{1}{c}{ Surface Condition } & & Ratio, $\frac{\Delta W \text { in-flux }}{\Delta W \text { out-of-flux }}$ \\
As-etched & $\begin{array}{l}1 \text { to } 1.2 \\
\text { Prefilmed, pretransition }\end{array}$ & 4.0 to 6.2 (Zircaloy-2) \\
Prefilmed, posttransition & 1.0 to 4.8 (Zircaloy-4) 1.5
\end{tabular}

Prefilming adversely affected the in-flux corrosion resistance.

3. Corrosion rates were similar for Zircaloy-2 and Zircaloy-4, but prefilmed Zircaloy-4 was superior to prefilmed Zircaloy-2 from the standpoint of hydrogen absorption.

4. Hydrogen absorption was much lower on specimens exposed as-etched than on prefilmed specimens.

(6) Debray, W., Stieding, L., and Rosler, U., "Influence of Initial oxideLayer Formation on the Hydrogen Pickup of Zircaloy," J. Electrochem. Tech., 4, No. 3-4 pp. 113-117 (1966) March-April. 
Corrosion and Hydriding of PRTR Zircaloy-2 Process Tubes - A. B. Johnson, Jr. and B. Griggs

During FY 1967, two Zircaloy-2 PRTR process tubes were examined to determine oxide thickness and hydrogen content. Oxide thicknesses were determined metallographically from Filar eyepiece measurements at several points around the inner and outer tube surfaces. Sample rings cut at various points along the length of the tube provided corrosion information as a function of reactor flux.

Hydrogen absorption was evaluated by hot vacuum extraction of metal samples machined from each ring.

Exposure history and conditions for the two tubes are summarized in Table IV. Corrosion and hydriding data appear in Table V.

\section{Table IV}

\section{Zircaloy Process Tube Exposure History}

\begin{tabular}{|c|c|c|}
\hline & Tube 5690 & Tube 5696 \\
\hline Charge Date & $5 / 1 / 61$ & $5 / 1 / 61$ \\
\hline Discharge Date & $10 / 31 / 65$ & $4 / 3 / 66$ \\
\hline Exposure, MWd & 511 & 742 \\
\hline Maximum Flux $\mathrm{n} / \mathrm{cm}^{2},>12 \mathrm{keV}$ & $1.7 \times 10^{2}$ & $2.6 \times 10^{21}$ \\
\hline Maximum Flux $\mathrm{n} / \mathrm{cm}^{2},>1 \mathrm{MeV}$ & $3.4 \times 10^{20}$ & $5.0 \times 10^{20}$ \\
\hline
\end{tabular}

The preautoclave weight gain is taken as $16 \mathrm{mg} / \mathrm{dm}^{2}$. To convert from oxide thickness to weight gain, a factor of $1 \mu=14.9 \mathrm{mg} / \mathrm{dm}^{2}$ is used. In-Flux Corrosion

Clearly, accelerated flux-induced corrosion occurred on the inner tube surfaces, in contact with the reactor coolant. On Tube 5696, corrosion increased by a factor of 16 between an out-of-flux control position and the maximum in-flux position. No out-of-flux control data are available for Tube 5690, but the maximum corrosion is similar to that for Tube 5696. The general pattern of weight gain varying with 


\section{$\underline{\text { Table V }}$}

\section{In-Flux Corrosion and Hydriding of PRTR Zircaloy-2 Process Tubes}

Tube 5690

Tube Position

Distance from Outlet End ( $f t$ )

Flux

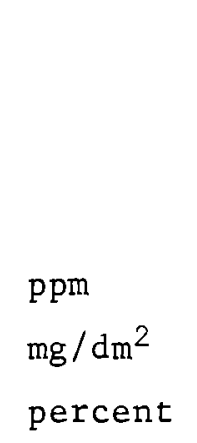

$$
\begin{aligned}
& \text { ppm } \\
& \mathrm{mg} / \mathrm{dm}^{2} \\
& \text { percent }
\end{aligned}
$$$$
\mathrm{mg} / \mathrm{dm}^{2}
$$

Temperature, ${ }^{\circ} \mathrm{F}$

Oxide, ${ }^{a}$ ID, $\mathrm{mg} / \mathrm{dm}^{2}$

Oxide, ${ }^{a} \mathrm{OD}, \mathrm{mg} / \mathrm{dm}^{2}$

Hydrogen Pickup: ${ }^{b}$

\begin{tabular}{rrcrrr}
1 & 2 & 3 & \multicolumn{1}{c}{4} & \multicolumn{1}{c}{5} & \multicolumn{1}{c}{6} \\
3.6 & 5 & 6.8 & 8.8 & 10.6 & 12.3 \\
Low & \multicolumn{5}{c}{ High } \\
530 & & & & & Low \\
25 & 80 & 75 & 180 & 130 & 60 \\
15 & 20 & 30 & - & 100 & 20 \\
0 & 0 & 10 & 20 & 28 & 30 \\
0 & 0 & 2.0 & 4.0 & 5.6 & 6.0 \\
0 & 0 & 8 & 8 & 10 & 30
\end{tabular}

\section{Tube 5696}

Tube Position

Distance from Outlet, ft.

Temperature, ${ }^{\circ} \mathrm{F}$

Oxide, ${ }^{a}$ ID, $\mathrm{mg} / \mathrm{dm}^{2}$

Oxide, ${ }^{a} \mathrm{OD}, \mathrm{mg} / \mathrm{dm}^{2}$

Hydrogen Pickup: ${ }^{b}$

\section{ppm}

$\mathrm{mg} / \mathrm{dm}^{2}$

percent
Out-of-Flux

$\begin{array}{llllll}\text { Control } & 10 & 11 & 12 & 13 & 14\end{array}$

$\begin{array}{llllll}0.5 & 4.3 & 6.6 & 9.9 & 10.2 & 12.1\end{array}$ $530 \quad 475$

$\begin{array}{llllll}10 & 15 & 150 & 165 & 110 & 50\end{array}$

$\begin{array}{llllll}7 & 14 & 12 & 13 & 12 & 9\end{array}$

$\begin{array}{llllll}0 & 6 & 34 & 28 & 34 & 40\end{array}$

$\begin{array}{llllll}0 & 1.2 & 6.8 & 5.6 & 6.8 & 8.0\end{array}$

$\begin{array}{llllll}0 & 18 & 16 & 32 & 22 & 54\end{array}$

a. Corrected for a preautoclave weight gain of $16 \mathrm{mg} / \mathrm{dm}^{2}$.

b. Assumed to be deuterium. Corrected for 20 ppm hydrogen base value. 
the flux profile is consistent with experience from the examination of previous PRTR process tubes. (7) However, the maximum weight gains on the tubes reported here are higher than on previous tubes, due to higher exposures.

On the outer surfaces, in contact with moist helium, weight gains were generally much lower than on inner surfaces. However, on both tubes, flux effects were evident. The corrosion behavior on Tube 5696 is typical of experience on previous tubes, (7) where weight gains on outer surfaces increased by factors of two to four between low-flux and high-flux positions. On Tube 5690, corrosion on the outer surface is unusually high, particularly at position 5. At this position, the corrosion was nonuniform, as opposed to relatively uniform oxide thicknesses on the remainder of the tube. The untypical behavior perhaps resulted from some irregularity in surface preparation at that point on the tube. In-Flux Hydriding

In both tubes, in-flux hydrogen absorption was $40 \mathrm{ppm}$ or less. However, in both tubes, the hydrogen level increased going toward the cooler end of the tube, probably due to thermal diffusion.

The percentage of the corrosion hydrogen absorbed was generally low, but rose as high as $54 \%$ in the cool end of Tube 5696.

Conclusions

1. Accelerated corrosion, generally following the flux profile, occurred on both PRTR Zircaloy-2 process tubes. The accelerated corrosion was higher on the coolant side than on the moist helium side of the tubes.

2. Hydrogen absorption was relatively low, being $40 \mathrm{ppm}$ or less in both tubes. However, hydrooen tended to distribute toward the cooler ends of the tubes, likely cue to thermal diffusion.

(7) Quarterly Progress Report, Metallurgy Research Section, October, November, December, 1965, edited by J. J. Cadwell, BNWL-207, Battelle-Northwest, Richland, washington. January 17, 1966, p. 5.16. 


\section{Chemistry Studies}

Ceramic Fuel Dissolution Studies - Lyle D. Perrigo

Ceramic fuel dissolution processes are being developed to provide techniques for chemically decontaminating reactors that use ceramic fuel materials. Work during the past year has been centered on determining, (a) the dissolution characteristics of candidate procedures, (b) the mechanism and kinetics of the OPG (oxalic-peroxide-gluconic) dissolution process, (c) the dissolution effectiveness of anhydrous liquid ammonia sodium metal procedures, and (d) corrosion effects in concentrated acid solvents.

\section{OPG Dissolution}

Dissolution experiments on molten $\mathrm{UO}_{2}$-water reaction products were begun to determine effective procedures for removing ceramic fuel element rupture debris from reactor systems. The urania residue whose physical and chemical properties have been described earlier by R. L. Gibby in BNWL-198, was treated with the OPG decontamination process at $80^{\circ} \mathrm{C}$. The friable urania broke into a fine aggregate with moderate agitation. The reaction was essentially complete in twenty minutes; over $99 \%$ of the ceramic material was dissolved.

Application of the OPG solution to the 9-29-65 PRTR rupture debris produced highly satisfactory results. Laboratory experiments showed that $97.8 \%$ of the $\mathrm{UO}_{2}$ and $95.4 \%$ of the $\mathrm{PuO}_{2}$ were in solution within four hours at $80^{\circ} \mathrm{C}$. These data indicated that there were no serious problems with preferential dissolution of $\mathrm{UO}_{2}$ in the PRTR rupture debris. The OPG decontamination was recommended for PRTR rupture loop decontamination and subsequently effectively applied to the cleanup of this facility. Process details are given elsewhere.

The satisfactory dissolution of the molten urania-water reaction products and PRTR rupture debris prompted a more definitive study of OPG solution kinetics and dissolution mechanisms. Data obtained from the reaction of this solution with sintered $\mathrm{UO}_{2}$ pellets were used for an Arrhenius plot. Over the normal OPG operating range of 35 to $95^{\circ} \mathrm{C}$, 
instantaneous reaction rates varied by a factor of 24 . The Arrhenius coefficient was found to be about $12.3 \mathrm{kcal} / \mathrm{mole}$ of $\mathrm{UO}_{2}$. This coefficient is similar to the value in $\mathrm{HNO}_{3}$ solutions, $14.8 \mathrm{kcal} / \mathrm{mole}$ of $\mathrm{UO}_{2}$, reported by R. F. Taylor and his coworkers in "Dissolution Rates of Uranium Dioxide Sintered Pellets in Nitric Acid Systems," Journal of Applied Chemistry, Vol. 13, January 1963. The instantaneous reaction rates of the standard OPG solution and $4 \underline{\mathrm{N}} \mathrm{HNO}_{3}$ were the same at $95^{\circ} \mathrm{C}$.

Flow experiments at $50^{\circ} \mathrm{C}$ were run on sintered $\mathrm{UO}_{2}$ to study reaction mechanisms. Dissolution rate drops of a factor 10 were found in $4 \mathrm{~N}_{3} \mathrm{HNO}_{3}$ as the flow was increased from $1 \mathrm{ft} / \mathrm{sec}$ to $3 \mathrm{ft} / \mathrm{sec}$. Taylor and his coworkers noted a similar drop in rate in $\mathrm{HNO}_{3}$. Flow increases in the standard OPG solution resulted in increased dissolution rates. Apparently reaction products catalyze $\mathrm{HNO}_{3}$ dissolution of $\mathrm{UO}_{2}$. Increases in flow result in low reaction product concentrations at the surface which lowers the reactor rate. The OPG reaction mechanism is the simple dissolution of $\mathrm{UO}_{2}$ where reducing the reaction product concentration at the surface accelerates the reaction.

Dissolution in Concentrated Minera1 Acids

Following the experimental results which showed that the dissolution rates for $\mathrm{PuO}_{2}$ sintered at $1650^{\circ} \mathrm{C}$ were much lower than those obtained with $\mathrm{PuO}_{2}$ fired at $900^{\circ} \mathrm{C}$, efforts were made to find more effective procedures. Emphasis has been placed on using more concentrated $\mathrm{H}_{3} \mathrm{PO}_{4}$ at higher temperatures. Phosphoric acid of about $99 \%$ concentration produced by heating $85 \% \mathrm{H}_{3} \mathrm{PO}_{4}$ at $210^{\circ} \mathrm{C}$ for one hour, gave higher dissolution rates. Use of this acid at $200^{\circ} \mathrm{C}$ resulted in a dissolution rate for sintered $\mathrm{PuO}_{2}$ of $0.165 \mathrm{gm} / \mathrm{cm}^{2} / \mathrm{hr}$. Inhibition with $6 \mathrm{gm} /$ liter $\mathrm{Fe}\left(\mathrm{NO}_{3}\right)_{3} \cdot 9 \mathrm{H}_{2} \mathrm{O}$ reduced stainless steel corrosion by a factor of ten to $0.12 \mathrm{mil} / \mathrm{hr}$ but also lowered the dissolution rate to $0.024 \mathrm{gm} / \mathrm{cm}^{2} / \mathrm{hr}$. The latter was still more than four times as effective as the uninhibited $85 \% \mathrm{H}_{3} \mathrm{PO}_{4}$ at $155^{\circ} \mathrm{C}$. Corrosion studies began in FY 1966 to determine general and nonuniform corrosion effects in concentrated acid solvents were continued in FY 1967. Average corrosion losses under quiescent conditions for Inconel-600 and 
AISI 446 stainless steel in $155^{\circ} \mathrm{C}$ concentrated sulfuric acid were 0.033 and $0.039 \mathrm{mil}$, respectively, in seven days. Exposure of these alloys to a 90 vol\% concentrated $\mathrm{H}_{2} \mathrm{SO}_{4}-5$ vol\% concentrated $\mathrm{HNO}_{3}-5$ vol\% concentrated $\mathrm{H}_{3} \mathrm{PO}_{4}$ solution at $140^{\circ} \mathrm{C}$ for seven days resulted in corrosion losses of $0.03 \mathrm{mil}$ and $0.007 \mathrm{mil}$. A seven day test of an Incone1-600/carbon steel galvanic couple in $155^{\circ} \mathrm{C}$ concentrated sulfuric acid resulted in an accelerated attack on the carbon steel; about $70 \%$ of the carbon steel specimens was dissolved. Only minor corrosion losses were found on Inconel-600/AISI stainless couples after seven days in $155^{\circ} \mathrm{C}$ concentrated sulfuric acid and $140^{\circ} \mathrm{C} 90$ vol\% concentrated $\mathrm{H}_{2} \mathrm{SO}_{4}-5$ vol\% concentrated $\mathrm{HNO}_{3}-5$ vol\% concentrated $\mathrm{H}_{3} \mathrm{PO}_{4}$ solutions. Couples of stainless steel and carbon steel in the triacid mixture of $140^{\circ} \mathrm{C}$ showed a nonuniform attack on the carbon steel. Pits having a depth of greater than $10 \mathrm{mils}$ were observed after seven days exposure. No cracking failures were observed on sheared specimens of AISI 316 or 347 stainless steel after exposure to concentrated sulfuric acid at $250^{\circ} \mathrm{C}$ for one week.

Dissolution in Liquid Ammonia

The feasibility of reducing ceramic fuel materials in sodium metalliquid ammonia solutions were explored during FY 1967. Familiarization runs were made with rusted steel specimens and magnetite to obtain qualitative information on their behavior in a highly basic reducing environment. Atmospheric corrosion products on steel were reduced. Treatment of magnetite under pressure at $100^{\circ} \mathrm{C}$ resulted in limited $\mathrm{Fe}_{3} \mathrm{O}_{4}$ reduction. The primary reaction product appeared to be the formation of sodium amide. Although no $\mathrm{PuO}_{2}$ reduction studies were tried, this dissolution scheme was abandoned. Failure to achieve significant $\mathrm{Fe}_{3} \mathrm{O}_{4}$ reduction and the $\mathrm{Fe}_{3} \mathrm{O}_{4}$ catalyzed decomposition to sodium amide did not show sufficient promise for a successful reduction reaction to proceed further.

Corrosion and Boron Deposition in $\mathrm{H}_{3} \underline{\mathrm{BO}}_{3}$ Solutions $-G$. R. Bloom and T. F. Demmitt

The Plutonium Recycle Test Reactor (PRTR) has been modified to permit operation with a higher power density core. This change will expedite 
development of the technology associated with utilizing plutonium fuels in thermal power reactors. One of the critical requirements for this type of operation was to increase the shim capability for transient and long-term fuel burnup reactivity compensation. A chemical shim control system employing boric acid $\left(\mathrm{H}_{3} \mathrm{BO}_{3}\right)$ as a neutron poison in the $\mathrm{D}_{2} \mathrm{O}$ moderator, offered substantial advantages over a mechanical control system for this application; and this method of control will be used exclusively.

An extensive experimental program was conducted to assess the existence and significance of potential corrosion and boron deposition problems associated with using $\mathrm{H}_{3} \mathrm{BO}_{3}$ in the PRTR moderator system. The results of a series of in-reactor, pilot plant and laboratory tests designed to evaluate these potential problems are summarized in the following:

1. Materials representative of the PRTR moderator system have been exposed to boric acid solutions in pilot plant facilities and in the PRTR moderator system during the in-reactor chemical shim demonstration tests. Pilot plant tests of a PRTR dump valve, shim rod assembly, and process shroud tube bellows assembly were performed. The pilot plant tests have demonstrated the potential for localized aluminum corrosion in the process shroud-tube bellows assembly. No other significant corrosion problems should result from using boric acid in the moderator system if (1) shim well refreshment flow is guaranteed or the mechanical shim rods remain out of the reactor, (2) the boron concentration does not exceed 50 wppm* and (3) the moderator water purity is maintained within established control limits.

2. Laboratory studies were performed to determine the amount of boron deposition that would occur on the moderator system surfaces. Boron deposition did not exceed three micrograms of boron per square centimeter of surface area during these laboratory tests at proposed PRTR operating conditions. The reactivity worth of these deposits (if $92 \%$ enriched $\mathrm{H}_{3} \mathrm{~B}^{10} \mathrm{O}_{3}$ were used) would be about 1.5 to 2.1 milli-K at full power with 18 to $20 \mathrm{wppm}$ boron in the PRTR moderator. This is well within the PRTR reactivity control capabilities. 
3. In-reactor studies were performed to determine actual boron deposition and the effects on core reactivity during the in-reactor boron shim demonstration tests. Boron deposition measurements on specimens exposed in the PRTR calandria were less than one tenth of a microgram of boron per square centimeter. Reactor critical tests before and after in-reactor boron shim demonstration tests showed no measurable change in core reactivity. Complete data are contained in BNWL-520, June 1967, to be published.

\section{PRTR Pressure Tube Technology and Surveillance}

Specification for Flaw Detection Limits - P. J. Pankaskie and T. R. Ostrom

A tentative specification for defect detection limits for inspection of PRTR process tubes was prepared and distributed June 14, 1967.

Based on an over-all safety factor of four, electronic inspection of PRTR process tubes must be able to detect:

a) with regard to potential catastrophic failure, a crack defect or flaw one inch long by one-eighth inch deep;

b) with regard to potential leakage of coolant from the process tube, a crack defect or flaw one-quarter inch long by one-eighth inch deep.

Until adequate experience is gained with interpretation of signals from non-destructive electronic inspections, it is suggested that visual inspections of indicated flaws or defects also be made.

When inspections signal the presence of flaws or defects with dimensions half of those specified above, increased surveillance should be initiated to ascertain rates of approach to service limits. Reactor operation, just prior to detection of flaws $1 / 16$ inch deep or more. should be critically reviewed in an effort to ascertain cause so tha if and when appropriate, operating conditions may be altered to halt or slow down the approach to service limits.

Process Tube Examination - M. C. Fraser and T. R. Ostrom Process Tube No. 5696

Process tube number 5696 was removed from PRTR because of an unidentified mark in its tapered section, and the fact that it had the 
highest exposure $\left(3 \times 10^{21} \mathrm{nvt}\right)$ of any of the tubes in PRTR.

The following was done in evaluating tube number 5696. The tube was first Pi taped (the circumference was measured) every 6 inches along its length, and then examined ultransonically to find the axial location of the transition from cold worked to annealed structure. The tube was then sectioned into five 20-inch specimens with 2 -inch rings being taken from between each specimen. The 2-inch rings were analyzed for hydrogen and oxide thickness by Corrosion and Coolant Chemistry.

A replica was made of the tapered section, and the tube was then cut open for visual examination. It was determined that the mark was caused by a falling alignment mandrel. The depth of the flaw was not enough to cause concern over the strength of the tube. Hydrogen analyses were taken at three positions around the flaw; the results were 19, 27, and 29 ppm hydrogen, which is the same as the nominal "as-received" hydrogen concentration of $25 \mathrm{ppm}$.

Burst tests were run on two of the five 20 inch specimens. A room temperature test was performed with a hoop stress at failure at 147,000 psi. A $300^{\circ} \mathrm{C}$ test failed at a hoop stress of $81,000 \mathrm{psi}$. Both of these values are higher than any previously reported and show that burst strength is still increasing with increasing nvt up to and exposure of $3 \times 10^{2:}$.

The three other 20 inch specimens had $1-1 / 2$ inch slots milled 1/16 inch wide and $80 \%$ through their maximum wall thickness and were broken at room temperature, $100^{\circ} \mathrm{C}$, and $200^{\circ} \mathrm{C}$. These tests (see Figure 1) showed no decrease in crack propagation strength when compared to "as-received" tubing tests.

\section{Crack Propagation Tests - T. R. Ostrom}

\section{Hoop Strength Vs. Temperature}

Curves of hoop strength at failure vs. temperature have been prepared on "as-received" tubing with constant crack lengths of $3 / 4$ in., 1-1/2 in., and 3 inches (see Figure 1). The room temperature stress to propagate 
a $3 / 4$ inch flaw is 60,000 psi. As the temperature increases, the stress to cause propagation decreases $104 \mathrm{psi} /{ }^{\circ} \mathrm{C}$. The slope of the curve for the $1-1 / 2$ inch flaw in $-10 \mathrm{psi} /{ }^{\circ} \mathrm{C}$, and the slope for the 3 inch flaw in -36 psi/" $\mathrm{C}$. The slope for the 1-1/2 inch flaw appeared low; however, additional tests confirmed the previous results. This apparent strength anomaly for the tubes containing 1-1/2 inch flaws may be caused by a geometry effect related to the diameter of the tube and the bulging associated with elevated temperature tests. When the webs were broken, the cracks arrested for all of the 150 and $300^{\circ} \mathrm{C}$ tests of the "as-received" tubing. Effect of Hydrogen on Crack Propagation

Tests were run at room temperature on crack propagation specimens with 1-1/2 inch flaws and varying amounts of hydrogen to see the effect the hydrogen would have on the failure stress and the mode of failure. The test specimens contained 30, 150, and 275 ppm hydrogen. A11 three of the specimens failed at approximately the same hoop stress.

Replicas for fractography were prepared from these three specimens from three different areas: the web, $1 / 4$ inch from the web, and 3 inches from the web. Electron fractographs of the replicas revealed the mechanisms of failure (ductile dimpling, transgranular and intergranular cleavage) to be the same for all hydrogen concentrations. More careful study may reveal that the amount of failure by any one mechanism may vary, but the general appearance was the same for all specimens. Effect of Hydrogen on Elevated Temperature Crack Propagation Tests

Curves were prepared for hoop stress at fallure vs. temperature for tubes with $275 \mathrm{ppm}$ hydrogen and flaw lengths of $3 / 4$ and $1-1 / 2$ inch (see Figure 1). The data showed no decrease in strength compared to the as"received" tubing, with increasing temperature. Although there was no decrease in strength due to the hydrogen, the crack arrest temperature for the $3 / 4$ inch slot increased to over $300^{\circ} \mathrm{C}$ and that for the $1-1 / 2$ inch slot increased to between 150 and $300^{\circ} \mathrm{C}$. 


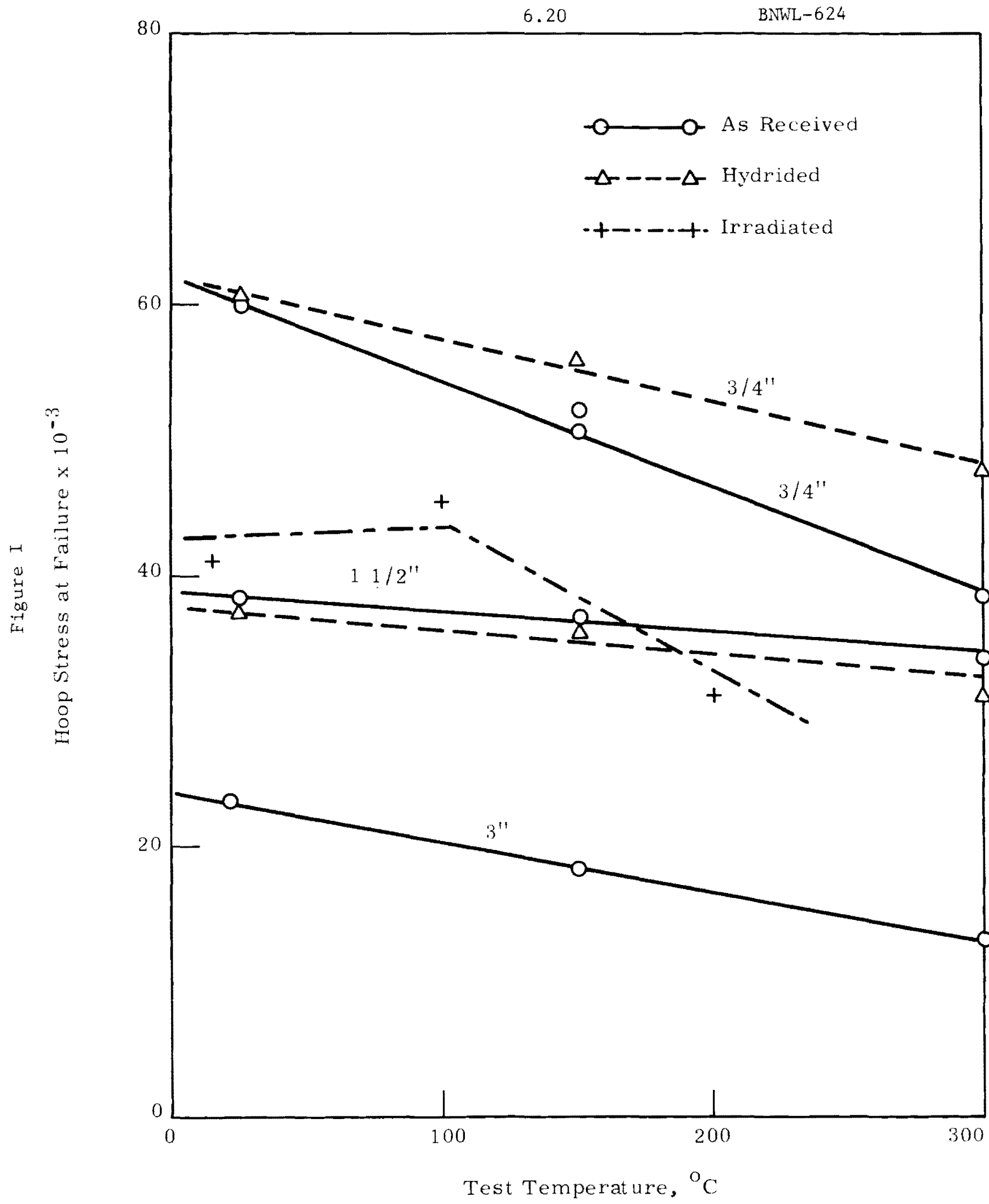




\section{PUBLICATIONS}

1. M. D. Freshley, F. E. Panisko, and R. E. Skavdahl, "The Irradiation Behavior of $\mathrm{UO}_{2}-\mathrm{PuO}_{2}$ Fuels in PRTR," BNWL-SA-791, presented at the 1966 AIME Nuclear Metallurgy Symposium, July, 1966.

2. M. D. Freshley, R. E. Sharp, and R. E. Skavdahl, "Plutonium Utilization Program: PRTR Irradiation Plans," BNWL-314, August, 1966.

3. G. R. Horn, "Atlas of Irradiated Fuel Structures," BNWL-225, October, 1966.

4. R. L. Gulley, "Plutonium Handling and Control Practices of Pacific Northwest Laboratory," BNWL-287, October 1966.

5. M. D. Freshley, R. C. Liimatainen, and R. J. Testa, "Transient Irradiations of Vibrationally Compacted $\mathrm{UO}_{2}$ Fuel in TREAT," Trans. Am. Nuc1. Soc., $\underline{9}$ (2) 395, November, 1966.

6. M. D. Freshley, F. E. Panisko, and R. E. Skavdah1, " $\mathrm{UO}_{2}-\mathrm{PuO}_{2}$ High Power Density Fuel Element Experience in PRTR," Trans. Am. Nuc1. Soc., 9 (2) 398, November, 1966.

7. M. D. Freshley, R. G. Wheeler, J. M. Batch and G. M. Hesson, "The Combined Failure of a Pressure Tube and Defected Fuel Rod in PRTR," Trans. Am. Nucl. Soc., 9 (2) 297, November, 1966.

8. M. D. Freshley and W. J. Bailey, "Irradiation Properties of High Energy Rate Pneumatically Impacted $\mathrm{UO}_{2}-\mathrm{PuO}_{2}$ Fuel," BNWL-356, January, 1967.

9. J. P. Keenan, S. Goldsmith, and D. R. de Halas, "Fabrication and Irradiation Factors Influencing Plutonium Recycle Economics," Presented at the IAEA Symposium on the Use of Plutonium as a Reactor Fuel, Brussels, Belgium, March 13-17, 1967. To be published in Conference Proceedings.

10. M. D. Freshley and F. E. Panisko, "The Irradiation Behavior of :$\mathrm{PuO}_{2}$ Fuels in PRTR," BNWL-366, February, 1967.

11. C. H. Bloomster, "Fabrication Costs for Plutonium Fuel Elements Part E; The Variation in Fabrication Cost with Some Fuel Design Parameters," BNWL-131E, February, 1967.

12. M. D. Freshley, "Proposal to Irradiate an Intentionally Defected UO Element in the ETR P-7 Loop: GEH-12-40," BNWL-CC-1181, April 24, 1967.

13. R. C. Smith, "High Exposure Plutonium Studies-Analysis of Shippingport Fue 1," BNWL-478, July, 1967. 
14. J. P. Keenan, R. E. Sharp, "PRTR Fuel Element Quality Control System," BNWL-349, January, 1967.

15. K. D. Hayden, "Washout Testing of Mixed Oxide Ceramic Core Fue1 Elements," BNWL-295, October, 1966.

16. J. A. Christensen, D. R. de Halas, and G. R. Horn, "Stoichiometry Effects in Molten Center, Oxide Fuels - Oxygen Redistribution and Thermal Conductivity Effects," BNWL-SA-814, August 5, 1966.

17. L. G. Merker, D. E. Deonigi, J. B. Burnham, "Comparative Cost of Oxide Fuel Elements," Volumes 1, 2, 3, BNWL-273, July, 1966.

18. W. J. Bailey, "Irradiation of Impacted $\mathrm{UO}_{2}-\mathrm{PuO}_{2}$ Packed Powder Fuel," BNWL-SA-1065, Trans. Am. Nuc1. Soc., 10 (I) 121-122, 1967.

19. C. H. Bean, R. E. Sharp, and W. J. Bailey, "The EBWR Plutonium Recycle Demonstration Experiments," BNWL-SA-1199, April 5, 1967. This paper is to be presented at the IMD-AIME, 1967 Nuclear Metallurgy Symposium on "Plutonium Fuels Technology" to be held at Phoenix, Arizona, October $4-6,1967$.

20. D. H. Thomsen and A. G. Gibbs, "New Analytical Results from SlowingDown Theory and Their Application to a Check Out of the RBU SlowingDown Routine," BNWL-307, November, 1966.

21. L. J. Page, "Theory Experiment Correlation of Burnup Data from A1-1.8 wt\% Pu Fuel (Initially 6 at\% $\mathrm{Pu}^{240}$ )," BNWL-393, July, 1967.

22. V. O. Uotinen, "A Poison Free Loading of $\mathrm{UO}_{2}$ and Pu-Al in the PRCF With $\mathrm{D}_{2} \mathrm{O}$ Moderator," BNWL-372, May, 1967.

23. R. C. Liikala and U. P. Jenquin, "Physics Survey Calculations for a $\mathrm{PuO}_{2}-\mathrm{UO}_{2}$ Fuel in Idealized $\mathrm{H}_{2} \mathrm{O}$ Power Reactors," BNWL-305, July, 1966.

24. D. E. Christensen, E. B. Reppond, W. A. Reardon, "Burnup Data from Low Exposure Plutonium-Aluminum Fuel," BNWL-CC-904, Pacific Northwest Laboratory, November, 1966.

25. D. E. Christensen, E. B. Reppond, W. A. Reardon, "Burnup Data from High Exposure Plutonium-Aluminum Fuel," BNWL-CC-905, Pacific Northwest Laboratory, December, 1966.

26. W. A. Reardon and D. E. Christensen, "Atom Ratios and Effective Cross Section Ratios in Highly Depleted Plutonium-Aluminum Alloy Fuel," Nucl. Sci. and Eng., in press.

27. V. O. Uotinen, "Measurement of the Reactivity Worth of Hafnium Oxide Rods in a $\mathrm{PuO}_{2}-\mathrm{UO}_{2}-\mathrm{H}_{2} \mathrm{O}$ Lattice," presented at the Winter meeting of the American Nuclear Society held at Pittsburgh, Penn., October 30November 3, 1966. Published in Trans. Am. Nucl. Soc. 9 , 520 (1966). 
28. V. 0. Uotinen and L. D. Williams, "Experiments and Calculations for $\mathrm{H}_{2}$ O-Moderated Assemblies Containing $\mathrm{UO}_{2}-2 \mathrm{wt} \% \mathrm{PuO}_{2}$ Fuel Rods," presented at the Thirteenth Annual Meeting of the American Nuclear Society held at San Diego, Calif., June 11-15, 1967. Published in Trans. Am. Nuc1. Soc., 10 and as BNWL-SA-1107.

29. D. H. Thomsen, "Analysis of a UO U $^{-19-R o d ~ C l u s t e r ~ E x p e r i m e n t ~ w i t h ~ t h e ~}$ RBU Monte Carlo Code," presented at the Thirteenth Annual Meeting of the American Nuclear Society held at San Diego, Calif., June 11-15, 1967. Published in Trans. Am. Nucl. Soc., 10238 (1967) and as BNWL-SA-1176.

30. F. G. Dawson, D. E. Deonigi, U. P. Jenquin, and R. C. Liikala, "Analysis of Plutonium Fueled Light Water Reactors," presented at the IAEA Symposium on the Use of Plutonium as a Reactor Fuel held at Brussels, Belgium, March 13-17, 1967. To be published in Conference Proceedings.

31. L. C. Schmid, D. E. Christensen, B. H. Duane, R. C. Liikala, and R. P. Matsen, "Experimental and Theoretical Methods Used for Burnup Analysis at Battelle-Northwest," presented at the British Nuclear Society International Conference on Physics Problems of Thermal Reactor Design held at London, England, June 27-29, 1967. To be published in Conference Proceedings.

32. J. W. Kutcher, J. H. Lauby, W. L. Purcell, L. C. Schmid, L. D. Williams, and J. R. Worden, "Critical Experiments with $\mathrm{PuO}_{2}-\mathrm{UO}_{2}$ Moderator," presented at the Winter Meeting of the American Auclear Society held in Pittsburgh, Penn., October 30-November 3, 1966. A summary was published in Trans. Am. Nuc1. Soc., 9, 448 (1966).

33. R. I. Smith, J. W. Kutcher, J. H. Lauby, "Critical Experiments With The $\mathrm{UO}_{2}-2 \mathrm{wt} \% \mathrm{PuO}_{2}$ Batch Core in the PRTR," presented at the 1967 Annual Meeting of the American Nuclear Society held in San Diego, Calif., June 11-15, 1967. A summary was published in Trans. Am. Nucl. Soc., 10, 185 (1967).

34. 0. K. Harling, "Compilation of Doubly Differential Cross Sectionis and Scattering Law for $\mathrm{H}_{2} \mathrm{O}$ and $\mathrm{D}_{2} \mathrm{O}$ at $299^{\circ} \mathrm{K}$ and for $\mathrm{H}_{2} \mathrm{O}$ at $268^{\circ} \mathrm{K}$," BNWL-436, 1967.

36. R. B. Smith, "Some Measurements of the Neutron Scattering Law for Light Water at $95^{\circ} \mathrm{C}, "$ BNWL-345, 1967.

37. L. J. Page, "Program GAMMAX," BNWL-CC-773, August 8, 1966.

38. L. J. Page, "Program BETA, A Reactor Kinetics Code," BNWL-CC-788, August 23, 1966. 
39. V. 0. Uotinen, "Reactivity Worth of a Central Safety Rod With and Without an Internal Scatterer," BNWL-618, 1967.

40. 0. K. Harling, "High Resolution Neutron Inelastic Scattering Study of Water and Ice," presented to the American Crystallographic Association, January 26, 1967.

41. N. A. Hill, E. P. Lippincott, D. F. Newman, D. D. Lanning, R. E. Heineman, "Comparison of PCTR Measurements Using Unpoisoned and Poisoned Techniques on $\mathrm{PuO}_{2}-\mathrm{UO}_{2}$ Graphite Systems," BNWL-472 (1967).

42. A. G. Gibbs and C. W. Lindenmeier, "Analytical Evaluation of the Large Time Contribution to Neutron Scattering Cross Sections," IAEA Symposium on Neutron Thermalization and Reactor Spectra (Ann Arbor, Michigan, July 1967), paper SM 96/51.

43. H. S. Zwibel, "An Angular Synthesis Approximation Applied to Thin Critical Slabs, 13 th Annual Meeting of the American Nuclear Society (San Diego, California, June 1967), ANS Transactions, Vol. 10, No. 1, June 1967 , p. 213.

44. E. L. Kelley, Jr. and D. R. Marr, "The 1107 Manual for Physics Chain, A Reactor Analysis Code," April, 1967, BNWL-413.

45. F. R. Czerniejewski, "PuO 2 Grain Reactivity Effects, "June, 1967 , BNWL-427.

46. D. W. Glasgow and D. G. Foster, Jr., "9 $\mathrm{Be}(\mathrm{d}, \mathrm{n}){ }^{10} \mathrm{~B}$ Reaction and the Existence of the $2.86 \mathrm{MeV}$ State in $1{ }^{\circ}$ " Nuclear Physics A99, 170 (1967).

47. D. W. Glasgow and D. G. Foster, Jr., "n-d Total Cross Section, ThreeNucleon Problem, and the Dineutron," Physical Review 157, 764 (1967).

48. Quarterly Progress Report, "Metallurgy Research Operation, July, August, September, 1964," edited by J. J. Cadwe11, HW-84281, pp 5.29, October, 1964.

49. A. B. Johnson, Jr., "In-Reactor Oxidation of Zirconium Alloys in pH- $\mathrm{O}$ LiOH and $\mathrm{pH}-10 \mathrm{NH}_{4} \mathrm{OH}, " \mathrm{BNWL}-\mathrm{SA}-822$, presented at the $23 \mathrm{rd}$ Annual Meeting, National ${ }^{4}$ Association of Corrosion Engineers, Los Angeles, March, 1967.

50. A. B. Johnson, Jr. and J. E. Irvin, "Radiation-Enhanced Oxidation of Zircaloy-2 in pH-10 LiOH and $\mathrm{pH}_{-10} \mathrm{NH}_{4} \mathrm{OH},{ }^{\prime}$ BNWL-463, July, 1967.

51. Quarterly Progress Report, "Metallurgy Research Section, October, November, December, 1965," edited by J. J. Cadwell, BNWL-207, pp. 5.16, Battelle-Northwest, Richland, Washington, January 17, 1966. 
52. J. H. Nail and D. E. Deonigi, "Economically Optimum Plutonium Lattices for Water Reactors," BNWL-SA-738, Trans. Am. Nucl. Soc., 9, pp. 541, November, 1966.

53. R. T. Thompson and D. E. Deonigi, "Some Nuclear Characteristics of PWR's Recycling Plutonium at Minimum Fuel Cycle Costs," BNWL-SA776S, Trans. Am. Nucl Soc., 9, pp. 542, November, 1966.

54. J. R. Sheff, "Short Term Dynamic Effects Upon the Utilization of Plutonium as a Reactor Fuel," BNWL-475 and BNWL-SA-563, Trans. Am. Nucl. Soc., 9 , No. 1, pp. 283

55. J. B. Burnham and D. E. Deonigi, "Major Factors in Plutonium and Uranium Fuel Fabrication Costs," Nuclear Applications, January, 1967.

56. D. E. Deonigi, "Fuel Cycles for Crossed Progeny Fuels in Conventional and Novel Configurations", Nuclear Applications, January, 1967.

57. E. A. Eschbach and D. E. Deonigi, "Possible Optimum Use of Thorium and Uranium Employing Crossed Progeny Fuel Cycles," BNWL-289, May, 1966.

58. Reactor Physics Department Technical Activities Quarterly Report, July, August, September, 1966, edited by F. G. Dawson, October 15, 1966.

59. Reactor Physics Department Technical Activities Quarterly Report, October, November, December, 1966, edited by F. G. Dawson, BNWL-400, Apri1 15, 1967

60. Reactor Physics Department Technical Activities Quarterly Report, January, February, March, 1967, edited by F. G. Dawson, BNWL-472.

61. Reactor Physics Department Technical Activities Quarterly Report, Apri1, May, June, 1967, BNWL-534. 
. 
(3) Argonne National Laboratory

R. Avery

C. H. Bean

R. E. Machery

(2) AEC, Chicago Patent Office

C. H. Lee

R. K. Sharp

(4) AEC, RDT Site Representative

W. E. Fry

P. G. Holsted (2)

J. B. Kitchen

(4) AEC, RLO

H. A. House

C. L. Robinson

C. R. Qualheim

Technical Files

(9) AEC, Washington

G. Boyer

D. E. Erb

A. Giambusso

J. Kruth

M. Shaw

J. Simmons

E. E. Sinclair

M. J. Whitman

I. F. Zartman

(1) Babcock and Wilcox

H. M. Jones

(3) Battelle Memorial Institute

(1) Brookhaven National Laboratory J. Chernick

(3) Combustion Engineering

W. P. Chernock

R. Harding

S. Visner

(1) CNEN - Centro Studi-Nucleaire

Casaccia, Rome, Italy

Ugo Farinelli

(5) Division of Technica1

Information Extension
(8) Douglas United Nuclear

T. W. Ambrose

F. Bouse (3)

C. D. Harrington

C. W. Kuhlman

W. S. Nechodom

G. F. Owsley

(2) E. I. duPont de Nemours

$\&$ Co., Inc., SRL

G. Dessauer

H. Honeck

(3) General Electric Co., San Jose

D. L. Fischer

S. Levy

R. B. Richards

(3) Genera1 Electric Company,

Vallecitos Atomic Lab.

L. P. Bupp

B. F, Judson

T. M. Snyder

(1) Idaho Nuclear Corp.

D. deBoisblanc

(2) Nuclear Materials and Equipment Corp.

C. S. Caldwe 11

K. Puechl

(2) United Nuclear Corp.

T. B. Holden

G. Sofer

(6) Westinghouse

R. J. Allio

R. J. French

H. Graves

R. S. Miller

W. H. Ray

J. H, Wright

(67) Battelle-Northwest

F. W. Albaugh

J. M. Batch

C. A. Bennett

S. H. Bush

G. J. Busselman

J. J. Cadwell

D. E. Christensen 
Battelle-Northwest (Cont'd)

R. F. Dickerson

F. G. Dawson (10)

D. R. deHalas

D. E. Deonigi

R. F. Dickerson

R. L. Dillon

E. A. Eschbach

E. A. Evans

J. R. Fishbaugher

J. C. Fox

M. D. Freshley

S. Goldsmith

W. P. Hampson

R. E. Heineman

H. L. Henry

P. L. Hofmann

J. W. Kutcher

D. D. Lanning

J. H. Lauby

B. R. Leonard

R. C. Liikala

C. W. Lindenmeier

R. P. Matsen

D. F. Newman

H. M. Parker

R. S. Paul

L. T. Pedersen

W. L. Purcell

W. D. Richmond

L. c. Schmid

R. C. Smith

R. I. Smith

D. H. Stewart

W. P. Stinson

D. H. Thomsen

V. O. Uotinen

A. D. Vaughn

R. G. Wheeler

L. D. Williams

N. G. Wittenbrock

J. R. Worden

D. C. Worlton

F. R. Zaloudek

Technical Publications (2)

Technical Information Files (5) 